\title{
A SOCIOLOGICAL ANALYSIS OF MAN-LAND RELATIONS IN CENTRAL AMERICA
}

By

WILLIAM KENNEDY UPHAM

\begin{abstract}
A DISSERTATION PRESENTED TO THE GRADUATE COUNCIL OF THE UNIVERSITY OF FLORIDA

IN PARTIAL FULFILLMENT OF THE REQUIREMENTS FOR THE DEGREE OF DOCTOR OF PHILOSOPHY
\end{abstract}

UNIVERSITY OF FLORIDA

1969 


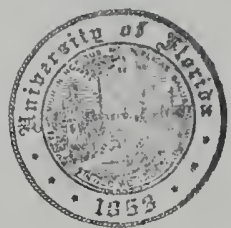

UNIVERSITY OF FLORIDA

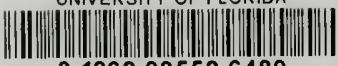

31262085526480 
DEDICATED

to Joy 


\section{PREFACE}

This dissertation is the culmination of a period of study that had its roots in Guatemala in 1956. In that year I made my first visit to Central America, and in only a short few days I discovered a land and people that I determined to come to understand, and to interpret to my fellow "norteamericanos."

Eventually this interest led me to the University of Florida and to Professor $T$. Lynn Smith in particular. over the last decade Professor Smith has continually stimulated my interest in Latin America, at the same time guiding me in the refinement of my own sociological frame of reference. In addition, he has been a willing consultant as problems arose in the pursuit of this topic. He has believed in me when my own faith wavered, and without his encouragement this study would never have reached fruition.

During my years of study at the University of Florida I have benefited from the teaching and counsel of many persons, professors and fellow students alike. While some others have been almost equally important, I will single out for mention only the members of my supervisory 
conmittee who have aided me on various occasions by reacting to my ideas and helping me to interpret data, as well as enriching my background through their classes. Most of all, these men have stood behind me with encouragement, and accepted the responsibility of reading these many pages. I offer my sincere thanks to Professors Joseph S. Vandiver and John V. D. Saunders of Sociology, and to Professor Raymond E. Crist of Geography, and Professor Lyle N. MCAlister of History.

I must especially thank the Henry I. and Grace Doherty Charitable Foundation for the fellowship which helped to support me during my field research in Central America. Without that award I would probably have had to attempt a different kind of study. I also want to acknowledge the aid of a National Science Foundation fellowship during the academic year following my return from the field.

In Central America I met wonderfully helpful people at every occasion, but they are much too numerous to name. Suffice it to say that I greatly appreciated the aid of the dozens of persons in the ministries of agriculture, the census bureaus, the agricultural extension services, the universities, and the cartographic agencies. In many cases I was provided with preliminary or special data, or 
given access to unpublished reports that were extremely helpful. The same was true at the Inter-American Institute of Agricultural Sciences at Turrialba, and at the Escuela Agrícola Panamericana at Zamorrano.

I am especially indebted to the many ordinary people whom I met because of their own personal relationships to the land, and not because of any office or position that they held. These included hacendados, plantation owners, family-sized farm operators, sharecroppers, and just plain laborers. Almost without exception they invited me into their homes and made me truly welcome while patiently telling me about life and farming as they experienced these.

The University of Florida has offered two specialized services which must be mentioned. Its Latin American Data Bank provided "data sets" of the Costa Rican agricultural census of 1963 and the Guatemalan population census of 1964 , both of which enabled me to make special tabulations. Also, the map collection of the University Library provided me with the opportunity to study topographic maps of virtually the entire country of Guatemala, from which Figure 11 was eventually made.

The Directors General of the Institutos Geograficos Nacionales of Guatemala and Costa Rica, Ing. Manuel A. Castillo Barajas and Ing. Mario Barrantes Ferrero, 
respectively, kindly granted me permission to reproduce the copyrighted maps of their respective countries for Chapter VI. For this I thank them.

On the mechanical side I want to express profound appreciation to Mrs. Carolyn Lyons who undertook to type this dissertation in Gainesville, Florida, while I was located in Texas. As the reader can see, she has done a beautiful as well as conscientious job in presenting my manuscript in final form.

Finally, the greatest debt of all goes to my wife, Joy, who, in addition to being my companion, has labored with me at every stage. She has been the typist for the preliminary drafts, the map maker for many of the figures, and a proficient proofreader of tables and text. Most of all, she has maintained faith that this effort would be satisfactorily concluded even when my own confidence wavered. She, of course, was right. 
TABLE OF CONTENTS

Page

PREFACE $\ldots \ldots \ldots \ldots \ldots \ldots \ldots \ldots \ldots \ldots \ldots \ldots \ldots \ldots \ldots \ldots \ldots \ldots \ldots \ldots \ldots \ldots$

LIST OF TABLES $\ldots \ldots \ldots \ldots \ldots \ldots \ldots \ldots \ldots \ldots \ldots \ldots \ldots \ldots \ldots \ldots \ldots$

LIST OF FIGURES $\ldots \ldots \ldots \ldots \ldots \ldots \ldots \ldots \ldots \ldots \ldots \ldots \ldots \ldots \ldots \ldots$

Chapter

I. INTRODUCTION $\ldots \ldots \ldots \ldots \ldots \ldots \ldots \ldots \ldots \ldots \ldots$

objective of the Study ................ I

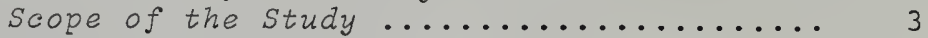

Sources of Data and Methods ............... 5

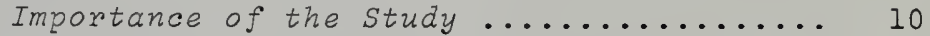

Order of Presentation ............... 12

II. A REVIEW OF RELEVANT LITERATURE $\ldots \ldots \ldots \ldots \ldots 14$

The Development of a General Frame of Reference for the Study of Man-Land

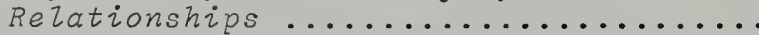

Studies of Man-Land Relations in

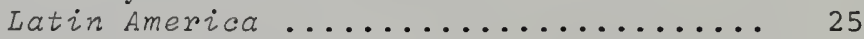

The Study of Man-Land Relations in

Central America ................. 34

III. THE SIZE OF EXPLOTACIONES $\ldots \ldots \ldots \ldots \ldots \ldots \ldots . \ldots . \ldots$

Farms, Landholdings, and Explotaciones... 55

A Functional Classification of Sizes

of Explotaciones ................. 58

Distribution of Explotaciones by Size

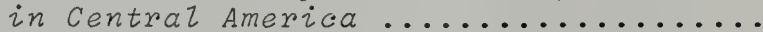

Size of Explotaciones and Land Use ....... 114

The Historical Evolution of Sizes

of Holdings ....................... 141

Trends in the Size of Explotaciones ...... 146

Summary and Conclusions ............. 162 
IV.

Evolution and Development of Property

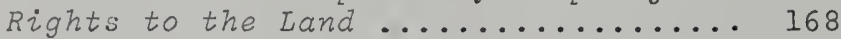
The Nature of Property Rights

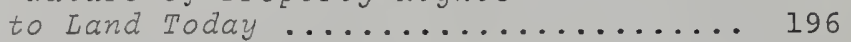

Tenure Status of Central American

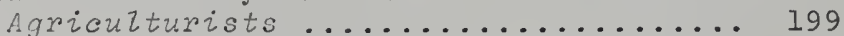

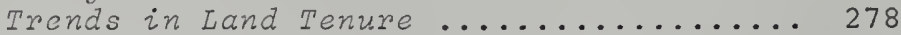

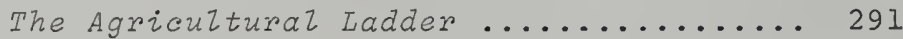

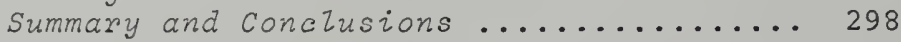

V. SYSTEMS OF AGRICULTURE ............. 303

The Nature of Systems of Agriculture ... 303 Contemporary Systems of Agriculture

in Central America ..................306

Evolution of Systems of Agriculture

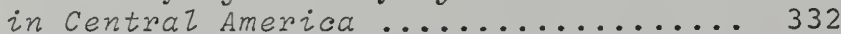

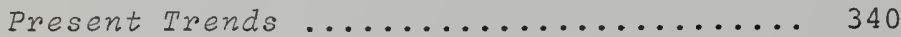

VI. PATTERNS OF SETTLEMENT ............... 343

The Conceptual Framework ..............344

Contemporary Settzement Patterns

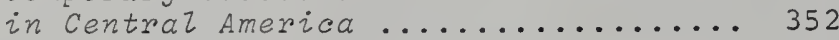

Evolution of Settiement Patterns

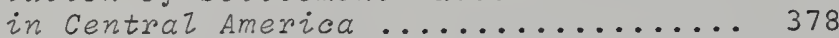

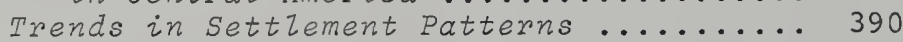

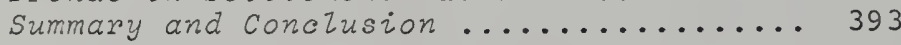

VII. SUMMARY AND CONCLUSIONS .............. 395

APPENDICES $\ldots \ldots \ldots \ldots \ldots \ldots \ldots \ldots \ldots \ldots \ldots \ldots \ldots \ldots$

APPENDIX A LEGAL PROVISIONS TO REQUIRE THAT LAND BE MADE TO FULFILL A SOCIAL FUNCTION IN CENTRAL AMERICA ...

APPENDIX B ORIENTATION MAP

(FIGURE 18)

APPENDIX C TABLE OF EQUIVALENT MEASURES OF IAND AREA ............. 
TABLE OF CONTENTS-Continued

Page

APPENDIX D LIST OF ABBREVIATIONS ........ 421

SELECTED BIBLIOGRAPHY $\ldots \ldots \ldots \ldots \ldots \ldots \ldots \ldots \ldots \ldots .423$

BIOGRAPHICAL SKETCH $\ldots \ldots \ldots \ldots \ldots \ldots \ldots \ldots \ldots \ldots$ 


\section{LIST OF TABLES}

Table

Page

1. The family-sized farm as defined in some of current literature on Iatin America .......668

2. Absolute and relative number of explotaciones, and absolute and relative amount of land in explotaciones, in three major size classes: Central American countries and Central American region in the 1960's ...73

3. Number of large, multi-family farms, together with the relative amount of national territory and of total farmland operated by these farms: five Central American countries at latest census ..............

4. Absolute and relative number of explotaciones, and absolute and relative amount of land in explotaciones, by size of explotación:

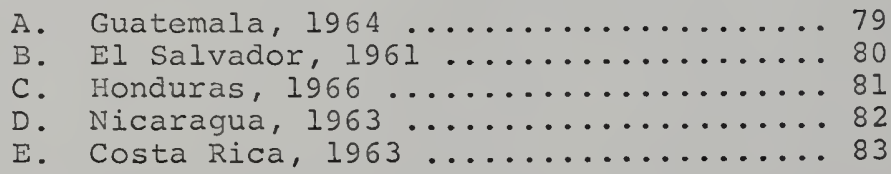

5. Relative amount of land in explotaciones devoted to selected uses, by size of explotación: Central American countries, latest data

6. Relative distribution of land in explotaciones, and of selected crops and livestock, among four size-of-farm classes: Central American

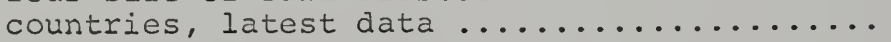

7. Absolute and relative numbers of explotaciones of stated sizes, together with absolute and relative change:

A. Guatemala, 1950 to $1964 \ldots \ldots \ldots . . . . . . . .148$

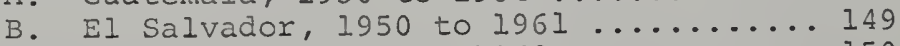

C. Costa Rica, 1950 to $1963 \ldots . . . . . . .150$ 
Table

8. Absolute and relative amounts of land in explotaciones of stated sizes, together with absolute and relative change:

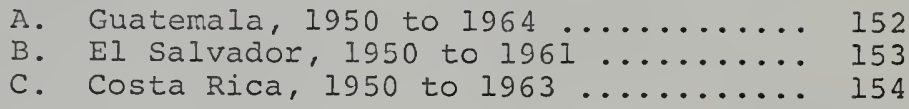

9. Data employed in estimating the number of households which derive a livelihood from agricultural and pastoral activitics: Central American countries

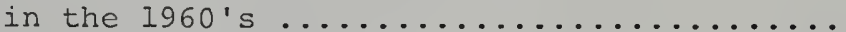

10. Estimates of the number of genuine farms among explotaciones agropecuarias in the agricultural censuses of the Central American countries since 1960 .....

11. Estimates of the numbers and proportions of households deriving a livelihood from agricultural and pastoral occupations whose heads were farm operators and farm laborers in the Central American

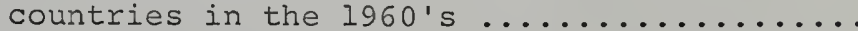

12. Explotaciones agropecuarias and land in explotaciones (excluding colonos) classified according to tenure of the producer: Central American

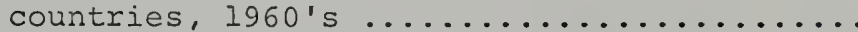

13. Explotaciones agropecuarias and land in explotaciones classified according to tenure of producer in selected size classes:

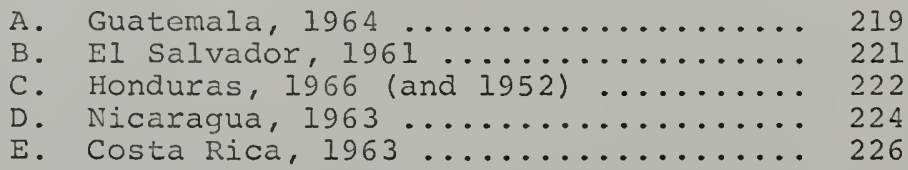




\section{LIST OF TABLES-Continued}

Table

Page

14. Absolute and relative numbers of explotaciones agropecuarias managed by administrators, and absolute and relative amounts of farmland in such explotaciones, by size of explotación: Guatemala, 1964, and Costa Rica, 1963 ...... 233

15. Number of permanent agricultural workers per explotación, by size of explotación:

El Salvador, 1961, and Costa Rica, 1963

16. Numbers of persons employed in agriculture and estimated number of farm operators, and the ratio of farm-employed persons to farm operators at the time of the two most recent censuses: Guatemala, El Salvador and Costa Rica .............. 281

17. Change in the number and area of explotaciones agropecuarias classified according to tenure of the producer in selected size classes:

A. Guatemala, 1950 to $1964 \ldots . . . . . . .284$

B. El Salvador, 1950 to $1961 \ldots \ldots . . . . . .286$

C. Costa Rica, 1950 to $1963 \ldots . . . . . .287$

18. Numbers and proportions of explotaciones agropecuarias reporting no power except human effort, by size of explotaciones:

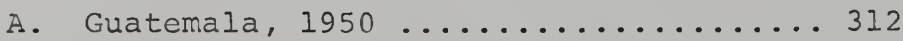

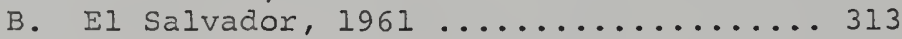

C. Costa Rica, $1963 \ldots . . . . . . . . . . . . .314$

19. Numbers and proportions of explotaciones agropecuarias reporting the use of animal power, by size of explotaciones:

A. Guatemala, $1950 \ldots \ldots \ldots \ldots \ldots \ldots . \ldots . \ldots . \ldots$

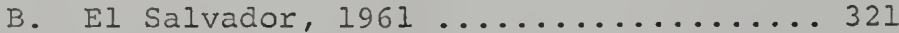

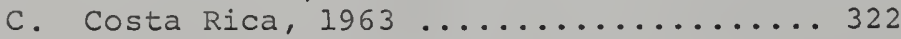

20. Numbers and proportions of explotaciones agropecuarias reporting the use of animal- and tractor-drawn plows, by size of explotaciones: Costa Rica, 1963 ... 324 


\section{LIST OF TABLES-Continued}

Table

Page

21. Numbers and proportions of explotaciones agropecuarias reporting the use of tractors, by size of explotaciones:

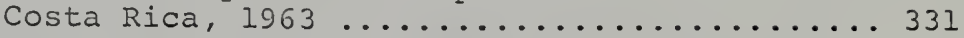

22. Changes in the number of farms employing different sources of power, by three size categories: Costa Rica, 1950 to 1963

23. Relative number of individual producers who lived on their explotaciones, by size of explotación and occupation of producer:

Costa Rica, $1963 \ldots \ldots \ldots \ldots . \ldots . \ldots . \ldots 375$

24. Relative number of heads of households who were farmers and cattlemen living on an explotación agrícola, by ethnic group and region: Guatemala, $1964 \ldots \ldots . . . \ldots 377$

25. Relative numbers of producers residing off the explotación, and employment of farm administrators, by size of explotación: Costa Rica, 1950 and $1963 \ldots \ldots \ldots \ldots . \ldots . \ldots 2$ 


\section{LIST OF FIGURES}

Figure

1. Number of permanent agricultural workers per explotación by size of explotacion: El Salvador, 1961, and Costa Rica, $1963 \ldots . . .$.

2. Number of agricultural workers at work per explotacion, on one specified day or week, by size of explotacion: Guatemala, 1950; Honduras, 1952; and Costa Rica, 1955 ........

3. Median size of explotaciones agropecuarias, by major civil divisions: Central America

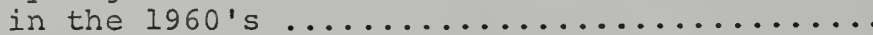

4. Proportion of all land in explotaciones which was included in large multi-family farms, by major civil divisions: Central America

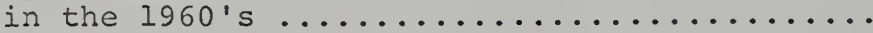

5. Relative number of explotaciones which were in the range of family-sized farms, by major civil divisions: Central America

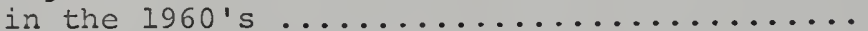

6. Proportion of farmland devoted to annual crops, by size of explotación: five Central American countries

7. Proportion of farmland devoted to permanent crops, by size of explotación: five

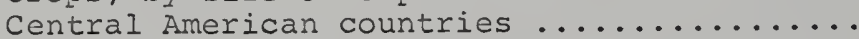

8. Proportion of farmland devoted to pastures, woodlands, and other noncrop uses, by size of explotación: five Central

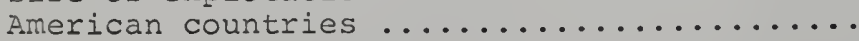

9. Number of owner-operated explotaciones per 100 males employed in agricultural occupations, by major civil divisions:

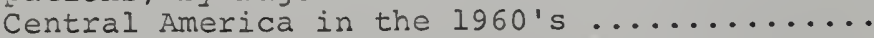




\section{LIST OF FIGURES-Continued}

Figure

10. True agricultural village of San Lucas Tolimán at the southeast corner of

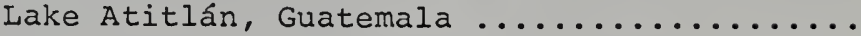

11. Schematic representation of the predominant settlement patterns in Guatemala, generalized from large-scale topographic maps showing house locations throughout

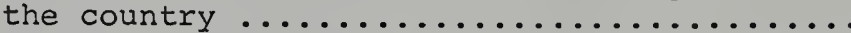

12. A rural section of Usulután Department, El Salvador, showing the distribution of rural houses in hamlets (caserios) which lack virtually all services, but are clustered enough for considerable

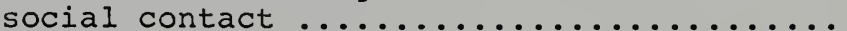

13. Fruit company settlements in the Sula

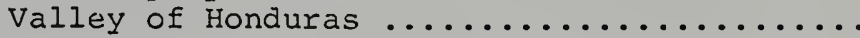

14. A line village development extending to the east and west of the village of Turrúcares, Province of Alajuela, Costa Rica ..........

15. False line village of Chichipate, near El Estor, Guatemala

16. Scattered farmsteads in the cereal and cattle zone of Pozo Azul, Guanacaste, Costa Rica ..

17. Scattered farmsteads in a zone of minifundios, Santa Cruz del Quiché, Guatemala ..........

18. Map identifying the major civil divisions of

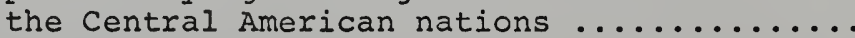




\section{CHAPTER I}

\section{INTRODUCTION}

For the understanding of the overwhelmingly rural and agricultural countries of Central America, an appreciation of man's social relationships with regard to the land is fundamental. / The majority of the more than 14 million people of this region of Latin America live out their lives intimately bound up in the systems which have developed around the size of farms, land tenure, ways of farming, and forms of settlement./ Nevertheless, the fact that each of these sociocultural systems is institutionalized as part of the total rural social system is frequently overlooked. It is a goal of this study to show that all of these must be taken into account in any effort to comprehend the nature of rural life, and more especially, in any endeavor to introduce changes in these systems.

\section{Objectives of the Study}

The principal objective of the present study is to apply a well-developed sociological frame of reference to the analysis of the relationships between men and the land 
in Central America. This is something which has never been attempted in the area on a regional basis, although several national or sectional studies have been made previously (see T. Lynn Smith, 1945b; Whetten, 1961; Nesman, 1969). Part of the significance of the effort is that the same investigator is responsible for making the observations, applying the analytical framework, and performing the detailed analysis for all of the countries included.

A second goal of the study is to assemble, evaluate, and organize the most significant facts about the chosen relationships in Central America. This is a selective effort, therefore, and many other important and valid facts and relationships have had to be omitted from consideration.

The description of the contemporary rural social systems with regard to the size of farms, tenure of the land, systems of agriculture, and settlement patterns also is a major objective. In connection with this, many national and local variations are identified.

Finally it is hoped that sufficient historical information is provided to place the present-day situation in proper perspective, and to indicate the trends currently under way. 
Scope of the Study

The geographic limits of this investigation are drawn so as to include the five nations which historically have been bound closely together. Guatemala, El Salvador, Honduras, Nicaragua, and Costa Rica began their independent existence as the constituents of the United Provinces of Central America. Since the breaking up of that confederation the dream of reunification has been expressed frequently, and at present the Central American Common Market seems likely to be the forerunner of more and greater integration. Since Panama's history and sense of self-identification are distinct from the other five nations, this country is not included. Neither is British Honduras (or Belice) incorporated in the area of investigation. Of course attention is directed only to the rural and agricultural regions of Central America, and not to the distinctive social arrangements affecting urban life.

It will be apparent in the tables and in the discussion that I have chosen to present the information country-by-country in the order in which $I$, personally, think of them, that is, in the sequence in which they

${ }^{1}$ The recent armed clashes between El Salvador and Honduras have raised serious questions about the future of the common market, and about any other cooperative efforts. It is too early to tell how important or lasting the effects of this war will be. 
occur in traversing the Inter-American Highway from Guatemala to costa Rica. This has the advantage of placing the countries in a geographically-meaningful order, and at the same time it is also in descending rank according to the size of their total populations. An alphabetical arrangement has little to commend it.

The basic subject matter of this study is a complex of four basic relationships between man and the land. These four areas are selected from among a much larger universe of distinct sociocultural systems which have been identified and studied in the rural segments of societies. 1 The particular elements of rural life included in this analysis are those having to do with the size of agricultural units (explotaciones agropecuarias), the tenure patterns, the ways of extracting products from the soil, and the arrangement of rural homes with regard to one another and to the location of the farmland.

The emphasis in this study is placed on the contemporary situation, with most discussion describing the situation as it exists today. This is the only study known to the writer which has had available to it the

${ }^{1}$ The fourteen separate systems listed by $T$. Lynn Smith (1969c:272-273) give a good idea of the variety and multiplicity of the complexes which make up rural life. 
data from the agricultural censuses taken during the 1960's in all five of the countries. Wherever possible, data and observations have been assembled to provide insight into the evolution of the present situation during past centuries, and also to indicate the changes that are occurring.

Sources of Data and Methods

The principal substantive materials used in this analysis are the result of approximately ten months of travel and residence in Central America in 1962 and 1963. During this interval I travelled the length and breadth of the region, from the Mexican border to the Panamanian frontier, in vehicles of all sorts. Most of the mileage was covered in my own Volkswagen microbus, but I also flew in private and commercial planes, hitched rides by jeep and truck, rode buses, and made one extensive journey of four days in a dugout boat.

During the entire field investigation I kept a personal journal in which pertinent observations were recorded. Notes were made as soon as possible after seeing or discussing anything of value, and I could often be seen jotting away at a restaurant table while awaiting a meal. As a precaution against the loss of this record I also wrote rather extensive descriptive letters to my wife and parents, with instructions that these be preserved for me 
to use upon my return to the United States. Since these were written at less frequent intervals, they served the additional purpose of providing opportunity for my thoughts to be seasoned by time and further consideration.

In the course of time I spoke with countless persons of all social strata, and endeavored to obtain relevant information from their particular perspectives. These included peasants, sharecroppers, owners of family-sized farms, and operators of large haciendas and plantations. of course, I also discussed my project with persons in positions of responsibility in the ministries of agriculture, the missions of the United States Agency for International Development, agrarian reform agencies, and producers' organizations of commodities such as coffee, cotton, and the like. Notes on all of these conversations are a part of the field data.

In order to increase the opportunities to raise such sensitive questions as those dealing with size of farms and tenurial relationships, I also conducted some structured interviews with some of the farm operators and sharecroppers. I found that having a formal questionnaire sometimes helped and occasionally hindered in dealing with the rural residents. Frequently, when my relationship was already somewhat biased by an introduction from the agricultural extension agent of the locality, I employed 
a mimeographed questionnaire which I filled out in the presence of the informant.

I had little assistance from other persons in conducting any of the interviews on which this study is based. This is due to the lack of sufficient financial support to make it possible for me to have local persons travelling with me as interviewers, translators, or assistants. Therefore the observations and notes are consistently mine, but suffer from lack of that additional quality which could have been gained if persons thoroughly familiar with the local colloquial expressions and regional practices had been collaborating with me. Needless to say, the entire field investigation was conducted in the Spanish language, and I had to rely upon secondary sources for material regarding certain Indian practices. I was pleasantly surprised at the extent to which $I$, as a "gringo," was welcomed into the homes of persons of all social levels.

The statistical data upon which so much of the study depends are drawn largely from the published reports of the agricultural and population censuses taken by each of the countries between 1961 and 1966. Since the first agricultural censuses in Central America were taken in 1950 and 1952, there have not been any long series of sources to be traced, but the reports of all of these 
censuses are utilized in this investigation. In addition, some special tabulations of data from the agricultural censuses of Guatemala and Costa Rica have been facilitated by the use of data sets in the Latin American Data Bank of the University of Florida.

The use of census data involves certain wellrecognized problems regarding completeness of coverage and adequacy of definitions which are necessarily accepted by the investigator. 1 There are other problems, however, which deserve a passing comment in hopes that the next endeavors to enumerate the farms of Central America will take these matters into account. The first of these is the lack of consistency in definitions and procedures. Much of the value which should accrue to a nation as a

${ }^{1}$ Although the reported census figures are employed throughout the dissertation, they are known to vary widely from the reality, and my discussion will frequently use drastically-rounded figures. In a post-census evaluation, Guatemalan authorities estimated that 22.8 per cent of the explotaciones agropecuarias were missed (mostly small units), for a deficiency of 5.1 per cent of the area in farms (see Guatemala, DGE, 1965:Tabla 5, page 39). On the other hand, Costa Rican census officials reported that 2,808 explotaciones were probably missed, or 4.3 per cent of the farms and 9.5 per cent of the farmland (Costa Rica, DGEC, 1965b:26). No evaluation was issued by the other countries, but an estimate of the uncounted land in the 1952 agricultural census in Honduras is given in organization of American States (1963, III:6I). Data from the 1952 farm survey in Nicaragua are not used at all, owing to their acknowledged deficiency in coverage, and the fact that the survey was made directly by the jueces de mesta (rural authorities directly under orders of the political chief of the departments) who seem to this writer to be too politically involved to obtain reliable data (see Lanzas, 1954:435). 
result of having the results of two inventories available is lost in Central America. In this regard, Costa Rica deserves commendation, for in that country's effort to improve its statistics care has been taken to preserve the comparability of most concepts and tabulations. For example, when it was decided to make the 1955 and 1963 size-of-farm categories compatible with the international metric system, additional class limits were introduced. These made the presentation a bit more cumbersome but preserved the integrity of the time series. Regarding land tenure, every census authority except that of Costa Rica made such serious modifications that the data from the 1950 and 1960 censuses are difficult to compare.

The worst problem is that regarding the units of land measurement that were employed for census purposes. The common measure of land in everyday use in Central America is the Spanish manzana, equivalent to a square tract of land 100 varas on a side (see the Appendix for a table of equivalent measures). However, the metric system is the preferred one for legal and international comparative purposes, and so hectares are used in a few tabulations. This makes it impossible to find common measures for comparing each of the Central American nations with the others. Moreover, Honduras complicated the matter further by publishing its 1952 census with hectare sizes, and its 1966 data 
only in terms of manzanas, eliminating any possibility whatsoever of making comparisons over time for that country. Finally, in Guatemala the larger farms are measured in terms of another Spanish unit, the caballeria, which is equivalent to approximately 64 manzanas. Farms measured in caballerías are not even comparable to those in manzanas in the other countries employing the Spanish units.

Census statistics are supplemented by data from other sources, such as the yearbooks (anuarios) published by the census authorities, and the reports of government ministries and other agencies. The universities and agrarian reform institutes were able to provide some quantitative information.

No new techniques of manipulating data were developed in connection with this study. Instead, the tried and tested methods of making cross-tabulations, computing percentages, and determining ratios are employed extensively. In many cases the numerical data are presented graphically instead of in tabular form, since this enables the reader to grasp the important variations in a geographic as well as proportional sense.

Importance of the Study

The nations of Central America are all in the category commonly referred to as "developing," and in order 
for them to develop in the most satisfactory manner it is important that rural social systems be understood. This study attempts to provide a comprehensive picture of four interrelated sociocultural systems which combine to affect the well-being and potential for development for the farming population of Central America. Hopefully it will counteract to some extent the overly simple presentations of rural development which are sometimes employed in planning endeavors.

Since this is the first effort to apply a consistent sociological frame of reference to this developing area of Latin America it also has a certain academic importance simply as a ground-breaker. In this respect it both adds to the available knowledge of the Central American area and adds Central America to the areas about which such studies have been made.

The importance of the study will be enhanced when it is possible to move it from the academic setting into the public domain where its observations and facts may be taken into consideration by "social engineers" in their day-to-day tasks of planning. The pressures of population growth, rural-urban migration, rural unrest, the invasion os estates by the landless, and many other contemporary phenomena make an understanding of the total rural social system essential if planning is to forestall widespread social disorganization. 


\section{Order of Presentation}

The materials of this study are presented in three major sections: an introductory part, the principal findings and considerations regarding man-land relationships, and the summary and conclusions. The introductory section is comprised of this present chapter, and a chapter in which the literature contributing to the study is reviewed. The review of the literature is designed to trace the development of the frame of reference employed in this analysis, and also to evaluate previous studies of man-land relationships in Latin America and in the Central American region specifically.

The heart of the dissertation lies in the second part, where a chapter is devoted to each of the four sociocultural systems studied. Chapter III is concerned with the analysis of the size of explotaciones in each of the nations, and in the region as a whole. It includes both conceptual and empirical discussion. Chapter IV covers the large matter of land tenure, including the relationship of tenure to the size of explotaciones. Chapter $\mathrm{V}$ takes up the matter of the ways in which men extract products from the land, or the systems of agriculture employed in Central America, and Chapter VI presents what the investigation has been able to reveal about rural settlement patterns and their relationship to rural life. 
The final part consists of Chapter VII, the Summary and Conclusions. Supplementary materials are presented in appendices, which include a listing of the laws of Central American nations requiring that land be made to fulfill a social function. There is also a map which identifies each of the major civil divisions of the five countries of the region, and a table of equivalent measures in the Spanish and metric systems. For convenience in citing sources, I have also appended a list of abbreviations which are used in the text. Finally, there is a selected bibliography which includes full information about each of the publications referred to textually, and also some general volumes which were of particular value to the investigator in his preparation for the field phase of the study. 


\section{A REVIEW OF RELEVANT LITERATURE}

In order for a scientific study to make a significant contribution to its discipline it must meet two prerequisites. First, the investigator must be thoroughly familiar with the frame of reference that has been evolved with regard to his subject of study by those who have made prior studies of the same problem. Second, he must be aware of the substantive findings and the conclusions of previous analyses of the question under investigation. The main purpose of this chapter is to trace the development of the frame of reference which is employed in the analysis of man-land relationships. In addition, the principal studies of this question in the Central American setting are identified and evaluated. Thus the present chapter is the very foundation for the remainder of this dissertation.

The Development of a General Frame of Reference for the Study of Man-Land Relationships

The study of rural man-land relationships lies at the heart of the discipline of rural sociology, and this field of investigation and analysis has developed concurrently with other facets of the young science of sociology. 
The first book intended as a text for college sociology courses was published in 1894 by Albion $W$. Small and George E. Vincent as An Introduction to the Study of Society. In treating "The Natural History of a Society," mention is made of the nature of the community, including the subject of settlement patterns. The authors also refer briefly to land tenure and elements of the system of land ownership and titles. Thus these facets of man-land relationships which are so much a part of the present study have been recognized as being important ever since the appearance of the very first general sociology text.

The development of rural sociology as a separate discipline began largely in the concern of church leaders and rural pastors who wanted to do something about the decline of the small villages and the considerable movement of rural people to the towns and cities. ' Thus the first book written specifically as a text for rural sociology courses, John M. Gillette's Constructive Rural Sociology (1913), devoted much attention to the problem aspects of rural society. Nevertheless, he also stated that the main responsibility of rural sociology as a discipline was to "take á full inventory of the conditions of life in rural communities. It must discover their tendencies and deficiencies, map out the special

${ }^{1}$ An excellent overview of the development of the entire field of rural sociology has been published by T. Lynn Smith (1957b). 
problems, and indicate ways of betterment. . . " Among the subjects he thought it necessary to discuss were those of the size and tenure of farms, and those of rural isolation, based mostly on the isolated farmstead pattern of settlement. Another text was soon forthcoming at the hand of Paul I. Vogt, entitled Introduction to Rural Sociology (1917), which further developed the interest in the size of farms and land tenure. Vogt stressed the fact that tenancy and small farms were both related to low levels of living.

A major event in the development of rural sociology occurred in 1915 with the publication of a 34-page bulletin entitled The Social Anatomy of an Agricultural Community by Charles Josiah Galpin. The bulletin contained the brief report of a systematic empirical study of the rural communities of Walworth County, Wisconsin. Galpin had carefully delineated the boundaries of social significance for a dozen villages and towns in the county, determining just how far the influence of each penetrated out into the hinterland of scattered farmsteads. In doing this his greatest contribution was not his clear statement of the nature of the rural community so much as his use of carefully controlled observation and data-gathering techniques which enabled any investigator to repeat what he had done 
and obtain the same results. This carefully systematized observation and analysis became a strong part of the tradition of rural sociology, carrying over to the present study.

Galpin also made another major contribution to the scientific study of rural society when he published his own first volume on Rural Life in 1920. In this case his major contribution was that he tried to synthesize the various facts about the nature of rural life which he and others had already reported. Since the rational development of any science requires the careful integration of all available facts into a consistent whole, this systematizing element is at least equally important when compared with the derivation of individual "facts." The problem-oriented nature of concern for rural sociology was again demonstrated when this same author published another volume entitled Rural Social Problems in 1924. The two most relevant problems relating to the present topic of man-land relations were those of "Landlords and Farm Tenants," and "The Farmer's Standard of Living," each of which made up a chapter in its own right.

In the 1920's the field of rural sociology began to come into its own as Galpin, from his position as chief of the Division of Farm Population and Rural Life, pushed forward cooperative research with the state agricultural 
experiment stations, and Edmund des. Brunner began a series of surveys of agricultural villages in the United States. Each of these men contributed mostly (with regard to manland relationships) by his insistence on the careful and consistent collection of empirical data as the basis on which analysis and conclusions should be based. The effort to survey 140 American villages which Brunner headed during the interval from 1923 to 1925 resulted in five volumes, typical of which was that of Brunner, Gwendolyn S. Hughes, and Marjorie Patten on American Agricultural Villages (1927). Teams of investigators had personally probed conditions in and around these villages, and references abounded to the tenure and living conditions found. As a result of the depression of 1929 and the ensuing years, the President's Research Committee on Social Trends decided to resurvey the same communities with the same teams of investigators to learn what had happened in them and why. The results were published in 1933 as Rural Social Trends by Brunner and J. H. Kolb. A third study of these selected villages was made in the mid-thirties, confirming, among the findings, that farm tenancy was an increasing problem. This was reported in Edmund des. Brunner and Irving Lorge's volume entitled Rural Trends in Depression Years: A Survey of Vizlage-Centered Agriculturaz Communities, 2930-2936 (1937). The contribution of this unique series of studies 
was mostly in the area of research procedures, since the repeated, consistent study of the same places and populations demonstrated in unmistakable terms the value of longitudinal analyses in the study of social and institutional change. Meanwhile, during the same period of time that empirical research was being pushed forward, the effort to refine and develop the framework for understanding rural life was being carried on. In 1922 Gillette wrote a new text entitled simply Rural Sociology, in which he says (p. vii) that he is trying to correct the "obvious defects" in his pioneering work. A great deal of his attention was focused on the matter of developing a rational land policy for the United States in which methods of alienating land and promoting tenure changes vied for prominence with the question of restructuring rural communities. In Chapter XXV, on "Mitigating Rural Isolation," he reviewed various patterns of settlement and argued against the creation of small agricultural or farm villages. In spite of the isolation of the single farmstead, he found the small villages virtually dead as places to raise children, and quite lacking in values which overcame the farming values of open-country living.

Carl C. Taylor prepared a text, Rural Sociology: A Study of Rural Problems, in 1926 which placed renewed 
stress on the need for systematic studies of rural life, and made proposals for how these might be done. (A few years later as head of the Division of Farm Population and Rural Life of the Department of Agriculture he was in a position to carry these into practice.) Among the contributions of this work to the understanding of man-land relations were his analyses of the relationships between tenancy and plantation ("one-crop") agriculture on the rural standard of living. Statistically he found that the presence of each of these "universally" (p. 120) depressed the level of living. In Chapter VIII, "The Problem of Tenancy and Ownership," he employed data from the 1920 and earlier censuses to trace the trend regarding tenancy, and concerned himself with the problem of the concentration of control over the land. Chapter XVIII treats the relations between "The Farmer and His Community," tracing the various types of communities in the United States, and their historic evolution as settlement patterns. He concluded with the statement that in the American colonies there was established "the isolated farm residence for the first time in the history of the world" (p. 399). The accuracy of the statement is not the important thing, but rather the evident concern with understanding this important facet of rural social organization. 
Another rural sociologist, Lowry Nelson, published a significant series of monographs and studies of settlement patterns and landholding practices during the interval 1927 to 1933 in which he analyzed the uniquely American practices of the Mormons in Utah. The most important of these was his The Mormon Village: A Study in Social Origins (1930).

A few years later Walter A. Terpenning issued Vizzage and Open-Country Neighborhoods (1931) which advanced the understanding of rural settlement patterns considerably, as it treated the American experience in one chapter, followed by eight chapters detailing the typical rural arrangements in Swiss, English, German, French, Italian, Irish, Danish, and Russian societies. This volume was one of the early ones to employ international comparisons in a systematic way.

In the late $1920^{\prime} \mathrm{s}$ a unique intellectual partnership between an outstanding European sociologist, Pitirim A. Sorokin, and a young American, Carle C. Zimmerman, began at the University of Minnesota. Drawing on a thorough knowledge of studies on both sides of the Atlantic, Sorokin and Zimmerman published Principles of Rural-Urban Sociology (1929), followed in the next three years by the volumes of A Systematic Source Book in Rural Sociology (1930) on which Galpin also collaborated. Their effort was the first to 
try to be a cross-cultural rather than simply a national rural sociology, and also the first to make a clear analysis of rural social stratification and social mobility, all of which are important for the understanding of manland relations in any setting. Serious study was also applied to the developing understanding of settlement patterns. Perhaps the major point of original theoretical distinctiveness was their decision to treat the tenure of land and the size of holdings as two distinct characteristics of the rural social system, whereas previously these had traditionally been mixed in one category. It is unfortunate that most studies of the Central American area even today fail to make this critical distinction. The period of the later 1930's, with the exception of the work of Brunner and his associates already cited, was not as productive as the earlier years of rapid growth of the discipline. One work of the period was the volume by J. H. Kolb and Brunner entitled A Study of Rural Society: Its Organization and Changes (1935). Only limited attention was given to man-land relationships, but the chapter on "The Social Economics of Agriculture" treats the matters of size of farms, land tenure, and the usual expression of concern for increasing tenancy with its usually adverse effects. 
In 1940 a synthesis of the understanding of manland relationships achieved to that time was undertaken by T. Lynn Smith in The Sociology of Rural Life. In Part III, "Rural Social Organization," Smith developed the four basic divisions of the field that he recognized at that time, including, as chapters, the form of settlement, land division, land tenure, and size of holdings. In this volume for the first time the systems of land division and titles were handled as a major subdivision of rural social organization, with their importance for rural community organization, the provision of various services, and the general effect of land titles on the degree of harmony and permanence in a community. This book was also apparently the first to completely separate the topics of land tenure and size of farms into distinct analytical units, although it was foreshadowed by Sorokin and $\mathrm{Zimmerman} \mathrm{(1929).}$ The general treatment of man-land relationships in rural sociology has not changed greatly since this statement, except in the refinements introduced within the framework established by Smith.

Endeavors to improve the whole subject of rural sociology continued, of course, and in 1942 Dwight Sanderson produced Rural Sociology and Rural Social Organization, in which he decried a lack of sound study on which to base a good rural sociology text. He said, "It is my belief that 
rural sociology will not be able to make the contribution to rural social organization which it should unless it pursues a strictly scientific method and creates new knowledge concerning its phenomena, through a more scientific analysis of their elements" (p. ix). In his own analysis he tried to find material to improve the study of rural problems and made extensive use of the size of farms as a variable in the study of "Some Problems of American Agriculture" in Chapter 7. He also emphasized the matter of size of farms in Chapter 25 as he discussed "Class and Caste in Rural Society."

Other books, each producing a slightly different balance in the treatment of the several relationships between men and the land, were produced in succeeding years, but without significant changes in the overall understanding of the field. Among the better of these are Rural Life in Process by Paul H. Landis (1940), Rural Life in the United States by Carl C. Taylor and others (1949), and Rural Social Systems by Charles P. Loomis and J. Allan Beegle (1950). The latter devotes considerable attention to the matter of rural social stratification and deals with the relationship of land tenure to these strata. It also contains repeated references to the family farm as a value and as a practical facet of the rural social system. On pages 293 and 294 Loomis and Beegle stressed 
the results of a study of the family farm which emphasized the claim that no other form of agricultural organization provides greater development of individual abilities and competences (see Ackerman and Harris, 1947).

The growth of the frame of reference employed in this dissertation was nearly complete as early as 1940. However, T. Lynn Smith's extensive experience in Brazil and Colombia following the publication of his first edition of The Sociology of Rural Life (1940) led to a further area of investigation, namely the sociocultural complexes by which agriculturists extract a livelihood from the soil. First in publications dealing with Brazil (1946), and later in a broader setting (1949), Smith developed a new area of analysis and termed it "systems of agriculture." The full development of this new aspect of the rural social system was presented in the third edition of The Sociology of Rural Life (1953). With this publication the essence of the general framework with which the present study approaches the study of man-land relationships was complete. Further refinements have occurred largely in the literature dealing specifically with Latin America, to which attention is now turned.

Studies of Man-Land Relations in Latin America

The earliest writings about what we now include in "man-land relations" in Latin America were written before 
the framework for this type of analysis had progressed very far even in the United States. The first North American to observe and report some of the facets of the size of agricultural holdings and the relation of these to the class structure in rural areas was Edward Alsworth Ross, who published South of Panama in 1915, after having made careful observations during his travels there. Ross later also wrote The Social Revolution in Mexico (1923), in which he analyzed the efforts to restructure both size of holdings and tenure in that revolution-wracked country.

A geographer, George McCutchen McBride, in a series of studies beginning with his The Land Systems of Mexico in 1923, undertook to comprehend and explain the development of the rural society in Latin America in relation to the large haciendas and the system of social and economic relationships surrounding these establishments. His time in these countries (Mexico and Chile) was well spent, for he mastered much of the historical evolution of the land systems as well as their contemporary practices. The volume on Chile: Land and Society (1936) was perhaps even better than that on Mexico. McBride's studies are certainly among the best that were done by scholars in any discipline at that point in time. 
Another early scholar undertaking serious field study in Latin America was Eyler N. Simpson, who published his analysis of The Ejido: Mexico's Way out in 1937. This study traced the development of discontent in the masses who labored under the system of large haciendas, and showed what was being done to try to establish an improved tenurial arrangement for very large numbers of people.

At about the same time, the Foreign Policy Association responded to an invitation from President Carlos Mendieta of Cuba that it appoint a Commission on Cuban Affairs. Among those named was Carle C. Zimmerman, who directed the study of rural life and applied the frame of reference which had been developing in the United States. Thus, when the report was published as Problems of the New Cuba (Buell, 1935), it contained a substantial analysis of the relations between men and the land.

When World War II broke out and the United States became a participant there was great concern in the United States government about what might happen in Latin America. Accordingly, the Department of state and the office of Foreign Agricultural Relations agreed to invite three of the leading rural sociologists to accept assignments to the three largest nations in Latin America for the purpose 
of studying rural patterns there. As a result, carl C. Taylor went to Argentina, Nathan L. Whetten to Mexico, and T. Lynn Smith to Brazil, each prepared to spend a year in becoming thoroughly familiar with the respective country to which he had been sent. Since the three men involved were dedicated to the advancement of their discipline as well as to their individual studies, they met together to review progress and share ideas on occasion during the field investigation, as well as regularly exchanging memoranda with one another. As a result, the three volumes which were produced were comprehensive, and covered very much the same aspects of the respective societies. These included Smith's Brazil: People and Institutions (1946), Taylor's Rural Life in Argentina (1948), and Whetten's Rural Mexico (1948).

Later on during the war, additional assignments of North American sociologists to Latin America were made. Charles P. Loomis was sent to Peru; Olen E. Leonard to Bolivia, Ecuador, and Peru; Smith was assigned to Colombia as adviser on colonization and settlement, then later returned to Brazil; and Lowry Nelson was sent to Cuba. Again, after a period of time to analyze and digest the observations which had been made and the data which had been collected, reports were issued which treated the important aspects of rural social organization, including 
land tenure, the size of farms, settlement patterns and systems of land division. These included Loomis' Studies of Rural Social organization in the United States, Latin America, and Germany (1945), Smith, Díaz, and García's Tabio: A Study in Rural Social Organization (1945), Smith's "The Cultural Setting of Agricultural Extension Work in Colombia" (1945a), and Leonard's Pichilingue (1947), Cantón Chuzzpas (1948a), and Santa Cruz (1948b). In 1950 Nelson published his volume on Rural Cuba, and in 1952 Leonard released the fifth full report on rural life in a Latin American country with his Bolivia: Land, People, and Institutions.

Unfortunately, comparable studies of the other Latin American nations were slow in being made, and the only ones which have yet come forth from rural sociologists have been made by two members of the original group who were sent out in World War II: Whetten and Smith. The former published a substantial volume entitled Guatemala: The Land and the People in 1961, while the latter added Colombia to the list of societies about which national studies had been made when Colombia: Social Structure and the Process of Development was made available (1967a). Another study of the people of an entire nation is entitled Costa Rican Life, by John and Mavis Biesanz (1944), but it is neither 
very comprehensive nor clear with regard to the several facets of man-land relationships. The study by Monteforte, Guatemala: Monografia sociológica, which was first published in 1959, is a substantial analysis of Guatemalan society, but further comment is reserved for the ensuing section on Central American studies.

The general effort to refine the tools for the sociological analysis of man-land relations continued, and the work done at the University of Florida under T. Lynn Smith's guidance was among the most fruitful. In 1954 Sam Schulman completed his dissertation on A Sociological Analysis of Land Tenure Patterns in Latin America, in which he made a careful historical analysis of the evolution of contemporary tenure patterns from their aboriginal and Iberian roots. He collected and evaluated the materials available up to that time from the agricultural censuses of the Americas, discussing the conceptual problems found in the census methodology and in the systems of classification employed. To the extent that it was possible, he also provided the quantitative data which he was able to obtain, showing the distribution of the agriculturists among the two major classes of farm operators and farm laborers. Following the completion of the dissertation, three articles reporting his findings were also published (1955, 1956a, and 1956b). 
Some other studies done under Professor Smith include the following, each limited to the area of manland relations: Thomas Ford's Man and Land in Peru (1955), Orlando Fals-Borda's A Sociological Study of the Relationships between Man and the Land in the Department of Boyaca, Colombia (1955), Harold M. Clements' A Sociological Study of the Mechanization of Agricuzture in Minas Gerais, Brazil (1966), Joseph Sardo's A Comparative Study of Selected Aspects of Rural Social Organization in Valle del Cauca, Colombia and Sicily, Italy (1968), and Nesman's study of Nicaragua (1969) which is discussed below.

Using the same frame of reference, John V. D. Saunders made a careful analysis of the size of holdings, land tenure, and systems of agriculture in Ecuador in his article entitled "Man-Land Relations in Ecuador" (1961). other scholars, many of them Latin Americans, have more recently begun to give serious consideration to these institutionalized relationships between men and the land in rural life. Among these might be included Antonio M. Arce and Manuel Alers Montalvo, both connected with the Inter-American Institute of Agricultural Sciences, who wrote, respectively, Sociologia y desarrolzo rural (1961), and Sociologia: Introducción a su uso en programas agricolas rurazes (1960), and João Goncalves de Souza, 
who drew attention to several aspects of man-land relations in his article on "Aspects of Land Tenure Problems in Latin America" in Rural Sociology in 1960. Unfortunately, the latter article reflects the frequent inaccurate use made of the term "land tenure" in Latin America by sociologists as well as others, since it actually includes a much broader range of topics than simply tenure.

During the 1950's a great deal of attention was focused on the "land problem" in Latin America, and two international conferences were held, sponsored by the Food and Agriculture Organization and other world and regional bodies. These dealt principally with the institutional problems of land tenure and its defects, the use of land, and the broad area of agrarian reform. The report of the first conference, held in 1953, was quite general, including only one recommendation: that a regional center for research in land problems be established (see Thomas F. Carroll, 1953). The second conference, in 1959, was a review of studies and projects undertaken since the 1953 meeting (Carroll, 196la).

During this same period, in an effort to identify the principal social problems of Latin American societies, T. Lynn Smith published a monograph entitled Current Social Trends and Problems in Latin America (1957a). "Latifundismo and Minifundismo" figured among the four major social 
problems identified. The others were illiteracy, health, and rural-urban migration. Among the important treatments of this problem in the context of agrarian reform are those of Carroll (1961b), Smith (1965a), and Arce (1965).

In the entire field of man-land relations analysis, the most recent developments have been in studies related largely to Latin America. In $1964 \mathrm{~T}$. Lynn Smith presented a paper entitled "Aportaciones para el estudio de los dos sistemas sociales rurales" at the VII Latin American Congress of Sociology in Bogotá, which was published in the proceedings of that meeting $(1965 \mathrm{~b})$, and later included in his monograph on The Process of Rural Development in Latin America (1967b). The foregoing monograph also includes a translation of his paper on "The Development of Familysized Farms" which was delivered before the 1959 regional conference on land problems (mentioned above), and a significant study concerning the "Improvement of the systems of Agriculture in colombia." Even more recently there have been two new additions to the field. "AgriculturalPastoral Conflict: A Major Obstacle in the Process of Rural Development," by Smith (1969a) introduces the interests of two opposing groups into the whole matter of the size of holdings, while a manuscript (as yet unpublished) on the general "Sociology of Agricultural Development" will make a broader application of principles learned in Latin America (Smith, 1969b). 
The Study of Man-Land Relations

in Central America

Genuinely sociological analyses of any aspects of the Central American societies are comparatively recent, the earliest being the volume by John and Mavis Biesanz on Costa Rica (cited earlier: 1944). The following year Smith made the first contribution to the understanding of man-land relations when he visited El Salvador and wrote "Notes on Population and Rural Social Organization in El Salvador," which was published in Rural Sociology (1945b). He pointed out the fact that a few families controlled the bulk of the land and that the independent family-sized farm was conspicuous by its absence. He also discussed the several elements of the agricultural technology and cultural practices which he soon came to call "systems of agriculture," though that term is not used in this article (see his "Sistemas agricolas," 1947b, for the first use of the term).

In the ensuing years there have been a number of genuinely sociological studies touching on man-land relations in Central America. The earliest ones were done in connection with the Inter-American Institute of Agricultural Sciences at Turrialba, Costa Rica. Charles P. Loomis, who had earlier worked in Peru, headed a series 
of studies of rural life in the vicinity of the Institute. These were done as experiments in the introduction of social change as well as for the more immediate value they had in training students in practical field research methods. Many of the studies are included in the volume which Loomis and his associates edited in 1953 entitled Turrialba: Social systems and the Introduction of Change. One of the basic ideas in the whole series of studies was the testing of differences created by (or associated with) the size of farms. Therefore many of the efforts involved the comparison of a community of small peasant farmers (San Juan Sur) with the hacienda community at Aquiares. Roy A. Clifford (1953) wrote a report on the evaluation of "Levels of Living in Hacienda and Small-Farm Villages" which showed that the hacienda workers were at a definite disadvantage. Thomas $L$. Norris analyzed the economic differences in the systems of large and small landholdings (1953a and 1953b). Prior to these studies, Paul Morrison and Jorge León (1.951) reported on the evolution of landholding and economic and social relationships in the central district surrounding the Institute, and provided a great deal of detail about one of the largest coffee plantations, Aquiares, in their "Sequent Occupance, Turrialba Central District, Costa Rica." 
Other sociological studies include several by Whetten, and those by Monteforte, Marroquín, Upchurch, and Hill. Nathan Whetten turned his attention to Guatemala after completing Rural Mexico, and his first contribution relating to our subject was an article, "Land Reform in a Modern World," dealing with Guatemala (1954). Next, in a volume published by the Seminario de Integración Social Guatemalteca in 1956, came his "Patrones de población," in which he reported on the settlement patterns found in Guatemala. This study was based upon a questionaire distributed to the alcaldes (mayors) of all the municipios of Guatemala in 1952, in which these officials were asked to indicate the nature of the settlements in the rural districts of their jurisdictions. Data on the large farm centers from the 1950 census were also employed, and the result was one of the few statistical studies of settlement patterns of which the present writer is aware. Later, in 1961, Whetten completed a full-length book on Guatemala which has already been cited among the few comprehensive studies which presently exist on Latin American societies. In it a careful treatment of the systems of land tenure is developed, and the study of size of holdings based on the 1950 agricultural census is effectively done. Descriptive material about the agricultural techniques is provided, 
but this section lacks an adequate conceptual organization. The settlement patterns are further described in the book.

Another study of Guatemala is the major effort by Mario Monteforte Toledo (1959) which must be included with Whetten's volume as one of the few national studies which exist for Central American societies. Monteforte lacked an adequate frame of reference with which to organize his analysis or presentation of man-land relationships, but the materials he gathered and the grasp of the social setting in which man-land relations are couched are good. Unfortunately, many of his observations are framed in ideological rather than objective terms. In chapters XXII and XXIII most of the relations of men to the land are treated, including a brief but revealing analysis of the implements used in agriculture (pp. 429-432).

Another Central American who turned his attention to his own country is Alejandro Marroquín, of El Salvador. This scholar, who may be his nation's only experienced sociologist, produced an excellent study of one community in his Panchimalco: Investigación sociológica (1959). Again, although he did not have a consistent framework for the organization of materials on man's social relationships with regard to the land, he discussed the various forms of land tenure very well, and conceptualized the study of 
sizes of farms and ranches effectively. This report was followed by another on San Pedro Nonualeo (n.d.), but in this case the investigation of rural social organization was less well done than it had been in his first study. Marroquin also wrote an article in 1965 in which he tried to generalize about all of Latin America. In my judgment, the article is useful, but shows that much more investigation is needed to provide the information for such a summary (see "Cambios en la agricultura y sus repercusiones sociales," 1965).

A master's thesis at the University of Florida by Harley M. Upchurch entitled "Magdalena Milpas Altas: A Study of Society in Miniature" (1960) applied the full sociological frame of reference concerning man and the land to the Guatemalan community indicated in the title, and demonstrated how the several elements are related to one another. Two studies by George W. Hill and others complete the review of the more distinctly sociological studies. The first of these concerned the area of San Vito de Java, site of an Italian colonization project in Costa Rica, and was written with Manuel Gollas and Gregorio Alfaro (1964). Later, Hill turned his attention to Guatemala, and he and Gollas produced The Minifundia Economy and Society of the Guatemalan Highland Indian (1968). During these studies, 
Dr. Hill was working on projects of the Land Tenure Center of the University of Wisconsin.

A great deal of other excellent information is available about Central American society and culture. For one who needs to see the historic evolution of the rural social systems there is no better source than a careful reading of some of the earliest travel accounts. In these, when the traveler was a keen observer, one gets a fresh and clear view of how the people behaved and thought in a particular era. In this regard I have found it particularly useful to peruse the delightful account left by Friar Thomas Gage of his sojourn in the Captaincy General of Guatemala in the 1630's and 1640's: The English American: A New Survey of the West Indies, 2648 (1946). Gage spent years serving the Church in and around Guatemala City, and as a consequence had plenty of time and opportunity to sharpen his observations. Another useful record was left by the Archbishop of Guatemala in 1768-1770, Pedro Cortés y Larraz (see his 1958). Among more recent travellers whose accounts have been read for this study are Henry Dunn (1828), John Lloyd Stephens (1841), Robert Glasgow Dunlop (1847), Ephraim George Squier (1855 and 1860), Carl Scherzer (1857), and W. T. Brigham (1887).

Other historical data have been found in the account left by Fuentes y Guzman (1932), covering the early years 
of the colony at Guatemala. Later events are chronicled by Bancroft in his three-volume History of Central America (1886), in Valentín Solórzano F. (1963), and in Soley Güell's Compendio de historia económica y hacendaria de Costa Rica (1940).

Regarding the Spanish colonial institution of the encomienda, the works of Silvio Zavala are importantparticularly his De encomiendas y propiedad territorial en aZgunas regiones de Za América Española (1940). Zavala clearly demonstrates that encomiendas and landholdings were distinct and separate, in spite of a great deal of traditional confusion over this matter.

During the 1950's two important field studies were conducted in Central America, and both contributed much information about man-land relations. The first is a series of cultural surveys sponsored by the Pan American Sanitary Bureau and directed by Richard N. Adams. The final report of the study was written by Adams (1957), and includes a separate section on each country of Central America and Panama except Costa Rica. Each report includes information on the extent of farm tenancy, and the relative prevalence of plantations and haciendas or of medium-sized farms and minifundios. Agricultural practices are reviewed, and some information on levels and standards of living is given. In the report for each country there is an extensive 
section summarizing the observations for the nation as a whole, and also a place-by-place account of distinctive observations from each of the many communities and localities visited in the course of the survey.

The second regional survey was made by a geographer under a financial arrangement with the office of Naval Research, Geography Branch. The survey was conducted by Craig Lanier Dozier and is entitled Indigenous Tropical Agriculture in Central America: Land Use, Systems, and Problems (1958). It deals with all five countries. This survey also provides information on many specific localities, covering-in a rather spotty fashion-the topics of land tenure, size of farms, title arrangements, and systems of agriculture (not identified as such). Some excellent comments in it supplement my own experience for regions I was unable to visit.

Also during the 1950 's, stimulated by the prospects of American economic assistance for development projects, the governments of Central America contracted for international teams of experts to make analyses of the prospects and priorities for economic development. Two such teams were commissioned by the International Bank for Reconstruction and Development, one studying and reporting on The Economic Development of Guatemaza (1951), and the other doing the same for Nicaragua (1953). These studies included as 
important variables the size of farms, land tenure arrangements, and rural levels of living. Considerable attention was focused on the need for credit facilities, agricultural extension, improved roads and schools, and better seeds, and animals. The Food and Agriculture Organization of the United Nations also was invited to make a number of studies in Costa Rica, Nicaragua, and El Salvador, but many of these could no longer be found in government offices in 1963, and, therefore, they have been reviewed only spottily. One of the better ones was made by Feuerlein (1954) for El Salvador, but it contains no information about man-land relations, even though its author was commissioned to study "economic and social development."

A similar study, sponsored by the Twentieth Century Fund, was made in Costa Rica under the direction of stacy May (May, et al., 1952). It was supplemented later by a report made under a contract with the United States Agency for International Development (AID), and carried out by International Development Services, Inc. (1960). The analysis included an excellent, if brief, review of the history of land settlement and titles in Costa Rica, and made concrete proposals for a new land law that would establish national policies and priorities for the handing of squatters and the alienation of the remaining national domain. 
Another Twentieth Century Fund effort to aid in the development of Central America was made during the 1950's, the result of a field investigation in Honduras by Vincent Checchi and his associates (1959). The title, Honduras: A Probzem in Economic Development, indicates something of the findings, for the problem nature of the area was evident. In spite of the official statistics, the authors emphasized considerable inequity in the holding and use of land, and grave deficiencies in agricultural systems.

About 1960, Honduras petitioned the Organization of American States (OAS) to assist her in planning agricultural development and agrarian reform in that country. In response, a technical assistance team was established as Mission 105 of the assistance program of the OAS. Subteams for many subjects were created, including one on rural sociology composed of George W. Hill and Marion $T$. Loftin. These teams all conducted field studies in sample areas of the country, and then wrote team reports to be edited as the final report and recommendation of the Mission to the government of Honduras. The report of the rural sociology team (Hill and Loftin, 1961) was never published separately, but the typescript of it contains some very acute observations on the nature of man-land 
relations in this part of Central America. The official report appeared in three volumes (OAS, 1963) as Informe oficial de la misión 105 de asistencia técnica directa a Honduras sobre reforma agraria y desarrozzo agricola. It gives a more complete analysis of man-land relations than any others of the missions and reports cited here had done. The report includes specific proposals for the development of a large area of the Aguan Valley which at that time consisted of public lands that were infested with squatters. The recommendation for a national policy favoring the family-sized farm was adopted in the agrarian reform law of 1962 .

In 1961 an international study of "Central American Land Tenure and Conditions of Agricultural Labor" ("Proyecto Tenecia de la Tierra y Condiciones del Trabajo Agrícola en Centroamérica") was undertaken by the Instituto Centroamericano de Investigaciones Económicas y Sociales. ${ }^{1}$ As is frequently the case, "land tenure" was amplified to include the consideration of the sizes of farms or holdings,

${ }^{1}$ In prosecuting this study, the Institute, a subsidiary organ of the Consejo Superior Universitario Centroamericano, enjoyed the support of UNESCO and of the Food and Agriculture Organization, the UN Economic Commission for Latin America, the International Labor Organization, the Iatin American Center for Social Research (Rio de Janeiro), and the Inter-American Development Bank. The Institute was under the direction of Lic. Oscar Chaves Esquivel, and the principal investigators were Sergio Maturana Medina, Jorge Ochoa, and Walter E. Chryst. 
and an effort was made to determine the limits of four (sometimes five) size categories: micro-farms (in Guatemala alone), subfamily-sized farms, family-sized farms, medium-sized multi-family farms, and large multifamily farms. ${ }^{1}$ A general framework was established which outlined a series of studies to be made in each country under the auspices of the national university. These were to be based on existing sources, such as the censuses. The results of these investigations vary in quality, but many of their findings were useful to the present investigator. ${ }^{2}$ Those of Ramirez (1961) and UNAH, IIES (1961a) were unique in that they analyzed each major civil division of their respective countries separately to determine the limits of their size groups. Therefore the family-sized farm, for example, is given different size boundaries in different departments or provinces.

'In the Spanish (from which I have translated the terms indicated) these are micro-fincas, fincas subfamiliares, fincas familiares, fincas multifamiliares medianas, and fincas multifamiliares grandes (Maturana, $1962: 6)$.

${ }^{2}$ Among the studies of individual countries are the following by country: Costa Rica-Aníbal Ramírez Fajardo (1961) and José Manuel Salazar N. (1962); El Salvador-Rafael Menjivar (1962) and Abelardo Torres (1961): Guatemala-José Luis Paredes Moreira, et al. (1961) and Roberto Lopez Porras (1961); Honduras-Universidad Nacional Autónoma de Honduras (UNAH), Instituto de Investigaciones Económicas y Sociales (IIES) (196la, 196lb, 196lc); Nicaragua-Nemesio Porras Mendieta (1962). 
Summary studies of the region as a whole were made and reported by Maturana (1962) and Chryst (1962) but these reports were not published in full. These studies went beyond the census and other available statistics, and included field surveys in selected areas. Later, Maturana presented a summary of his findings at a UNESCOsponsored conference in Mexico City (see Maturana, 1966). The reports deserved a greater distribution than they received-especially that of chryst, which concentrated on the distribution of income among different size and tenure groups, based on his own survey data.

Central America has been the focus of other studies recently as well. The Inter-American Committee for Agricultural Development (ICAD, or CIDA in its spanish form) ${ }^{1}$ has been actively promoting studies in the rural sector in Latin America, beginning with an Inventory of Information Basic to the Planning of Agricultural Development in Latin America. The volume of this inventory which deals with Central America (ICAD, n.d.) contains a review of the existing information on size of farms, land tenure, and

${ }^{1}$ ICAD is an international agency created when the Charter of Punta del Este was signed in 1961, and composed of the following bodies: the Food and Agriculture Organization of the United Nations, the Organization of American States, the Inter-American Development Bank, the UN Economic Commission for Latin America, and the InterAmerican Institute of Agricultural sciences. 
systems of agriculture which emphasizes again the paucity of substantial information. (The inventory, though undated, contains materials as recent as 1965.)

Another study by the Committee (CIDA, 1965) is concerned with Guatemala. The Committee sponsored a team of investigators who made field studies in selected areas of different sizes and types of farms. Heading the field work was a Cornell University Ph.D. candidate in agricultural economics: Sebald Manger-Cats. His own dissertation (1966) and the CIDA study are complementary, providing many valuable insights, but still relying almost entirely on 1950 statistics. Manger-Cats was particularly good in his treatment of the minifundistas, and in his analysis of relative incomes of agriculturists of different sizes (his Chapter XI).

Several other recent doctoral dissertations have contributed to the understanding of man-land relations in specific parts of Central America. Philip L. Wagner's study of the Nicoya peninsula in Costa Rica (1958) was a sensitive report by a cultural geographer. His style is informal and relatively unstructured, but provides a wealth of information.

Two other dissertations in geography have dealt with Costa Rica. Ulv Masing (1964) executed a very detailed study of two foreign agricultural colonies-the Italian 
settlement at San Vito de Java, and the Quaker settlement at Monteverde. Of necessity he included information on the area surrounding these colonies, and some comparisons between the immigrants and their Costa Rican neighbors. In the following year, Pierre stouse (1965) completed his study of Agricultural Settlement in Former Costa Rican Banana Regions. In the study he employed a new classification of settlement patterns combined with typical farm size, and evaluated areas on both coasts of costa Rica which had been withdrawn from banana production. It was particularly significant that he found a great deal of fire agriculture being employed in coastal areas by persons who had practiced perennial crop culture in the highlands previously (p. 163).

Another geography graduate student, Melvin Frost (1964), studied Pioneer Settrements in the Pacific Lowland of Guatemaza. His was a lengthy study of two "agrarian development" projects of the Guatemalan government, which were assisted by USAID financial and advisory support. Frost was concerned with two of the larger projects, La Máquina and Nueva Concepción. The effect of planning scattered settlement in these two largest programs $(1,288$ and 1,252 parcels, respectively) is clearly spelled out, as is the use of parcels averaging about 20 hectares for family-sized farms. 
Among other geographic studies of particular value must be included the general summary by Raymond E. Crist entitled "Central America: Aspects of the Physical and Cultural Landscapes" (1961). Frequently drawing on the reports of travelers and the observations of other scholars, Crist has fashioned a brief statement which succinctly suggests the extent of the concentration of the control of land in the hands of a few and the consequent use of marginal areas for the production of the basic food crops of the area. Older geographic studies include the McBrides' study of "Highland Guatemala and Its Maya Communities" (1942), and Felix Webster McBryde's Cultural and Historical Geography of Southwest Guatemala (1945), the latter also a doctoral dissertation.

The geographic works of the prolific German scholar, Gerhard Sandner, cannot be passed by, since they are cited so frequently in this present report. Sandner, of the University of Kiel, has been studying part-time in Costa Rica since 1958, and probably no man knows the situation with regard to agricultural colonization in that country as well as he. His studies of one region after another have included the tracing of the settlement frontiers, the evolution of the land tenure arrangements in each area, the analysis of the sizes of farms and of the settlement patterns. His many separate explorations have been 
adequately summarized in his two-volume work on $\mathrm{La}$ colonización agricola de Costa Rica (1962, 1964), which integrates the findings of the smaller regional studies into the total national picture.

Two studies of the banana industry deserve mention. The first, Social Aspects of the Banana Industry, by Kepner (1936), is over 30 years old, and is severely dated. Nevertheless, it is a reasonably good analysis of the way in which the companies formerly operated, and it exposes the philosophy of the managers in contrast to the workers. The more recent probe, sponsored by the National Planning Association and conducted by Stacy May and Galo Plaza Lasso (The United Fruit Company in Latin America, 1958) is an objective study which benefited from access to Company records not ordinarily available. May and Plaza employed a balanced approach, indicating many Company shortcomings and especially the cavalier attitude toward local interests it has sometimes expressed. At the same time credit is given for the many public services developed by the Company and for the extent to which it was doing more for its employees than other farm employers. This was the best source I was able to find regarding the extent of the Company's landholding and its use of land. Finally, in gaining perspective on the dynamic population of the region, two articles proved to be 
deserving of note. T. Lynn Smith presented a concise statement of the principal aspects of the demographic situation in each of the countries and of the region as a whole in his paper entitled "The Population of the Central American Countries" (1961). Based on the 1950 censuses, the composition and distribution of the population are treated, followed by the vital processes and the growth of population. The other study emphasizes the relationship between population characteristics and social and economic development ("Population and Economic Growth in Central America," by Robert S. Smith, 1962). The demographic pressures are related to factors such as illiteracy, disease, and real per capita income, and a pessimistic picture regarding short-run gains is presented.

This review of the most important literature has traced the development of the conceptual framework which is employed in this study, both in the United States and in Latin America. The development of rural sociological study in Latin America is also sketched to show that the present study continues considerable tradition in the analysis of key aspects of man-land relations in these predominantly-rural countries. Finally, the endeavors of previous investigators are reviewed to indicate how various persons have attempted to study the several elements of 
man-land relationships in Central America. The present analysis builds upon those previous efforts, bringing the key elements together in one volume and making several attempts to improve upon the conceptual framework and to refind the data. The present study is the first to employ the results of the 1960 censuses of the region. 


\section{CHAPTER III}

THE SIZE OF EXPLOTACIONES

Among the several elements in the total system of man-land relationships, no single factor is more important than the size of the landholding units. In general, it is the size of the holdings which is most closely related to the manner in which ownership and control of land are distributed among the agricultural population. This, in turn, affects the general wellbeing of the rural population.

The overwhelming importance of the size of landholdings has been best expressed by $T$. Lynn Smith in his studies of Brazil and Colombia (1963a:318; 1963c:6-11; 1967a: 8-24), and in his general exposition of the two major rural social systems as they relate to rural development in Latin America (1967b:11-29). He has identified ten characteristics which are highly correlated with the predominance of large holdings. These, paraphrased from the studies cited, include: (1) a high degree of social stratification, with a vast gulf separating the large landholder from the laborer; (2) little vertical social mobility; (3) the caste-like inheritance of social position; (4) low 
average levels of intelligence, and a high proportion of illiterate persons; (5) restricted personality development, due to lack of practical experience in decision-making; (6) a system of personal relationships emphasizing the unquestioned acceptance of orders from the dominant class; (7) a way of life which emphasizes the routine performance of tasks in traditional ways instead of innovation and experimentation; (8) a strong stigma attached to manual labor; (9) very low levels of living for nearly all the rural people, due in large part to low productivity; and, finally, (10) the virtual absence of any stimulus to work hard and to save for a better future.

On the other hand, where the family-sized farm is the basis for a middle-class rural society one finds the situation is reversed. For example, social class differences tend to be minimized, and the agricultural ladder provides the opportunity for vertical mobility to many of the people. The mental abilities of the inhabitants are developed, both by formal schooling and by the managerial experience gained in operating the family farm. An atmosphere of relative social equality prevails, and average levels and standards of living. are considerably better than in the areas of large-farm domination.

This chapter is concerned principally with what may broadly be identified as the well-being of all of the 
people of the rural areas of Central America. We are not particularly interested in the question of the relative efficiency of production per unit of land or capital, but are vitally concerned with the level of living that the land is able to provide for all those who derive their living from it. ${ }^{3}$ Thus the discussion of holdings of various sizes will be related to their capacity, in the given cultural setting, to provide a living which is satisfactory both economically and socially for those who are dependent upon the landholding units.

Farms, Landholdings, and Explotaciones

In the United States it is common to think in terms of "farms" when the size of agricultural holdings is under consideration. However, farms and landholdings are not always the same, and in Central America the agricultural censuses actually provide information about an entity which is neither a farm nor a landholding. This is the explotación agropecuaria. It is in order, therefore, to define terms briefly.

For sociological analysis it is best to think of a farm as all of the land under the immediate management

${ }^{3}$ An excellent classic discussion of the differential returns to labor, capital, and land in different sizes of farm units is given in Sorokin, zimmerman, and Galpin, 1930 , I: $387-395$. 
and control of a genuine farm operator. A farm operator is the person who assumes the responsibility of decisionmaking or management of an agricultural unit (see chapter IV for a fuller discussion). The farm is further defined as necessarily being of sufficient size to absorb at least the great majority of the operator's time and attention. Thus the category of genuine farms does not include small tracts of land which are used by agricultural laborers merely to supplement their wages; neither are such nonoperators as sharecroppers to be considered as having true farms. A farm is the total area under the operator's immediate control, regardless of whether it is composed of a single parcel of land or of a number of separate and distinct parts, and regardless of the ownership of the land, so long as the operator has full operational control during the time he uses it.

The concept of a landholding includes all the land under the control of an individual or group. It may include places too small to be farms, and may also at times be composed of several farms when these are controlled by one person but operated as separate units by different administrators.

The census concept of the explotación agropecuaria does not coincide with either of the preceding. The 
explotación agropecuaria is generally defined as all of the land under the technical managerial direction of one person, whether it consists of one or several parcels, and regardless of whether it is owned by this person or controlled by him through rental or other arrangements. In addition, as a matter of operational practicality, the census authorities have deemed it necessary to rule that the parcels must be in the same or neighboring minor civil divisions. Guatemalan (DGE, 1968:22) and Honduran authorities (DGEC, 1965:2-5) insist that all parcels be in the same municipio; parcels in different municipios are counted as separate explotaciones. (For the other definitions see El Salvador, DGEC, 1967:x; Nicaragua, DGEC, 1966:vii; and Costa Rica, DGEC, 1965a:xxi-xxii.)

In most cases one would expect that these three units would coincide, and many times they do. However, many explotaciones are too small to be considered as farms. In an effort to estimate the number of genuine farms (in Chapter IV), I found it necessary to classify 462,132 explotaciones (46.7 per cent of all reported) as supplementary subsistence plots of agricultural laborers which are too tiny to qualify as farms. Moreover, the census unit differs considerably from a landholding because of the separate counting of parcels which are too far distant 
from one another to be included as part of the same explotacion. Many single landholdings appear in the censuses as several explotaciones. Also, tracts falling in the same administrative jurisdiction but managed by different administrators are counted as separate explotaciones. Among the holders of large tracts the practical effect is to conceal the extent to which very large acreages are actually held by one person.

The census data on which this study is based all refer to the explotación, which includes more units than can qualify as farms, and which understates the concentration of landholdings. Nevertheless, efforts to adjust to either of the more desired concepts are not practical in this chapter. (But see the estimate of the number of genuine farms in Chapter IV.)

A Functional Classification of Sizes of Explotaciones

To grasp the more important distinctions between explotaciones of various sizes it is necessary to group them in broad size classes as well as to see the full range of sizes as reported by the censuses. The rationale for the groupings employed in this study is simple. The present section presents the reasoning involved and the operational sizes ultimately selected. 
Conceptually Defined Sizes

There are three easily-distinguished sizes of explotaciones which are employed throughout the ensuing analysis. While a further division into a more detailed range of sizes would be possible, the conceptual differentiation would become considerably more complex, and the practical or operational equivalents would be far less secure. It is adequate for present purposes to divide all explotaciones into the following three categories: small units (comonly called minifundios), family-sized farms, and multi-family farms. The latter two groupings approximate genuine farms and are so designated, while the first includes many places clearly too small for this term to be applied to them.

The family-sized farm.-This is the form widely desired and almost universally encouraged by experts for Latin America, ${ }^{\prime}$ and its definition provides a logical

'Note, for example, the following quotation from a Seminar on Land Problems in Latin America (Carroll, 1953:32): "Throughout the Seminar, the Group affirmed and reaffirmed its faith in the family farm as the ideal or optimum type." It must be stressed, however, that the encouragement of the family-sized farm is not universal, as may be indicated by the reaction of a San Salvador banker's wife to the Alliance for Progress when President Kennedy announced it: "That man [Kennedy] wants to give everything we have to. . . to... to.. . those animals with names" (Lavine, 1964:89). 
point of departure for the analysis of the full range of sizes of explotaciones. No total agreement exists as to just what constitutes a family-sized farm, but the basic idea is that of a unit operated as a family enterprise, which is sufficiently large to give full employment to the available family labor force and likewise large enough to provide an acceptable living for the family. A more complete definition includes the following basic elements :

1. Farming is the principal occupation of the operator

2. The lower limit of land area is such that the farm:

a. is sufficient to fully employ the family labor force

b. is sufficient, with reasonably efficient utilization, to support the family at an acceptable level of living without recourse to supplementary off-farm employment of family members

c. is large enough to provide a salable surplus beyond family consumption needs, both to provide for non-home-produced goods, and the accumulation of capital

d. is large enough to permit good land management practices, and to avoid soil depletion

e. is large enough to permit improvement in technology as the knowledge and ability of the operator are increased

3. The upper limit of land area is set by the requirements that: 
a. the farm operator and his family perform the bulk of the labor required, hiring only farm hands to assist themselves

b. reliance on the family labor force does not mean the inability to utilize the farm area effectively and appropriately.

If these qualifications for a family-sized farm are accepted, then conceptually it is easy to define at least two other sizes of explotaciones: those smaller than the family-sized unit, and the larger ones above the capacity of family operation. Basically, this is the rationale for the three-fold division of farms by size in this study.

Smalz explotaciones or minifundios.-Logically, those explotaciones which are too small to qualify as family-sized farms are placed in this category. The term minifundio is often applied to such tracts. The largest such places are subsistence plots from which the operator barely is able to eke out a livelihood. However, throughout Central America there are many places too small even to be self-sufficient on a subsistence basis. The users of the latter typically work for others as

${ }^{1}$ The above elements of the family-sized farm are, of course, not original with the writer, although this specific combination of them is new, to my knowledge. Many of the above requirements are found in T. Lynn Smith, 1953:301 and 304; Carroll, 196la:15; and Carroll, 1953:32-40. The Ley de Reforma Agraria Social of Colombia has a very good statement of the basic characteristics of the unidad agricola familiar (see T. Lynn Smith, 1967a:241). 
farm laborers, supplementing their wages with the produce of their tiny tracts. This size category also includes the sharecropper and the colono-the latter being a person who is allotted the use of a small patch of land as part of his remuneration for laboring regularly for the landholder. (See Chapter IV for a full discussion of the colono's tenurial status.)

In conceptual terms this type of explotación is ambiguous. Many of the persons who hold such plots are simultaneously farm "operators" on a small scale and farm laborers in the employ of others. Some of the holders are employed most of the time outside of the agricultural field, farming their own small parcels on a supplemental basis. These places run the gamut of sizes from tiny garden patches to nearly self-sufficient farms. About the most that can be said is that the minifundios are clearly no more than marginal farms. Their possessors rarely enjoy more than a very low level of living.

The multi-family farm-The third major category into which explotaciones may be classified readily on the basis of size is that of the multi-family farm. Obviously, this grouping includes all those farms for which the size exceeds the capacity of a family to operate. However, there are two basic subclasses of multi-family farms which, by their nature, are clearly distinct from one another. 
The traditional hacienda, or large, relatively little-used cattle ranch, is one type of multi-family farm. Typically the hacienda has a considerable expanse of good fertile land at its disposal. This land is used in an extensive manner to graze a herd of relatively low-grade cattle for as many as six years before they are marketed. In order to ensure that the needed laborers will always be available, the hacienda also devotes some land to the production of food and fibers. This production is accomplished on small plots of the poorer or more hilly land which are assigned to colonos or sharecroppers. From these tracts the food and other necessities of both the workers and the farm operators are obtained, making the hacienda a virtually self-contained economic and social unit. This type of multi-family farm has been frequently described (see Tannenbaum, 1962:Chapter 5; Marroquín, 1959 :185; Carroll, 1961b:164; and T. Lynn Smith, 1967a:2526). An illustration from Honduras is given below. The other class of large farm is the plantation. It also requires the labor of many families and a great deal of land, but its principal raison d'etre is the production of one or two commercial crops on an intensive basis.'

${ }^{1}$ See the acute discussions provided by Smith (1967a:44, and 1959:126-127). On some of the effects of the single-crop emphasis, Marsh (1947) has given particular attention to the case of coffee plantations in El Salvador. Whetten (1961:124137) describes many facets of the plantation in Guatemala. 
On the traditional plantations there may be a semi-feudal relationship between the operator and his workers which provides some paternalistic "benefits," but on the more modern farms of this class the relationships tend to be strictly impersonal. In Central America the plantation is closely linked with the production of coffee, bananas, cotton, and sugar cane. Other crops such as palm nuts, and henequen are generally produced on plantations, and occasionally such a place will undertake the raising of tomatoes, cucumbers, or pineapples for shipment to the United States.

Empirically Defined Size Classes in Central America

It is much easier to have a mental concept of a size-of-farm class than it is to put the idea into operational terms. Nevertheless, for the analytical purposes of this study it is necessary to set some definite limits for each of the major categories of farms and explotaciones. The problem is greatly compounded when the only measure available for farm size is the physical dimension of the land controlled. However, recognizing that there are vast differences between different types of farming, and that varying technologies, soils, topography and water resources all complicate the matter further, a general definition has been established for each of the three size classes. Family-sized farms. - A single definition for the family-sized farm throughout Central America is desirable, 
and for the present analysis it is felt that a broad size class can be justifiably employed. After reviewing the many limited studies in the area which revealed that both intra-country and inter-country variations were considerable (see, for example, UNAH, Instituto de Investigaciones Económicas y Sociales, 196la:51-57, and cuadros 30-47), I feel that the vast majority of geruine family-sized farms fall within the limits of 10 to 99 manzanas of farm area. This conclusion is based on an analysis of the labor force employed on farms in all of the countries except Nicaragua (see Figures 1 and 2), and on the results of many studies, including those noted in Table 1.

Most investigators have preferred a smaller upper limit for the family-sized farm classification, and, based on the systems of agriculture which are predominant today, a smaller area would be justified. Recognizing, however, that the trend is toward the progressive improvement of agricultural technology, I have chosen the widest practical dimensions with the goal of including the places which are potentially of family size. Among contemporary operators only the most capable and ambitious could handle over 100 manzanas on a family-operated basis, and the number of such persons is quite small. Few of the owners of places of 50 or more manzanas actually perform the majority of the work on their own farms. Instead, throughout the region 


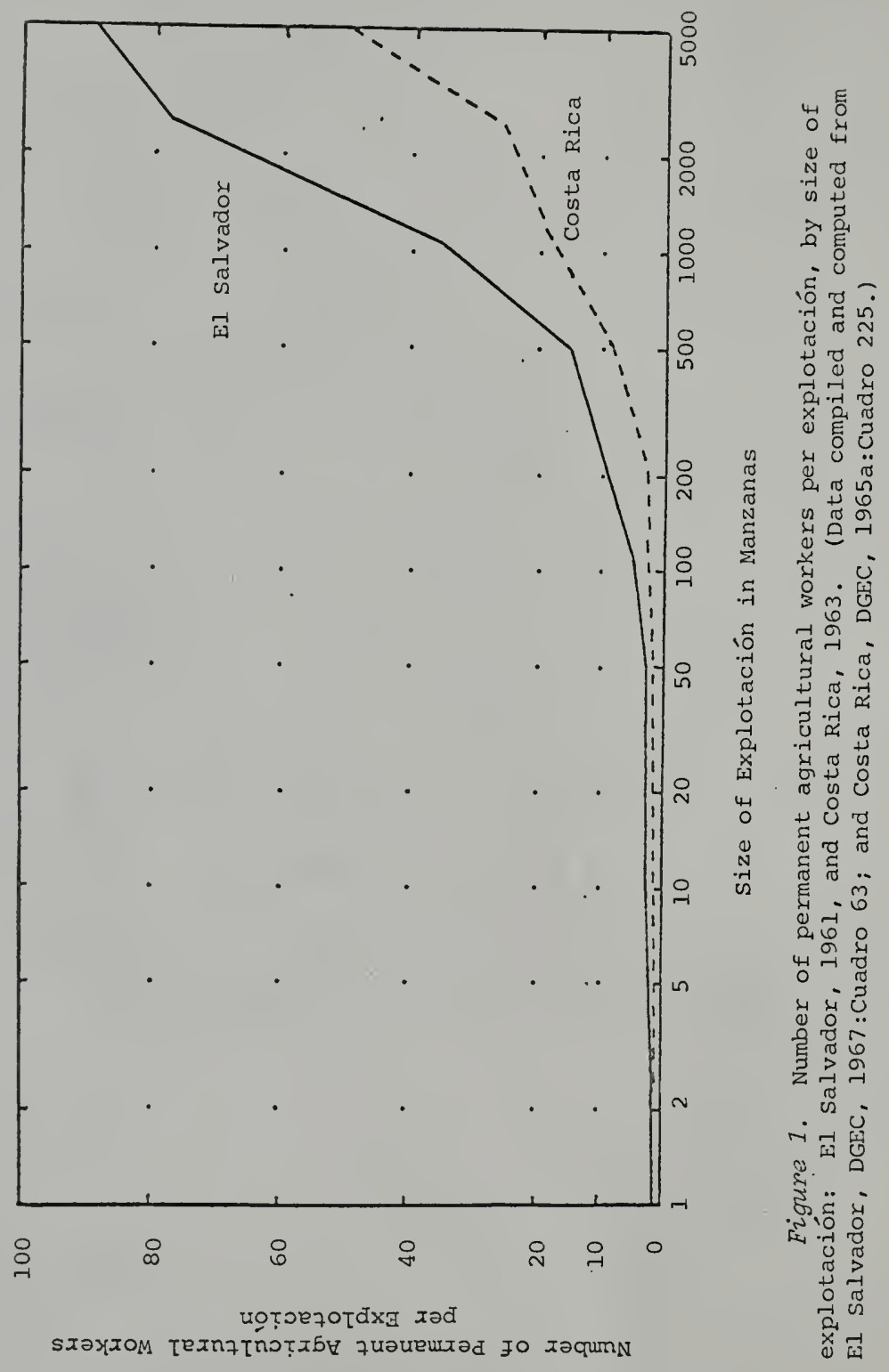




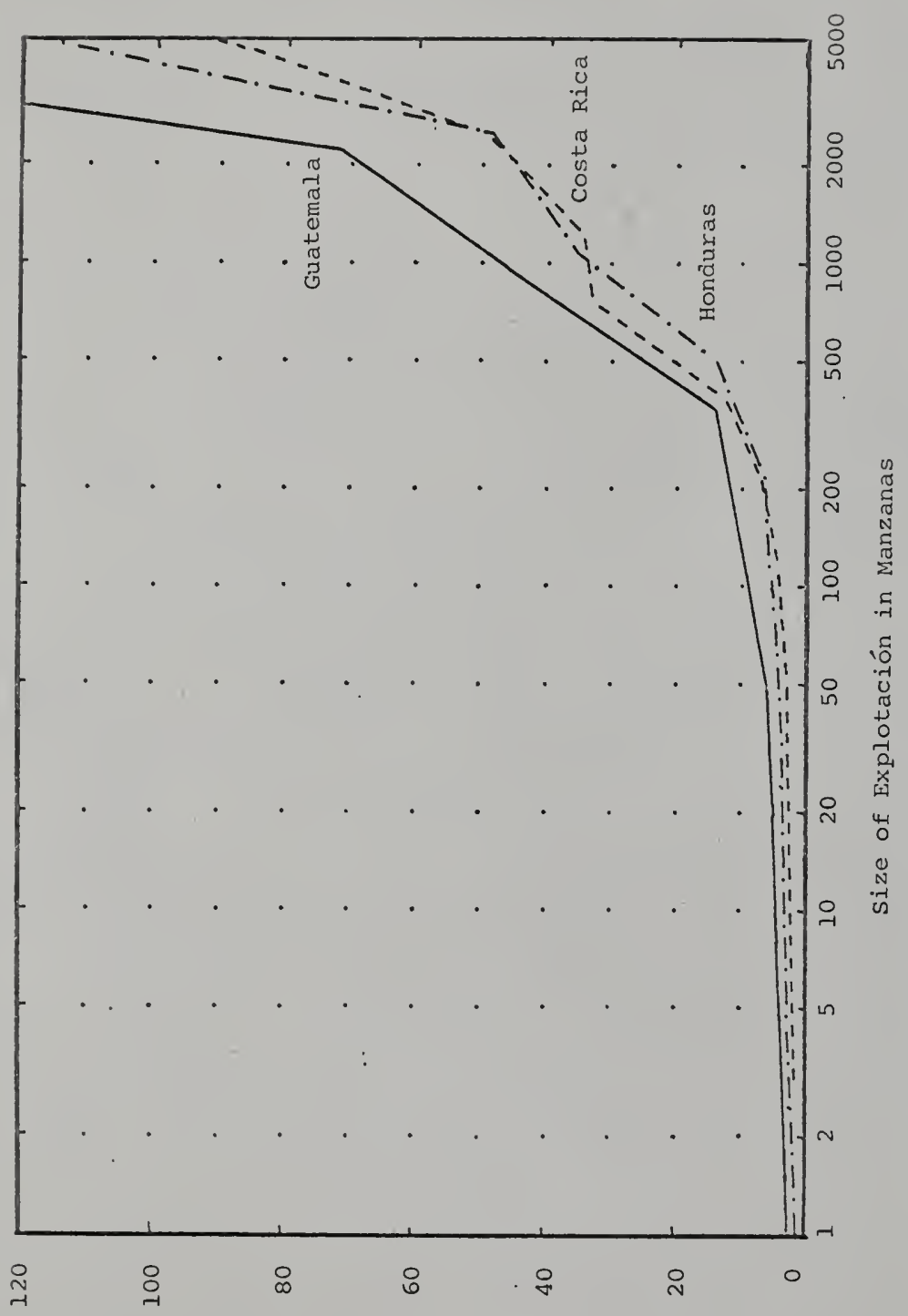

ชู

ज्ञ

-1

एँ के.न

है

我出

ธㅇํㅇㅇㅣ

त क

की

Uี

กี 거 , in in

प्र 40

औ

ป

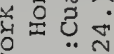

उ.. $\ddot{u}$ స

○

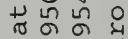

ज

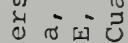

जै

0 ह

उ.

तี

भुำ

ㄱ.

उ. 3

-7

पू山 ซ

范要

फू

400

0)

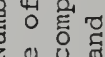

N

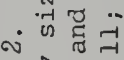

है त्व ठृ ट्ञ

Sँ

तथ

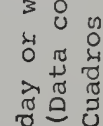

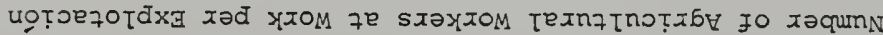


Table 1. The family-sized farm as defined in some of the current literature on Latin America

\begin{tabular}{|c|c|c|}
\hline Size Limits & $\begin{array}{l}\text { Country of } \\
\text { Reference }\end{array}$ & Citation \\
\hline 6-20 ha. & Costa Rica & Montealegre, 1942a:597 \\
\hline 10-16 ha. & Honduras & OAS, 1963, III: 156 \\
\hline 15-29 ha. & El Salvador & $\begin{array}{l}\text { Menjivar, 1962:II; Maturana, 1962: } \\
\text { I28 }\end{array}$ \\
\hline 10-45 ha. & Costa Rica & Montoya, 1954:6 \\
\hline 10-99 ha. & Latin America & Goncalves de Souza, 1960:31 \\
\hline $10-200$ ha. & Ecuador & Saunders, 1961:58 \\
\hline $5-29 \mathrm{mz}$ & Costa Rica & Maturana, 1962:31 \\
\hline $5-49 \mathrm{mz}$ & Nicaragua & Nesman, $1969: 36$ \\
\hline $5-64 \mathrm{mz}$ & Guatemala & Frost, $1964: 135$ \\
\hline $10-49 \mathrm{mz}$ & Nicaragua & $\begin{array}{l}\text { OAS, Interamerican Economic and } \\
\text { Social Council, 1962: Cuadro } 74\end{array}$ \\
\hline $10-49 \mathrm{mz}$ & Nicaragua & Maturana, 1962:318 \\
\hline $10-63 \mathrm{mz}$ & Guatemala & $\begin{array}{l}\text { Maturana, } 1962: 177 ; \text { CIDA, 1965:56; } \\
\text { Manger-Cats, 1966:13 }\end{array}$ \\
\hline $10-99 \mathrm{mz}$. & Costa Rica & $\begin{array}{l}\text { International Development Services, } \\
\text { Inc., 1960:Appendix pp. 5, } 6\end{array}$ \\
\hline
\end{tabular}


the writer found numerous families who were cultivating only a small part of their land themselves $\rightarrow$ ften around 30 manzanas and who were utilizing tenants or medieros (sharecroppers) to work the rest. Sometimes this pattern appeared to be due as much to the desire to hold the status of a landlord as to any personal inability to work all the land available. Thus many places in the chosen category of family-sized farms are actually run as small haciendas or little plantations.

The designation of 10 manzanas as the lower limit of the family-sized farm grouping is also arbitrary. Many studies have chosen a smaller minimum (see Table l). However, Barraclough and Domike (1966:396) reported that in Guatemala

a large portion-as many as half-of the family-sized units (using the ICAD classification [10-63 manzanas]) were found upon field investigation really to be "minifundia" although this is obscured in the census data because of the prevalence of disguised underemployment on the smaller farms.

In addition to the disguised underemployment on the smaller places, the same trend toward more efficient agricultural systems which justifies a larger upper limit is applicable to the minimum as well. One could reasonably argue that family-sized farms should be no smaller than 20 manzanas, as the Law of Agrarian Transformation specifies for Guatemala (INTA, 1964 :Article 75). 
As indicated, the preferred limits for the category of family-sized farms are a minimum of 10 manzanas and a maximum of 99.9. Owing to the varied methods of tabulating farm sizes in the censuses, and the different units utilized in measuring land area, however, the closest approximations to the desired limits have had to be substituted in this study. Therefore the actual limits used in describing the class of family-sized farms are:

$\begin{array}{ll}\text { Guatemala } & 10-63.9 \text { manzanas } \\ \text { EI Salvador } & 10-99.9 \text { hectares } \\ \text { Honduras } & 10-99.9 \text { manzanas } \\ \text { Nicaragua } & 10-99.9 \text { manzanas } \\ \text { Costa Rica } & 10-99.9 \text { manzanas }\end{array}$

While these limits are admittedly arbitrary, they provide a simplified base for the description of the situation in Central America with regard to the general size of farms and the relationship of size to several facets of man-land relationships.

Small explotaciones or minifundios. - Setting the limits of the family-sized farm class necessarily creates another class of places too small to qualify as familysized. These are the minifundios and subsistence tracts already described above. In this study all explotaciones of fewer than 10 manzanas ( 10 hectares in El Salvador) are considered as belonging in this class. Since the labor force data show that two or more persons are employed 
even on these small places it is worthy of note that often a farm family will use all its able-bodied members equally even if fewer persons could accomplish the work. This is done both to spread such work as there is among the available hands equally, and perhaps also to justify the right of each person to a share of the product.

Multi-family farms. -Basically those farms and

ranches larger than 100 manzanas in extension are considered to be multi-family operations. This says nothing about the extent to which the land is utilized, or whether its use is extensive or intensive, if used at all. From the available census reports there appear to be no data sufficient to distinguish between (I) the large properties which are inadequately farmed with hired hands, (2) large haciendas virtually uncultivated, and (3) large, reasonably efficient plantations. There is plenty of evidence to substantiate that all three sorts of multi-family establishments exist in Central America, as is shown in the discussion of the various sizes below. In this study multi-family farms and ranches are those within the following limits:

$\begin{array}{lr}\text { Guatemala } & 64 \text { manzanas or more } \\ \text { El Salvador } & 100 \text { hectares or more } \\ \text { Honduras } & 100 \text { manzanas or more } \\ \text { Nicaragua } & 100 \text { manzanas or more } \\ \text { Costa Rica } & 100 \text { manzanas or more }\end{array}$


No effort is made here to define the latifundio or uneconomically developed and underutilized large property, but at times the more or less conventional 1,000 hectare (or manzana) and larger farms will be singled out as a separate grouping.

Distribution of Explotaciones by Size in Central America

The agricultural censuses of the Central American nations have recently provided a wealth of data about the farm enterprises and the explotaciones agropecuarias of the region. In this section a broad picture of the general distribution of farms by size is followed by the analysis of the concentration of control over land. The familysized farm also is treated as a separate topic, and then some examples of farms of various sizes from the area are used to give reality to the statistical picture.

\section{The Broad Central American Picture}

The minifundio is the predominant size of explotacion in Central America. In summarizing the most important facts about the size of farms in the region, including that about the minifundios, Table 2 has been prepared, Employing the broad categories previously defined, the number of explotaciones and the amount of farmland encompassed by each are 
Table 2. Absolute and relative number of explotaciones, and absolute and relative amount of land in explotaciones, in three major size classes: Central American countries and Central American region in the $1960^{\prime} \mathrm{s}$

\begin{tabular}{|c|c|c|c|c|}
\hline \multirow{2}{*}{$\begin{array}{c}\text { Country, Year, and } \\
\text { Size Class }\end{array}$} & \multicolumn{2}{|c|}{ Explotaciones } & \multicolumn{2}{|c|}{ Land in Explotaciones } \\
\hline & Number & Per Cent & Manzanas & Per Cent \\
\hline Guatemala (1964) & 417,344 & 100.0 & $4,926,766$ & 100.0 \\
\hline $\operatorname{Small} 1^{a}$ & 364,879 & 87.4 & 916,616 & 18.6 \\
\hline Family-sized $b$ & 43,656 & 10.5 & 928,674 & 18.8 \\
\hline Multi-familyc & 8,809 & 2.1 & $3,081,476$ & 62.6 \\
\hline El Salvador (1961) & 226,896 & 100.0 & $2,261,442^{d}$ & 100.0 \\
\hline Smalla & 207,299 & 91.4 & $495,022^{d}$ & 21.9 \\
\hline Family-sized $b$ & 17,449 & 7.7 & $687,484^{d}$ & 30.4 \\
\hline Multi-familyc & 2,148 & 0.9 & $1,078,936 d$ & 47.7 \\
\hline Honduras (1966) & 178,361 & 100.0 & $3,452,933$ & 100.0 \\
\hline $\operatorname{Smal1}{ }^{a}$ & 120,442 & 67.5 & 427,463 & 12.4 \\
\hline Family-sized $b$ & 53,518 & 30.0 & $1,374,596$ & 39.8 \\
\hline Multi-familyc & 4,402 & 2.5 & $1,650,874$ & 47.8 \\
\hline Nicaragua (1963) & 102,201 & 100.0 & $5,461,162$ & 100.0 \\
\hline Smalia & 51,926 & 50.8 & 190,098 & 3.5 \\
\hline Family-sized $b$ & 38,925 & 38.1 & $1,293,105$ & 23.7 \\
\hline Multi-familyc & 21,340 & 21.1 & $3,977,959$ & 72.8 \\
\hline Costa Rica (1963) & 64,621 & 200.0 & $3,815,350$ & 100.0 \\
\hline Smalla & 27,925 & 43.2 & 110,984 & 2.9 \\
\hline Family-sized $b$ & 29,949 & 46.4 & $1,032,877$ & 27.1 \\
\hline Multi-familyc & 6,747 & 10.4 & $2,671,489$ & 70.0 \\
\hline Central American Region & 989,423 & 100.0 & $19,917,653$ & 100.0 \\
\hline Smalla & 722,480 & 78.1 & $2,140,183$ & 10.7 \\
\hline Family-sized $b$ & 183,497 & 28.5 & $5,316,763$ & 26.7 \\
\hline Multi-family $y^{c}$ & 33,446 & 3.4 & $12,460,734$ & 62.6 \\
\hline
\end{tabular}

SOURCE: Compiled from data in Tables $4 \mathrm{~A}$ to $4 \mathrm{E}$.

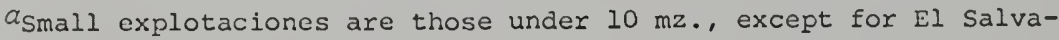
dor where they are under $10 \mathrm{ha}$.

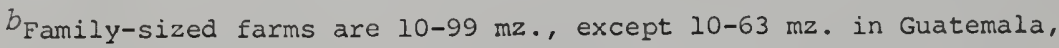
and 10-99 ha. in El Salvador.

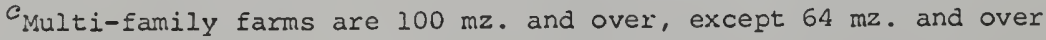
in Guatemala, and $100 \mathrm{ha}$. and over in El Salvador.

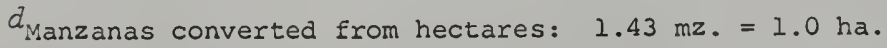


presented for the region as a whole, and for each of the countries. Of a regional total of nearly l million explotaciones, some 770,000 places ( 78 per cent) are too small to be classed as family-sized farms. Since explotaciones in this grouping generally are so limited that their operators must seek other employment as well, it is clear that only a small proportion of the agricultural personnel of Central America may be thought of as "independent" farmers. 1

Family-sized farms, on the other hand, prove to be only a small minority of the agricultural units of the region, as only about 183,000 farms (18.5 per cent) fall in the fairly generous size range assigned to this category. Multi-family farms and plantations make up slightly more than 3 per cent of all units.

The very large number of explotaciones which are smallex than family-sized takes on aditional meaning when the data showing amounts of land in various classes of farms are considered (see the last two columns in Table 2). Together these small places embrace just over 2 million manzanas ( 10.7 per cent) of the land in farming units. They average about 2.8 manzanas each.

${ }^{1}$ The division of the agricultural personnel between farm operators and farm laborers is left to the next chapter (IV), where estimates of the numbers of each are given. 
Family-sized farms, on the other hand, encompass over 5 million manzanas of farmland, with an average size of 29 manzanas. They contain 26.7 per cent of all the land in farms. The multi-family farms average 373 manzanas each, and together they embrace 62.6 per cent of the land in explotaciones.

In order to indicate the geographic variation in the sizes of explotaciones, the median size of agricultural and stock raising units has been computed for each major civil division of Central America. The results of these computations are shown in Figure 3 , where the darker shadings represent the larger medians. From the figure it is evident that the typical explotacion is smallest in El Salvador, with Guatemala presenting a similar situation. The average farm is progressively larger as one examines the data for Honduras, Nicaragua, and Costa Rica in that order. In Costa Rica the national median is 14.8 manzanasbarely within the family-sized range; comparable figures for the other countries are: Nicaragua, 9.7 manzanas; Honduras, 5.6; Guatemala, 2.5; and El Salvador, 1.6. For Central America as a whole the median is estimated to be

\section{2 manzanas. ${ }^{1}$}

${ }^{1}$ This estimate is relatively crude due to the necessity of employing data with different size-of-class intervals and different dates of reference. It is, nevertheless, the best single indicator I am able to provide. 


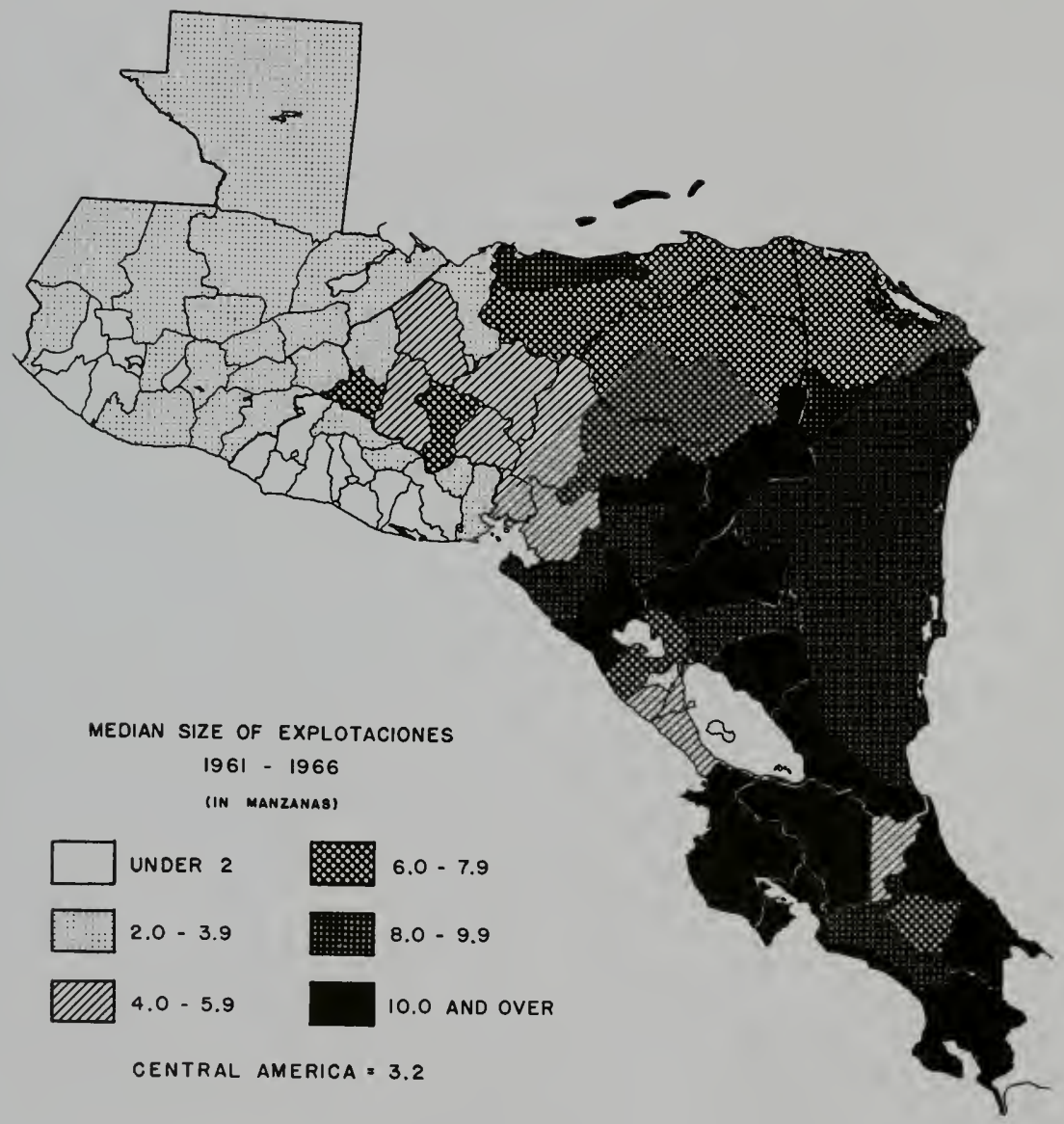

Figure 3. Median size of explotaciones agropecuarias, by major civil divisions: Central America in the 1960's. (Data compiled and computed from Guatemala, DGE, 1968:Cuadro 1-1; El Salvador, DGEC, 1967: Cuadro 31; Honduras, DGEC, 1967 :Cuadro 1 for each department; Nicaragua, DGEC, 1966:Tabla 26; and Costa Rica, DGEC, 1965a:Cuadro 8.) 
The areas in solid black are the only divisions in which the median falls in the family-sized category. In general, these are areas of relatively little population density, although some less densely settled areas have mostly small farms: e.g., El Petén, in Guatemala, and Olancho and Gracias a Dios, in Honduras.

The High Degree of Concentration of Control over Land One of the important facets of man-land relationships is the degree to which the ownership and control of land are concentrated in the hands of relatively few people. In the Central American region 3.4 per cent of the explotaciones (the multi-family category) account for 62.6 per cent of the land in explotaciones, a fact which indicates a great degree of concentration in the effective control of land. The larger ones of the multi-family farms, generally those of 1,000 or more manzanas, are treated separately in Table 3, where the data for each country are shown in relation to the total farmland and the entire national territory. The conventional, complete presentation of explotaciones and farmland by size of explotación is given for each country in Tables $4-A$ to $4-E$. For Central America as a whole, 1,777 farms ( 0.2 per cent of the explotaciones) include 26.0 per cent of the land in farms and 8.5 per cent of the entire territory. As may be seen, there are many 


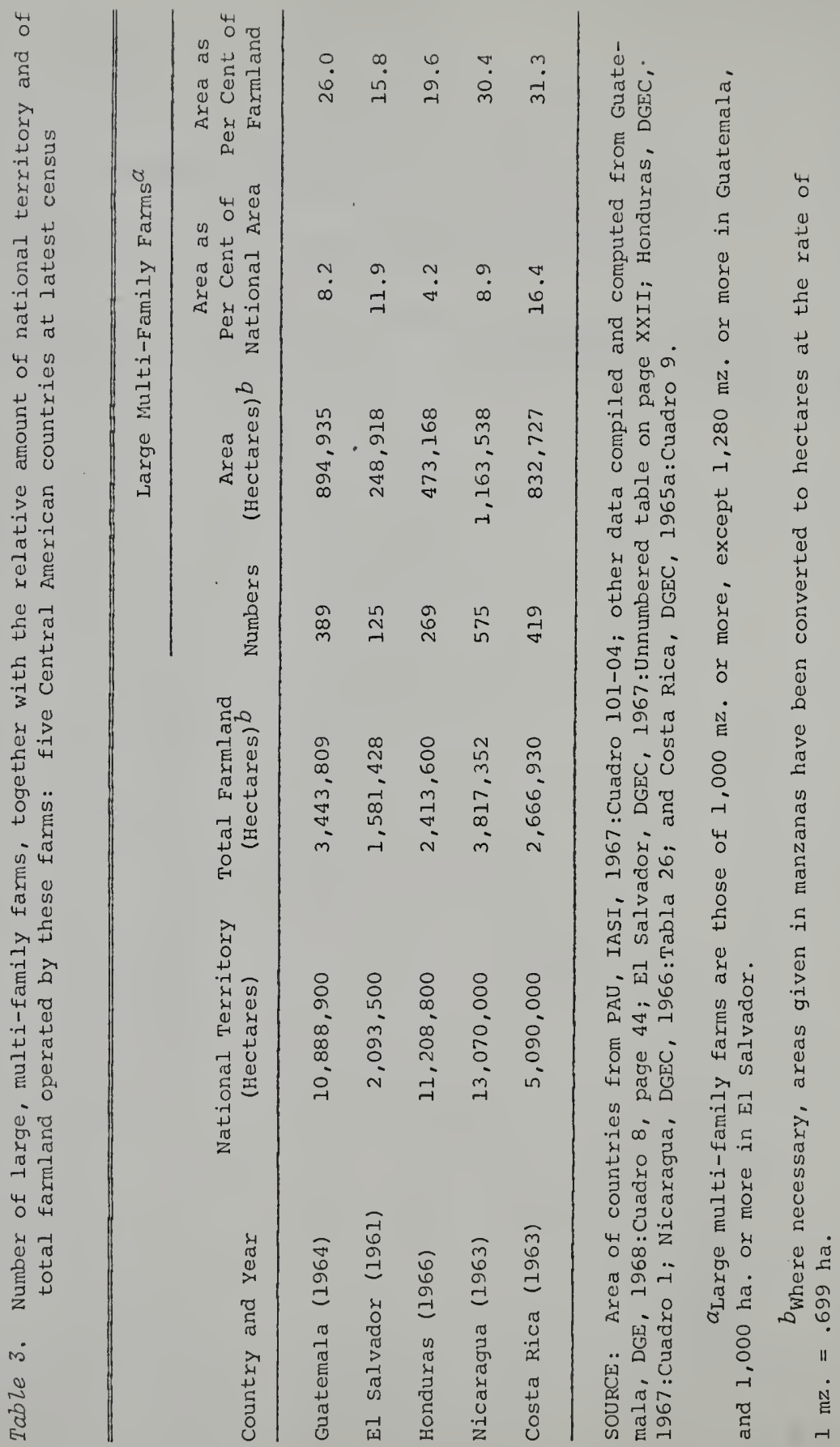


Table 4A. Absolute and relative number of explotaciones, and absolute and relative amount of land in explotaciones, by size of explotación: Guatemala, 1964

\begin{tabular}{|c|c|c|c|c|}
\hline \multirow{2}{*}{$\begin{array}{c}\text { Size of Explotaciones } \\
\text { (Manzanas) }\end{array}$} & \multicolumn{2}{|c|}{ Explotaciones } & \multicolumn{2}{|c|}{ Land in Explotaciones } \\
\hline & Number & Per Cent & Manzanas & Per Cent \\
\hline Under 1 & 85,083 & 20.4 & 46,683 & 0.9 \\
\hline $1-1.9$ & 98,658 & 23.6 & 136,325 & 2.8 \\
\hline $2-4.9$ & 129,115 & 30.9 & 386,704 & 7.9 \\
\hline $5-9.9$ & 52,023 & 12.5 & 346,904 & 7.0 \\
\hline Under 10 & 364,879 & 87.4 & 916,616 & 18.6 \\
\hline $10-31.9$ & 37,025 & 8.9 & 637,948 & 12.9 \\
\hline $32-63.9$ & 6,631 & 1.6 & 290,726 & 5.9 \\
\hline $10-63.9$ & 43,656 & 10.5 & 928,674 & 18.8 \\
\hline $64-639.9$ & 7,859 & 1.9 & $1,307,255$ & 26.6 \\
\hline $640-1,279.9$ & 561 & 0.1 & 493,913 & 10.0 \\
\hline $1,280-3,199.9$ & 294 & 0.1 & 552,990 & 11.2 \\
\hline $3,200-6,399.9$ & 56 & $---\alpha$ & 242,496 & 4.9 \\
\hline $6,400-12,799.9$ & 30 & $---a$ & 254,926 & 5.2 \\
\hline 12,800 and Over & 9 & $---a$ & 229,896 & 4.7 \\
\hline 64 and Over & 8,809 & 2.1 & $3,081,476$ & 62.6 \\
\hline Total & 417,344 & 100.0 & $4,926,766$ & 100.0 \\
\hline
\end{tabular}

SOURCE: Compiled and computed from Guatemala, DGE, 1968:Cuadro 7, page 43. $a_{\text {Less than }} 0.05$ per cent. 
Table $4 B$. Absolute and relative number of explotaciones, and absolute and relative amount of land in explotaciones, by size of explotación: El Salvador, 1961

\begin{tabular}{|c|c|c|c|c|}
\hline \multirow{2}{*}{$\begin{array}{c}\text { Size of Explotaciones } \\
\text { (Hectares) }\end{array}$} & \multicolumn{2}{|c|}{ Explotaciones } & \multicolumn{2}{|c|}{ Land in Explotaciones } \\
\hline & Number & Per Cent & Hectares & Per Cent \\
\hline Under 1 & 107,054 & 47.2 & 63,365 & 3.9 \\
\hline $1-1.9$ & 48,501 & 21.4 & 68,542 & 4.3 \\
\hline $2-4.9$ & 37,743 & 16.6 & 117,471 & 7.4 \\
\hline $5-9.9$ & 14,001 & 6.2 & 98,791 & 6.3 \\
\hline Under 10 & 207,299 & 91.4 & 346,169 & 21.9 \\
\hline $10-19.9$ & 8,524 & 3.7 & 117,426 & 7.4 \\
\hline $20-49.9$ & 6,711 & 3.0 & 208,628 & 13.2 \\
\hline $50-99.9$ & 2,214 & 1.0 & 154,704 & 9.8 \\
\hline $10-99.9$ & 17,449 & 7.7 & 480,758 & 30.4 \\
\hline $100-199.9$ & 1,121 & 0.5 & 158,499 & 10.0 \\
\hline $200-499.9$ & 713 & 0.3 & 219,204 & 13.8 \\
\hline $500-999.9$ & 189 & 0.1 & 127,880 & 8.1 \\
\hline $1,000-2,499.9$ & 91 & $---a$ & 132,310 & 8.4 \\
\hline 2,500 and over & 34 & $---a$ & 116,608 & 7.4 \\
\hline 100 and Over & 2,148 & 0.9 & 754,501 & 47.7 \\
\hline Total & 226,896 & 100.0 & $\underline{1,581,428}$ & 100.0 \\
\hline
\end{tabular}

SOURCE: Compiled and computed from El Salvador, DGEC, 1967:Cuadros 31 and 32 .

$\alpha_{\text {Less than }} 0.05$ per cent. 
Table $4 \mathrm{C}$. Absolute and relative number of explotaciones, and absolute and relative amount of land in explotaciones, by size of explotación: Honduras, 1966

\begin{tabular}{|c|c|c|c|c|}
\hline \multirow{2}{*}{$\begin{array}{c}\text { Size of Explotaciones } \\
\text { (Manzanas) }\end{array}$} & \multicolumn{2}{|c|}{ Explotaciones } & \multicolumn{2}{|c|}{ Land in Explotaciones } \\
\hline & Number & Per Cent & Manzanas & Per Cent \\
\hline $1-4.9$ & 84,128 & 47.2 & 187,843 & 5.5 \\
\hline $5-9.9$ & 36,313 & 20.3 & 239,620 & 6.9 \\
\hline $1-9.9$ & 120,441 & 67.5 & 427,463 & 12.4 \\
\hline $10-19.9$ & 27,112 & 15.2 & 359,607 & 10.4 \\
\hline $20-49.9$ & 19,977 & 11.2 & 588,750 & 17.1 \\
\hline $50-99.9$ & 6,429 & 3.6 & 426,239 & 12.3 \\
\hline $10-99.9$ & 53,518 & 30.0 & $1,374,596$ & 39.8 \\
\hline $100-199.9$ & 2,449 & 1.4 & 322,668 & 9.3 \\
\hline $200-499.9$ & 1,286 & 0.8 & 379,270 & 11.0 \\
\hline $500-999.9$ & 398 & 0.2 & 272,015 & 7.9 \\
\hline $1,000-2,499.9$ & 196 & 0.1 & 288,576 & 8.4 \\
\hline 2,500 and Over & 73 & $---a$ & 388,345 & 11.2 \\
\hline 100 and Over & $\underline{4,402}$ & 2.5 & $\underline{1,650,874}$ & 47.8 \\
\hline Total & 278,361 & 100.0 & $3,452,933$ & 100.0 \\
\hline
\end{tabular}

SOURCE: Compiled and computed from Honduras, DGEC, 1967:Cuadro 1. $a_{\text {Less }}$ than 0.05 per cent. 
Table 4D. Absolute and relative number of explotaciones, and absolute and relative amount of land in explotaciones, by size of explotación: Nicaragua, 1963

\begin{tabular}{|c|c|c|c|c|}
\hline \multirow{2}{*}{$\begin{array}{c}\text { Size of Explotaciones } \\
\text { (Manzanas) }\end{array}$} & \multicolumn{2}{|c|}{ Explotaciones } & \multicolumn{2}{|c|}{ Land in Explotaciones } \\
\hline & Number & Per Cent & Manzanas & Per Cent \\
\hline Under 1 & 2,258 & 2.2 & 1,328 & $--a$ \\
\hline $1-4.9$ & 33,948 & 33.2 & 83,042 & 1.5 \\
\hline $5-9.9$ & 15,730 & 15.4 & 105,728 & 2.0 \\
\hline Under 10 & 51,936 & 50.8 & 190,098 & 3.5 \\
\hline $10-19.9$ & 13,273 & 13.0 & 173,976 & 3.2 \\
\hline $20-49.9$ & 14,703 & 14.4 & 440,159 & 8.1 \\
\hline $50-99.9$ & 10,949 & 10.7 & 678,970 & 12.4 \\
\hline $10-99.9$ & 38.925 & 38.1 & $1,293,105$ & 23.7 \\
\hline $100-199.9$ & 6,291 & 6.1 & 768,633 & 14.1 \\
\hline $200-499.9$ & 3,554 & 3.5 & 961,015 & 17.6 \\
\hline $500-999.9$ & 920 & 0.9 & 583,736 & 10.7 \\
\hline $1,000-2,499.9$ & 405 & 0.4 & 563,303 & 10.3 \\
\hline 2,500 and Over & 170 & 0.2 & $1,101,272$ & 20.1 \\
\hline 100 and Over & $3.1,340$ & 11.1 & $3,977,959$ & 72.8 \\
\hline Total & 102,201 & 100.0 & $5,461,162$ & 100.0 \\
\hline
\end{tabular}

SOURCE: Compiled and computed from Nicaragua, DGEC, 1966:Tablas C and D, pages xiv, xvi.

$a_{\text {Less than } 0.05 \text { per cent. }}$ 
Table 4E. Absolute and relative number of explotaciones, and absolute and relative amount of land in explotaciones, by size of explotación: Costa Rica, 1963

\begin{tabular}{|c|c|c|c|c|}
\hline \multirow{2}{*}{$\begin{array}{l}\text { Size of Explotaciones } \\
\text { (Manzanas) }\end{array}$} & \multicolumn{2}{|c|}{ Explotaciones } & \multicolumn{2}{|c|}{ Land in Explotaciones } \\
\hline & Number & Per Cent & Manzanas & Per Cent \\
\hline $1-3.9$ & 14,931 & 23.1 & 31,368 & 0.8 \\
\hline $4-9.9$ & 12,994 & 20.1 & & 2.1 \\
\hline $1-9.9$ & 27,925 & 43.2 & 110,984 & $\underline{2.9}$ \\
\hline $10-19.9$ & 9,542 & 14.8 & 129,532 & 3.4 \\
\hline $20-49.9$ & 13,167 & 20.4 & 414,545 & 10.9 \\
\hline $50-99.9$ & 7,240 & 11.2 & 488,800 & 12.8 \\
\hline $10-99.9$ & 29,949 & $\underline{46.4}$ & $\underline{1,032,877}$ & 27.1 \\
\hline $100-249.9$ & 4,441 & 6.9 & 649,605 & 17.0 \\
\hline $250-499.9$ & 1,291 & 2.0 & 436,312 & 11.4 \\
\hline $500-999.9$ & 596 & 0.9 & 394,360 & 10.3 \\
\hline $1,000-1,499.9$ & 191 & 0.3 & 225,940 & 5.9 \\
\hline $1,500-3,499.9$ & 169 & 0.2 & 349,240 & 9.2 \\
\hline 3,500 and over & 59 & 0.1 & 616,132 & 16.2 \\
\hline 100 and Over & $\underline{6,747}$ & 10.4 & $2,671,489$ & 70.0 \\
\hline Total & 64,621 & 100.0 & $3,815,350$ & 100.0 \\
\hline
\end{tabular}

SOURCE: Compiled and computed from Costa Rica, DGEC, 1965a:Cuadros 8 and 9 . 
variations from country to country. The greatest concentration of control of both farmland and territory by the holders of the largest farms occurs in Costa Rica. Over one-quarter of the farmland is held by operators of these larger properties in Costa Rica, Nicaragua, and Guatemala. The farms involved represent less than 1 per cent of the enumerated explotaciones in every country: they are 0.64 per cent in Costa Rica, 0.56 per cent in Nicaragua, and $0.15,0.09$, and 0.05 per cent in Honduras, Guatemala, and El Salvador, respectively.

Even the data just cited do not reflect the full extent to which control over the land-frequently the better land-is vested in the hands of a few families. Statements such as the following often appear in print relative to this matter:

The Somozas at present control about one tenth of the cultivable land in Nicaragua-and just about everything else worth owning. . . The Somozas are, of course, an extreme case (Lavine, 1964:103).

The agriculture [of El Salvador] of the modern period is under the control of some fifty wealthy families. . . The same landowners who control the planting of coffee, control also the planting of other commercial crops (James, 1959:677).

Census methodology makes it impossible to evaluate such assertions for two reasons. First, since each tract of land with a different administrator is a separate explotación regardless of ownership, there is no way to know how many owners are involved. It is known that many 
owners of large plantations or haciendas have several properties in different parts of their countries-each counted as at least one explotación agropecuaria. For example, no one knows to what extent the 125 farms of 1,000 or more hectares in El Salvador actually belong to the 50 families to whom James referred. That a relatively small group holds the majority of the land is clear, since in no country are as many as 5 per cent of the explotaciones required to constitute a majority of the land in farms (see Tables $4-A$ to $4-E$ ).

The extreme cases in three of the countries are the lands of the United Fruit Company. Salazar (1962:49, 140141) reports that this entity owned more than 400 "fincas" in Costa Rica in 1955. According to May and Plaza Lasso (1958:80, Table 8) the Company owned 497,000 acres (287,800 manzanas) in 1955. My computations indicate that this area would have been 10.9 per cent of the total area in explotaciones according to the 1955 census of agriculture (Costa Rica, DGEC, 1959:Cuadro 1) if the entire area was counted as part of explotaciones. The Company's control and influence at that time was over more than simply land, however. By comparing the 15,500 company employees in 1955 (cited by May and Plaza Lasso, 1958:148) with the total number of workers in agriculture who worked as much 
as two days during the census week in 1955 (162,945, according to Costa Rica, DGEC, 1959:Cuadro 37), it is clear that the Company also employed 9.5 per cent of the nation's agricultural labor force. Moreover, the Company's 1955 taxes constituted over 18 per cent of the revenue of Costa Rica's central Government; and in Honduras the Company paid an average of 10 per cent of the national revenue during the years 1951 to 1955 (May and Plaza Lasso, $1958: 148,159)$.

That the United Fruit Company is a unique case must be granted. But there are innumerable references and allusions to the wealth and power of the Catorce Grande (Big Fourteen) families of El Salvador, who are pictured as virtually controlling both business and agriculture in that republic. Moreover, the following analysis of the situation in Costa Rica (Biesanz and Biesanz, 1944:150-151) indicates that the statistics understate the degree of concentration for nationals as well as foreigners:

Statistics typically given on land distribution deal with the number of fincas, and these figures are sometimes carelessly used to signify the number of landowners. This is very misleading, since the big farmers do not usually have their land all in one piece, but divided into little fincas which they have bought or foreclosed at different times. Thus, one person often owns a number of the best fincas, while others own nothing.

The second thing that produces an understatement of the degree of control by a few large landowners is the 
practice of counting colonos and other farm laborers as independent operators of the small subsistence tracts on which they live. On the Aquiares Hacienda in Costa Rica, for example, the colonos cared for two-thirds of the coffee land. The system employed in this case has been described by Morrison and León (1951:196) as follows:

The colono contracts with the landowner to care for and harvest, under the supervision of an employee of the landowner, a lot of coffee for a fixed payment per fanega of coffee produced. At the end of the harvest, the colono is paid any difference due him after the total of weekly advances he has received is deducted from the value of the crop at the contract rate. He also receives a house to live in, the right to any plantains or other food that may be produced among the coffee and often the use of a plot of noncoffee land upon which he can produce fruits and vegetables for home use or sale. He in turn is under obligation to work for wages on land operated by the landowner when needed, as at harvest time. The size of the lot cared for by the colono under contract, including land in food crops and pasture, is usually between two and twenty acres.

In 1948 the Aquiares Hacienda had about 75 colono families. Each of these had its own assigned plot of coffee trees and a house lot. Together these tracts amounted to a probable 400 of the 1,372 manzanas in the plantation. For census purposes, the Aquiares Coffee Company would be counted as having a farm of 972 manzanas, and the remainder of the hacienda as 75 additional explotaciones agropecuarias, even though it is clear that the colonos' tracts actually are integral parts of the plantation operation. In El Salvador and Guatemala the counting of such tracts has a 
very much greater effect on the apparent distribution of control over farmland than is true in the other three nations.

The relative importance of the large multi-family farms in each of the 77 major civil divisions of central America is displayed in Figure 4. For this figure the proportion of all land in explotaciones which was in explotaciones of 1,000 manzanas or more ${ }^{1}$ is shown, since the numbers of such farms are invariably small. Six of the nine departments or provinces shown in solid black have more than 50 per cent of the land in explotaciones in places of 1,000 or more manzanas. Altogether, 290 farms of this class control the majority of the land in these six divisions:

$\begin{array}{lll}\text { Guatemala: } & \text { Escuintla } & 94 \text { farms }=50.8 \text { per cent of farmland } \\ & \text { Izabal } & 11 \text { farms }=60.4 \text { per cent of farmland } \\ \text { Nicaragua: } & \text { Managua } & 74 \text { farms }=56.0 \text { per cent of farmland } \\ & \text { Rio San Juan } 23 \text { farms }=73.3 \text { per cent of farmland } \\ & \text { Rivas } & 54 \text { farms }=56.0 \text { per cent of farmland } \\ \text { Costa Rica: } & \text { Heredia } & 34 \text { farms }=55.8 \text { per cent of farmland }\end{array}$

These 290 farms undoubtedly represent fewer than 290 different owners; nevertheless, assuming each is actually a separate landholding, these large farms are only 1.3 per cent of the explotaciones in the areas named.

${ }^{1}$ Except 1,280 mz. in Guatemala, and 1,000 hectares in EI Salvador. 


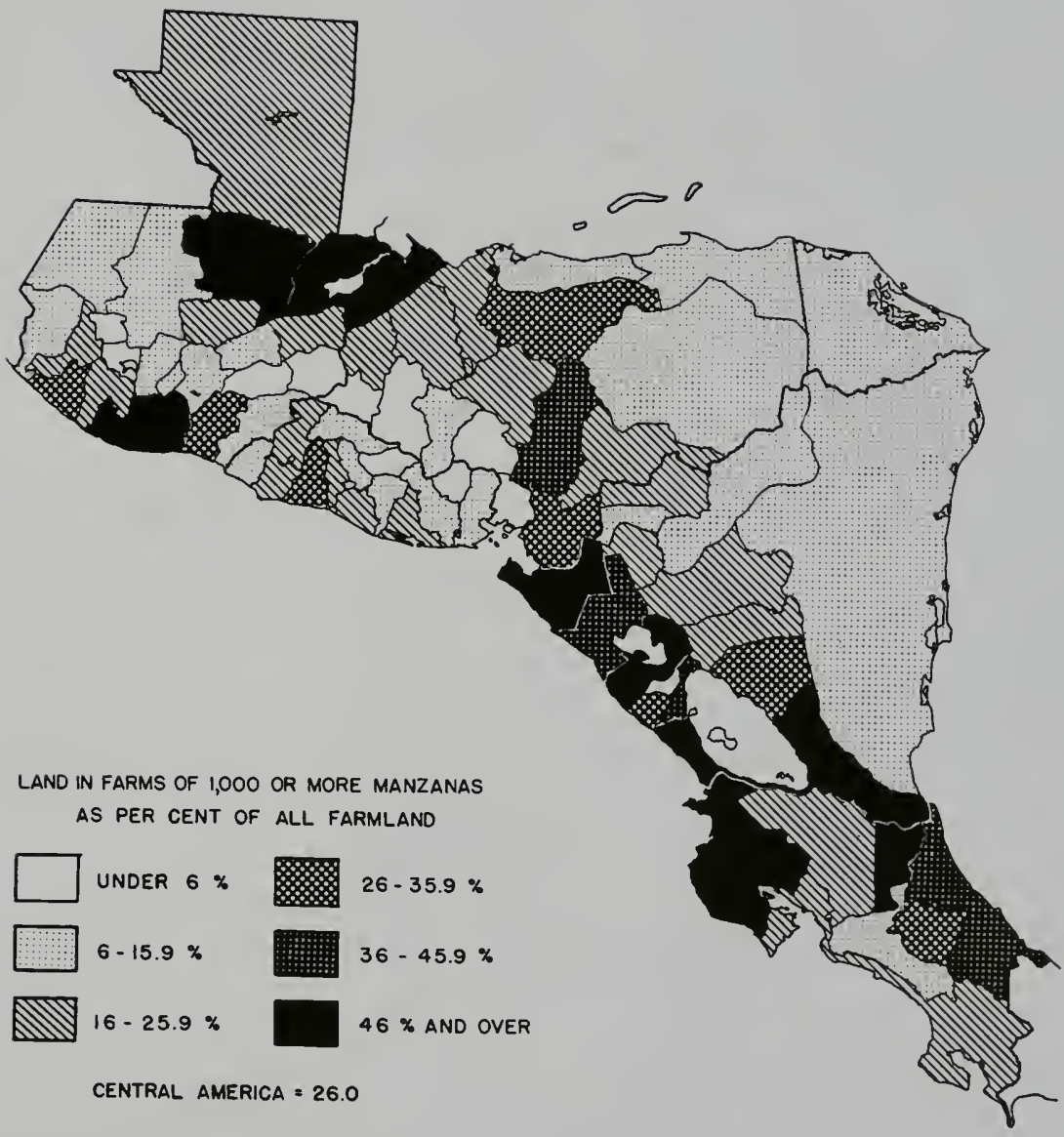

Figure 4. Proportion of all land in explotaciones which was included in large multi-family farms, by major civil divisions: Central America in the 1960 's. (Large multi-family farms defined as those of 1,000 or more $\mathrm{mz}$. , except 1,280 or more $\mathrm{mz}$. In Guatemala, and 1,000 or more ha. in El Salvador. Data compiled and computed from Guatemala, DGE, 1968 :Cuadro 1-1; El Salvador, DGEC, 1967:Cuadro 32; Honduras, DGEC, 1967: Cuadro 1 for each department; Nicaragua, DGEC, 1966:Tabla 26; and Costa Rica, DGEC, 1965a:Cuadro 9.) 
Two of these areas, Escuintla and Izabal, contain banana plantations of the foreign fruit companies, but other areas in which they have extensive operations show much less concentration. These are Atlántida and Cortés in Honduras and Puntarenas in Costa Rica. Limón, on the Atlantic coast of Costa Rica, had a percentage of 42.2 . Some of the black areas are ones of more potential than present development, such as Heredia (Costa Rica) and Rio San Juan and Rivas (Nicaragua), the first two of which still lack adequate means of transportation, but which would benefit greatly should a new interoceanic canal be developed in that region. The Department of Managua, the last case, shows many of the earmarks of the classic latifundio since, in spite of enjoying the best roads of the nation, and being very close to both services and markets, it had 93.5 per cent of the area in its very large farms in non-crop uses (5.4 per cent fallow land and 88.1 per cent pastures, woods and other uses). This was only a slightly more intense utilization than that of similar farms for the nation $(95.8$ per cent not used for crops, including 3.7 per cent fallow and 92.2 per cent in pasture, woods, etc.), many of which are better suited to stock raising and lack the other advantages Managua enjoys. The large areas in Figure 4 which are so lightly shaded as to represent less than 25 per cent of the land 
held in very large units can be explained by two principal factors. First, many of these areas are virtually lacking in means of ready access and communication, and were apparently not particularly attractive to really large landholders. This includes Zelaya, Jinotega and Nuevo Segovia in Nicaragua, Gracias a Dios, Olancho and Colón in Honduras, and El Petén in Guatemala, in particular. To a lesser extent this would also characterize Huehuetenango and El Quiché in Guatemala, and the unshaded departments of Honduras But a second element is the extremely rugged, mountainous nature of much of the land in western and eastern Guatemala, and of the area adjacent to the border with El Salvador in Honduras which has lowered its attractiveness to large proprietors. The Province of San José in Costa Rica is affected mostly by the very wide distribution of small farms in the Meseta Central-the basin surrounding the capital. Remaining areas fall somewhere between the two extreme proportions of land in large farms.

The Distribution of the Family-Sized Farm

The family-sized farm is of primordial importance to the socioeconomic development of the nations of Central America, if such development is understood to include the very substantial improvement of levels of living of the masses of agriculturists. It has already been shown that 
in the region as a whole about four of every five explotaciones are too small to be counted as either family-sized or multi-family farms (see Table 2). Nevertheless, the one-fifth of the farms which are family sized are not distributed in the same fashion as are all explotaciones. Figure 5 presents graphically the results of determining the proportion of the explotaciones in each major civil division which fell into the family-sized range, and the variations are great.

At the one extreme it is notable that in Costa Rica the family-sized farm is more common than the minifundios (Table 4-E), and that in five of the seven provinces over 40 per cent of all explotaciones are family sized. The only other major civil divisions with a majority of family-sized farms were in Nicaragua, where Rio San Juán reached a high of 70.7 per cent, and Jinotega and Nuevo Segovia tallied 53.0 and 53.2 per cent respectively. Chontales, adjoining Rio San Juan, was just below the midpoint with 48.2 per cent of its farms family-sized, and in Honduras, Atlántida registered 45.0. At the opposite extreme, neither Guatemala nor El Salvador had a single department with as high as 20 per cent of its farms in the family-sized category. From the fact that 83.2 per cent of Guatemala's farms were smaller than 10 manzanas, it is clear 


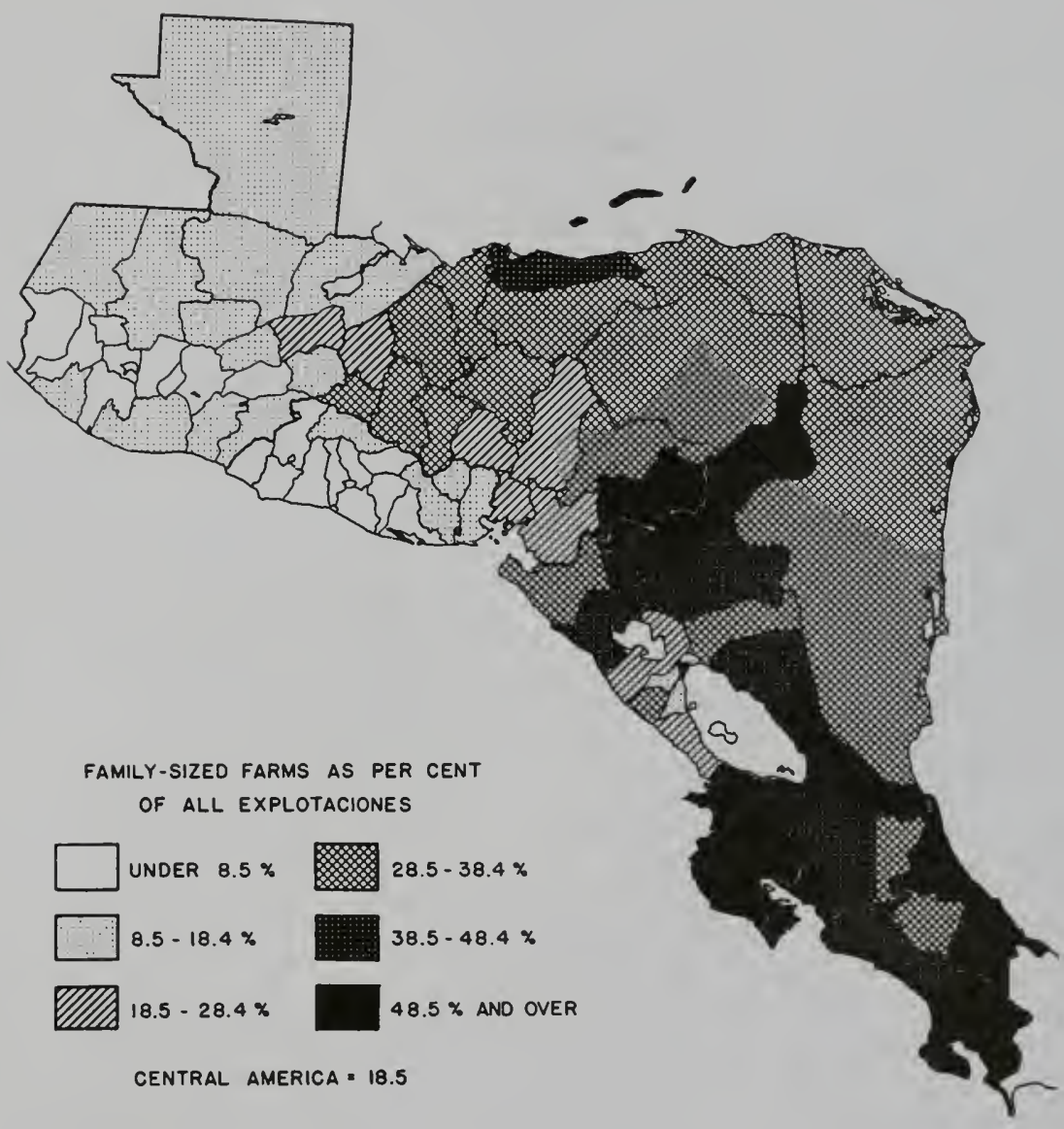

Figure 5. Relative number of explotaciones which were in the range of family-sized farms, by major civil divisions: Central America in the 1960 's. (Family-sized farms defined as 10-99 mz., except 10-63 mz. in Guatemala, and 10-99 ha. in El Salvador. Data compiled and computed from Guatemala, DGE, 1968:Cuadro 1-1; El Salvador, DGEC, 1967 :Cuadro 31; Honduras, DGEC, 1967 :Cuadro 1 for each department; Nicaragua, DGEC, 1966:Tabla 26; and Costa Rica, DGEC, 1965a:Cuadro 8.) 
that the nonfamily-sized explotaciones were virtually all smaller than of family dimensions. In El Salvador only three departments had as many as 10 per cent in the familysized grouping, while Honduras and costa Rica had no divisions in which the percentage was less than 20, and Nicaragua had 2 such areas-Masaya and Granada.

Clearly, if the data summarized in Figure 5 are a reasonably correct presentation of the situation as it exists today, the distribution of family-sized properties is most uneven, and such units are scarce indeed in large sections of Central America. In many ways, moreover, the figures presuming to represent family-sized farms overstate the case, since with presently existing social values (and the present levels of technology commonly employed) many of those who control land areas in the potentially family-sized category actually work it with a colono or peon labor force as if they were themselves large landowners possessed of substantial haciendas. Therefore in terms of both social consequences and economic productivity it is probable that the proportion of family-sized farm operations is much smaller than is indicated in the figures throughout this chapter, and that the "large" farm grouping should be credited with many of the family-sized holdings.

If one assumes, as the present writer does, that the family-sized farm is the keystone for the socioeconomic 
development of the rural and agricultural people of Central America, then the short-term outlook is bleak indeed in El Salvador and Guatemala. The provision of opportunity to farm more adequate amounts of land for the hundreds of thousands of minifundistas-and for their multiplying offspring-is hard to envision, even in Guatemala where a great deal of land is potentially available.

The situation is much less acute in Honduras and Nicaragua, where in most areas family-sized farms make up at least 30 per cent of all farm units. It is in some of the most densely settled areas of both of these countries that the proportions of family-sized farms is leastFrancisco Morazán, Copán, Valle, Choluteca, and La Paz, in Honduras, and Masaya, Granada, Rivas, and Managua, in Nicaragua. In some of these departments the high proportions of very large farms (over 1,000 manzanas) is a major factor in producing the relatively low numbers of familysized farms-particularly in Managua, Rivas, Francisco Morazán, and Choluteca. In others, especially Masaya and Valle, the density of population and the subdivision of the land into tiny minifundios is the basic explanation. Most encouraging is the relative predominance of the family-sized farm in Costa Rica. This fortunate country has the greatest opportunity to maintain and expand 
the medium-sized farm, both because of the further availability of land, and because the educational levels of the rural people offer a greater potential for developing the genuine family farm.

Some Examples of Explotaciones of the Various Size Categories in Central America

With the background of the region now sketched broady, it is well to take a look at some examples of actual farms and areas which fit into the various categories. Limitations of space prohibit an extensive and detailed series of illustrations, but the following observations should suggest something of the circumstances of the operators and families which possess farms of varied sizes.

Smazl explotaciones or minifundios. - Nearly half of the minifundios of Central America are found in Guatemala, and the greatest concentration of these is in the western highlands region of the country where the Indian population $\mid$ is very dense. I visited the northern area of the Department of Quezaltenango in 1963, and talked for some time with Dr. Dudley Peck, a retired anthropologist-missionary who had worked among the Mam Indians of the region for 42 years. I had to borrow a four-wheel drive Jeep to make the trip from San Juan Ostuncalco up to Cajolá, where Dr. Peck and his wife had settled in active retirement. The following notes were made in my journal on september 2 : 
My informant and guide in Cajola says that it has taken a great many of his 40 years with the Mam people of the Ostuncalco market area to come to know fairly accurately how much land they have and how their livings are made. They are quite secretive about such matters because the closeness of kinship ties leads the less fortunate to seek out those who are better endowed with goods and a continuous "leveling" process occurs. On the average, around Ostuncalco and Cajola the Mam families own about 20 cuerdas ( $1-1 / 4$ manzanas), with some running up 50 cuerdas (about 3 or 4 manzanas), and some as low as 2 or 3 cuerdas. The average, he says, will support a family of five or so persons for about 5 months, with very good cultivation and farming practices [as they know them] at every stage of the year. For the rest of their meager livelihood they have to look elsewhere.

Their agricultural techniques are virtually alz by hand, working their fields with a hoe in spite of a government offer to plow at about $Q 4.00$ per acre. Dr. Peck says they can hoe it just as cheaply, and they hoe deeper than a plow will go. (He says they don't hoe so deeply when they work for others, so each man feels to get a good hoeing he has to do it himself.)

With their limited land they have to use fertilizer, which comes from the flock of perhaps 10 sheep each family keeps. Each day someone takes them out to the hills to graze, and all along the way the herdsman collects the manure, since it is more valuable than either the wool or the meat! But the more the population grows the less land they can spare for sheep and the smaller the crops get.

As for the supplementary income, most families have two sources. Many rent land "on the coast" to grow corn, usually getting two crops in a year. Since the lowland. growing season is different from that in the highlands, they can personally harvest both. They also tend to work a few weeks in the coffee harvest.

In San Miguel Ixtahuacán, west of Huehuetenango, Peck and some local people actually made a mental count and found 90 per cent of the population went to the coast. This is possible because with the extended family system all cousins, etc., are "brothers" and so a few could watch out for the interests of all.

Such small holdings predominate in the western highlands area of Guatemala-Sololá, Totonicapán, and Quezaltenango, particularly-and are quite commonplace also 
throughout the highlands. The population throughout this area is strongly Indian, and his cultural attachment to the land is very strong.

Another extreme example of the social aspects of the small land holding was reported by a nurse at the Mam Christian Center at San Juan Ostuncalco, Guatemala, where she and a team are engaged in health, education, and agricultural extension work in addition to religious instruction. She told of one Indian family near the center with 20 living children born of one mother (who then came to be sterilized), where the oldest child is now 25 and married. The father has only 5 acres of land, and the next two sons who are old enough to marry cannot do so because they will not inherit enough land to be "economically safe" husbands. One of them had chosen a girl and she liked him, but the father vetoed the match. (Above from an interview with Roberta Winters, Sept. 3, 1963.) Needless to say, the effect of such pressures on the social and political institutions is great and not entirely unpredictable. Multiplying this sort of situation to relate it to the hundreds of thousands of small farms throughout Central America is not pleasant, but it is the reality of life to such families.

One of these small explotaciones which I visited was in the Salvadoran department of Cabañas. The following 
observations are summarized from notes in my journal, recorded on August 14, 1963 :

The family of don Lino consists of his wife, 38 years of age, and six children ranging in age from eight to 19 years. Five of the children are still in school. The family lives in their own three-room adobe house, and they have a total of 4 manzanas of land in four parcels scattered over a one and one-half kilometer area. The farm produces corn, beans and coffee for home consumption, and there is a cash crop of sugarcane planted on two of the manzanas. The cane harvest requires the temporary hiring of three workers, and don Lino also hires four yoke of oxen to haul his cane to a neighbor's trapiche for grinding.

Don Lino himself does not work as a hired hand for any other farmers, although his 19-year-old son does so as a migrant laborer for several months in another part of the country. However, the sale of duzce (brown sugar) does occupy some of his time.

The level of living of this family of eight is scarcely above pure creature existence. The home has very little in the way of furnishings: three chairs and a table, and one hard bed are all that are visible in two of the rooms. There is no type of public utility available-neither water, electricity or waste disposal. Light comes from candles; there is not even a latrine for disposal of human excrement. Drinking and cooking water is obtained (during the rainy season) from springs on a neighbor's property 300 yards away; in the dry season they carry water a distance of a kilometer. In both cases their water is obtained on the property of other persons, by their leave. . .

Like the other small farms I have visited in this district (Ilobasco), the family has no radio, nor any evidence of reading material except school texts. The family does, however, have a foot-powered singer sewing machine, an item which has proved to be more common in this area than the transistor radio!

one of the four manzanas don Iino farms is rented from a neighbor for a two-year term for growing cane. This particular farmer is ambitious, and hopes to be able to buy some more small plots of land in time. As he says, "Three manzanas doesn't go very far when you have to divide it among six children." 
These examples of the small explotaciones are reasonably typical of the average place in this size grouping. Additional space could have been devoted to the tiny parcels of the colonos and sharecroppers whose situation is more adequately described as farm laborers-working for others and supplementing their wages with some home-grown produce. It is among this group that I found the heads of families most Erequently illiterate, and it is also where other studies have suggested that the infant mortality rate is often so high that one out of three or four babies born is unable to survive for a full year of life (interview with Dr. David Burleson in San Salvador, August 13, 1963).

Multi-family farms: plantations and haciendas.The system of large plantations in Central America varies a great deal with different crops, but also shows a considerable similarity in its broad outlines. Since a great deal of descriptive material has been published about the banana plantations, including May and Plaza's volume (1958), and Kepner's (1936), nothing further need be said about these. However, two illustrations, from a coffee plantation and a very large cotton farm, are presented, followed by one of a cattle hacienda.

(1) A coffee farm. From a four-day visit to one of the large coffee fincas on the Pacific piedmont of Guatemala, 
some insight into the nature of the plantation system was gained personally by the writer. The finca visited was owned by a man of foreign origin, a Guatemala City businessman, who makes his home in a comfortable urban residential area. However, he regularly visits the finca on weekends, driving down in his Landrover, since no lesser vehicle can traverse the road to the casco (headquarters) of his place in the mountains of Chimaltenango. In contrast to many of the estate-like fincas, this one has nothing palatial about it at all. Four rooms of the main building serve as a home for the owner, and this same building also contains the storehouse for coffee, the grading and sorting areas, the dryers, and some of the beneficio machinery. ${ }^{1}$ The casco has running water and electricity, both of which are supplied by the farm, and has its own beneficio to process its coffee. The farm has 11 caballerías of land, or about 700 manzanas, and a great deal of it is planted in coffee. At the height of the season the hired labor force totals about 500 men, many of whom bring their families with them so that there may be 1000 actually working. The colonos live in individual houses about typical of the poor farmer who is

${ }^{1}$ The finca is in the same region as the Americanowned Finca Pacayal, which Addison Burbank described in 1939 (p. 239) as "one of the largest and princeliest fincas in Central America." 
independent, but the cuadrizzeros or temporary workers are lodged in temporary housing called galeras (sheds). The extent to which the patrón (owner) and his manager took advantage of the workers also is fairly typical. The worker is supposed to be paid by the weight of the coffee cherries he picks, though this may be gauged by use of a standard "box" which is supposed to hold a quintal (100 pounds) instead of by a scale. The cherries here were measured over a wooden grating that covered the pool of water into which they were dumped when weighed. Any berries that were spilled just did not get counted at all. The foreman kept hurrying them and as a consequence a good many spilled. Fractions of a box also were estimated exceedingly conservatively.

Then there was the matter of pay. In addition to his cash payment, for which he was required to wait sometimes interminably if his name was far down the list (the pay line sometimes lasted until midnight Saturday), each worker was entitled to 14 pounds of corn, 5 pounds of beans, and a "measure" of salt (about $4 " \times 4 " \times 1 "$ ) per week. Many of the measures used in the rapid disbursement of this ration clearly were not full (they were supposed to be level), and there was a careless attitude that seemed a bit like feeding cattle. The foreman or helper would dump a measure toward 
the receptacle the worker preferred, but sometimes the aim was poor and part of the food would be added to the trash on the storeroom floor. The finca did not regain this material as a form of cheating-but the laborer lost it. The patrón saw to it that there was pure water at the casco, and it was available in a piza (tap and pool) to all who wanted it, but it was not handy to the areas where the galeras for temporary workers were located several hundred yards away. Neither were there any provisions for sanitation. His statement was that they would use the woods anyway, and he may be right, but with 40 or 50 to one room (a galera had only one room) the sanitary problem could be serious. There is no privacy.

The law requires that a school be provided for the children of workers. There was a one-room school. There was one teacher. There was also a small chapel, but a priest came only once a year. On Saturday the casco turned into a marketplace as travelling merchants brought in all sorts of goods. Some stayed in the area all night and reopened Sunday morning. Medical care was of the first-aid variety. While I was there one man brought in his wife who had suffered a serious sting and she had to be taken to the hospital at Escuintla in the jeep.

After all the negative impressions above, it is only fair to say that the owner of such a place also has problems. 
He has a low-skilled labor force that can cost him badly if they do not pick just the ripe cherries, and they can also cost a great deal at times by their stealing. Getting a reliable and reasonable manager is a problem since he has had trouble with stealing and falsifying at that level, too. The maintenance of even the poor quality roads in the finca runs to considerable money for bulldozing and grading when slides occur, and the hauling of his coffee from the casco has to be done by the jeep-load due to steep grades. It is not an easy venture for him, but it is not unprofitable, either.

All in all, after comparing notes with people with broad experience, and also after reading other reports, the above appears to be a reasonable picture of the operation of a coffee fince in Guatemala. It is certainly not among either the most oppressive or enlightened.

(2) A cotton farm. A very different sort of property is one of the large "haciendas" (better described as plantations) at Usulután, El Salvador. The plantation in question was said by several people to be one of the largest intensively cultivated properties in the nation. Consisting of several thousand manzanas, the land was in the following uses in 1963 when I visited the plantation (August 15): 
50 per cent in cotton

60 per cent in pasture for the oxen (about 250)

and for milk cows, and 200 horses

4 per cent in corn

4 per cent in cacao

2 per cent in rice

1 per cent in plátanos

13 per cent of marshland and a salt works

The above figures comprise 80 per cent of the total area, and in addition the estate had 1,300 hens and devoted a good deal of space to the main caserio or village and to outlying camps for workers. Most of the waste land is in mangrove tangles and swampland.

In terms of agricultural technology this is one of the most modern plantations one can find. It has fairly level land but is carefully worked on a contour, with exacting attention to insecticides and to fertilization by soil types. There were 46 tractors on the farm and oxen were used only when wet conditions made tractors useless. His administrator referred to the owner as "progressive," saying that he is trying to improve things all the time. He was in the process of adding potable water and electric lighting in those camp areas (for temporary workers) that still lacked these benefits. There were TV sets in some locations on the place for workers, and a massive kitchen operation to serve meals to the work force during the harvest, when the total of laborers runs up to 5,000. At that season they use all 200 
horses for field supervisors and still do not have enough to do the job, says the administrator, who incidentally wears a pistol regularly (as did many people in the nearby departmental capital of Usulután).

In spite of all this modern and sophisticated technology it was true here also that some of the basic human considerations were limited. Each permanent worker receives housing and a small garden plot, plus a guaranteed year-round job. The workers live in clusters, and in 1963 the owner was planning to have new permanent housing built for some workers in multi-family apartments of 16-20 units each, "next year." For its 800 permanent workers and their families the hacienda provides a school (attended by only 106 pupils!), a chapel, a weekly clinic, and hospitalization. But for the temporary workers a very minimum was provided: two-story thatched roof sheds for shelter from above, but open sides graced some of the camps. There was water at those I saw, and some space for cooking, although at least in the height of the harvest the central kitchen delivers food to all the camps. Protection from insects came from the general aerial spraying the farm gets during the entire season. The workers slept in the large porch-like area either in hammocks or on the floor. The temporary workers did not fare as badly as on some other establishments where 
no shelter at all was provided, but an investment in more permanent type housing seemed desirable to the writer, even though this was a "progressive" farm.

The owner flew to the plantation for Saturdays and Sundays "every week," and usually came there on Wednesdays as well, according to the administrator. The rest of the time he lived and worked in San Salvador, where he headed a number of companies. Actually this is one of the most technologically advanced and socially enlightened farms of large size the writer has seen, and the comments or criticisms must be understood in that context, for compared to many this was very good in spite of the poverty of its temporary workers.

(3) A hacienda. The multi-family farms in Honduras, with the exception of those of the banana companies, are commonly of the "hacienda" type, stressing cattle raising on an extensive basis. One example of this type of operation was seen in Danli, El Paraiso. The owner had served in a number of public posts, and was quite willing to describe his hacienda approximately thus, as I noted in my journal for July 26, 1963:

There is a headquarters center with farm buildings, and some of the permanent workers and their families live there in houses supplied by the hacienda. Other workers live in other locations on the property, or have their own houses on their own plots of land off the hacienda. The worker commonly receives a plot 
of land to farm for himself, plus the loan of oxen, the gift of seed, and meals at the hacienda cook house. On days they work the laborers also receive a cash wage of L 1.50 , (or 75 cents, U. S.), but there are slack seasons without work. In order to seek work off the hacienda in slack seasons, the worker must take his family with him-they cannot stay in hacienda houses while he works elsewhere. Some haciendas, including his, make it a practice to pay for medicines and hospitalization for permanent workers, too, but some do not. The labor force in peak seasons is supplemented by temporary workers hired strictly for a particular job, and for whom the patron does not feel responsible.

As he described the situation his tone was very paternalistic. Notable deference was paid this man as he met people around town. One got the impression that he took care of his own in what he deemed an adequate fashion, but there was the overtone of definite implicit social control, also-those who want to stay on know what is expected of them. I could not help but think of that as this man, a member of one of the powerful families of the region, held a political meeting that night in his homea meeting attended largely by his social inferiors. The holdings of this man and other members of this family consisted of many thousands of manzanas, literally from mountain to mountain across some valleys. He pointed out, however, that in the dry season there is no water on those hillsides and that the land then was not even good for cattle unless the owner also had land in the valley where a permanent stream provided drinking 
for the animals. Thus the year around carrying capacity of this land was not nearly so great as its area might lead one to expect. I was unable to obtain figures on actual acreage or the number of animals he raised, but the impression I got was that the efficiency was pretty low, although he did have some high-quality cattle.

It is apparent from the examples given that there is a great deal of variety among the multi-family farms. All of those cited were above average in efficiency and quality of their product. The cotton plantation was the most modern and rational operation; the cattle ranch, the least so. But, in every case, the level of living of the workers was extremely low, and opportunities to develop a well-rounded personality through education were very limited. A lack of experience in decision-making and independent thinking was one of the major handicaps which a worker would have to overcome if he ever sought to become a self-sufficient farm operator. But his wages were so low in each case that saving any significant amount of money toward land purchase was virtually impossibleand no encouragement in that direction was provided. The plantations cited had the virtue of being quite efficient in the production sense, while many other plantations in Central America are not particularly productive, even for the owner. The notable thing for all 
of the plantations and haciendas was the relatively poor living afforded the average worker, and the very limited prospects for advancement available to his children.

Famizy-sized farms. The writer visited many family-sized farms throughout Central America. Some were genuine family farms. In other cases an extension of land that could have been operated by a family actually was treated by the owner as a small hacienda.

An example of the latter was a 70-manzana finca near Ilobasco, El Salvador. The owner lived in San Vicente, and had an "administrator" who was in charge for him. This administrator was illiterate, never having had any formal schooling. Both he and his wife were 48 years old. He received an undisclosed salary and also had a single manzana of land allotted to him for his own use. He and his two older sons performed most of the work on the place, aided occasionally by hired hands as required. There were 9 manzanas of sugarcane, and 2 of corn. Most of the rest was in pasture, but there was no significant animal production-just 10 oxen for field work. A dozen or so manzanas were described as "rented" to three sharecroppers to raise corn and beans during two-year rotation cycles between sugarcane plantings. Thus four families were regularly involved in the use of this family-sized tract. 
With that many people to support, it was inevitable that fairly low levels of living resulted, although the administrator's family was provided with one of the best farmhouses I saw on fincas of comparable size in Central America. It had a well with water piped into the house (by a hand pump), a flushing toilet, tile floors, and generally substantial construction. It also enjoyed the benefit of glass windows, which are a relative rarity in rural areas.

One of the best examples of the real family-sized farm in El Salvador was located in Usulután, and was smaller than the one just mentioned. The operator of this second farm was Tomás , 36 years of age with one year of secondary school education. Don Tomás owned 6 manzanas and leased an additional 29, operating these himself with a good deal of pride and success. He had nearly 9 manzanas of cotton as his principal cash crop, but also raised chilis, sorghum and plátanos, and made bricks (adobe) and tiles during the summer with material from a pit on his land. He had a single man as his steady hired hand, and had to hire 10 to 12 temporary hands at cotton harvest time. He had five daughters but no sons to help him. This family had a distinctly above average level of living: its own electrical generator, and thus 
electric lights as well as a refrigerator, a latrine, and two water wells. Don Tomás also was careful to have a recorded title to his inherited property, and to have a written lease contract for his cash-rented land. He was insisting that his eldest daughter, who had completed the local school, had to walk the several kilometers to the city school (where she was in the fourth grade at age 14). He felt a good education for his children was very important. In order to demonstrate the fact that at least some farms at the upper end of the family-sized classification are not simply little haciendas or plantations, one more example may be cited. In the vicinity of San Isidro del General, Costa Rica, I visited a 100-hectare farm. (Admittedly this farm was slightly too large for this class, but nevertheless, it was a real family-sized farm.) The owner had come to the valley of the Rio General some 35 years earlier as one of the pioneers in its early settlement. He judged that he had one of the larger farms of that part of the valley where his property was located. He and a thirty-year-old son operated the farm with one or two hands to help a good share of the time. He raised coffee, sugarcane, beans, corn, and tobacco, and had some cows as well. He owned a small ford tractor and harrow, 
but said most of his land was either too steep or too rocky to use it. He employed mostly hand tools, with oxcarts for transportation.

The level of living of this family was quite high. The house was a wood frame one of above-average size and well constructed. It was furnished with plain but adequate furniture, and both the husband and wife were obviously well educated (meaning, in this context, probably secondaryschool level). This man was definitely a commercial farmer and he took as great an interest in farm policies and farm prices as the average North American family farmer. In him the functions of the capitalist, the manager, and the one who labors were very clearly and effectively combined, as they should be in the family-sized farm.

In summary, some of the family-sized farms were effectively run as such, and in these cases they seemed to offer a reasonably high level of living by local standards. If the operators were to have a commercialfarming outlook, as did the last two mentioned, and a reasonably good level of education could be provided as well, the family-sized farm unquestionably would be the most desirable arrangement for the well-being of the rural population of Central America.

On the other hand, land area alone is not enough. Some family-sized farms were visited which were simply used 
for subsistence purposes-only as much being cultivated as would produce the needed food, while other land was left idle. Other cases showed the cultural inclination to reject the personal farming of land in favor of acting like the large landowner and employing colonos, sharecroppers, or others to work the land. Thus it is clear that the truly desirable characteristics of the family-sized farm will not come into being simply through obtaining enough land. In addition, an acceptance of farming as a desirable way of life, a commercial orientation toward production, and adequate levels of education commonly will be found in the successful operators of family-sized farms as family-operated farms.

\section{Size of Explotaciones and Land Use}

A great deal of difference exists between explotaciones of distinct sizes with regard to a number of factors. This section reports the results of the analysis of the Central American situation concerning the general use of land in explotaciones of the several size categories, and also the relative shares of different agricultural and livestock products produced by farms of different sizes.

The General Use of Farmland by Size of Explotación

The use of farmland has often been cited as a major element of difference between the farms of small and 
large size in Latin America. In a forum on agrarian reform in Honduras, Orđóñez (n.d.:Il) complained that in the Pacific coast departments of Choluteca and Valle 91.9 and 74 per cent, respectively, of the land in farms of 1,000 or more hectares was in pastures or woodlands, while small farms were intensively used.

In order to show what kind of use is actually made of the land in farms of various sizes, appropriate data were assembled, percentages were computed, and Table 5 was prepared. From these figures it is apparent that for each country the relative amount of crop land ranges from twothirds to over four-fifths of the area of the small explotaciones or minifundios, and that this relatively intense use of land declines to under 30 per cent of the area of multi-family farms (the haciendas and plantations). With regard to pastures and woodlands the reverse is true. The same relationships, but in more detail, can be seen graphically in Figures 6, 7, and 8, where the proportions of land in annual crops, permanent crops, and pastures, woodlands and other non-crop uses are shown.

The steady decline in the percentage of land in annual crops is almost perfect. The situation is not so clear with regard to permanent crops, which include coffee in all five countries, and in which bananas are a major factor in Honduras and Costa Rica. (In Guatemala bananas 
Table 5. Relative amount of land in explotaciones devoted to selected uses, by size of explotación: Central American countries, latest data

Country, Year, and size of Explotaciones $a$

\section{Percentage of Land in Explotaciones of Stated} Size Devoted to:

\begin{tabular}{ccccc}
\hline & Cropland & & Pasture & $\begin{array}{l}\text { Woodlands } \\
\text { and Other }\end{array}$ \\
\hline Total & $\begin{array}{l}\text { Annual } \\
\text { Crops }\end{array}$ & $\begin{array}{c}\text { Permanent } \\
\text { Crops }\end{array}$ & & \\
\hline
\end{tabular}

Guatemala (1950)

$\begin{array}{lrrrrr}\text { Small } & 83.3 & 80.8 & 2.5 & 3.8 & 12.9 \\ \text { Family-sized } & 47.9 & 45.1 & 2.8 & 17.8 & 34.3 \\ \text { Multi-family } & 29.5 & 24.6 & 4.9 & 17.6 & 52.9\end{array}$

El Salvador (196I)

Small

Family-sized

72.3

63.4

8.9

15.3

12.4

$39.8 \quad 27.3$

12.5

42.9

17.3

$28.0 \quad 18.9$

9.1

45.5

26.5

Honduras (1966)

Small

67.9

52.1

15.8

24.0

14.9

9.1

8.5

3.7

4.8

$--b$
$---b$
$---b$

32.15

$76.0 \mathrm{~b}$

$91.5^{b}$

Nicaragua (1963)

Small

Family-sized

66.2

56.0

10.2

23.5

10.3

$35.9 \quad 29.4$

6.5

37.1

27.0

17.0

13.9

3.1

50.6

32.4

Costa Rica (1963)

Small

Family-sized

Multi-family
70.4

34.8

16.2
35.0

24.1

11.1
35.4

10.7

5.1
18.6

31.9

37.0
9.0

32.4

45.9

SOURCE: Compiled and computed from Guatemala, DGE, 1954a:Cuadro 13; El Salvador, DGEC, 1967:Cuadro 34; Honduras, DGEC, 1967:Cuadro 1; Nicaragua, DGEC, 1966:Tabla 28; and Costa Rica, DGEC, 1965a:Cuadro 11.

a Size classes defined as in Table 2.

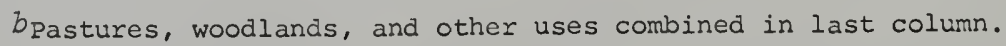




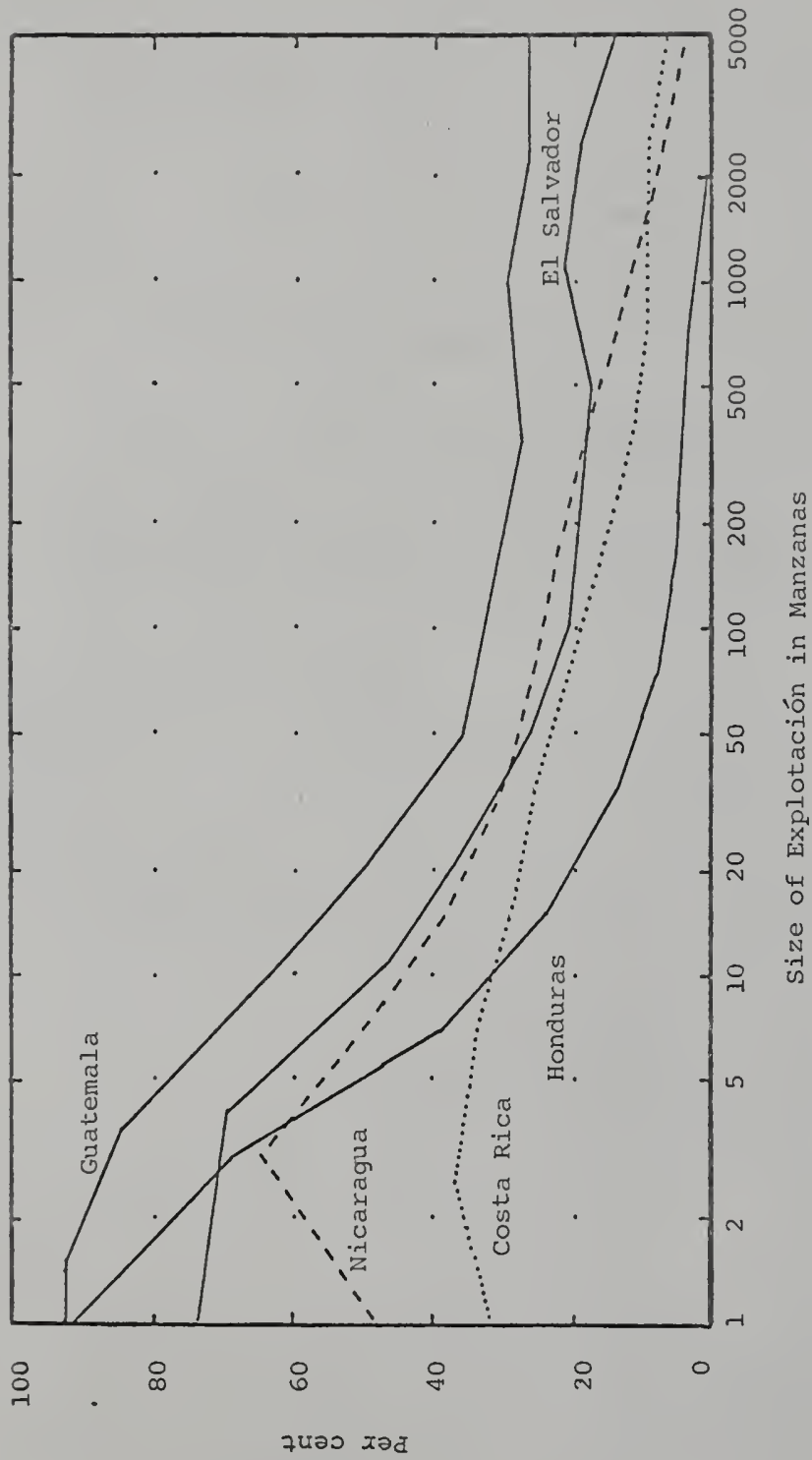

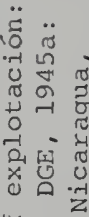

㟧

N

is +0

ती

iิ

杄

प्रेत

o g

तु

द 잍

तु 0 i 0

아유

व

प0 800

ㄱ. ‥ ด

() व्य

r o 0 ن

ะ

ᄀ

है

幽

स. ڤூ

0 जो

ฮี

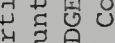

엉

द में

ฉ.

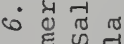

\& द्ये

हैन ज्ञ

- लै ..

ध्य

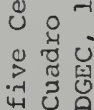




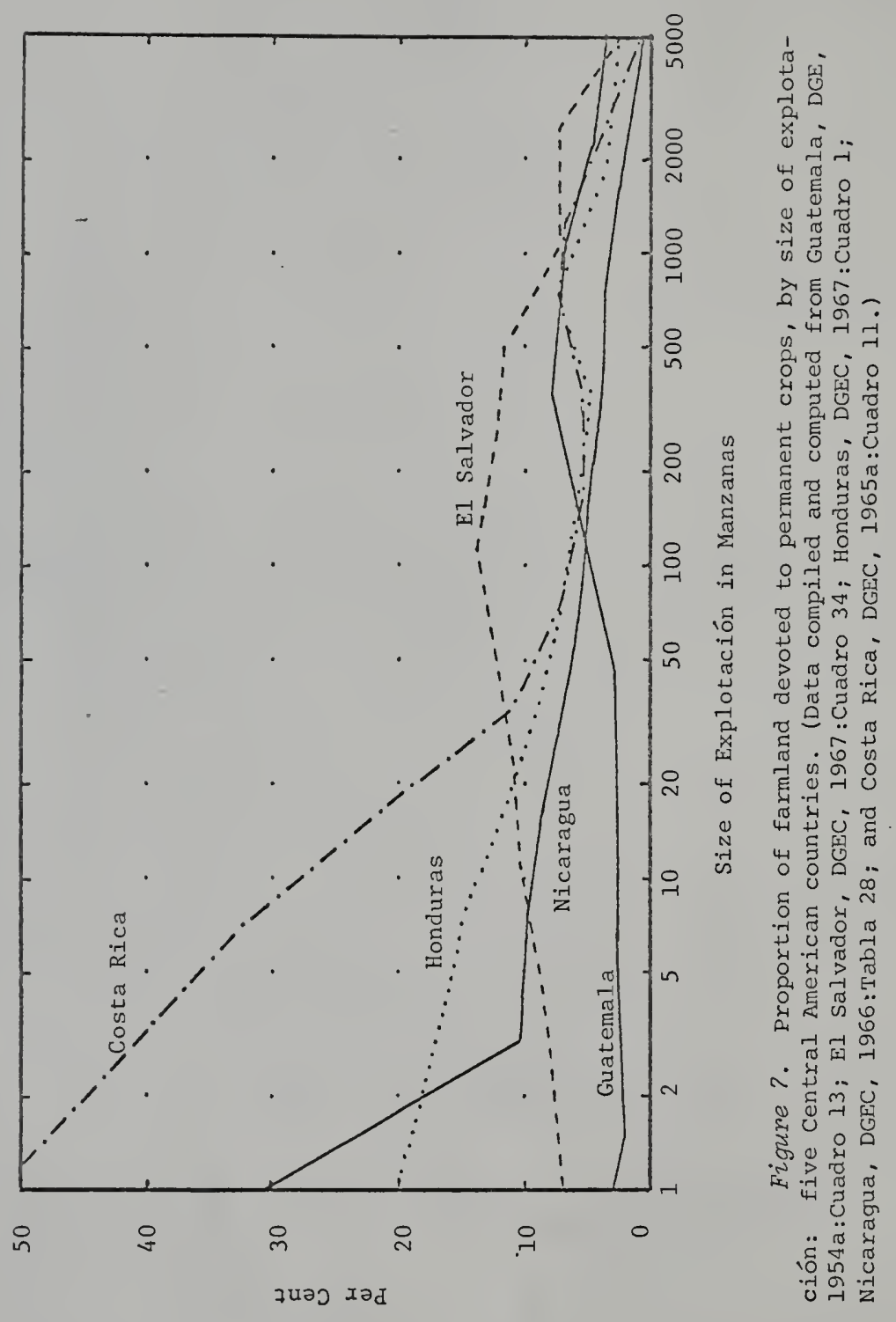




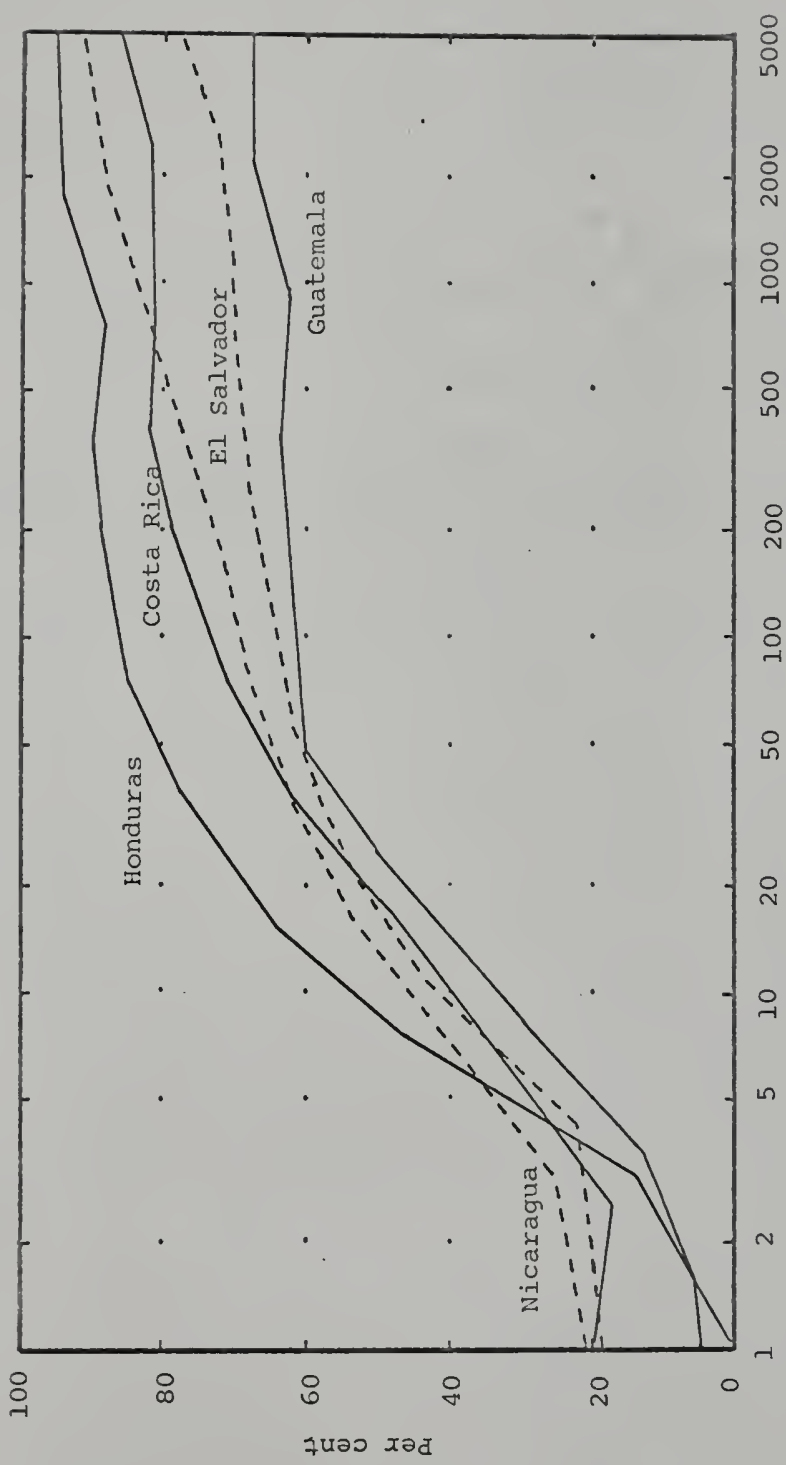

ข

4 열

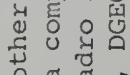
म ल ช च ल ब त 0 i

-

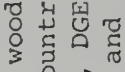
- 0 i in 0 î

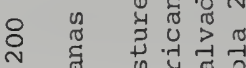

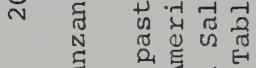
○ $\quad$ ¿

न व

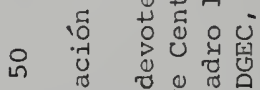
$0>0$ वृ है तै

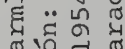
$4 \cdot-1-0$

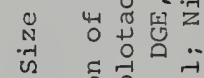

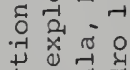
艹 م. $\begin{array}{llll}0 & 0 & \text { t } & 0 \\ 0 & 0 & 0\end{array}$ $\begin{array}{lllll}4 & 0 & 0 & 0 \\ 4 & N & 0 & 0\end{array}$ जी जै है $\infty$ حิ हैं जे

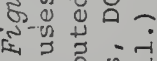
टी है ज

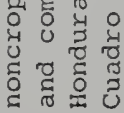


were counted among annual crops, which probably produced the rise in land in annual crops at about 1,000 manzanas.) As is shown shortly, the growing of coffee is done on relatively small farms in Honduras, on family-sized farms in Costa Rica, and mostly on the large farms elsewhere. This crop, plus bananas, largely determines the shape of the graphs for permanent crops. For Costa Rica, Honduras and Nicaragua the generalization can be made that the proportion of land in permanent crops declines as the size of the farm increases. For El Salvador and Guatemala it is clear that the proportion of land devoted to permanent crops reaches its peak in the farms in the moderately large range, and then declines. In all five countries less than 5 per cent of the land of the largest places is planted to permanent crops.

The proportion of farm land not used for crops in each narrow size-of-farm category is shown in Figure 8 . Since this is the remaining land not shown in the two preceding figures, it is not surprising that the average use of land for other than annual or permanent crops surpasses 50 per cent at a very moderate size-ranging from just under 10 to about 30 manzanas, depending upon the country. In every Central American country on farms of 50 or more manzanas, at least 60 per cent of farm land 
is not used from crops. Except for the case of Guatemala, and even there when sizes beyond the scope of the chart are included, the generalization is that the larger the farm-that is, the more land it has available to it-the smaller the proportion devoted to harvested crops and the larger the amount of land in pastures, woods, second growth and unused condition.

For Latin America as a whole Jacques Lambert (1967:73) says "The latifundios. . . waste land and try to avoid paying wages." His statement is typical, and the very definition of latifundio to the average Latin American requires a great deal of unutilized land. In Central America there is apparently a good deal of idle or at least underutilized land on the large farm properties.

While the point must be made that on the minifundios pressure to produce crops almost at any cost forces the farming of land that should be left in grass or trees to avoid erosion, still there is a lack of adequate utilization of land fit for use on many of the large ones. In the case of Guatemala, the 22 farms of 12,800 manzanas or larger in 1950 had 82.8 per cent of their land classified as woodlands or "unusable" lands, with only 10.4 per cent in crops (nearly half of this was bananas, on only 6 farms), and 6.8 per cent was in natural pastures (planted pastures are part of the non-banana "cropland"). Moreover, these 
large farms are not in inaccessible parts of the country where it is not economically practical to use the land more productively. Higbee (1947:199-200), writing of the entire Pacific region of Guatemala, including the upper and lower piedmont and the coastal plain, continually felt constrained to mention the idleness of much of the property. He states that the low level of'living "may" be due to the inefficiency of the agricultural system, when much of the best land lies idle and many of the rural people are forced to work marginal land in a bare subsistence fashion. He concludes with the statement that

much land lies idle or little used from generation to generation because the enormous size of some of the estates enables them to return satisfactory incomes despite their low level of exploitation. . . The principal agricultural taxes are levied on crops rather than on land, with the result that the most active operators pay the heaviest assessments. A reversal of this policy, which would exempt crops but tax land, might exert sufficient pressure to develop idle but potentially productive soils.

Another indication of the poor use of resources by those who control great expanses of land is given by Checchi (1959:54-55) in his study of Honduras.

With the exception of cotton and bananas, the large farming units of Honduras are principally devoted to livestock production. For all size classes over fifty acres, the area in pasture exceeds the area in crops. But it would be an error to assume that because of the greater financial resources and educational level of their operators these large units are efficient, productive enterprises. . .

A large livestock enterprise can earn a comfortable return for its owner with no outlay of money or effort 
for pasture improvement, supplemental feeding, culling or controlled breeding. True, monetary profits are not maximized in this way, but they are adequate; and they are supplemented by a substantial return in the form of leisure and freedom from responsibility. It is in this way that the greatest part of the farming zand in Honduras is managed. (Italics added.)

To be sure, Honduras is a land where the means of communication are limited, and transportation facilities are quite inadequate. Nevertheless, even in the best connected parts of the country one sees large areas of relatively good land virtually unused. This was apparent in the Comayagua Valley where, as I passed.through, I noted in my journal for July 31, 1963 that

for a long time one can see little use made of the valley floor. A very small per cent is farmed-most has trees or small scrub on it (some appearing to be xerophytic). The land appeared poor, but certainly not so poor as the hillsides around the valley, and on the mountains enclosing it. On the slopes were scattered many patches of corn and some beans-evidently produced in the fire agriculture system so widespread in Central America, since land in all stages of this process was visible.

A review of topographic maps and the Mapa parcial de Honduras: Clasificación de Tierras and Mapa ecológico de Honduras (both in OAS, 1963 :Tomo II) after that trip indicated that although there is some very poor and a great deal of moderately good land in the Comayagua Valley, it also contains some of the best land in Honduras, and almost uniformly the steep hillsides are rated poorly. My observations, then, agree with those of an investigator (Dozier, 1958:16) a few years earlier who wrote that: 
The incongruous feature is that the slopes display such usage [patch agriculture] while much of the Comayagua Valley lands are unused and grown up in brush. . . This is undoubtedly due to a great part of the valley being expropriated [sic] in large holdings, while the small farmers have been pushed. into the hills and mountains, onto much poorer land.

According to the advance figures from the 1966 agricultural census, about 95 per cent of the very large (1,000 manzanas or more) farms in Honduras are in noncrop uses, largely either pasture or woods. Having seen the very casual use made of much pasture it is clear that the nearly 270 farms of this size must frequently qualify as genuine latifundia. Certainly the family in the Department of El Paraiso in which one man and his brothers and their sons each own "thousands of acres, including several large hills and mountains" and keep most of it as "cattle land," represents vast under-utilization. The same maps indicated above show this area has some very good land-though I cannot know how it compares with their holdings. The Rancho Jamastrán in this department (formerly Halliburton Ranch) is 19,000 acres that formerly produced melons, tomatoes and cucumbers for shipment by DC-3 to the United States. During my inspection much of it was simply idle-the rest largely in cattle-and the reason given was that they lost the tobacco crop the preceding year in a windstorm and could not pay their 
debts, and could not get any more credit. The ranch is known throughout Honduras and appeared from a number of reports to be a speculative type of agriculture making little contribution to its area even when actively operated. The family alluded to above is said to have an interest in this property along with its other lands. (Notes from my journal, July 26-August 3, 1963.)

The problem of a great deal of tierra ociosa or idle land is found in all of the Central American nations, and was seen personally by the author as well as documented in many reports by others. (See, for example, Menjivar, 1962:53; Dozier, 1958:86; and Maturana, 1962:51.) One of the most careful studies of land use in Central America was made by Peterson and West in Costa Rica in 1953. In their effort to delineate type of farming areas they tried to define "large farms," with the goal of identifying "important producers." The basic definition was to have 200 "units of production" in a large farm. ' In addition to these genuine production measures they felt they ought to include all farms of 500 manzanas of land (1,000 manzanas in the Province of Guanacaste). This composite definition produced 713 "large" farms, but they commented (pages 31-33):

IThe "units" could be: one manzana of land in annual crops, one-half manzana of permanent crops, onehalf of a "cow milked yesterday" distant from the main market, etc. 
The inclusion in the large farm definition of farms which were large in extension only was unfortunate because many farms were included which had a small volume of business. Of the . . . 713 large farms, 213 had less than 200 production units and were included because of total area only. These 213 farms represented 30 percent of the 713 large farms but accounted for only 15 percent of the area of annual crops in large farms, 2 percent of the area of permanent crops, 7 percent of the milk cows and 9 percent of the other cattle.

The largest of the large farms measured by area, are found in the Extensive Livestock Region with an average size of 17,042 manzanas . . [and] average only 22 manzanas in [annual and permanent] crops.

Since many of these farms had to be very large in order to produce an average of 17,042 manzanas of land, the idleness is apparent when on the average only 5,261 manzanas were used for any kind of cropland (including land fallow) or pasture. On the average nearly 12,000 manzanas must have been wasteland, forests, woods, etc. They averaged "almost 1,000 head of cattle per farm" (Peterson and West, 1953:Table 32, and pages 24, 25). As an extreme example of the idleness of a large property, the Finca Jesús María near Turrialba, Costa Rica, can be cited. This farm, belonging to José Rodríguez Mora, was virtually abandoned well over two decades ago, and in 1948 a trial census showed over 50 parásitos or squatters claiming various plots of land from it (Morrison and Le6n, 1951:196). Fifteen years later, in 1963, the Instituto de Tierras y Colonización (the agrarian reform agency of the Costa Rican government), took another census 
of the 409-manzana farm and found 118 parásitos, claiming 390 of the manzanas (Costa Rica, ITCO, 1963a:1). There had been no opposition from the owner. In 1963 the Institute estimated there might be as many as 20,000 such parásitos in Costa Rica, affecting hundreds of large properties.

To summarize the general use of land in farms briefly, it can be said that the intensity of land use declines sharply as the size of the place increases. While conservationists and agricultural experts alike recognize the need not to cultivate land on slopes that are too great, or where soil quality is inadequate, or where water is not dependable, it is still clear that a great deal of quite usable land is left idle by those who can afford not to use it, and those who have no alternative make even the most erosion-prone and poor land do its best. This is hardly justifiable in terms of future land resources, and seems to the writer and many others also to be unjust in relation to the reasonable needs of all members of the community or society. It certainly is provoking a great deal of unrest, as costa Rica (with its reputed "good" distribution of land) testifies with its thousands of "invaders" of unused, unguarded lands. 
Relative Shares in Agricultural Production

Many persons have asserted that the production of the basic staple crops in Central America is very largely in the hands of the small and medium-sized farms, and that the main commercial and export crops are grown on large farms (variously defined). I In order to provide an overview of the production of major crops by size of explotacion, the data for some of the most important products have been computed and assembled in Table 6 . In the preparation of this table it seemed useful to make a division of the multifamily class so that farms of 1,000 or more manzanas could be examined separately.

Staple foods. - Over 70 per cent of the basic food crops of corn and beans are produced on small or familysized explotaciones in each of the five countries of the region; in the cases of Guatemala, El Salvador, and Honduras well over half of the national production of corn, beans, and rice as well come from the minifundios. In Honduras about 95 per cent of these three crops came from farms of fewer than 100 hectares in 1952. In the case of rice production, small explotaciones in the three northern

1 Among the references that can be cited to this effect are: International Development Services, Inc., 1960:Appendix pages 4-6; Guillen Villalobos, 1963:43; Hill and Loftin, 1961:7; OAS, 1963, I:31; Porras Mendieta, 1962:99; Feuerlein, 1954:18; and Agri Research, Inc., $1962: 13$. 
Table 6. Relative distribution of land in explotaciones, and of selected crops and livestock, among four size-of-farm classes: Contral American countries, latest data

\begin{tabular}{|c|c|c|c|c|}
\hline \multirow{2}{*}{$\begin{array}{l}\text { Country, year, } \\
\text { and Crop }\end{array}$} & \multicolumn{4}{|c|}{$\begin{array}{l}\text { Percentage Distribution of Land and Crops } \\
\text { Among Explotaciones of Stated Sizes: }\end{array}$} \\
\hline & Smalla & Family-sizeda & $\begin{array}{l}\text { Moderate } \\
\text { Multi-familya }\end{array}$ & $\begin{array}{l}\text { Large } \\
\text { Multi-familya }\end{array}$ \\
\hline \multicolumn{5}{|l|}{ Guatemala (1950) } \\
\hline Farmland & 14.3 & 13.5 & 31.4 & 40.8 \\
\hline$\overline{\operatorname{corn}}$ & $\overline{66.0}$ & $\overline{16.6}$ & 9.9 & $\overline{7.5}$ \\
\hline Beans & 67.7 & 19.2 & 9.6 & 3.5 \\
\hline Rice & 61.6 & 19.1 & 14.8 & 4.5 \\
\hline Sugarcane & 9.2 & 15.3 & 39.2 & 36.3 \\
\hline coffee $^{b}$ & 0.4 & 5.1 & 61.7 & 32.8 \\
\hline Tobacco & 43.8 & 26.0 & 28.8 & 1.4 \\
\hline Bananas & 3.8 & 3.3 & 15.9 & 77.0 \\
\hline Bovine cattle & 26.6 & 17.2 & 32.6 & 23.6 \\
\hline \multicolumn{5}{|c|}{ El Salvador (1961) } \\
\hline Farmland & 21.9 & 30.4 & 32.0 & 15.7 \\
\hline$\overline{\operatorname{corn}}$ & $\overline{63.6}$ & $\overline{17.3}$ & $\overline{12.9}$ & $\overline{6.2}$ \\
\hline Beans & 68.6 & 18.7 & 7.3 & 5.4 \\
\hline Rice & 55.9 & 27.2 & 14.2 & 2.7 \\
\hline Sugarcane & 25.8 & 28.0 & 24.4 & 21.8 \\
\hline Coffee & 10.4 & 38.4 & 42.2 & 9.0 \\
\hline Cotton & 6.4 & 24.2 & 52.6 & 16.8 \\
\hline Tobacco & 43.2 & 50.3 & 6.2 & 0.3 \\
\hline Bovine cattle & 39.8 & 33.5 & 19.5 & 7.2 \\
\hline \multicolumn{5}{|l|}{ Honduras (1952) } \\
\hline Farmland & 16.1 & 37.6 & 25.7 & 20.6 \\
\hline$\overline{\operatorname{Corn}}$ & 59.0 & 35.8 & $\overline{4.5}$ & $\overline{0.7}$ \\
\hline Beans & 57.2 & 37.1 & 4.3 & 1.1 \\
\hline Rice & 56.9 & 39.2 & 3.5 & 0.4 \\
\hline Coffee & 37.4 & 52.1 & 9.7 & 0.8 \\
\hline Cotton & 6.9 & 15.4 & 69.2 & 8.5 \\
\hline Tobacco & 52.6 & 39.3 & 5.0 & 3.1 \\
\hline Bananas & 15.2 & 16.3 & 56.2 & 12.3 \\
\hline Bovine cattle & 31.3 & 42.7 & 18.7 & 7.3 \\
\hline
\end{tabular}




\begin{tabular}{|c|c|c|c|c|}
\hline \multirow{2}{*}{$\begin{array}{l}\text { Country, year, } \\
\text { and Crop }\end{array}$} & \multicolumn{4}{|c|}{$\begin{array}{l}\text { Percentage Distribution of Land and Crops } \\
\text { Among Explotaciones of Stated Sizes: }\end{array}$} \\
\hline & Smalia & Family-sized $a$ & $\begin{array}{l}\text { Moderate } \\
\text { Multi-familya }\end{array}$ & $\begin{array}{l}\text { Large } \\
\text { Multi-familya }\end{array}$ \\
\hline \multicolumn{5}{|l|}{ Nicaragua (1963) } \\
\hline Farmland & 3.5 & 23.7 & 42.4 & 30.4 \\
\hline Corn & $2 \overline{5.2}$ & 45.3 & 25.9 & 3.6 \\
\hline Beans & 32.8 & 49.4 & 16.8 & 1.0 \\
\hline Rice & 22.8 & 30.8 & 26.6 & 19.8 \\
\hline Sugarcane & 1.2 & 11.7 & 54.1 & 33.0 \\
\hline Coffee & 5.0 & 35.0 & 52.0 & 8.0 \\
\hline Cotton & 1.6 & 15.2 & 69.5 & 13.7 \\
\hline Bovine cattle & 4.5 & 26.0 & 44.8 & 24.7 \\
\hline \multicolumn{5}{|l|}{ Costa Rica (1963) } \\
\hline Farmland & 2.8 & 27.1 & 38.8 & 31.3 \\
\hline$\overline{\operatorname{Corn}}$ & $2 \overline{0.4}$ & $\overline{56.2}$ & $\overline{19.2}$ & $\overline{4.2}$ \\
\hline Beans & 17.9 & 61.3 & 20.5 & 0.4 \\
\hline Rice & 8.2 & 39.0 & 33.8 & 19.0 \\
\hline Sugarcane & 7.4 & 25.4 & 36.8 & 30.4 \\
\hline Coffee & 17.5 & 44.3 & 30.4 & 7.8 \\
\hline Cotton & 0.1 & 5.4 & 49.4 & 45.0 \\
\hline Tobacco & 52.0 & 40.8 & 7.2 & 0.0 \\
\hline Bananas & 2.4 & 20.3 & 51.1 & 26.2 \\
\hline Bovine cattle & 4.2 & 29.7 & 42.8 & 23.4 \\
\hline
\end{tabular}

SOURCE: Compiled and computed from Guatemala, DGE, 1954a:Cuadros 1, 17, 21, 25, 55, and 61, and 1954b:Cuadro 1, and 1953:Cuadro 13; El Salvador, DGEC, 1967:Cuadros 32, 35-42, 46, and 55; Honduras DGEC, 1954:Cuadros 1, 12, 17, 19, and 27; Nicaragua, DGEC, 1966:Tablas D, 29-32, and 35; and Costa Rica, DGEC, 1965a:Cuadros 9, 23, 28, 33, 43, 49, 79, 103, 121, and 277.

a Size groupings have the following limits:

Guatemala--under 10, 10-63.9, 64-1, 279.9, and 1,280 mz and over; El Salvador--under 10, 10-99.9, 100-999.9, and 1,000 ha. and over; Honduras--under 10, 10-99.9, 100-999.9, and 1,000 ha. and over; Nicaragua--under $10,10-99.9,100-999.9$, and $1,000 \mathrm{mz}$. and over; Costa Rica--under 10, 10-99.9, 100-999.9, and 1,000 mz. and over.

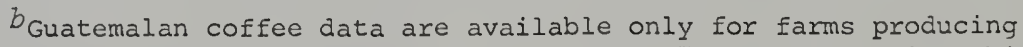
200 or more sacks of coffee in 1949-1950. The 1,744 farms meeting this production minimum accounted for 86.9 per cent of the crop, but the published figures are an understatement of production on smaller explotaciones (of which only 79 qualified for tabulation, although many more produced coffee on a small scale). 
republics accounted for 80 to 96 per cent of the national totals, while Nicaraguan and Costa Rican multi-family farms contributed about half of their countries' production. In Costa Rica, where a series of three agricultural censuses makes a trend analysis possible, the entrance of multifamily farms-particularly those over 1,000 manzanas-into rice growing is very recent. In 1950 and 1955 multifamily farms produced about 31 per cent of the rice. By 1963 the comparable figure was 52.8 per cent. In the principal rice-growing province, Guanacaste, only 30.2 per cent of the crop was grown on places of 100 or more manzanas in 1955, while in 1963 this amount rose to 67.5 per cent. The same phenomenon appears to be occurring in Nicaragua.

Sugarcane growing, although basically for domestic consumption, is concentrated on the multi-family farms. This is probably owing to the fact that the cane must be processed when cut, and capital investment in a trapiche (mill for crude sugar) or refinery is required. In the Central American region there are a number of sizable refineries which grind the cane produced on 500 or more manzanas of their own land, as well as other cane they purchase. A report of the Salvadoran Ministry of Agriculture (MAG, Dirección General de Economía Agropecuaria, Sección de Previsión de Cosechas, 1963:23) presents data for 8 such ingerios (refineries) in 1961-1962. 
of the food crops analyzed here, corn and beans are clearly left largely to the small and family-sized producers, while sugar and to some extent rice are operated as much or more by large farms. Comparing the share of each crop with the proportion of farm land controlled by farms in each size category provides an easy way to see just how productive different sizes of farms tend to be. Concerning corn and beans the small farms of all the countries produce at least three times as much of the crop as their proportion of the land in farms. The greatest excess of production over area in farms is in the case of beans in Nicaragua-nearly 10 times their pro rata share of beans are produced in Nicaragua's farms of less than 10 manzanas. Sugarcane production on small farms was less than their share of the land in the cases of Guatemala and Nicaragua.

In Guatemala and Honduras, the family-sized grouping of farms produced approximately the same share of corn, beans, and rice as their land area constituted, in about 1950. El Salvador's family-sized units produced considerably less than their pro rata share, while in Nicaragua and Costa Rica family-sized farms produced double their share of corn and beans and well over their pro rata share of rice. In Guatemala, El Salvador and Costa Rica the 
family-sized lands also produced nearly a full share of sugarcane.

Both moderate and large multi-family farms produced less than their pro rata share of the three staple crops. The extreme case is costa Rica where farms with nearly a third of all territory in farms produced only 1/250th of the three crops! As to sugarcane, in Guatemala and Nicaragua large farms of both sizes produce more sugarcane than their share of land, and in EI Salvador and costa Rica, just slightly less than their share.

Commercial crops. -The relative distribution of three or four common commercial crops by size of explotación is also presented in Table 6 . The "coffee countries" of Central America have quite different distributions of coffee production on farms of varied sizes. In Guatemala the coffee bean is produced almost entirely on large farms, with only a small percentage grown on farms under 64 manzanas and nearly one-third on farms of 1,280 manzanas or more. 1

${ }^{1}$ Actually, these Guatemalan data are defective, since production figures are only provided for the 1,744 farms that produced 200 or more quintales of coffee cherries in 1949-1950. These farms must include all of the large ones, and progressively fewer of the rest as size of farm decreases. The average production per manzana of the 1,744 farms was 34.2 quintales of coffee cherries. An "average" farm of 5 manzanas, alz of which was planted in coffee of producing age, would have a production of onlv 171 quintales, and so would have been excluded. Since a farm of 5 manzanas would not likely have all of its area in coffee, it would have to have an average production of better than 40 quintales 
At the opposite extreme is neighboring Honduras, where (in 1952) most of the coffee was grown on family-sized farms of 10 to 99 hectares, and altogether 89.5 per cent was produced on farms of less than 100 hectares. The difference reported is very real in this case, and the statistics are not deceiving. The principal explanation may very well lie in the strong manner in which Guatemalan governments for a century or more, until the 1940's, encouraged the growth of the crop and devised one law after another to see to it that large-scale planters would be able to have the necessary labor force or mano de obra to operate this labor-intensive enterprise at

per manzana if it were to be included in the published "coffee census." Actually only 12 farms under 5 manzanas were counted, and only 67 between 5 and 9 manzanas - which must indicate that hundreds of operators were not counted. But the production on these excluded farms, since it had to be less than 200 quintales, and frequently much less, amounted to only 13.1 per cent of all production. (The census tabulated simple production from all farms, but did not include any figures except that 86.9 per cent of production was covered in the coffee census of 1,744 farms.) Even adding an estimated increment of 809,000 quintales (for unpublished production) entirely to the small and family-sized farms-assuming it was all produced on farms of those sizes, which would not be true-the sharo of total production attributable to farms of less than 64 manzanas would be 17.9 per cent. The true figure lies somewhere between the 5.5 per cent of Table 6 , and 17.9 per cent. I cannot tell what the true figure is (See Guatemala, DGE, 1953). 
harvest time. ${ }^{1}$ Honduran proprietors of large estates, on the contrary, seem to have seen cattle-raising as their chief source of income and social and political status, and so coffee has been left to the smaller operators just as corn and beans have been neglected.

An additional important factor has been Guatemala's openness to European capital and immigration. The development of the coffee-growing industry into one dominated by multifamily farms is mostly due to both foreign capital and foreign operation. Farms owned by foreigners (until World War II when many were "intervened" by the government because their owners were Germans) were generally larger and more productive than those of Guatemalan citizens, and the financial resources available to these alien operators were also greater (Jones, 1940:206-208). In contrast, no particular stimulus to foreign operation was exerted by Honduras, and the necessary transportation is still relatively deficient.

Coffee raising in Costa Rica, Nicaragua and El Salvador is mostly done on family-sized or moderately large multi-family-sized properties, with Costa Rica showing the

${ }^{1}$ Many and varied historical and economic studies have discussed these laws and the circumstances of their promulgation. Perhaps one of the best in terms of detail and availability is Jones, 1940:Chapter 12, "Labor: Mandamiento to Vagrancy Laws," pages $141-167$ and notes. A brief and simplified review is that of whetten, 1961:116-123, and 102-105. A somewhat different view is given in solorzano F., 1963 :passim. 
greater proportion on family-sized farms and the other two countries being weighted toward the moderately large grouping. The description of the system of raising coffee on the Aquiares hacienda at Turrialba (reported above on page 87), in which "colonos" were in charge of plots of trees belonging to the hacienda, suggests that much of Aquiares' coffee has been credited to many small and family-sized operators when it really should be attributed to one 1,372 manzana operation. The extent to which this occurs on other farms is unknown, but correcting it would give Costa Rica a larger proportion of its coffee production on multi-family estates. Actually the colono system as used on Aquiares is not widespread in Costa Rica, but this factor doubtless affects the statistics to some extent. In summary it can be said that (with the exception of Guatemala) family-sized farms consistently produce more coffee than their share of farmland would suggest, as is also often true for small farms. On the other hand, with the exception of Guatemala, again, the very large farms seem not to place as much emphasis on coffee as their land would "entitle" them to. The author's personal impression from talking with many small farmers in Costa Rica was that they felt quite successful if they could have a few manzanas of coffee trees as well as their basic 
food crops and some animals. It seemed that coffee was what gave them the greatest pride-as if to grow coffee made them hidargos. The economists may say that to gain maximum efficiency the operation must be large enough to support a beneficio (processing plant), but the crop appears to be relatively well suited to family-sized farms when the operator has reasonable access to technical information and can obtain credit and technical inputs such as insecticides and fertilizers, and a reasonable price for his crops at a nearby beneficio.

Cotton and tobacco production provide the clearest cases of differentiation of commercial crop growing by size of farms. Cotton, in the four countries reporting, is invariably concentrated on the two multi-family farm categories. Both small and family-sized farms produce relatively low proportions, and never approach the percentage of cotton production which could be said to be commensurate with the area involved.

On the other hand, little tobacco is grown on large farms, and its distribution is remarkably similar to that of corn, beans, and rice. Over 90 per cent of the production comes from farms of less than 100 manzanas or hectares in Honduras, El Salvador and Costa Rica, and about 70 per cent from farms under 64 manzanas in Guatemala. 
In Central America banana production has traditionally been the almost exclusive domain of the large foreign company, and the situation has not changed. In Guatemala (in 1950, before serious moves against "the company" were instituted) farms of 64 manzanas or more produced about 93 per cent of all bananas, while in neighboring Honduras 68 per cent were the result of multi-family farm operations and in Costa Rica the figure was 77 per cent in 1963. The Costa Rican figures are the only recent national data available. Although production figures for the fruit companies are not at hand for the recent census year, the United Fruit Company alone had 27,185 acres in bananas in Costa Rica (United Fruit Company, 1963:13), which amounts to 43 per cent of all land planted to bananas in the republic as reported in the 1963 census. The Standard Fruit and Steamship Company acreage, if known, would add materially to that percentage. Due to lack of recent census data, comparable figures for Guatemala and Honduras are available only for the early $1950^{\prime}$ 's, but at that time the United Fruit Company appeared to have 64 per cent of the banana land in Guatemala and 56 per cent in Honduras. 1

${ }^{1}$ Figures derived by comparing acreage in bananas at the appropriate year as given in company annual reports with census area in bananas converted to acres. 
Actually, in spite of the overwhelming position of the large corporate farms in banana production, this is virtually all for export, and the provision of bananas (and plátanos as well) for the internal consumption in each country is mostly in the hands of small and familysized operators. Guatemala again is the exception, and this may be due to the use of banana trees as shade in the coffee fincas, since the shade trees in that case would also produce a secondary product stemming from multifamily properties.

In summary it can be said that tobacco is the most clearcut case of a commercial crop being produced on small and family-sized farms, and that cotton and bananas provide the greatest contrast, with nearly all production on multifamily farms. Coffee is an ambiguous case, with Honduras clearly emphasizing production on units of family size, and Costa Rica appearing to do so as well, while in Guatemala, Nicaragua and El Salvador the large plantations dominate production.

Cattle Production by Size of Explotación

The extent to which large farms tend to stress pasture over cropland in their use of land has been pointed out. It remains, however, to note the relative shares of bovine cattle production by size of explotaciones (see Table 6). In Honduras and El Salvador the majority 
(over 70 per cent!) of the cattle were counted on small and family-sized farms, while in Guatemala 56 per cent were on multi-family farms, and in Nicaragua and Costa Rica over 65 per cent were concentrated on such large operations. In comparison with the availability of pasture land, the family-sized farms seem to have a moderate concentration of cattle-that is, a somewhat higher proportion of cattle than pasture-while small farms generally have a two to four times their share of cattle in relation to their pastures. On the contrary, multi-family farms tend to have much less than their pro rata share of cattle, based on the area of their pastures. This imbalance is not pronounced in Costa Rica, but stands out sharply on large haciendas in Honduras and El Salvador.

The number of head of cattle carried per 100 manzanas of pasture land has also been analyzed. There is no way of indicating what an appropriate carrying capacity might be for different sizes, but it is apparent that for the available pasture, cattle are very heavily concentrated on small farms. Part of the concentration on small farms is caused by the fairly extensive use of oxen as work animals, as well as the keeping of milk cows, especially in El Salvador. One can summarize the facts of animal production by saying that the farms that would appear from their land 
resources to be most capable of producing the cattle of the country are doing so quite inefficiently, and that small farms probably have more cattle than rational land use would permit.

The Historical Evolution of Sizes of Holdings

Farming was the basic economic activity for most of the people inhabiting Central America at the time the Spaniards discovered the area in the late fifteenth century. This was especially true of the several Maya groups of Guatemala, El Salvador, and Honduras, but even the less highly civilized tribes up and down the Pacific coast of the region were fully sedentary agriculturists. The other groups who ranged the Atlantic coastal plain were less sedentary, but these also practices some agriculture (see Steward and Faron, 1959:passim). It seems to be generally accepted that landownership was vested in the tribes or communities, and not in individuals at that time, so the units of ownership were relatively large. But the actual plots farmed by a given family were generally small (see Chapter IV).

Once the Spaniards arrived and claimed all the land in the name of the crown, they were free to transform the nature of landholding and the characteristic size of holding. As soon as they had formed the nucleus of a new settlement 
the founding settlers set up a cabildo (council) and applied to the representative of the Crown for grants of land for the establishment of estates. They applied, likewise, for grants of Indians in encomienda (trusteeship) who would be obligated to perform the work on these estates in return for the colonist's guidance and protection (the encomienda is described in detail in Chapter IV, in connection with the evolution of forms of labor in agriculture). The old favorite Iberian enterprise of cattle raising encouraged the early establishment of large haciendas, such as its suggested by the comment of Thomas Gage, the English priest who served in Guatemala during the 1620's (Gage, 1946: 184):

Of beef there is such plenty that it exceeds all parts of America, without exception, as may be known by the hides, which are sent yearly to spain from the country of Guatemala. There they commonly kill their cattle more for the gain of the hides in Spain, than for the goodness or fatness of the flesh... that in my time. . . was commonly sold at thirteen pound and a half for half a real, the least coin there is, and so much as threepence here.

In addition to cattle of all sorts, the Spaniards were soon growing a variety of crops which required some capital investment and showed promise of being profitable, either locally or for shipment to the mother country. Wolf (1959: 176-182) cites among the principal enterprises largely monopolized by the colonists, the production of sugar cane, 
the manufacture of both sugar and aguardiente, the raising of wheat in the higher valleys, and the cultivation of indigo near the coast. In each case the operations were carried out on large estates, which can be understood well with a further quotation from Gage (1946:203-204):

Within a mile and a half of this town [Petapa] there is a rich ingenio or farm of sugar belonging to one Sebastián de Zavaleta, a Biscayan born. . . He grew so rich [with a mule train] that he bought much land around Patapa, which he found to be very fit for sugar. - . This man maketh a great deal of sugar for the country, and sends every year much to Spain. He keepeth at least threescore slaves of his own for the work of his farm, is very generous in housekeeping, and is thought to be worth above five hundred thousand ducats.

[Near Amatitián is a] greater ingenio of sugar than is that of Zavaleta, and is called the ingenio of one Anis, because he first founded it, but now it belongeth unto Pedro Crespo, the postmaster of Guatemala. This ingenio seemed to be a little town by itself for the many cottages and thatched houses of Blackamoor slaves which belong unto it, who may be above a hundred, men, women, and children. The chief dwelling house is strong and capacious, and able to entertain a hundred lodgers. These three farms of sugar standing so near unto Guatemala enrich the city much, and occasion great trading from it to Spain.

The development of a considerable number of large tracts of land in the hands of the Spaniards in Central America followed the usual Spanish practice throughout their new empire. With the exception of the relatively uninhabited areas, including also Costa Rica where the Indian population either died or fled shortly after the conquest, the availability of a subject people to provide 
the labor for running large estates made such establishments very attractive to the adventurers who were the first settlers. In spite of the provisions in the laws of the Indies and in royal decrees for the protection of the Indians, and in spite of definite limitations on the size of land grants (see Spain, 1791:Libro IV, Título XII, Ley 1), land seemed abundant and the greed of the colonists was great. Consequently, the level valley lands soon became the extensive private preserves of the newcomers and the Indians were forced to make their cornfields on the sides of hills and mountains or in the more distant parts of the colony (West and Augelli, 1966:421). The same phenomenon has been traced more exhaustively by $T$. Lynn Smith for Colombia (1967a:62-69).

The situation was somewhat different in Costa Rica, owing to the fact that in that area the Indian population was less dense, and also less willing to accept the domination of the newcomers. As Rojas and Escoto León wrote (1960:3),

The lack of economic resources, . . the fortunate fact that the encomienda as an institution was not [in Costa Rica] an instrument of slavery, and the settlement of the largest nucleus of population in a zone of benign climate and fertile lands, in which each farmer could be the owner of his own parcel made it impossible-in the first years of our independent life-for the latifundio to appear. . .

Without Indian laborers each man had to do his own work, and a society of peasant proprietors of small 
tracts resulted. The introduction of coffee as a major crop produced the first strong pressure toward the consolidation of holdings and the development of great rural social stratification in Costa Rica. Since coffee was a highly commercial crop many small growers had to borrow money against the land they owned, and all too frequently they lost their land altogether through foreclosures (Soley Güell, 1940:82-83). The new class of large owners became known as the "coffee aristocracy" (Rojas, 1961:40-41). On Costa Rica's outlying lands the development of large properties in the form of cattle haciendas soon took place. These were established early in the Guanacaste area, and there were also some elsewhere. Stephens visited the hacienda Santa Teresa in Guanacaste in 1840. He reported (1841, I:393) that the place contained "a thousand mares and four hundred horses, more than a hundred of which were in sight from the door. It was grand enough to give the owner ideas of empire." He did not state its area, but the description shows that it must have been very large. Such large haciendas are still found in that area of the country. A recent report by Thomas (1960:23) tells of the hacienda Santa Rosa, belonging to Iuis Roberto Gallegos, which is said to include 86,000 manzanas. Since the large haciendas and plantations necessarily go hand-in-hand with the small tracts of the families who 
provide the labor to run them, the two are generally found together. Nevertheless, there are some areas of minifundios in which larger farms are lacking. Totonicapán, in Guatemala, is one such area, and apparently has been so for a long time (Brigham, 1887:137).

At any rate, until the recent advent of censuses of agriculture it was impossible to determine with any accuracy the distribution of holdings by size. Chester Lloyd Jones attempted to do this for Guatemala, but was unsuccessful (see his data in 1940:176-179 and 381). It is worth noting that very likely there has been a tendency for the average size of farms to decrease as the properties have been subdivided with each new generation, at the same time that a small number of owners have been able to materially increase the sizes of their estates. The balance between these is unknown, and the continual carving out of new properties from the public domain (except in EI Salvador) further complicates the picture. About all that can be summarized about the pre-contemporary period is that there has been a considerable degree of control over land by a few fortunate persons throughout the era since the arrival of the Spaniards.

Trends in the Size of Explotaciones

There is simply no way of determining the trends in the size of farms in the past in Central America, since 
there have been no concrete data that could pretend to be comprehensive regarding any of the countries. Many writers have made observations, but I dismiss them as of dubious value owing to their subjective character. Even those of reputable scholars like Jones are of little value due to the inadequacies of the data on which they relieddata from property registers, production estimates, and the like.

Recent Census Data

The situation changed materially when the countries of the region cooperated with the 1950 census of the Americas and took a census of agriculture in that year or shortly thereafter. ${ }^{1}$ This census became a benchmark against which changes of all sorts can be measured. Already additional agricultural censuses have been taken in four of the countries, and for three of them the final data have been tabulated and published. In Tables $7 \mathrm{~A}$ to $7 \mathrm{C}$ the relevant information on the number of explotaciones has been gathered and the necessary rates of change have been computed for Guatemala, El Salvador, and Costa Rica.

${ }^{1}$ Honduras took its first census of agriculture in 1952, and Nicaragua carried out an agricultural survey in that same year which was intended to take the place of a census, though it was quite incomplete. 
Tabie 7A. Absolute and relative numbers of explotaciones of stated sizes, together with absolute and relative change: Guatemala, 1950 to 1964

Size of Explotaciones (Manzanas)
Explotaciones

\begin{tabular}{|c|c|c|c|c|c|}
\hline \multicolumn{2}{|c|}{1950} & \multicolumn{2}{|c|}{1964} & \multicolumn{2}{|c|}{ Change, 1950-1964 } \\
\hline Number & Per Cent & Number & Per Cent & Number & Per Cent \\
\hline 74,269 & 21.3 & 85,083 & 20.4 & 10,814 & 14.6 \\
\hline 91,581 & 26.2 & 98,658 & 23.6 & 7,077 & 7.7 \\
\hline 99,779 & 28.6 & 129,115 & 30.9 & 29,336 & 29.4 \\
\hline 42,444 & 12.2 & 52,023 & 12.5 & 9,579 & 22.6 \\
\hline
\end{tabular}

$\underline{308,073} \quad \underline{88.3} \quad \underline{364,879} \quad \underline{87.4} \quad \underline{56,806} \quad \underline{18.4}$

$\begin{array}{rrrrrr}26,916 & 7.7 & 37,025 & 8.9 & 10,109 & 37.6 \\ 6,125 & 1.8 & 6,631 & 1.6 & 506 & 8.3\end{array}$

33,041

9.5

43,656

10.5

10,615

32.1

6,488

1.9

569

7,859

1.9

1,371

21.1

358

0.2

0.1

104

32

22

-.- $a$

--a

-. a

0.1

$-8$

$-1.4$

0.1

- 64

$-17.9$

- 48

$-46.2$

$-2$

$-6.2$

- 13

$-59.1$

7,573

2.2

8,809

2.1

1,236

16.3

Total

$\underline{68,657} \quad \underline{19.7}$

SOURCE: Compiled and computed from Guatemala, DGE, 1968:Cuadro 7, page 43. $\alpha_{\text {Less than }} 0.05$ per cent. 
Table 7B. Absolute and relative numbers of explotaciones of stated sizes, together with absolute and relative change: El Salvador, 1950 to 1961

\begin{tabular}{|c|c|c|c|c|c|c|}
\hline \multirow{3}{*}{$\begin{array}{l}\text { Size of } \\
\text { Explotaciones } \\
\text { (Hectares) }\end{array}$} & \multicolumn{6}{|c|}{ Explotaciones } \\
\hline & \multicolumn{2}{|c|}{1950} & \multicolumn{2}{|c|}{1961} & \multicolumn{2}{|c|}{ Change, 1950-1961 } \\
\hline & Number & Per Cent & Number & Per Cent & Number & Per Cent \\
\hline Under 1 & 70,416 & 40.4 & 107,054 & 47.2 & 36,638 & 52.0 \\
\hline $1-1.9$ & 35,189 & 20.2 & 48,501 & 21.4 & 13,312 & 37.8 \\
\hline $2-4.9$ & 34,868 & 20.0 & 37,743 & 16.6 & 2,875 & 8.2 \\
\hline $5-9.9$ & 14,064 & 8.1 & 14,001 & 6.2 & -63 & -0.4 \\
\hline Under 10 & 154,537 & 88.7 & 207,299 & 91.4 & 52,762 & 34.1 \\
\hline $10-19.9$ & 8,874 & 5.1 & 8,524 & 3.7 & 350 & -3.9 \\
\hline $20-49.9$ & 6,660 & 3.8 & 6,711 & 3.0 & 51 & 0.7 \\
\hline $50-99.9$ & 2,107 & 1.2 & 2,214 & 1.0 & 107 & 5.0 \\
\hline $10-99.9$ & 17,641 & 10.1 & 17,449 & $\underline{7.7}$ & 192 & -1.1 \\
\hline $100-199.9$ & 1,059 & 0.6 & 1,121 & 0.5 & 62 & 5.8 \\
\hline $200-499.9$ & 654 & 0.4 & 713 & 0.3 & 59 & 9.0 \\
\hline $500-999.9$ & 168 & 0.1 & 189 & 0.1 & 21 & 12.5 \\
\hline $1,000-2,499.9$ & 110 & 0.1 & 91 & $--a$ & 19 & $-17 \cdot 3$ \\
\hline 2,500 and over & 35 & $--a$ & 34 & $---a$ & - & -2.8 \\
\hline 100 and over & $\underline{2,026}$ & 1.2 & 2,148 & $\underline{0.9}$ & $\underline{122}$ & 6.0 \\
\hline Total & 174,204 & 100.0 & 226,896 & 100.0 & 52,692 & 30.2 \\
\hline
\end{tabular}

SOURCE: Compiled and computed from El Salvador, DGEC, 1954a:Cuadro 4, and 1967 : Cuadro 31.

$a_{\text {Less }}$ than 0.05 per cent. 
Table 7C. Absolute and relative numbers of explotaciones of stated sizes, together with absolute and relative change: Costa Rica,

1950 to 1963

\begin{tabular}{|c|c|c|c|c|c|c|}
\hline \multirow{3}{*}{$\begin{array}{c}\text { Size of } \\
\text { Explotaciones } \\
\text { (Manzanas) }\end{array}$} & \multicolumn{6}{|c|}{ Explotaciones } \\
\hline & \multicolumn{2}{|c|}{1950} & \multicolumn{2}{|c|}{1963} & \multicolumn{2}{|c|}{ Change, 1950-1963 } \\
\hline & Number & Per Cent & Number & Per Cent & Number & Per Cent \\
\hline $\begin{array}{l}1-4.9^{a} \\
5-9.9^{b}\end{array}$ & $\begin{array}{r}12,004 \\
6,972\end{array}$ & $\begin{array}{l}27.9 \\
16.2\end{array}$ & $\begin{array}{l}14,931 \\
12,994\end{array}$ & $\begin{array}{l}23.1 \\
20.1\end{array}$ & $--a$ & $--a$ \\
\hline \pm-9.9 & 18,976 & 44.1 & 27,925 & 43.2 & 8,949 & 47.2 \\
\hline $10-19.9$ & 6,572 & 15.2 & 9,542 & 14.8 & 2,970 & 45.2 \\
\hline $20-49.9$ & 9,004 & 20.9 & 13,167 & 20.4 & 4,163 & 46.2 \\
\hline $50-99.9$ & 4,703 & 10.9 & 7,240 & 11.2 & 2,537 & 53.9 \\
\hline $10-99.9$ & 20,279 & 47.0 & 29,949 & 46.4 & 9,670 & 47.7 \\
\hline $100-249.9$ & 2,620 & 6.1 & 4,441 & 6.9 & 1,821 & 69.5 \\
\hline $250-499.9$ & 638 & 1.5 & 1,291 & 2.0 & 653 & 102.4 \\
\hline $500-999.9$ & 328 & 0.8 & 596 & 0.9 & 268 & 81.7 \\
\hline $1,000-1,499.9$ & 90 & 0.2 & 191 & 0.3 & 101 & 112.2 \\
\hline $1,500-3,499.9$ & 106 & 0.2 & 169 & 0.2 & 63 & 59.4 \\
\hline 3,500 and over & 49 & 0.1 & 59 & 0.1 & 10 & 20.4 \\
\hline 100 and Over & 3,831 & 8.9 & 6,747 & 10.4 & 2,916 & 76.1 \\
\hline Total & 43,086 & 100.0 & 64,621 & 100.0 & 21,535 & 50.0 \\
\hline
\end{tabular}

SOURCE: Compiled and computed from Costa Rica, DGEC, 1953a:Cuadro 4, and 1965a: Cuadro 8 .

an 1963 this category is $1-3.9$ manzanas, since the nearest class limits were provided at 3.9 and at 5.9 manzanas.

$b_{\text {In }} 1963$ this category is $4-9.9$ manzanas, since the nearest class limits were provided at 4.0 and at 6.0 manzanas. 
Similar data on the area of land in explotaciones by size have been assembled as Tables $8 \mathrm{~A}$ to $8 \mathrm{C}$.

The interval between the censuses is short: only slightly over a decade. Nevertheless the statistical information may very well represent the trends in the three countries involved. Three distinctly different trends appear to be underway. In El Salvador there were 52,700 or so additional explotaciones added to the country's total in just 11 years, and these were virtually all in the minifundio category. There was even a decline in the number of places in the family-sized class. Thus it appears that this nation, which already has the highest proportion of small explotaciones in the region, is becoming even more a land of tiny farms. Moreover, the detailed breakdown in Table $7 B$ shows that over two-thirds of the increase was in places of less than 1 hectare in area, and that fully 94 per cent of the increase was comprised of plots no larger than 2 hectares. Land in farms increased by only 3 per cent, so most of the additional land added to the minifundio category has been withdrawn from the larger classes (Table 8B).

A different picture is found in Guatemala. Although the greatest numerical increase in explotaciones occurred among the small-sized explotaciones, these places did not multiply at a rate commensurate with their share of the 
Table 8A. Absolute and relative amounts of land in explotaciones of stated sizes, together with absolute and relative change: Guatemala, 1950 to 1964

\begin{tabular}{|c|c|c|c|c|c|c|}
\hline \multirow{2}{*}{$\begin{array}{l}\text { Size of } \\
\text { Explotaciones } \\
\text { (Manzanas) }\end{array}$} & \multicolumn{2}{|c|}{1950} & \multicolumn{2}{|c|}{1964} & \multicolumn{2}{|c|}{ Change, 1950-1964 } \\
\hline & Manzanas & Per Cent & Manzanas & Per Cent & Manzanas & Per Cent \\
\hline Under 1 & 40,822 & 0.8 & 46,683 & 0.9 & 5,861 & 14.4 \\
\hline-1.9 & 135,077 & 2.5 & 136,325 & 2.8 & 1,248 & 0.9 \\
\hline $2-4.9$ & 302,987 & 5.7 & 386,704 & 7.9 & 83,717 & 27.6 \\
\hline $5-9.9$ & 282,730 & 5.3 & 346,904 & 7.0 & 64,174 & 22.7 \\
\hline Under 10 & 761,616 & 14.3 & 916,616 & 18.6 & 155,000 & 20.4 \\
\hline $10-31.9$ & 444,164 & 8.4 & 637,948 & 12.9 & 193,784 & 43.6 \\
\hline $32-63 \cdot 9$ & 271,308 & 5.1 & 290,726 & 5.9 & 19,418 & 7.2 \\
\hline $10-63.9$ & 715,472 & 13.5 & 928,674 & 18.8 & 213,202 & 29.8 \\
\hline $64-639.9$ & $1,161,803$ & 21.9 & $1,307,255$ & 26.6 & 145,452 & 12.5 \\
\hline $640-1,279.9$ & 506,100 & 9.5 & 493,913 & 10.0 & $-12,187$ & -2.4 \\
\hline $1,280-3,199.9$ & 707,869 & 13.3 & 552,990 & 11.2 & $-154,879$ & -21.9 \\
\hline $3,200-6,399.9$ & 468,070 & 8.8 & 242,496 & 4.9 & $-225,574$ & -48.2 \\
\hline $6,400-12,799.9$ & 280,476 & 5.3 & 254,926 & 5.2 & $-25,550$ & -9.1 \\
\hline 12,800 and over & 714,069 & 13.4 & 229,896 & 4.7 & $-484,173$ & -67.8 \\
\hline 64 and Over & $3,838,387$ & $\underline{72.2}$ & $3,081,476$ & $\underline{62.6}$ & $-756,911$ & -19.7 \\
\hline Total & $5,315,475$ & 100.0 & $4,926,766$ & 100.0 & $-388,709$ & -7.3 \\
\hline
\end{tabular}

SOURCE: Compiled and computed from Guatemala, DGE, 1968:Cuadro 7, page 43. 
Table 83. Absolute and relative amounts of land in explotaciones of stated sizes, together with absolute and relative change:

El Salvador, 1950 to 1961

\begin{tabular}{|c|c|c|c|c|c|c|}
\hline \multirow{3}{*}{$\begin{array}{l}\text { Size of } \\
\text { Explotaciones } \\
\text { (Hectares) }\end{array}$} & \multicolumn{6}{|c|}{ Land in Explotaciones } \\
\hline & \multicolumn{2}{|c|}{1950} & \multicolumn{2}{|c|}{1961} & \multicolumn{2}{|c|}{ Change, 1950-1961 } \\
\hline & Hectares & Per Cent & Hectares & Per Cent & Hectares & Per Cent \\
\hline Under 1 & 35,203 & 2.3 & 61,365 & 3.9 & 26,162 & 74.3 \\
\hline $1-1.9$ & 48,013 & 3.1 & 68,542 & 4.3 & 20,529 & 42.7 \\
\hline $2-4.9$ & 106,973 & 7.0 & 117,471 & 7.4 & 10,498 & 9.8 \\
\hline $5-9.9$ & 99,446 & 6.5 & 98,791 & 6.3 & -655 & -0.6 \\
\hline Under 10 & 289,635 & 28.9 & 346,169 & 21.9 & . 56,534 & 19.5 \\
\hline $10-19.9$ & 122,477 & 8.0 & 117,426 & 7.4 & $-5,051$ & -4.1 \\
\hline $20-49.9$ & 206,334 & 13.5 & 208,628 & 13.2 & 2,294 & 1.1 \\
\hline $50-99.9$ & 147,640 & 9.7 & 154,704 & 9.8 & 7,064 & 4.7 \\
\hline $10-99.9$ & 476,451 & 31.2 & 480,758 & 30.4 & 4,307 & 0.9 \\
\hline $100-199.9$ & 145,692 & 9.5 & 158,499 & 10.0 & 12,807 & 8.8 \\
\hline $200-499.9$ & 198,025 & 13.0 & 219,204 & 13.8 & 21,179 & 10.7 \\
\hline $500-999.9$ & 115,402 & 7.5 & 127,880 & 8.1 & 12,478 & 10.8 \\
\hline $1,000-2,499.9$ & 171,662 & 11.2 & 132,310 & 8.4 & $-39,352$ & -22.9 \\
\hline 2,500 and Over & 133,456 & 8.7 & 116,608 & 7.4 & $-16,848$ & -12.6 \\
\hline 100 and Over & 764,237 & 49.9 & 754,501 & 47.7 & $-9,736$ & -1.3 \\
\hline Total & $1,530,323$ & 100.0 & $1,581,428$ & 100.0 & 51,105 & $\underline{3.3}$ \\
\hline
\end{tabular}

SOURCE: Compiled and computed from El Salvador, DGEC, 1954a:Cuadro 4, and 1967 : Cuadro 32 . 
Table $8 \mathrm{C}$. Absolute and relative amounts of land in explotaciones of stated sizes, together with absolute and relative change:

Costa Rica, 1950 to 1963

\begin{tabular}{|c|c|c|c|c|c|c|}
\hline \multirow{3}{*}{$\begin{array}{l}\text { Size of } \\
\text { Explotaciones } \\
\text { (Manzanas) }\end{array}$} & \multicolumn{6}{|c|}{ Land in Explotaciones } \\
\hline & \multicolumn{2}{|c|}{1950} & \multicolumn{2}{|c|}{1963} & \multicolumn{2}{|c|}{ Change, 1950-1963 } \\
\hline & Manzanas & Per Cent & Manzanas & Per Cent & Manzanas & Per Cent \\
\hline $\begin{array}{l}1-4 \cdot 9^{a} \\
5-9 \cdot 9^{b}\end{array}$ & $\begin{array}{l}29,273 \\
46,524\end{array}$ & $\begin{array}{l}1.1 \\
1.8\end{array}$ & $\begin{array}{l}31,368 \\
79,616\end{array}$ & $\begin{array}{l}0.8 \\
2.1\end{array}$ & $\begin{array}{c}-a \\
--b\end{array}$ & $\ldots-a$ \\
\hline $1-9 \cdot 9$ & 75,797 & $\underline{2.9}$ & 110,984 & $\underline{2.9}$ & 35,187 & 46.4 \\
\hline $10-19 \cdot 9$ & 88,074 & 3.4 & 129,532 & 3.4 & 41,458 & 47.1 \\
\hline $20-49 \cdot 9$ & 280,391 & 10.8 & 414,545 & 10.9 & 134,154 & 47.8 \\
\hline $50-99 \cdot 9$ & 309,890 & 12.0 & 488,800 & 12.8 & 178,910 & 57.7 \\
\hline $10-99 \cdot 9$ & 678,355 & 26.2 & $1,032,877$ & 27.1 & 354,522 & 52.3 \\
\hline $100-249.9$ & 386,139 & 14.9 & 649,605 & 17.0 & 263,466 & 68.2 \\
\hline $250-499 \cdot 9$ & 219,664 & 8.5 & 436,312 & 11.4 & 216,648 & 98.6 \\
\hline $500-999 \cdot 9$ & 224,312 & 8.6 & 394,260 & 10.3 & 169,948 & 75.8 \\
\hline $1,000-1,499 \cdot 9$ & 104,818 & 4.1 & 225,940 & 5.9 & 120,122 & 113.5 \\
\hline $1,500-3,499 \cdot 9$ & 213,557 & 8.2 & 349,240 & 9.2 & 135,683 & 63.5 \\
\hline 3,500 and over & 688,578 & 26.6 & 616,132 & 16.2 & $-72,446$ & -10.5 \\
\hline 100 and Over & $1,838,068$ & 70.9 & $2,671,489$ & 70.0 & 833,421 & 45.3 \\
\hline Total & $2,592,220$ & 100.0 & $3,815,350$ & 100.0 & $1,223,130$ & 47.2 \\
\hline
\end{tabular}

SOURCE: Compiled and computed from Costa Rica, DGEC, 1953a:Cuadro 4, and 1965a:Cuadro 9.

$a_{\text {In }} 1963$ this category is $1-3.9$ manzanas, since the nearest class limits were provided at 3.9 and at 5.9 manzanas.

$b_{\text {In }} 1963$ this category is $4-9.9$ manzanas, since the nearest class limits were provided at 4.0 and 6.0 manzanas. 
total, while the family-sized farms received more than their pro rata share of the increment (Table 7A). Farms of 64 to 639 manzanas also included disproportionately more than their share of the new explotaciones, while all those above 640 manzanas decreased in number. Changes in the area in farms (Table $8 \mathrm{~A}$ ) followed the pattern of the number of explotaciones quite accurately up to the multifamily category, but at that point the land area reported to be in farms shows a severe decline-so much so that the overall figures for the nation indicate a decline in farm area at the same time that the number of farms increased by 20 per cent. This may reflect a hedge against further applications of the current agrarian reform law, or some of the effects of the original law of 1952 .

In part, the 43,656 family-sized farms reported in the 1964 census are new creations, opened up as the result of the work of the Instituto Nacional de Transformación Agraria (INTA) in subdividing large properties. According to Alvarado (1964:16-19), between 1955 and. 1963 some 4,664 new family-sized farms averaging 21.2 hectares (30 manzanas) were created by the agrarian reform program. I If these had all remained intact as they were supposed to, they

${ }^{1}$ It has proven impossible to obtain satisfactory figures about any effects of the previous law of 1952 which might still have continuing effects. 
would have constituted over 10 per cent of the family-sized farms counted in 1964, and more than 1 per cent of all farms. In the departments in which the "zones of Agrarian Development" are located, the new family-sized farms are much more prominent. However, the new agrarian reform units have not remained intact. In Suchitepéquez, where the number of reform-created explotaciones was greater than the total number of census farms between 10 and 64 manzanas, the explanation must be that for census purposes (as has already been indicated) many of the reform units are counted as several smaller explotaciones. That is, when the agrarian reform beneficiary has not been able to utilize all of his land personally, he allows an additional person to enter onto his property as a tenant or sharecropper, thus creating an additional "farm" or explotación for census purposes. An American AID official working for INTA estimated that at La Máquina, where about 1,100 new 20-hectare farms had been created, there were an average of three families on each parcel: the owner, a renter, and a migrant laborer (interview with Sam M. Fullilove, AID Rural Housing and Potable Water Adviser, INTA, August 26, 1963). If this estimate is accurate, there would have been an average of two explotaciones per agrarian reform parcel in the 1964 enumeration. 
At any rate, in Guatemala about 80 per cent of the new explotaciones are in the minifundio category, which indicates clearly that even the largest effort in Central America to improve the sizes of farms and the tenure arrangements of their operators has had little impact. On the other hand, the relative increase of family-sized farms from 9.5 to 10.5 per cent of all explotaciones is significant.

The picture in Costa Rica is more encouraging with regard to the development of family-sized farms. In that country these places increased in a slightly greater degree than the minifundia, and farms having 50 to 99 manzanas increased proportionately more than the smaller ones. In each category up to 100 manzanas the land area in farms increased almost precisely in proportion to the growth in the number of explotaciones (see Table 8C).

on the other hand, the multi-family farms, plantations, and haciendas increased even more rapidly both in number and area. The multi-family class as a whole gained three new farms for every four that had been counted in 1950. Moreover, except for the places of more than 3,500 manzanas, there was no significant change in the average size of explotacion over the 13-year interval, the land area in farms of a given size growing apace with the increased 
number of farms themselves. As a matter of fact, there was no important change in the average size of any of the groupings shown in Table 7C except for those places of 3,500 manzanas or more, where the average area per farm or hacienda declined from more than 14,000 manzanas to about 10,400 .

The fact that the trend in costa Rica was not toward greatly increased numbers of tiny minifundia may be partly owing to the fact that places of less than 1 manzana do not figure in the census. There is no way of knowing the number of such tiny plots nor how it is changing. Nevertheless, Costa Rica presents the picture of most even expansion of farms of all sizes, while El Salvador is at the opposite extreme, reporting great absolute increases among minifundios, and a proportional gain in their number as well. In spite of the greater numerical gains among the smallest farms or subsistence tracts in Guatemala, on a relative basis the category of family-sized farms has received the greatest increment in that country.

On the basis of the available data from the three countries cited, about six of every seven explotaciones in the overall net increase fell into the smallest grouping, a fact which does not offer much prospect of immediate improvement in the levels of living and well-being of the 
farm families of the region as a whole. The extent to which the increase in the number of farms in concentrated at the minifundio level indicates the extent to which the agricultural landholdings of Central America are being subdivided by inheritance as one generation succeeds another.

Only Costa Rica shows promise, from the present data, of materially increasing the size of its farms in the foreseeable future. This is possible, in part, because of the fact that the land is not yet fully occupied, but a more important consideration may be the fact that most of the explotaciones at present are large enough to give their operators a sense of independence and pride in their land. Such pride in a tradition of landowning may provide the extra stimulus required to attract young men to the frontier areas where they may more readily obtain land of their own. In the other two countries where trends are discernible, the number of minifundistas is so overwhelming that it is difficult to arouse aspirations for acquiring enough land to establish a family-sized farm. At least this was the impression I received when speaking with small landholders in El Salvador and Guatemala. There is one basic difference, however. In El Salvador there is virtually no new land available, while the unclaimed areas 
of Guatemala are extensive and government programs are under way to make these areas accessible to settlement. Thus Guatemala still has the potential to improve the size of farms by the incorporation of new land, while in El Salvador any changes must come by modifying the present distribution of control over this resource, since there is little likelihood of reducing the number of families dependent upon agriculture.

Other Indications of the Trend

One empirical study in Costa Rica showed that in an area which was already fully occupied, "the laws of inheritance and the large size of family promote subdivision of farms . . . survey records indicating decreasing size of farm from father to son due to equal inheritance among a large number of heirs" (Reuss and Montoya, 1960:7). Reuss also stated in his final report of duty in Costa Rica (1960:not paged) that "inheritor sons of landowner fathers owned 17.4 manzanas on the average, compared to an average of 65.9 manzanas for their fathers." This same study showed that there was an agricultural ladder operating in the region, since most heads of families were able to obtain some land of their own, even though the size of the tracts available was declining through the years (see Chapter IV). 
Other studies have also pointed out the declining average size in established farming areas. In addition to the many area studies. of Sandner, Stouse (1965:99) states that "in all the areas of study [in Costa Rica], the process of making landholdings smaller has continued as the major trend since 1955." Reina (1960:83) sees the same thing occurring in Chinautla, Guatemala, and most other local studies have confirmed the increasing subdivision of the land (when they have taken not of the dynamics of the land question).

On the other hand, government policies are consistently established to favor the family-sized farm as far as formal agrarian policies are concerned. The Nicaraguan agrarian reform law, for example, specifically states that "family agricultural units [unidades agricolas famiziares]" are to be established in the agrarian colonies (Nicaragua, 1963:Dec. Leg. No. 797: Art. 44; April 19, 1963). Guatemala's Law of Agrarian Transformation (INTA, 1964:Art.75) specifies the goal of "family proprietorships" which must contain 20 hectares or more. Similar provisions are expressed in the other countries, without giving concrete measurements which must be fulfilled. But these apply in the efforts to establish organized colonies, and do not affect other land transactions (which are far more numerous). Thus their impact on the overall size structure is not great. 
The overwhelming impression for the region as a whole is one of the multiplication of very small farms, with little prospect of the opposite except in the case of Costa Rica. The situation in Nicaragua may be somewhat like that in Costa Rica, but no data on trends are available. Neither are there firm impressions about the trends in Honduras, in spite of the availability of two censuses, for one used hectares and the other manzanas in the measurement of size, thus making it difficult if not impossible to compare the data secured in the two enumerations.

\section{Summary and Conclusions}

A basic framework in this chapter has been the division of explotaciones into three size groupings: minifundios, family-sized farms, and multi-family farms.

Employing these three categories in the analysis, it has been shown that the vast majority of explotaciones in the region are too small to qualify as family-sized farms. Only in costa Rica are such places more numerous than the smaller ones, and even there the family-sized units do not constitute a majority of all explotaciones.

In spite of the large numbers of tiny agricultural holdings, the concentration of the control over land is 
shown to be very high. About 3 per cent of the explotaciones include over 60 per cent of all farmland, and fewer than 1,800 large haciendas and plantations encompass one-quarter of all farmland (while they make up less than 0.2 per cent of the farms).

The geographic variation in size of farms is shown by several figures, all of which indicate that farms tend to be largest in Costa Rica and Nicaragua, and smallest in El Salvador and Guatemala, with Honduras holding an intermediate position in this respect.

In order to supplement the statistical analysis, a section is devoted to some observations regarding several selected farms and farming areas. Information about plantations, haciendas, family-sized farms, and minifundios is included in this.

The analysis of the use of land and the production of crops and livestock on places of different size shows that most of the staple foods are grown on small and family-sized places, and that these contain less than their pro rata shares of the pastures and woodlands. The very largest farms make the least use of their territory for growing crops. In many cases they have so little land in productive uses that they qualify as genuine latifundia. The evolution of large plantations and haciendas during the Spanish colonial era is briefly sketched, and 
the distinctive development of smaller farms in Costa Rica is also traced. The main emphasis of this section is the fact that the concentration of control over land has been developing over a long historical period in most areas, and that it has been stimulated by the production of a few crops grown largely for shipment abroad.

Finally a few observations on present trends regarding the size of farms are made possible by the fact that three countries have published fairly comparable data from two or more censuses of agriculture. The most obvious fact which such analysis reveals is that minifundia constitute the great majority of the new farms in Central America. Nevertheless, in Guatemala there was in increase in the proportion of all farms which were family-sized (from 9.5 to 10.5 per cent), and in Costa Rica the familysized farms increased in number more than either the smaller places or the haciendas and plantations.

Costa Rica stands out sharply because of the extent to which it appears to have the potential for developing a preponderance of family-sized farms. It is difficult to envision this happening in EI Salvador unless there were a drastic subdivision of the existing large landholdings. In Guatemala there is still undeveloped land available, but the prospect of this country becoming a land of 
family-sized farms is not very good in spite of the new lands because of the overwhelming proportion of minifundia at present. Prior to the initiation of agrarian reform projects there was no evidence that family-sized farms were becoming more important in either Honduras or Nicaragua. In each of these countries, as well as in Guatemala and Costa Rica, the official reform policy is to favor such places, but no clear evaluation is yet possible. 


\section{CHAPTER IV}

\section{LAND TENURE}

Among the many institutionalized relationships between agriculturists and the land, the systems of land tenure are second in importance only to the more basic matter of the size of farms and landholdings. Land tenure comprises all of the various rights to the dominion and use of land. These range from the almost absolute rights of the owner who holds land in fee simple to the practically complete lack of rights to land on the part of the agricultural laborer held in slavery, serfdom, or peonage. The study of this subject includes the analysis of the nature of the rights of landowners to their property, and also embraces an examination of the various means by which persons may obtain the right to utilize land belonging to others, such as by rental or usurpation. Finally, the study is complete only when an indication has been made of the importance of those who lack virtually all rights to land themselves, and who derive a livelihood from the land by working for others.

Land tenure rightly has been recognized as being of extreme importance for the well-being of rural people, 
since it is the central factor in determining the distribution of the proceeds of efforts and investments in agriculture and stock raising. The tenure statuses of the members of a population are closely correlated with their positions in the system of social stratification of the society, and with their relative levels and standards of livingy Nevertheless, it is important to keep the scope of the topic well in mind, for many writers have used "tenure" as a catchall term for all sorts of agrarian matters, very commonly taking up the discussion of the size of farms under this heading, and sometimes adding such concerns as availability of agricultural credit, technical assistance, and others. Vital as these other questions are, land tenure is properly restricted to the legal and juridical rights and obligations that relate the people to the land, whether as owners, tenants of various classes, or laborers whose access to land is mediated through employment by landholders.

The subject of land tenure is readily divided into two major topics. The first of these involves tracing the evolution and development of the various rights to the land in Central America from their indigenous and Spanish roots down to the present. Also a part of the same topic is the statement of the contemporary nature of property rights to the land. 
The second part of the study of land tenure is the analysis of the absolute and relative numbers of agriculturists and stock raisers working under the various forms of tenure. The presentation and discussion of such information as the author has been able to gather on this subject for the region as a whole, and for the several nations that comprise it, constitute the remainder of the chapter.

Evolution and Development of Property Rights to the Land

The Central American situation today represents a composite of the Indian and Iberian land tenure systems which existed at the time of the Spanish conquest, modified by some four and a half centuries of colonial and national experience. Moreover, there is considerable variation among the parts of the region owing, more than anything else, to the relative numbers of indigenous people and to the differences in their cultural levels at the time of their subjugation. It is appropriate to begin with the circumstances existing prior to the Spanish conquest of Central America.

Aboriginal Tenure Before the Conquest

In spite of the fact that many scholars have focused their attention on the pre-Columbian life and customs of the early inhabitants of this area, there is no comprehensive 
information available as to the specific forms of landholding employed by the various indigenous people at the time of their first encounter with the Spaniards. Such reports as we have deal mostly with the Mayas of Guatemala and Yucatan, with only spotty references to the land tenure of the Pipils, Lencas, Matagalpas, Borucas, and others. A convenient summary of the salient facts regarding the Mayas may be found in Schulman (1956a), where details of many of the Maya sources are also cited. Some authors characterize the Guatemalan Maya land tenure system as similar to that of the Aztecs of Mexico, but not all agree (see Manger-Cats, 1966:61; Paredes Moreira et al., 1961:15). In general, Schulman (1954:134) found that the Maya concept of landholding was one of "tribal possessory rights in territoriality." Each community of Indians claimed a certain area of land in the vicinity where they lived, and in turn recognized similar claims by other tribes or towns. Doris stone $(1962: 40)$ reports that such a general understanding was current even in the twentieth century among the Talamancan tribes of Costa Rica. At the time of the conquest there appears to have been a system of assignment of land to individuals or families. Within the lands belonging to the community, each person was allotted his sites for planting, and had usufructuary rights to such plots as long as he used them. They were 
heritable, and could be lost by abandonment, but no evidence exists that they could be sold, traded or given away (Marroquín, 1965:9-10; Schulman, 1956:61-62; Landa, $1941: 96-97,230)$.

The closest thing to private ownership seems to have been the lands held personally by the caciques and lords of the communities, which were worked either by slaves or by their subjects for them, according to the chronicler Bernal Diaz del Castillo (cited in Solórzano F., 1963:23).1 Marroquin (1965:9) says these lands were held by the caciques to support the government, worship and the army, and were not really private. Apparently, land had no intrinsic value to them and it did not occur to them to claim that which they were not able to use immediately, since the concept of private property clearly existed with regard to other goods, such as personal items, and also slaves (Solórzano F., 1963:22). Thus, in summary, at the arrival of the spaniards under the Adezantado Pedro de Alvarado the Indians apparently knew well the rights to the use of land for their crops, but were unfamiliar with the idea of the voluntary transfer of ownership.

${ }^{1}$ Some records suggest outright ownership of lands, as for example in Fuentes y Guzman's Recordación florida (1932, II:92), where he writes of the inheritance of lands, houses and slaves among the rulers of the Pipils around Escuintla, even for women who were not in the legitimate line of succession to power. But no solid evidence of the meaning is given. 
Peninsular Antecedents of the Spanish American Colonial System ${ }^{1}$

The several kingdoms, counties, duchies, and other parts of Spain experienced a succession of cultural influences on their landholding rights through many centuries. Long before the Christian era the land had been overrun wholly or in part by the Celts, Phoenicians, Greeks, Carthaginians, and Romans-the latter leaving the most lasting imprint. Then came the Visigoths, and later the Moors, adding further layers of juridical background to what became largely a Roman and Germanic legal tradition.

In the Spanish kingdoms of the Middle Ages, as indeed in the European monarchies generally, all property rights were considered to be either directly or indirectly derived from the ruling sovereign. Individuals holding property owed their claim to a grant from the king, or from one of the lesser-ranked persons between themselves and the king, usually with explicit obligations to these superiors. The ruler, in turn, derived his rights from God as the ultimate lord of the entire world. Whether the rights of the crown were mediated through a donation of God's representative on earth, the Pope, or were thought of as a

\footnotetext{
${ }^{1}$ For the materials in this section I am particularly indebted to the excellent summary treatment given the subject by Weeks (1947a) and Schulman (1954), although I have also drawn considerably upon Haring (1963) and Rippy (1932).
} 
direct trust from the Almighty depended upon the circumstances of the case. In that of the Americas, a papal bull in 1493 had divided the entire New World between Spain and Portugal, laying the foundation for the famous Requerimiento which was read to the Indians as full justification for the intrusion of the spainards in their midst. ${ }^{1}$

${ }^{1}$ The full texts of a Requerimiento used in Central America and the Bull of May 4, 1493, are given in Spanish in Fuentes y Guzman (1932, II:187-192), and a Requerimiento in English is found in Hanke (1938:26-27). The central sentences of the Requerimiento in Fuentes $y$ Guzman are:

On the part of the Emperor and King, Don Carlos, and of Doña Juana, his Mother, Kings of Castille, Aragon, Leon, . . we . . their servants notify and make known to you as best we can, that the Lord our God, One and Triune, created the heavens and the earth, and one man and one woman, of whom we and you and all the men of the world, were and are descendents - . Of all these nations God our Lord gave charge to one who was called Saint Peter; that he should be Lord of all the men in the world, whom all should obey, and that he should be head of the whole human race. . One of these past Pontiffs, who succeeded that one - . as Lord of the world, made donation of these Isles and tierra firme of the Ocean sea to the aforesaid King and Queen and to their successors, our Lords, with all that there are in them.. . So their Highnesses are kings and lords of these Islands and of tierra firme by virtue of this donation, . . and indeed almost all those to whom this has been notified have received their Highnesses and have obeyed and served them... and [thus] their Highnesses received them gladly and kindly, and ordered them to be treated as their other subjects and vassals, and you are held and obliged to do the same...

If you do not do so: . we will attack you forcefully and make war against you in every way we can . . and we profess that the deaths and damages you receive from it will be your fault and not their Highnesses'. 
In the Spanish colonies the lordship came through the papal donation, as well as through conquest and discovery. In the "Spains" 1 of the fifteenth century there were five basic classes of land ownership (Weeks, 1947a: $62 \mathrm{ff.})$ : the royal lands of the supreme ruler, the communal properties of the municipalities, the private properties of the aristocracy, quasi-feudal landholdings, and the proprietary rights (and limitations) of the peasantry. Weeks provides a convenient and sufficiently detailed summary of how each of these types developed through the long historic process.

At the time of the conquest there were two basic categories of public property, whether royal or local. One class of lands was held as a source of revenue and support for the treasury. These were called realengos when belonging to the crown, and propios if owned by the county-like municipio. Public lands of the other class

${ }^{1}$ Spain was composed of a considerable number of separate territories called kingdoms, duchies, señorios, and the like, which were slowly consolidated through the centuries until the marriage of Ferdinand $V$ and Isabella I brought the majority of the Peninsula under united rule. Even so, the separate territories maintained their juridical distinctness so that in the Requerimiento of footnote 3 Carlos $V$ and his mother Juana listed some 35 separate entities over which they ruled individually or jointly. The American colonies were always under the rule of the king of Castille. 
were available for common use, and were the basic source of land grants and other forms of private property. At the national level these were known as baldios; at the local level they were the exidos or ejidos, which were generally used for pasture, the provision of firewood, straw and other necessities by all the residents of the locality. Often they were also subdivided temporarily among the residents on an equitable basis for the purposes of cultivation.

The result of these many traditions was a complex feudal land tenure pattern in which much of the property was burdened with multiple layers of ownership rights and obligations. Difficult problems arose in the adjustment of conflicting claims that had evolved without plan.

However, in the process of retaking the territories held by the Moors, valuable experience was gained by the rulers and their attorneys. One of the most effective devices employed was the office of adelantado de frontera. This title was given to a leader as a royal commission to gather forces and advance into an alien area to gain poIitical and religious control, to establish settlements, and to make the economy tributary to the king. The adelantado generally undertook this task at his own expense and was rewarded with broad powers in the area he conquered, including the grant (merced) of land for himself 
and the right to award some of the land to his supporters in the name of his king (Haring, 1963:19-21). By 1,500 such grants were often almost equivalent to ownership in fee simple. On the other hand, some spaniards-nobles, priests, or common peasants-simply encroached on the borders of the Moorish lands and settled there. If they were successful they, too, could seek a virtual fee simple title through a royal confirmation. Land thus gained was known as presura land (Schulman, 1954:95-98).

Largely as a result of the Reconquest a fuller type of land ownership had been developing in Spain during the years leading up to the founding of the Spanish colonies in the New World. Both the merced and the presura encouraged this, although these virtually allodial lands existed among the many other restricted and feudal types of holding.

At the same time, there was a long tradition of communal landholding by the towns and cities of Spain which had proven itself to be a satisfactory tenure arrangement in many ways. Both the relatively new concept of nearly absolute individual ownership of land, and the communal ownership of land by local governments were promptly put into practice in the new colonies as the mainstays of the system of alienating the royal patrimony. 
Practices in the Spanish Colonies ${ }^{1}$

Benefitting from the varied experience in the homeland, and intending to correct the awful confusion that existed there with regard to landholding, the Spanish kings set for themselves the goal of employing only the best devices they knew for their new colonies, and to this end they attempted to keep a tight rein on their subordinates. Every grant of land was made ultimately by the crown itself, so that no hierarchy of rights should develop between the king and the landowner which might create a feudalistic system. They established a title to holdings granted to individuals that was virtually in fee simple. Once the grantees had fulfilled the requirements of the grant, the crown decreed that "we concede the right that henceforth they may sell them and do with them freely as they will, as a thing of their own" (Spain, 179l:Libro IV, Título XII, Ley 1). The use of communal lands at the local level had

${ }^{1}$ Central America was colonized in much the same manner as were the other spanish territories in the western homisphere, and the general lines of development have been related many times by historians. The land system has also been given extensive treatment, among the better of which are those of McBride (1923), Zavala (1940), Weeks (1947b), Schulman (1954), T. Lynn Smith (1958 and 1967a), and Ots Capdequí (1959). A classic and extremely detailed study of the early colonial period is that of Solorzano Pereyra (1739), done by royal commission in the mid-seventeenth century, which is a basic source for more recent scholars, available in various editions. 
been successful in Spain and was employed as the basic attribute of the newly founded towns and cities in America. 1

In the era of exploration and settlement the crown made "capituzaciones of discovery, conquest and new population" with the adelantados, who received broad powers to enter into a new territory, win the allegiance of the Indians through the Requerimiento, or war if necessary, and establish spanish communities. It was expected that the adelantados, and later the viceroys, governors, and other representatives of the king, would protect the Indians in their lands and settlements, and that the colonists would be satisfied with grants of encomienda or trusteeship over the natives. These guardianships were supposed to provide that the Indians be protected and taught the christian religion, and that in return the indigenes would be obligated to work for or pay tribute to the holders of the trusts (encomenderos). The encomienda did not convey any land rights at all (Zavala, 1943:ch. VIII; Kirkpatrick, 1942). Although not given formal titles to their lands at this time, the lands which each Indian community was accustomed to using

${ }^{1}$ T. Lynn Smith has stressed the importance of the effort by the council of the Indies "to correct on the 'new cloth' represented by the extensive areas overseas some of the defects of the pattern to which social organization in Spain had been cut" (1960a:39). 
were supposed to be reserved to them and their communal tenure system was respected. ${ }^{1}$

Outside of the lands belonging to the Indians, the adelantado was commissioned to "populate" towns or cities, assigning the necessary lands for ejidos and propios, and also platting the town blocks and building lots. In each case he was to have due regard for the expected growth of population. Careful instructions were given (Spain, 1791:Libro IV, Título VII, Leyes 1, 7, 11, 13 and 14 particularly). Eventually Indian towns and reducciones (reservation towns) were also assigned lands in the form of propios and ejidos. Solórzano F. (1963:196) states that in 1763, except for five haciendas, all the land in Atitlán and Tecpan-Atitlán was ejidal.

Land not needed for town lots, propios, ejidos, or the Indians was available for granting to the conquerors and settlers. The adelantado himself was entitled to one-fourth of the amount he subdivided in town lots (Spain, 1791:Libro IV, Título VII, Ley 7), and to liberal amounts of rural territory. The usual grants by adelantados to settlers in Central America as elsewhere required that the grantee build a house on his town lot, cultivate his acreage,

${ }^{1}$ See Spain, Recopización de leyes de los Reynos de las Indias, 1791:Libro VI, Título III, Leyes 9 and 20; Libro IV, Título VII, Ley 26. Some of Alvarado's ordinances for the protection of the Indians are given in Fuentes $y$ Guzman (1932, I:183-184). 
and reside in the town a minimum of four years before his land grant or mereed de tierras would be validated (Libro IV, Título XII, Ley I). Rural lands were to be granted in accordance with the importance or "quality" of the settlers, the more important cavalrymen and their equivalent being eligible for up to three cabalzerias, ' while lesser persons might receive peonias which were about one-fifth as large as a caballeria. The truth is, however, that most mercedes exceeded the legal limits, their boundaries were poorly described and the titles to them were inadequately recorded. As a result disputes over land quickly arose.

By 1591 the situation was serious. The crown was fully aware that vast quantities of land had been given away improperly and that, moreover, many landholders had expanded their holdings far beyond their original boundaries. By this time many properties had changed hands, and the current owners might be claimants in good faith of illgotten lands usurped by the former owners. Therefore, by royal cédulas (formal notices) of November 1, 1591, Felipe II ordered that all titles be examined and that improperly

${ }^{1}$ In colonial grants a caballería was "a town lot of 100 feet in width and 200 in length, [together with] - 500 fanegas of arable land for wheat or barley, 50 for corn, 10 huebras [each equal to a day's plowing] of land for a garden, 40 for orchards, and pasture for 50 brood sows, 100 cows, 20 mares, 500 sheep and 100 goats" (Spain, 1791:Libro IV, Título XII, Ley I). McBride (1948a:40) suggests these were generally of some 500 to 1,200 acres. 
claimed territory either be restored to his patrimony, or else that it be purchased from him through a moderate composicion or fee for the settlement of rights lots Capdequí, 1959:29-32).

Up until this time the kings had been generously making the land grants free of charge to their subjects. However, land in the more desired locations was becoming quite scarce, and the demand made it quite valuable. The cédulas of 1591 mark the point at which such liberality ceased to be common, and the tierras baldías began to be sold at public auction.' some free grants were still made, but by 1617 the sale of public land appears to have become the general means of alienating land by the crown (Spain, 1791:Libro IV, Título XII, Ley 16). Additional demands for the review and reconfirmation of titles were made by the kings and Council of the Indies, notably in 1692, 1735, 1754 and 1795 (Méndez Montenegro, 1960:25-49).

Because the composición of lands became such an important means for the building of the large estates, it is necessary to recognize that this procedure provided a

${ }^{1}$ The cédulas of 1591 sent to the Audiencia of Guatemala are published in the volume of Méndez Montenegro (1960:19-21), which provides a convenient source for the texts of most of the major colonial laws relating to Central America. 
way to legitimize all sorts of irregularities, as well as to solve problems for the innocent. It was based on the rights of prescription which had grown up in Spain under similar circumstances. Ots Capdequí $(1945: 106,279)$ reports that the prescripcion (grant of title based on occupation) could be granted in as little as 10 years of occupation if the occupants had a "just" title, and held the land in good faith continuously for the prescribed years. Even lacking the title and good faith, confirmation might be granted after 30 or 40 years of continuous occupation. By this logic many large areas became private property. For example, the crown had been accustomed to grant grazing rights to settlers for estancias de ganado mayor (for cattle, horses or mules), or for estancias de ganado menor (for sheep and goats). These ranged from 2,000 to 5,000 acres or more, but specifically did not convey any ownership of land. After enjoying the grazing rights long enough, however, the holders eventually applied for and were awarded confirmed titles to these lands for the payment of only nominal fees of composición (West and Augelli, 1966:290-29l). The same process was used to gain titles to land which had been "occupied" in other ways. The venerable tradition of "squatters' rights" has continued right up to the present time to make a mockery of sound land policies. 
In spite of royal concern, Indian lands were often taken over by Spaniards. Since legally only vacant lands could be claimed, in numerous cases the conquistadores and their successors contrived to encourage the natives to abandon good lands which they might have held for centuries. Simply by allowing their swine to run loose near the Indians' fields, the crops were destroyed and the Indians often were forced to move. ${ }^{1}$ Marriage to native women who owned property was also practiced to gain land (McBride, 1923:52). The result was that in Guatemala, El Salvador and Nicaragua, particularly, many Indians either moved to less desirable mountain fastnesses, or in other cases became a landless proletariat forced to labor on the lands of the Spaniards.

In spite of all that has been said about the manner in which large privately owned estates were built up, there were extensive areas in the Presidency of Guatemala (which included all of Central America) where small, individually

IThe Laws of the Indies made strenuous efforts to protect the Indians, and in at least three laws there were specific orders to keep animals out of native fields. At least one specifically mentioned pigs. It was a case of the quixotic "obedesco pero no cumplo" (I acknowledge, but I don't comply). See Spain, 1791:Libro IV, Título VII, Ley 26, and Título XII, Ley 12; Libro VI, Título III, Ley 20. T. Lynn Smith $(1967 a: 63)$ has referred to the pigs as the "reliable 'shock troops' upon whom the conquistadores could depend for forcing the Indians to transfer their subsistence plots to more remote sections." (See also T. Lynn Smith, 1969a:22-25, for treatment of this same occurrence in Colombia.) 
owned farms were the rule. As has been thoroughly described by many writers (Monge Alfaro, 1958; Biesanz and Biesanz, 1944; Chester Lloyd Jones, 1935), Costa Rica throughout the colonial period was almost entirely a colony of peasants who owned their own land, though often their claims were traditional, and not supported by formal papers. In general, the same was true of Honduras, where similar difficulties in transportation and the rugged terrain reduced the desirability of large estates, although in the valleys such properties were to be found dedicated to the breeding of cattle.

At the close of Spain's dominion over Central America, then, the tenure situation was essentially as follows. Most of the desirable lands near population centers or conveniently accessible to ports were held in private ownership. The towns were doted with extensive communal holdings. Indian towns in many cases had the same, or even larger, communal holdings, but in other cases Indians were landless laboreres. The principal means of obtaining land from the still extensive public domain were by purchase at public auction, or by occupation and prescription.

Tenure Developments since Independence

When independence was declared in Guatemala City in 1821, the only basic change was the fact that henceforth 
the decision-making power would be held locally instead of overseas. The Spanish legal traditions and the prevailing laws remained intact, with the federal and provincial governments assuming the powers formerly held by the crown and Cortes. ' With regard to landholding there was no immediate attempt to enact an agrarian code, or to codify that which was carried over from spain.

Some general policies. The new government began. as a federation, the United Provinces of Central America, with five subdivisions that soon became the independent republics we know today. In the federal constitution, as well as in those of the provinces, the status quo was upheld; private property was protected and inviolable, and the right of eminent domain was conservatively expressed. The Federal Constitution of 1824 stipulated:

Art. 175. Neither the [federal] Congress, nor the [provincial] Assemblies nor the other authorities may - . take the property of any person nor disturb him in the free use of his goods, except on behalf of the public when grave urgency, legally proved, requires it, and a just and previous indemnification being guaranteed (Mariñas Otero, 1958:277).

The general land policies of the provinces and republics began with two basic goals: to further the

${ }^{1}$ There were some changes, such as the abolition of slavery and the abolition of special titles and privileges, but none in the area of land tenure. 
economic development of the territory by making land available to any enterprise that appeared likely to increase the general wealth, and to use the sale of public land to continuously replenish the treasury. The 1825 federal decree to reduce the baldios or national lands to private ownership was directed toward the latter end, as well as to attempt to resolve some landlessness (Solórzano F., 1963:278). After this decree, land"matters were generally left to the separate states.

While communal or ejido lands were extensive in some districts (see Solórzano F., 1963:278-280), in others they were considered insufficient. For half a century there was a consistent policy throughout the region of granting aditional lands to towns and villages as needed, even if the government had to buy land to be able to do so (Monteforte Toledo, 1965:143; Bourne, et al., 1946:87). In addition grants, including some huge ones, ${ }^{1}$ were made to commercial companies and individuals for such purposes as the building of railroads, canals and roads, improvement of ports, colonization by Europeans, and other enterprises that it was hoped would benefit the nation. Such efforts

\footnotetext{
${ }^{1}$ Griffith (1965) made a study of an effort by Mariano Gálvez, Chief of State of Guatemala, to promote the development of his country by a grant of some 15 million acres of land in Verapaz for a colonization scheme of the Eastern coast of Central America Commercial and Agricultural Company, in 1835. The plan failed and the title to the land reverted to the state.
} 
eventually succeeded in obtaining interoceanic railways in Guatemala and Costa Rica, but failed in Honduras in spite of generous grants. Many of these large grants were illdefined and only contributed to the worsening of land boundary problems which were already acute (see Chapter V). Beginning with Costa Rica and Honduras in the 1830's, the various governments found it expedient to grant public lands in payment of national debts, and even of salaries (Stokes, 1947:151; Soley Güell, 1940:30).

An additional aspect of government grants arose from the desire to promote "miracle" crops such as coffee, bananas, cacao, rubber and sarsaparrilla. Guatemala issued a number of laws making such grants between 1878 and 1886 (e.g., see Méndez Montenegro, 1960:decrees of August 22, and October 26, 1878, and December 16, 1886), and Costa Rica began as early as 1821 (Monge Alfaro, 1958:188-189). In many cases the hopes were frustrated, but particularly with coffee and bananas they were successful in stimulating production; albeit frequently on the part of a limited number of owners.

The right of prescripción, or squatters' rights, has endured down to the present. Laws have been issued over and over again with the goal of permitting the regularization of the existing situation, and ending prescription for all property after a stated date except under specified circumstances-usually a limited size of holding (for 
example, see Costa Rica, 1824:Dec. No. 11, October 22, 1926). The situation is such that one analysis reported:

Traditionally land has been the frcest of all commoditics in Costa Rica, a country in which cach citizen may be granted or may peacefully take unoccupied lands and use them according to his own desires, so long as his right to do so is not challenged. Under this system physical possession of land is usually the strongest. factor in determining actual or eventual ownership (International Development Services, Inc., 1960: Appendix, page 1).

The same could not be said for Guatemala and El Salvador, for land in those nations was more quickly taken up by either the powerful or the towns, both of which have been more efficient at protecting their claims. In some ways Honduras approaches the Costa Rican situation as far as available information is able to indicate (see the report of the Organization of American States, 1963, I:71-72), and Nicaragua may be in an intermediate state, with considerable land on the Atlantic slopes still in the national domain (UN, FAO, 1967:61-63).

Some reform efforts.-Beginning with the advent of "Liberal" governments around 1870, there have been a number of conscious efforts to introduce changes in the tenure strucutre of the several nations. Probably foremost among these concerns was the desire to do away with common lands and establish the much-revered private ownership system, which was idealistically intended to give individuals more 
freedom of action with regard to their land. Thus, under Justo Rufino Barrios, Guatemala decreed in 1877 that all ejido lands ${ }^{1}$ exploited under censo enfiteutico (a fixed form of rental) be transferred to individual ownership immediately by the communities. The censatario (traditional user of a particular plot) was allowed the first opportunity to buy the land. The charge for the land was fixed by law at 10 to 20 times the annual rent that he had been charged for the property, depending upon how long ago the rent had been set. Payment had to be completed in 18 months, with six payments at three-month intervals. If the censatario could not or did not choose to buy his plot, then others might do so (Méndez Montenegro, 1960:Dec. No. 170, January 8, 1877, page 136). Most small holders had very limited resources and the losses of lands were serious, particularly among the Indians who did not understand it all anyway (Solórzano F., 1963:348). Of course, one law is never sufficient, and others followed in 1891, 1920, 1929, 1931, and 1938 (Méndez Montenegro, 1960:221, 399, 450, 461, 578). Between 1877 and $1879,73,920$ hectares of ejido lands became private property (Monteforte Toledo, 1965:143).

l"Ejido" has come to represent all municipio-owned lands in Central America, whether used by all in common (its original meaning) or loaned or rented to individual farmers and ranchers (which used to be called "propios," though the term is rarely used any more). 
Much the same occurred in El Salvador in 1881 and 1882 under Rafael Zaldivar, the action here involving the abolition of indigenous communities as distinct political and economic units as well as abolition of their communal lands (Torres, 1961:13-26). A commentary on what happened is given by the noted jurist, Reinaldo Galindo Pohl (1948:140):

The system had degenerated, but nothing was done to replace it by anything else to protect the illiterate peasant [campesino]. Since then the country worker has been abandoned, and even if it is true that he was absolute owner of a small parcel, very soon he sold it and became a wageworker, thus making more acute the agrarian social problem which has at times had violent manifestations.

At least one additional effort in 1912 was required before the communal properties ceased to have importance.

Costa Rica disposed of its communal lands permissively and pragmatically instead of in a doctrinaire enthusiasm. As early as 1847 the municipios were given permission to sell their lands if they so desired. Thereafter there were repeated instances of grants of further baldios to the municipios specifically so that they might sell them to support some public work such as a water system (Costa Rica, 1824:Dec. No. 1, February 8, 1847). It was a case of using the land (which was called the "freest" commodity) to subsidize local governments, and apparently in time it virtually eliminated the ejido. The latter is not even mentioned in the agricultural censuses. 
Honduras and Nicaragua have generally maintained their ejidal lands, at least in theory. One statement has it that "in the series of agrarian laws emitted in the country [Honduras], there has prevailed in the mind of the legislator the criterion of maintaining and strengthening the ejido and the family farm in contrast to that which has occurred in other Central American countries" (UNAH, 1961b:3). On the other hand, Hill and Loftin (1961:2-3) found:

In the currently developed regions of the country, where vast areas were originally set aside as "national" or ejido lands, a relatively few individuals have managed to obtain possession of a title to these lands. Since large portions of the agricultural lands are now in their hands, and since the legal origin by which "title" was obtained is questionable, this makes fictitious renters, sharecroppers, occupants, or colonists out of the vast majority of Honduras' small farmers who are using these lands under agreement with their avowed "owners." Apparently there has never been any uniform and clear understanding of regulations concerning the use of national or ejido land, or if they have existed there has been no consistent enforcement of such regulations. As a consequence, it is obvious that the transfer or sale of these lands has been governed by personal rather than by uniform national land laws.

They go on to say that they found many cases of misappropriated ejido lands, such as the latifundista who had a "tremendous" amount of ejidal land granted to him. by a regional caudizzo (strong man) for 25 centavos per manzana, which he in turn rented to campesinos for 20 Lempiras (80 times greater). Moreover, they scarcely 
found any small farm operators classed as ejidatarios even when they actually used ejido land, since the actual operators got it from an hacendado rather than from the municipio (Hill and Loftin, 1961:163, 167).

Another of the reform measures has been the effort to make tracts of national lands available to prospective owners in moderate and small sizes, with the goal of converting nonowners into proprietors. It is still the official policy in these nations to favor the creation of small to moderate farm properties, sometimes even constitutionally affirmed (for El Salvador, for example, see PAU, Department of Legal Affairs, 1966b:Art. 147). In earlier years the practice was to pay attention to the larger grants and sales almost exclusively.

The creation of policies to alienate lots of moderate size was a triumph over more than simple inertia. When Manuel Estrada Cabrera wanted to settle Indians on government land in distant areas of Guatemala a hue and cry arose against the notion of improving the tenure status and level of living of the Indians. The claim was that if they had land of their own they would no longer work for the plantation owners, and the economy would suffer severely (C. I. Jones, 1940:172). Similar feelings were expressed at many other points in time, and throughout Central America, referring not simply to Indians but to the landless in general. 
The Social Function of Land

In his study of land tenure in colombia, Smith has pointed out that "many of the difficulties seem to have stemmed from the attempt to have in effect simultaneously two conflicting philosophies relative to the nature of property rights in land" (T. Lynn Smith, 1958: 371; 1967a:81). On the one hand there were the legal claims conveyed by the original land grant and its transfer from one party to another. On the other side there was recognition as early as 1513 that land titles, to be valid, must be confirmed by utilization. Ots Capdequí (1945:284) goes to considerable length to trace the development of this notion in royal decrees, and concludes:

Reflecting on the legal precepts taken together, which regulated the private dominion and use of realengo lands in the Indies, the conclusion is evident that all the legal doctrine promulgated by the Spanish state in this respect was inspired by the principle that private property in the lands in the Indies had to fulfizl a social function.

Under the Spanish crown the goals were to increase the value of the land and colony by making the land produce, and also to increase the tax revenue by raising the tributary capacity of the population. Ots Capdequí adds (1945: 286):

If these precepts had been faithfully complied with, the new independent nations of America would have become sovereign over a soil where the private appropriation of land would not have presented the 
existence of latifundios nor have registered a span of land belonging to private property which was yet to be cultivated. And it is well known that the reality has been otherwise.

In Central American Indian tradition there might also be found a basis for the idea that private land should be put to use in a productive manner. It has already been stated that among the Mayas there was no effort to monopolize land that was not currently being used, due to the emphasis on the use of land rather than the more abstract idea of "holding" it. Squier (1860:274-275) visited Subtiaba, the Indian barrio of León, Nicaragua, in 1850 and noted that the community owned lands by a colonial grant, for which he was shown the cédulas. Land of the community was leased to the inhabitant in "sufficient quantity to enable him to support himself and his family." This practice, he reported, was apparently of aboriginal origin,

for under the ancient Indian organization, the right to live was recognized as a fundamental principle in the civil and social system. No man was supposed. to be entitled to more land than the necessary to his support; nor was he permitted to hold more than that, to the exclusion or injury of others.

The basic foundation was available in both Spanish and Indian tradition, and in the trying days of the world depression Central America began to look anew at the possibility that landholding might require a social conscience. Under the Iiberal dictator Ubico, Guatemala became the first of the nations to redefine the nature of 
landholding in its constitution. The Charter of 1879 was amended in 1935 to read:

Art. 16. The Authorities of the Republic are instituted to maintain the inhabitants in the enjoyment of their rights, which are: liberty, equality, and security of the person, of his honor, and his goods.

The social interest prevails over private interest.

It is the function of the state to conserve and. improve the general conditions of existence and wellbeing in the Nation, maintaining the sanitary state of the country and achieving the elevation of the level of culture and propriety of its inhabitants, the increase of public and private wealth, the development of credit and welfare and social assistance and the cooperation of capital and labor. (Italics mine.)

Art. 28. Property is inviolable and will not be the object of confiscation. . .

Latifundios whose production is not adequate for their size and conditions will be the object of a particular system of tax imposition. A law wizl determine all matters relating to this subject (Mariñas Otero, 1958:578-581). (Italics mine.)

The italics have been added for emphasis, to show the new and important elements.

\section{The following year (1936) a tax law was passed}

levying a special tax on eriales, or uncultivated or unused. properties, and on latifundios of 4,502 hectares or larger which were an "obstacle to agrarian development or national land-division needs [necesidades parcelarias]." The tax was relatively mild but confirmed that property might be subjected to a social judgment (Méndez Montenegro, 1960:Dec. Gubernativo No. 1885, pages 560-565).

Since the actions by Guatemala in 1935 and 1936, each of the nations of the region has enacted constitutional 
provisions stipulating that property must be made to recognize social obligations. ${ }^{1}$ It is sufficient to state here that both Costa Rica (1944) and Guatemala (1949 and 1951) have resorted to laws requiring owners to offer unused land for rent at stipulated rates. In addition to the widespread expropriation of idle land that occurred in Guatemala in 1952-1954, in four of the five countries the powers of expropriation are readily available to deprive the landowner of his land if he does not put it to use. To a limited extent these powers have been employed. Also, each of the Central American nations except El Salvador had enacted laws levying taxes on inadequately cultivated land by 1963 .

It is too early to be sure of the effects of these social limitations on the ownership of rural property, but it is clear that some restrictions are being enforced upon landowners. As demands for "social justice" continue in the region it seems reasonable to expect that limitations imposed on the holding of land in idleness will be maintained, and that the absolute rights of the proprietor will have been somewhat reduced.

${ }^{1}$ The progression of these events is presented in Appendix A, where the pertinent passages of the constitutions are cited, followed by an indication of the principal laws which have been enacted to put them into practice. 


\section{The Nature of Property Rights to Land roday}

Since the earliest days of the Spanish colonial era, the traditional ownership rights to land in Central Anerica have been virtually absolute-such that "they may sell them, and do with them freely as they will as a thing of their own" (as stated in a royal cédula about 1513; see Spain, 1791:Libro IV, Título XII, Ley 1). Today, once ownership is fully confirmed by a title, the proprietor owes no rent nor service that results from his land. He may sell it, give it away, encumber it or dispose of it by will in whatever manner seems fitting to him. 1 such full property rights are virtually the same as those which are designated by the English term "in fee simple." The rights thus enjoyed are among the most liberal in the world, being the type toward which much of the world is still striving (see T. Lynn Smith, 1969b:Chapter 3).

Landowners in Central America are everywhere subject to the two principal claims maintained by the state: the right of eminent domain for purposes of public necessity,

${ }^{1}$ There are some limits on the power to dispose of property by will, since the civil codes provide various provisions by which an estate must provide for the maintenance of those the testator was legally obligated to support. 
and the right of taxation. ${ }^{1}$ In addition, there are other provisions of law which affect property in general. The Civil Code of Costa Rica specifies, for example, that a property owner has the obligation to allow passage to an adjacent owner who lacks public access to his land. He must also refrain from harming land of another by such acts as the planting of trees or building walls improperly Costa Rica, 1949:Articles 395-405). The new Guatemalan Civil code includes a feature which condemns "the abuse of property rights. It states that a proprietor may not do any act that causes harm to other persons. . . " (PAU, $1965: 85)$.

Property rights to the land refer generally to the surface of the earth only. Although the legal precepts have varied over history, currently all five countries reserve the subsoil rights to the state. In many cases even the colonial grants excluded mining rights from land grants (Ots Capdequí, 1945:163). The status of land patents made prior to the national claim to the subsoil is not entirely clear. Also there have been other restrictions

${ }^{1}$ The various principal constitutional provisions relating to landownership and tenancy in each nation are presented in Appendix $B$, but attention is called to the fact that these represent only the skeleton on which the whole body of land laws are erected. The civil codes and the agrarian and tax laws contain many more detailed restrictions and limitations. The extent to which provisions of law are actually enforced also varies from time to time and from place to place. 
placed in some titles, but they constitute only a small minority of cases stemming from particular historic periods. One case suffices to illustrate the point. In Guatemala in the 1920's and 1930's the baldios sold to claimants bore the stipulation that 10 per cent of land must be kept as a forest reserve, uncultivated (for example, see Méndez Montenegro, 1960:Dec. No. 2159, page 530).

There have also been grants of land made in less than full ownership. The chief example of this is Guatemala, where under Ubico and also under Arbenz grantees received only the usufructo vitalicio, or lifetime use, of the land parcel awarded. Needless to say, this placed the holder in a position of subservience to the state, since there was more fear of losing the land so long as the government held the strings. Whetten (1961:160) has said that the peasants "became state tenants. The implications.. . for possible political control appeared to be tremendous." A total of 86 per cent of grants under the Arbenz agrarian reform were limited to lifetime use (Whetten, 1961:163). Other agrarian reforms have generally restricted the right to encumber or alienate land awarded under the program for up to 25 years. These prohibitions eventually expire, and may be waived by the reform agencies.

There are still some lands held in a community name by municipios and towns. In this case, of course, the user 
does not have a full title. His tenure may be for a specified period of time or for an indefinite term which may include heritability of the plot. Generally these lands are not readily alienated by the local authorities, although they may be granted for family patrimonies, or small farms destined for family support. In general the family patrimonies are also restricted titles. They may be passed on undivided, but may not be sold or otherwise encumbered.

Finally there is the question of the requirement that property "obey" a social function. Clearly most properties may be said to be held in the equivalent of fee simple. On the other hand, some parcels have already been expropriated or had their use modified by the enforcement of the social use clauses, and undoubtedly more will be affected by this provision in time. It is too soon to determine the ultimate importance of the restriction, but since it has spread throughout the region it is a factor to be considered in the ownership of any land.

Tenure Status of Central American Agriculturists

The second major aspect of the sociological study of land tenure consists in the analysis of the tenure status of the agricultural population. It is the purpose of the remainder of this chapter to determine the absolute and 
relative importance of each of the forms of tenure, and to clarify their significance. An effort also is made to indicate the broad trends that are visible today.

Since the concern in this whole matter is with the families which are dependent upon agriculture and stock raising for their livelihood, the first data required are those which identify this segment of the population. Unfortunately at that point the censuses, the only basic sources of information about the people of any country, break down. The censuses of agriculture invariably take as their unit of enumeration the explotacion agropecuaria or production entity. Since these units are intended to be all inclusive with regard to agricultural production, presumably the entire population working in agriculture is dependent upon these explotaciones. However, the censuses concentrate on the "producer" who is in charge of each explotación, and it is impossible to gain adequate information about the other members of the labor force of these explotaciones agropecuarias.

The censuses of population which were taken at the same time as the agricultural enumerations throughout the region (except in Honduras) do not provide sufficient information on households dependent on any of the sectors of the economy. They do present figures for the number 
of "farmers" and "farm laborers" separately, but there is no provision for those who fill both statuses. The respondent must choose one or the other, and since he is generally counted wherever he is located at the time of the census, he will generally give the work status he has at that time. Nor can one simply rely upon using the number of rural households as being dependent upon agriculture, since there are always individuals working on farms who live in urban places, and rural residents who work in the towns and cities. ${ }^{1}$

The writer has employed the various forms of data available and estimates that there were about 1.3 million families dependent upon agriculture in Central America in the early 1960's (see Table 9). ${ }^{2}$ Even when available,

${ }^{1}$ Costa Rica, with the smallest labor force in the region, had 62,540 more rural people working at nonagricultural occupations than urban people working in agriculture. In Nicaragua the two residential areas exchanged nearly equal numbers of workers.

${ }^{2}$ All estimates have been rounded to only two significant figures, knowing that the estimating procedures are rough and that it is highly unlikely that they are accurate even to the extent of being within one per cent of the reality. On the other hand the original census data, because of their failure to identify the desired characteristics, are farther from the reality than even the crude estimates. No effort has been made in these estimates to rectify the data to a single year of reference. 
Table 9. Data employed in estimating the number of households which derive a livelihood from agricultural and pastoral activities: Central American countries in the 1960's

\begin{tabular}{|c|c|c|c|c|c|}
\hline country & $\begin{array}{l}\text { Household } \\
\text { Heads Em- } \\
\text { ployed in } \\
\text { Agriculture } \\
\text { and Related } \\
\text { Activitiesa }\end{array}$ & $\begin{array}{l}\text { Rural } \\
\text { Dwellings } \\
\text { or } \\
\text { Households }\end{array}$ & $\begin{array}{l}\text { Agricultural } \\
\text { Labor Forcea } \\
\text { Divided by } \\
\text { Mean Labor } \\
\text { Force Members } \\
\text { Per Household }\end{array}$ & $\begin{array}{l}\text { Other } \\
\text { Data }\end{array}$ & $\begin{array}{l}\text { Final } \\
\text { Estimate } \\
\text { of } \\
\text { Households } \\
\text { Dependent } \\
\text { on } \\
\text { Agriculture }\end{array}$ \\
\hline Guatemala & --- & $567,390^{b}$ & 540,547 & --- & 540,000 \\
\hline El Salvador & --- & $275,258 c$ & 276,002 & --- & 280,000 \\
\hline Honduras & 185,730 & $249,967 c$ & $219,056 d$ & $218,592 e$ & 220,000 \\
\hline Nicaragua & 129,202 & $140,708 b$ & 145,644 & --- & 140,000 \\
\hline Costa Rica & 100,918 & $145,396 c$ & 113,630 & $112,957 f$ & 110,000 \\
\hline
\end{tabular}

SOURCE: Compiled and computed from Costa Rica, DGEC, 1966:El Salvador, DGEC, 1965; Guatemala, DGE, 1964 :xix; 1966; Honduras, DGEC, 1964a; 1964b; and Nicaragua, DGEC, 1964; 1965b; 1967a; and 1967c. related occupations.

Farming, stock raising, fishing, hunting, and woodcutting, and

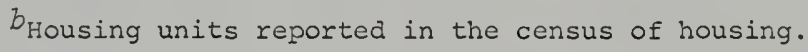

Census households, including unrelated persons.

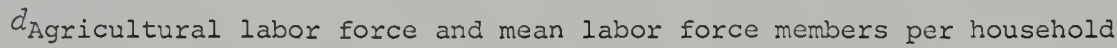
were divided separately for rural and urban areas, and then summed.

eThis figure represents the result of determining separately the percentages of rural and urban workers who were employed in agricultural occupations, and then assuming that the same percentages of rural and urban households were dependent on agriculture, and summing the two.

fThis figure represents the result of separately dividing the population dependent upon the agricultural industry (roma de actividad económica) in rural and urban areas by the average size of household in the respective area, and summing these figures. 
data on heads of households employed in agriculture must be inflated by an unknown number of heads of household who are not employed at all in order to indicate the actual families dependent on farming and stock raising. Thus this seemingly basic statistic could not be used as it existed. The number of rural households served as an approximate upper limit on the potential number of farm families, but the actual estimate was made by dividing the total agricultural labor force by the mean number of members of households in the economically active population. ${ }^{1}$ Of the figures in Table 9, nearly half of the farm families are in Guatemala, and the number decreases with notable regularity as one moves south and east through the region, until finally Costa Rica has fewer than one-tenth of the farm families of the entire area.

Farms, Farm Operators and Farm Laborers

The two fundamental categories of the farm labor force consist of farm operators and farm laborers, respectively. Theoretically these are two mutually exclusive groupings, the former assuming the responsibilities and

${ }^{1}$ Nesman (1969:81-82) used similar procedures to arrive at a figure of 142,00 for Nicaragua, but I have rounded my estimate still further as stated above. Using 1950 census data, Maturana (1966:93), CIDA (1965:59) and Guillen Villalobos (1963:16) arrived at 3 different estimates of this basic figure for Guatemala, ranging from 391,000 to 426,000 families in 1950 . 
risks of the economic management of the operation of the farm, and the latter working under the direction of the operator without any significant decision-making role. Each of these two major classifications has many subtypes which are the subject of analysis in the next major section. ${ }^{1}$ The probable number of farms and farm operators. In Central America even the basic distinction between farm operators and farm laborers is hard to make because of the extent to which the same individuals divide their efforts between the operation of a small parcel on their own initiative, and the earning of additional income as laborers for others (T. Lynn Smith, 1945b:360; Adams, 1957:304). All sources of data tend to overstate the number of operators by including in this category every individual who, with even the smallest amount of land, gains a part of his livelihood on land for which he himself is (or appears to be) responsible. This is true of both the population and agricultural censuses, but it is particularly true of the latter. Moreover, those who have made the several studies of the agricultural tenure situation in Central America, after mentioning that large numbers of so-called operators

${ }^{1}$ This basic division and its subdivisions have been developed over a period of several decades. See Sorokin, Zimmerman and Galpin, 1930, I:362 ff.; and T. Lynn Smith, 1953:280-285. 
were really laborers, blithely proceeded to discuss the whole matter with the original census data. (See, for example, Whetten, 1961; Maturana Medina, 1962; OAS, 1963; CIDA, 1965; Marroquín, 1965; Manger-Cats, 1966; and Barraclough and Domike, 1966. The sole exception is Nesman, 1969.)

The basic determination of the number of farms (and of farm operators, since each farm is assumed to have one operator) must rely upon the censuses of agriculture. There are two basic problems with the existing agricultural censuses. On the one hand, no meaningful distinction is made between a genuine farm and a small tract of land from which an agricultural laborer supplements his earnings. In fact in three of the countries (Guatemala, El Salvador and Nicaragua) parcels even smaller than 1 manzana ( 1.7 acres) are included among the explotaciones agropecuarias. Virtually all of these very small units are simply supplementary to their producers' main income from farm labor (although of course an unknown number of cases rely largely on income from nonfarm occupations).

Only a rough approximation is possible, but in this study an effort has been made to reduce the number of reported explotaciones to something reasonably approaching that of genuine farms. Based on my own observations and conversations with producers in all five countries, and 
also on the detailed reports of many other analysts, I have decided to eliminate arbitrarily all explotaciones of less than 1 manzana or 1 hectare in area from the number of genuine farms. In the extreme case of El Salvador, this results in the removal of 107,054, or nearly half, of the reported 226,896 explotaciones of 1961. In addition to these tiny plots, a large proportion of the units of fewer than 10 manzanas are also simply used by farm workers to add to their livelihoods. Similarly to the procedures employed by Smith ( $\mathrm{T}$. Lynn Smith, 1967a:111-113) and Nesman (1969:82-86), I have reduced the number of places of 1 to 4 manzanas by one-half, assigning equal numbers of these units to the farm operator and farm laborer categories. Moreover, it is felt that even in the range of 5 to 9 manzanas at least as many as one-third of the units are those of families mostly dependent upon paid farm labor for their sustenance and therefore not qualified to be counted as farm operators. Accordingly, the reported number of explotaciones in this grouping has been reduced to two-thirds of the official count and the remaining third has been included among the farm laborer households. There is no question but that even some of the larger places-those of 10 manzanas or more-represent the tracts of extremely poor land used by agricultural laborers, 
but in this rough adjustment no attempt is made to estimate their number, which is not large."

The results of these computations are shown in Table 10. For the region as a whole there were approximately 530,000 farms and a corresponding number of farm operators. Since this figure is not much more than half of the originally-reported 989,423 explotaciones, it may seem to be a very drastic adjustment indeed. It is exactly that, for it shows how far the statistical picture varies from the every day social reality. Studies by Hill, Gollas Quintero and Alfaro (1964), Alfaro (1966), Schmidt (1967), and Parsons (1967), among others, indicate the considerable extent to which farm "operators" of places under 10 manzanas work off their own parcels as agricultural laborers. My own observations throughout the area confirmed this.

${ }^{1}$ George Hill and Marion Loftin (1961:4-5) took the reverse approach in their field study for the OAS Mission 105 in Honduras. They suggested that the agricultural census of 1952 was deficient because they found even more small plots that were used for only a part of the year by asalc iiados (paid workers). They wanted to have these workers reclassified as operators. The plots were either ejidal, or came from their employers, or were simply "occupied," and were generally under 1 hectare in size. They stressed that including these tiny parcels as farms would show even more strongly the problem of the minifundios. My judgment is just the reverse. Counting them as simply laborers emphasizes even more the fact of their dependence on employment by others and their lack of development as significantly decision-making farmers. 


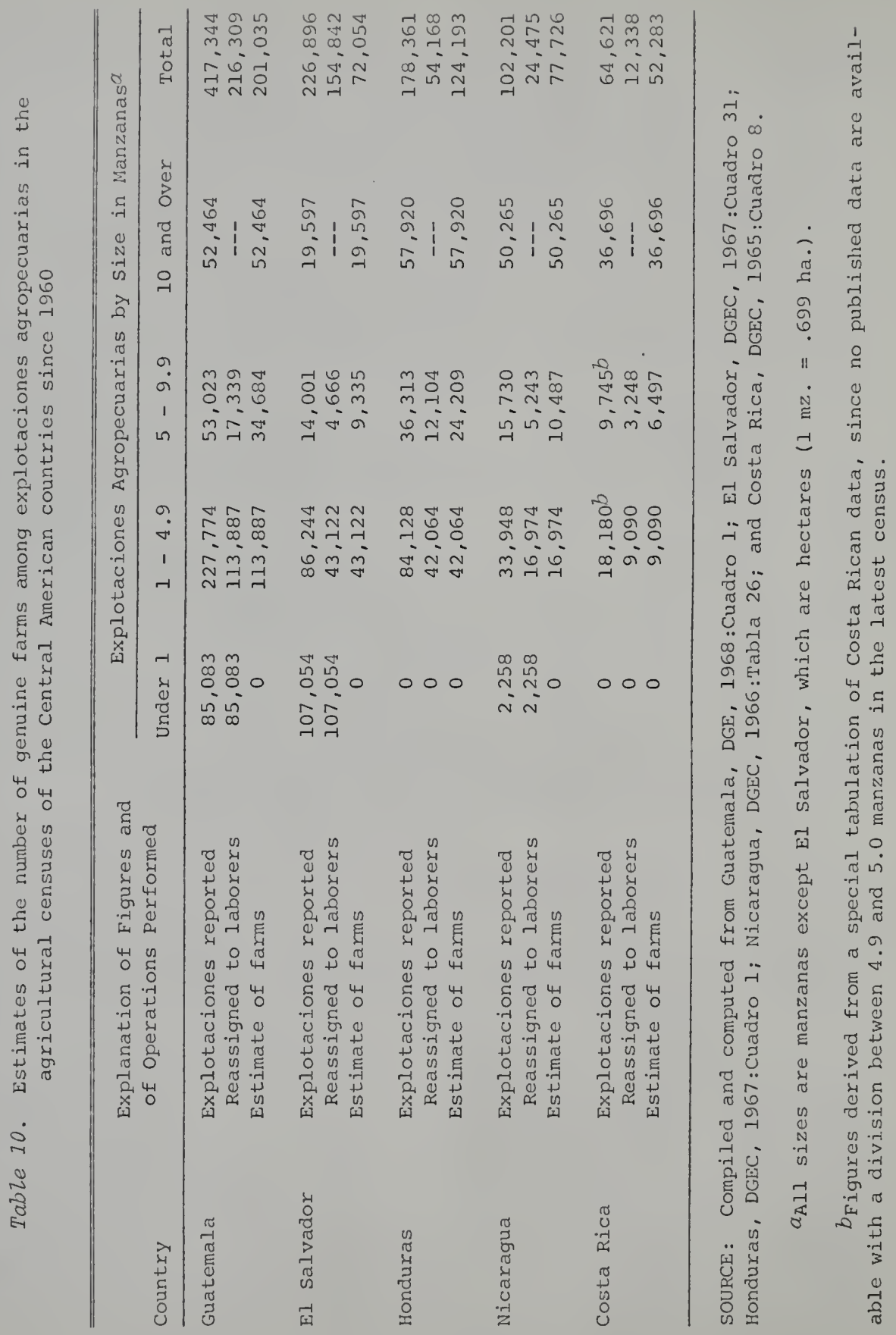


There is another census shortcoming which also helps to explain the overcounting of presumed "operators." This is the erroneous inclusion of certain laborers who are paid in either a share of the crop or the use of a plot of land. In the 1960 censuses over 100,000 colonos were identifiable among the producers in Guatemala, El Salvador and costa Rica. The colono as used here is a farm laborer who is paid for his work by being allowed the use of a plot of marginal land belonging to his employer. Usually he is paid a smaller cash wage than other workers. ${ }^{1}$ Workers of this type exist in Honduras and Nicaragua also, but they are not shown separately as a tenure class in the latest census. In addition, sharecropping (in the sense of a laborer who works for the landholder and is given a share of the resulting crop as his pay) is commonly counted as a form of rental. Since both of these types of laborer are commonly allowed only small plots of land to work, many of them were eliminated among the persons excluded in Table 10, and no separate computation is attempted. As a result of these adjustments in the census figures, it is possible to affirm that on the whole the number of genuine farms and farm operators in central America is considerably fewer than is commonly reported,

${ }^{1}$ See the section of this chapter on "Farm Laborers Today" for a more complete description of the colono. 
and that a correspondingly larger share of the agricultural population is dependent upon employment by others for their livelihood.

The estimated number of farm laborer households.The agricultural laborers and their families are even more difficult to quantify than are the farm operators, owing again to the concepts utilized in the agricultural censuses.' Data on agricultural laborers are collected explotaciónby-explotacion in the form of questions about the labor force employed in farming and pastoral activities. There is thus a great deal of duplication in the enumeration. A man I will call, Jaime Quintero, who has 2 manzanas of land which he owns, is counted as a "producer" on his own plot, and his plot as an explotación. At the same time he and his two sons are also counted, correctly, as jornaleros (day laborers) on the neighboring property of Roberto Cordero, along with some 12 others including several additional "producers" in their own right. Moreover, the workers enumerated may be defined in many and varied ways.

${ }^{1}$ This is not to be taken as too extreme criticism of the census planners, since they have been attempting to collect data which could satisfy the needs of people with many interests, and the sociological realities have in most cases not been properly considered and included among the international recommendations proposed for either the Census of the Americas or the World Census of Agriculture. These recommendations have generally had great influence, and meaningful changes need to occur at the international planning level. 
Some censuses of the region count all those cmployed the particular week before the census, while others are more restrictive and limit those counted to employees of at least four or six months duration in the preceding year. Population census statistics are no more useful. Therefore, it has been necessary to assume that those agricultural families not entitled to be numbered among the operators are simply those of farm laborers. Table 11 provides estimates of their numbers, based on simple subtraction of the families of farm operators from all agricultural and stock raising households.

Some 770,000 households of Central America fall in the class of farm laborers, compared to the 530,000 operator families, so that 59 per cent of the farm people of the region are basically dependent upon the farms of others for their livelihood. On the other hand, 41 per cent are shown to be reasonably independent operators of their own farms, although this is not to be taken to suggest that these are all owner operators. ${ }^{1}$ The division of both

${ }^{1}$ Schulman (1954:295) made a pioneering effort to determine numbers of farm operators and laborers for all of the Latin American countries. In my judgment, with the benefit of both personal observation, and census information which was not available when he wrote, his figures for Central America were far from adequate. He found El Salvador to have 1.9 farm laborers for each operator and ranked it best in the region, the ratios in the other countries ranging up to 4.2 to 1 in Nicaragua. Part of the difference is due to the fact that I have worked with households instead of individuals, but I have also made many of the sort of corrections he said must be made to obtain really meaningful data. 
Table 11. Estimates of the numbers and proportions of households deriving a livelihood from agricultural and pastoral occupations whose heads were farm operators and farm laborers in the Central American Countries in the 1960's

\begin{tabular}{llll}
\hline Country & $\begin{array}{l}\text { Total Households } \\
\text { Dependent on } \\
\text { Agriculture } \\
\text { and Related } \\
\text { Occupations } a\end{array}$ & $\begin{array}{c}\text { Households } \\
\text { of Farm } \\
\text { Operators }\end{array}$ & $\begin{array}{c}\text { Households } \\
\text { of Farm } \\
\text { Laborers } b\end{array}$ \\
\hline
\end{tabular}

$\begin{array}{lrrr}\text { Guatemala } & 540,000 & 200,000 & 340,000 \\ \text { El Salvador } & 280,000 & 72,000 & 210,000 \\ \text { Honduras } & 220,000 & 120,000 & 100,000 \\ \text { Nicaragua } & 140,000 & 78,000 & 62,000 \\ \text { Costa Rica } & 110,000 & 52,000 & 58,000 \\ \text { CENTRAL AMERICA } & 1,300,000 & 530,000 & 770,000\end{array}$

Per Centc

$\begin{array}{llll}\text { Guatemala } & 100 & 37 & 63 \\ \text { El Salvador } & 100 & 26 & 75 \\ \text { Honduras } & 100 & 55 & 45 \\ \text { Nicaragua } & 100 & 56 & 44 \\ \text { Costa Rica } & 100 & 47 & 53 \\ \text { CENTRAL AMERICA } & 100 & 41 & 59\end{array}$

SOURCE: Compiled and computed from data in Tables 9 and 10.

$\alpha_{\text {Farming, stock raising, fishing, hunting, and woodcutting, }}$ and related occupations.

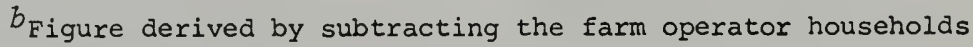
from all households dependent on agriculture and related occupations.

$c_{\text {All }}$ figures have been independently rounded to two significant digits to indicate the roughness of the estimates. As a result of rounding, some figures do not add properly to the totals. 
operators and laborers into their various subcategories is the next task at hand.

\section{Present Tenure of Farm operators}

There is considerable variety in the arrangements by which farm operators secure the use of land, and in the relative security of their tenure. Although many classifications are possible, those of T. Iynn Smith (1953:284; 1967a:129-144) and Schulman (1956b) have been most useful in the analysis of land tenure classes in Central America.

The raw material for this discussion comes from the various tabulations of the censuses of agriculture, and therefore the numbers and proportions of explotaciones do not closely correspond to the proper concept of the farm operator who exercises the independent management of his enterprise and assumes the majority of the economic risks involved. However, for explotaciones of 10 manzanas or more it can generally be assumed that these represent farm operators, although it would not be unusual for the same person to be counted as the "producer" on several different tracts he operated in different municipios.

In a greatly simplified form the most recent figures available are presented in Table 12, where the information is adjusted to include only those explotaciones of 1 manzana or 1 hectare in minimum area. Moreover, for 


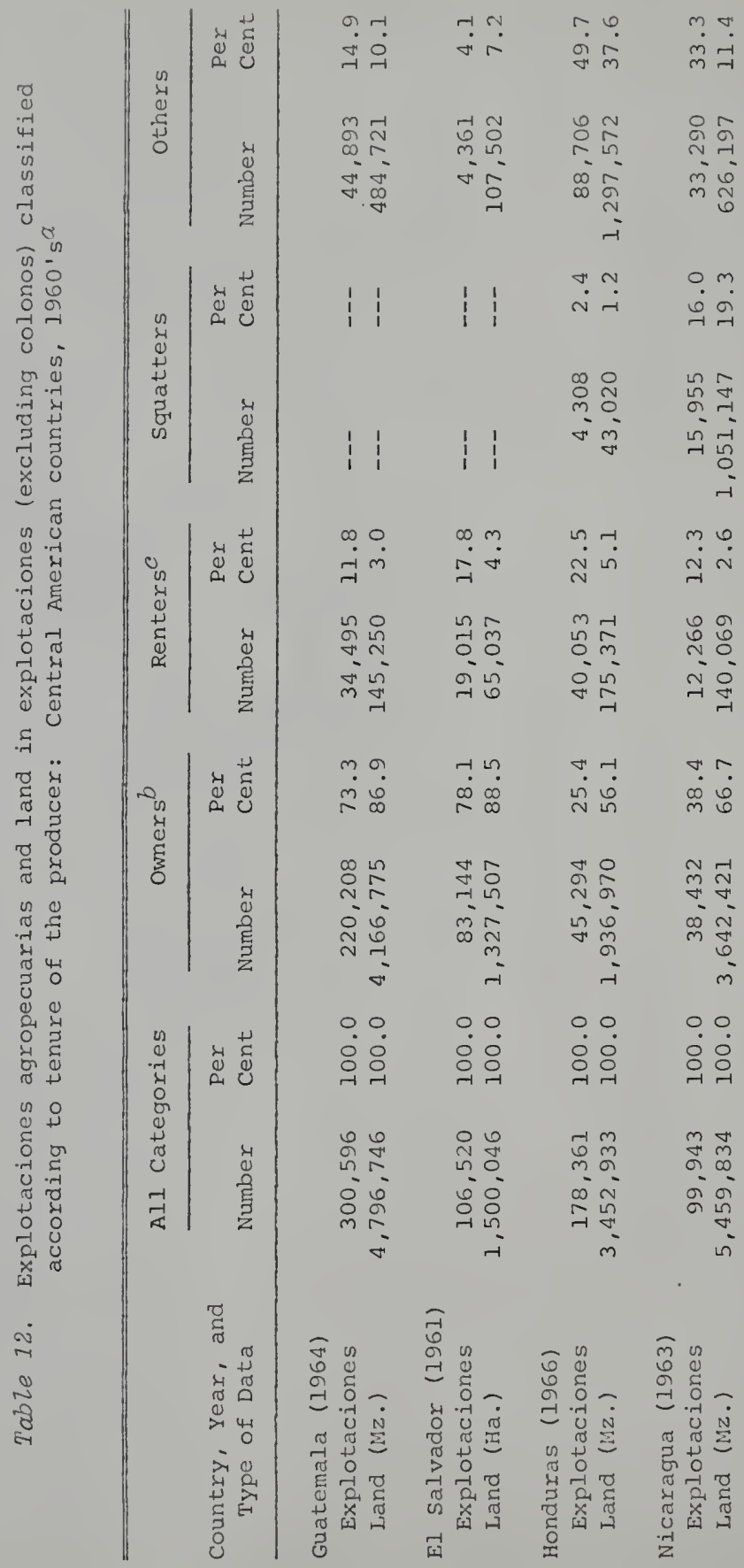




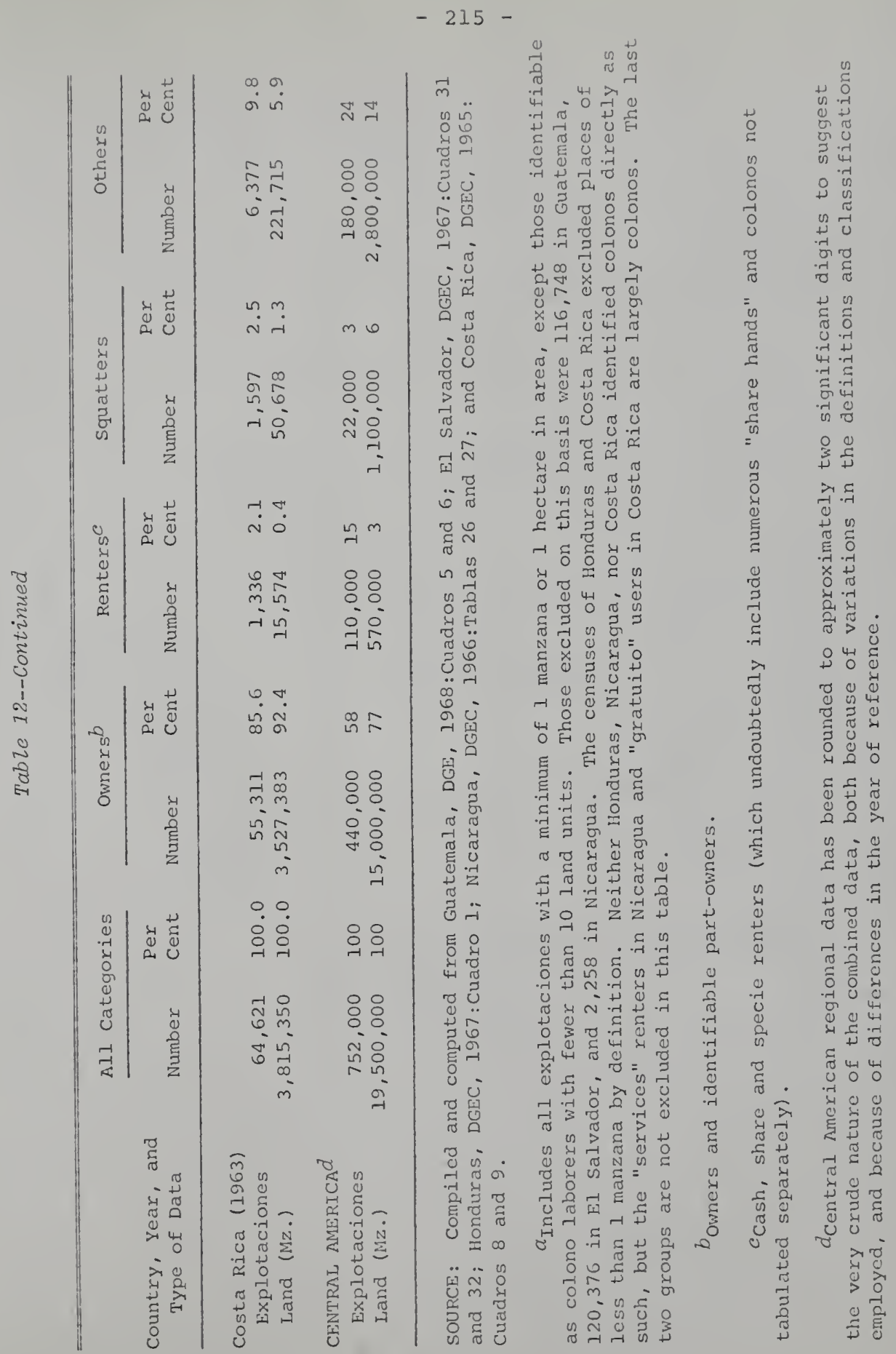


reasons already stated, the colonos have been eliminated in the case of Guatemala and El Salvador, although the same could not be accomplished for the remaining three nations. I refer to the persons in charge of these explotaciones as producers rather than operators, although with the size refinements given later in Table 13 it is possible to approximate operators to some degree.

Owners and part-owners. The most secure and satisfactory form of landholding is outright ownership, where the operator has the full control of his operation and can depend upon reaping the full benefits or consequences of his managerial decisions. Since he and his heirs will presumably have the land in perpetuity (unless choosing to dispose of $i t)$ he has the greatest incentive to protect and develop it. He will be likely to plant appropriate crops and endeavor to control erosion. He will also be more stimulated to upgrade his farmstead, and to improve his own and his family's managerial skills through the use of extension service aids himself and school attendance for his children. Studies by Painter (1956) and Clifford (1953) both show considerable evidence for this from costa Rica.

The propietario or person who operates a tract of tierra propia (owned land) is the most consistently gathered statistic in the censuses-the one in which there are the 
fewest variations of definition. Basically the owners are defined as having the legal rights conferred by a document of ownership, although sometimes these papers are more in the nature of a quitclaim deed from a previous claimant than what is referred to in English as a warranty deed. Except for the many owners of agricultural land who are simply minifundistas, gaining most of their living by farm labor on other places, these persons are truly farm operators. 1

${ }^{1}$ In Honduras, and perhaps elsewhere as well, there are "communal" land holdings that qualify as private property in addition to the usual individual holdings. In many cases these are held by the descendents of some early grantee who have agreed not to subdivide the property. In other cases the owners are residents of a community who have acquired lands as a community but not as ejidos granted as such by the government (Adams, 1957:541).

An example noted by the writer is a recent petition for a land title to 4,286.7 manzanas (about 7,400 acres) by a group of people in the department of Valle on behalf of their Asociación de Campesinos Pro Defensa Territorial. They claimed to represent all the 1,500 occupants, who had held the land publicly, peacefully and without interruption for over 100 years. They stated that there were on the land 10 settlements with 220 houses and five schools (from a legal notice in Honduras, 1963-1968:December 2, 1966).

This land at the time of the census was probably classified as "national land" in an "occupied" state, but if the title had been granted in time it would have become tierra propia, or land with a legal title held by individuals.

The 149 "colonos" in the costa Rican census are not the type of laborer colono about which several comments have 
The tenure of the smaller producers tends to be relatively insecure in every country of the region, with a lower proportion of owner-operated tracts of land than among the moderate and larger producers (Table 13). Only in Costa Rica was there a high percentage of owners in the 1-to-9 manzana class. On the other hand, the relative number of owners was very low in Honduras and Nicaragua, and only moderate in Guatemala and El Salvador. ${ }^{1}$

It is reasonable to assume that for explotaciones of 10 manzanas or more (in Table 13) the proportions of owners fairly represent the picture of owner-operatorship in Central America at the present time. In Guatemala, El Salvador, and Costa Rica the percentages are above 80 , and for the larger units close to 90 per cent are owners, which is an indication of a reasonably good and secure tenure position. This is true both of the explotaciones themselves,

already been made. Instead the costa Rican census counts members of legally constituted agricultural colonies as colonos or "colonists." Though these people do not yet have legal titles, they can expect to do so eventually, and I have counted them among the owners. Their number is too small to affect any of the percentages significantly.

${ }^{1}$ Stokes (1950:24) said, "Almost all Hondurans own land, and liberal agrarian laws make it possible for nonlandowners to obtain acreage suitable for agriculture or cattle raising, regardless of the financial condition of the applicant." From my observation I cannot see where he could have gotten this impression, although I grant that there had been no agricultural census when he wrote. Apparently he took the laws at face value and did not probe further. 


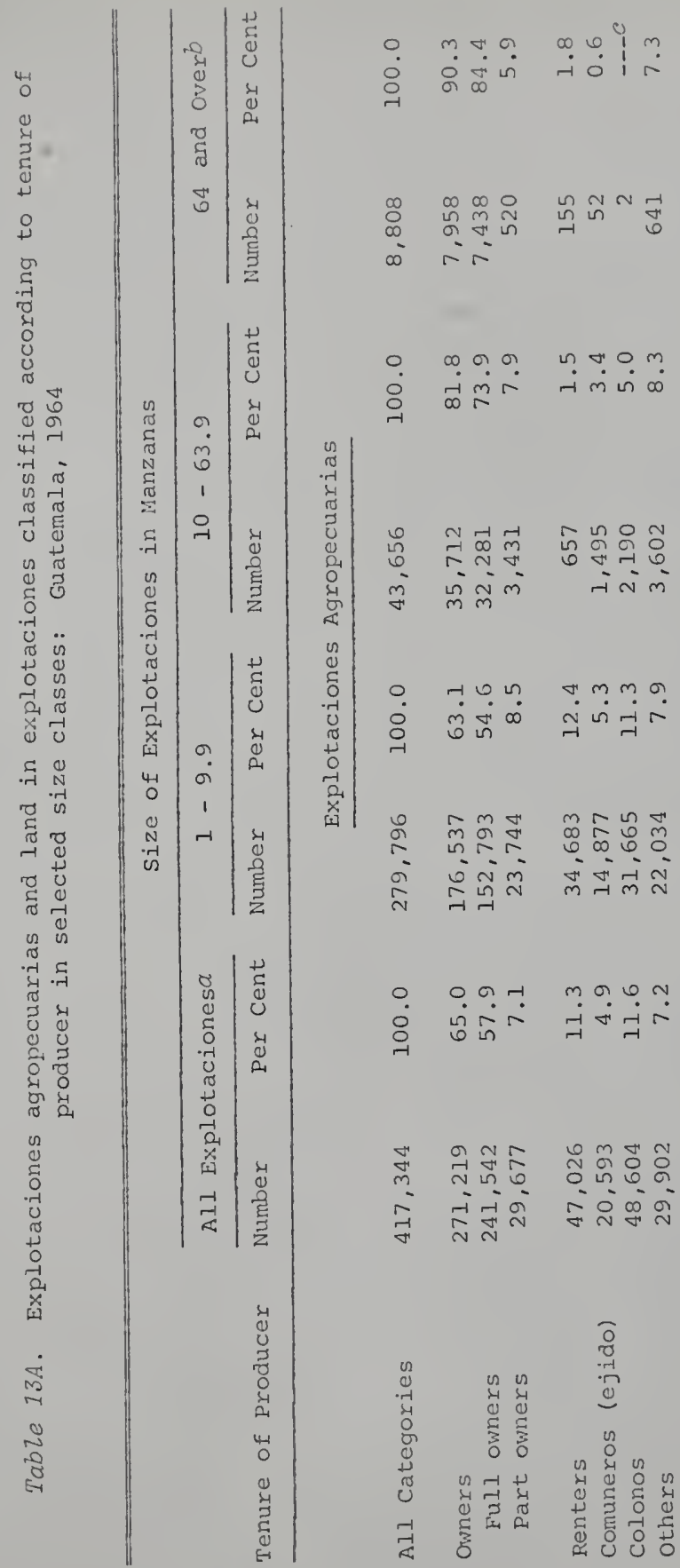




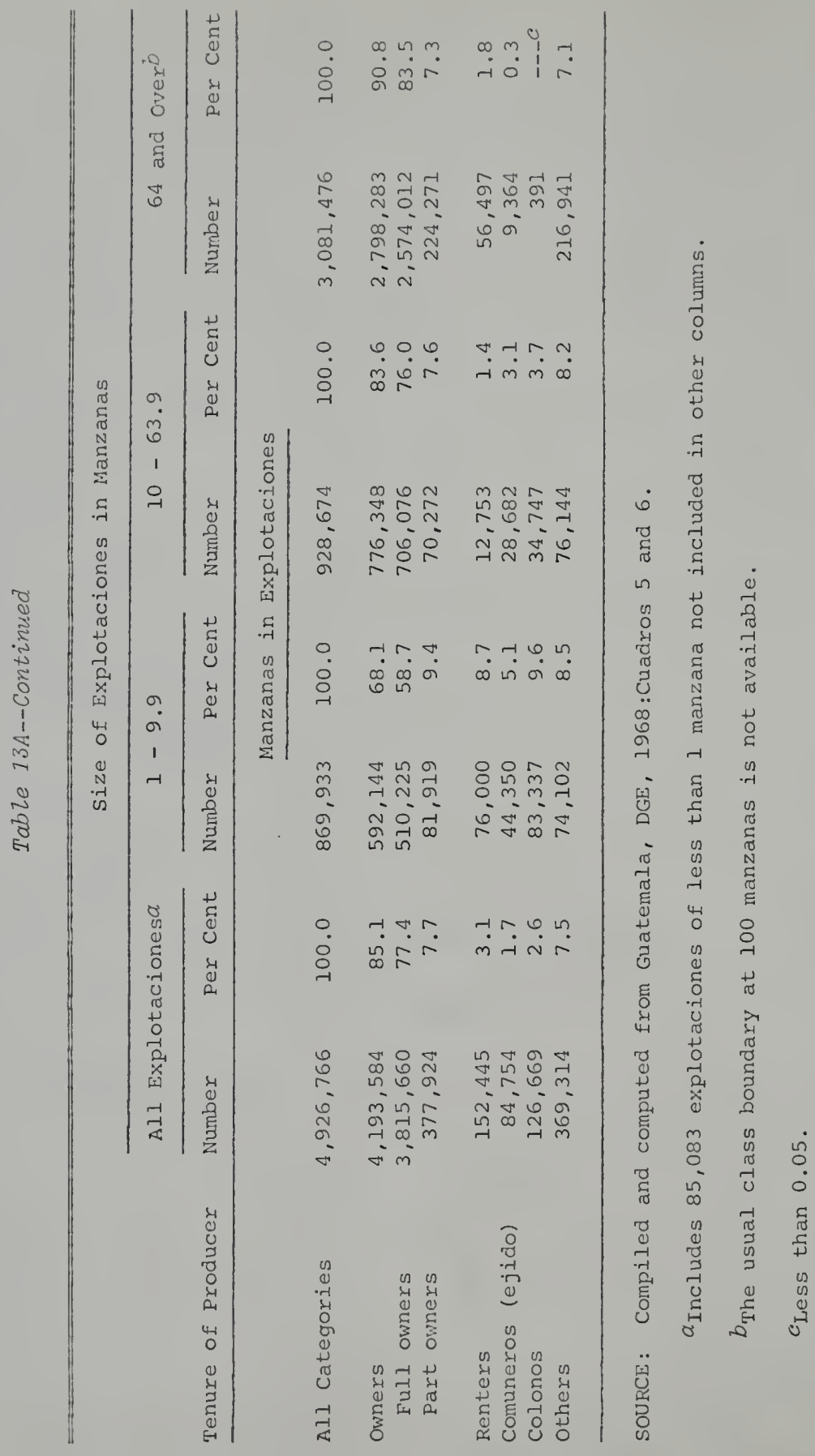




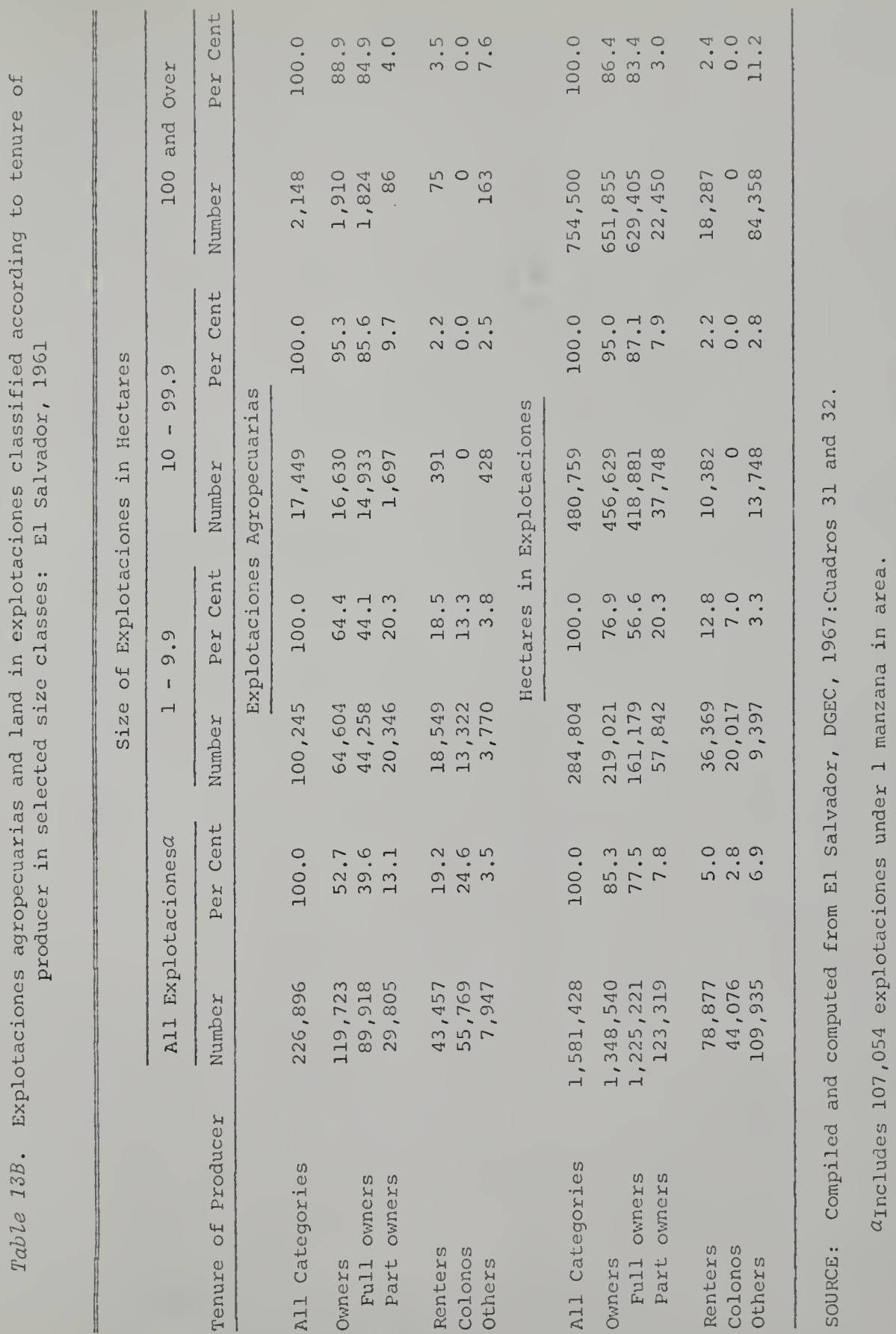




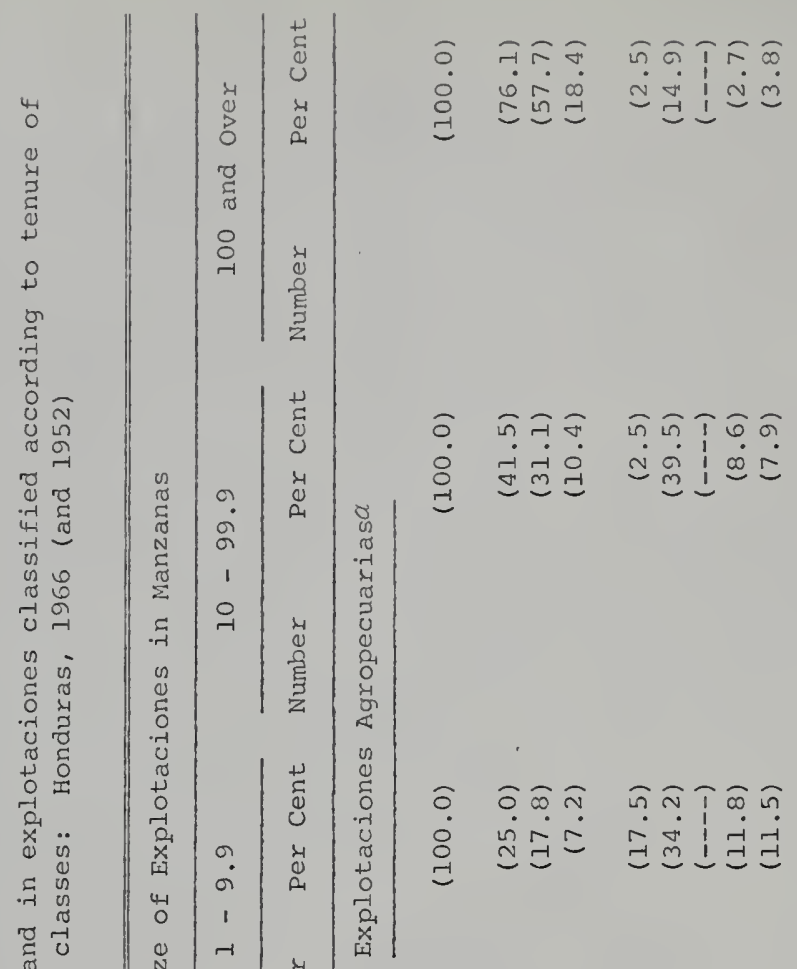

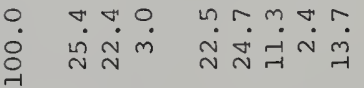
용.

मr

on 4

(2)

(1)

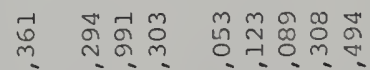
i 


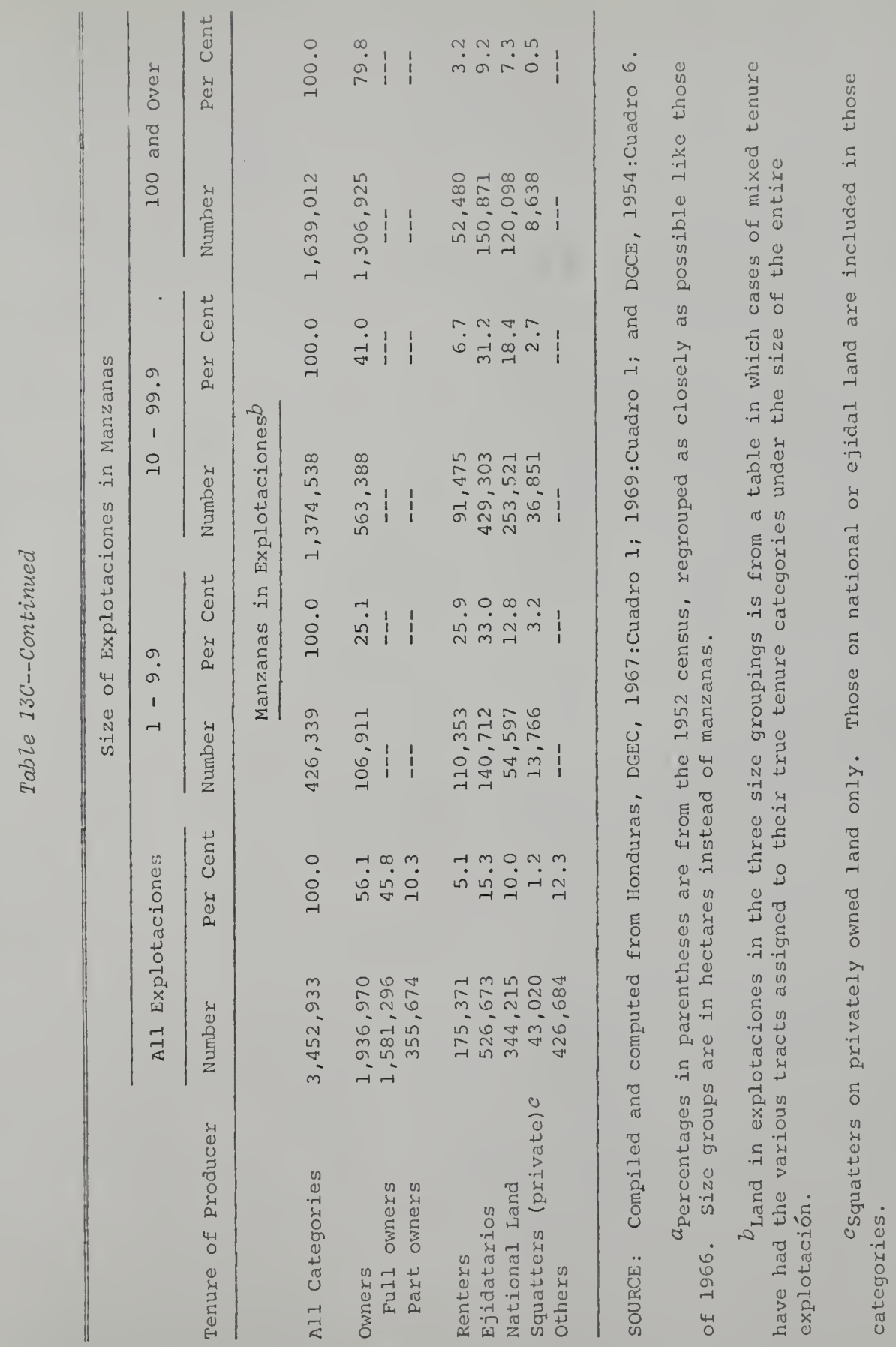




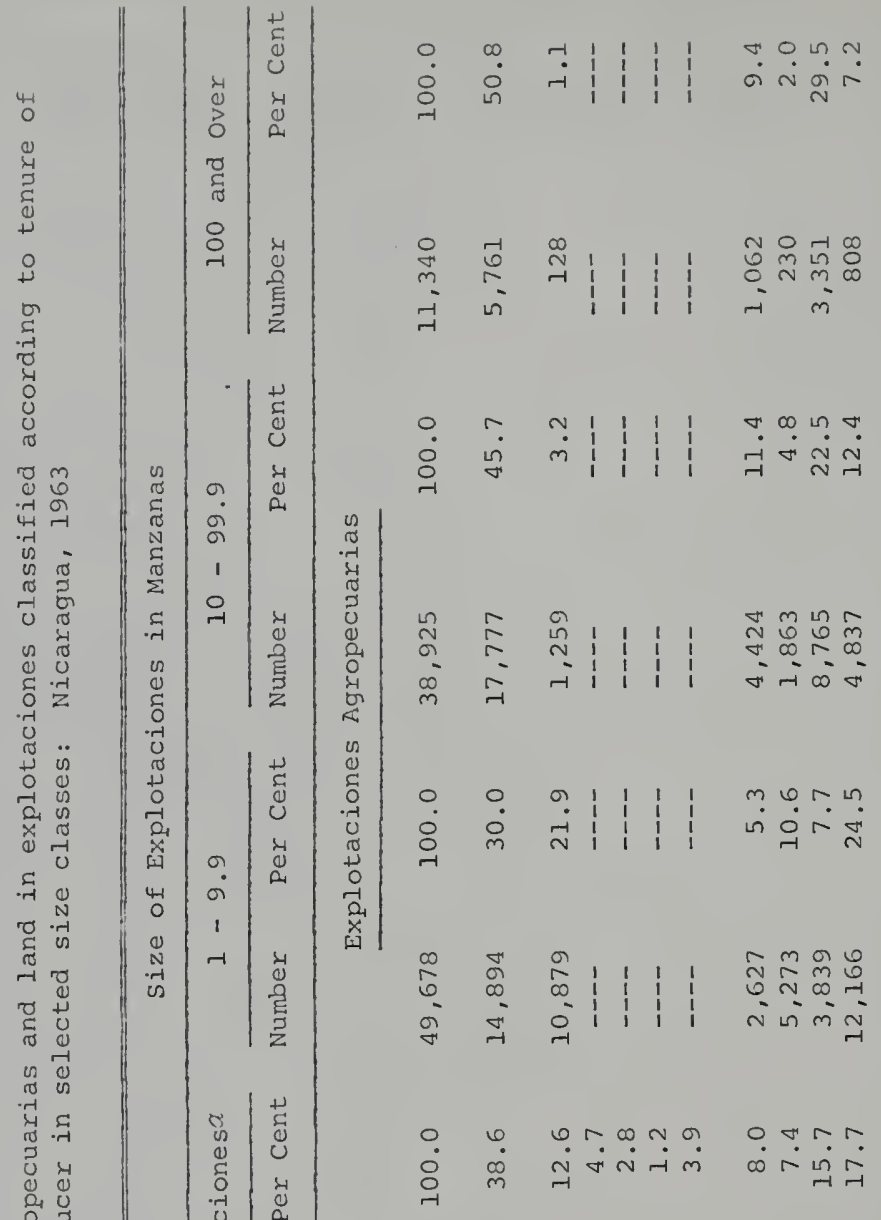

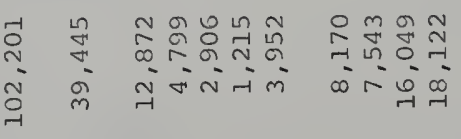

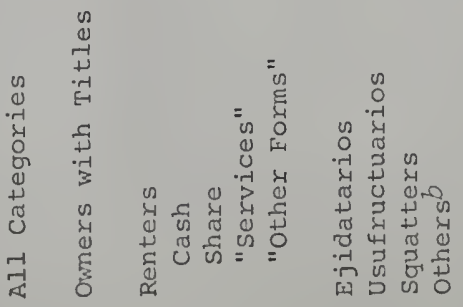




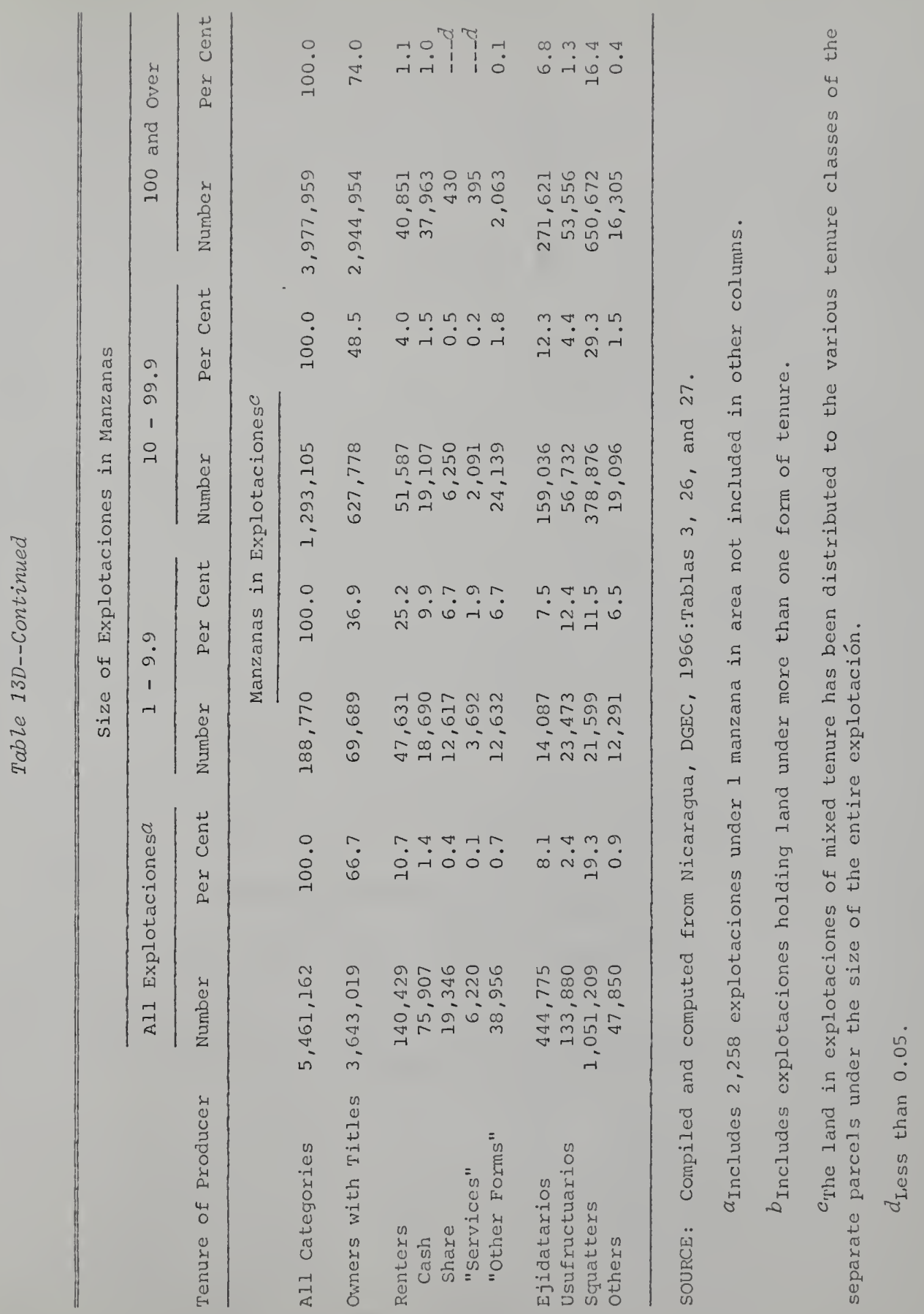




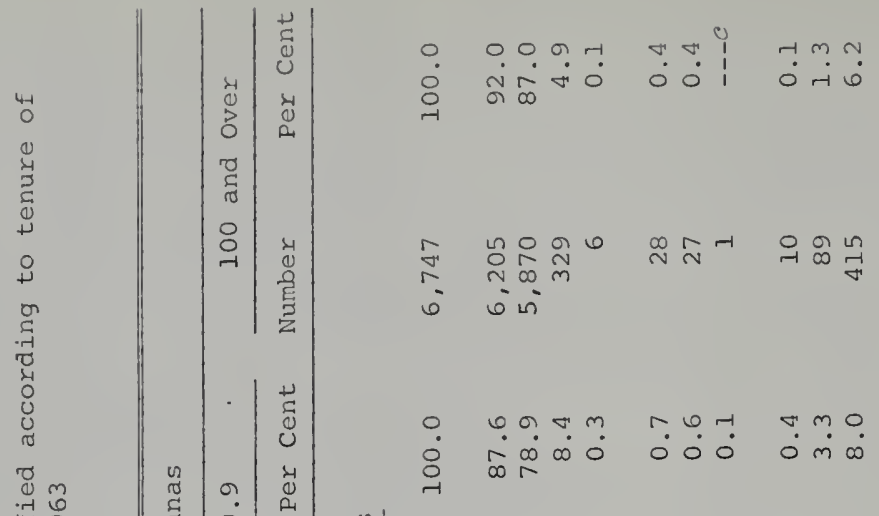

\begin{tabular}{|c|c|c|c|}
\hline 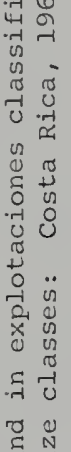 & 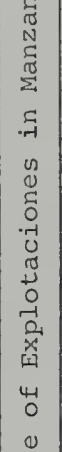 & $\begin{array}{c}0 \\
\sigma \\
1 \\
0 \\
-1\end{array} \mid$ & 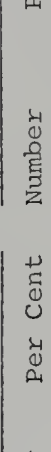 \\
\hline
\end{tabular}

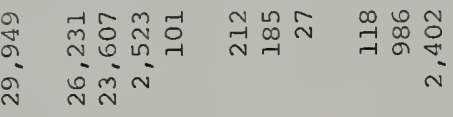

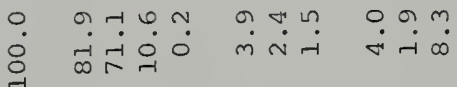

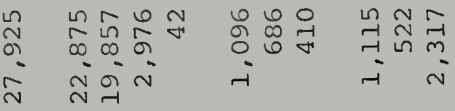

0
0
0

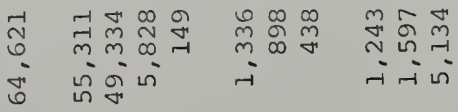

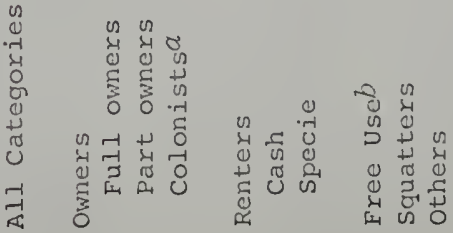




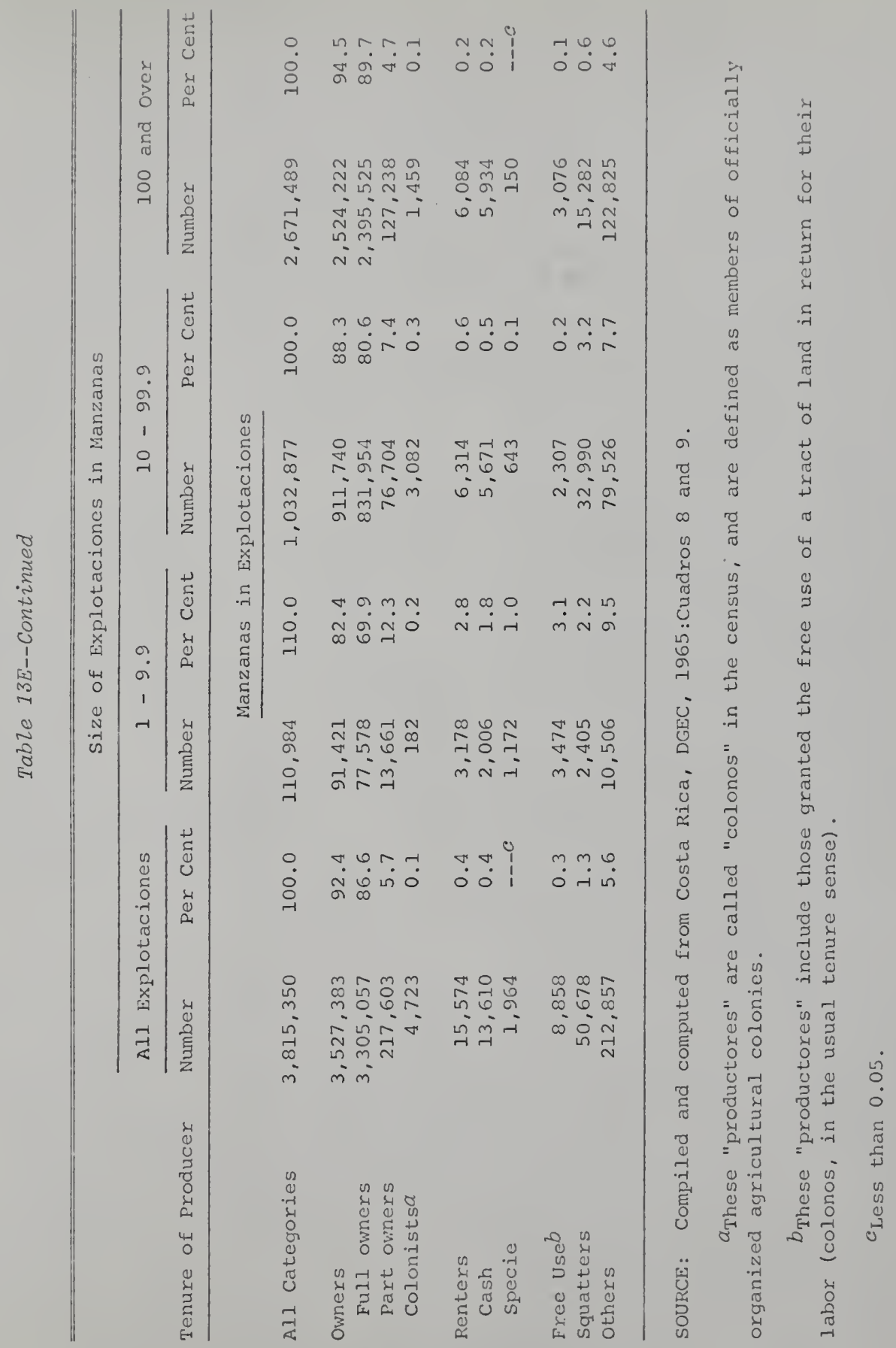


and of the area of land included within them. In Honduras and Nicaragua, on the other hand, the situation is far less adequate. Although some of the 1966 data for Honduras are still lacking, both of these nations present a picture of a minority of owner-producers in the 10-manzana and larger sizes. That this is partly due to problems in the system of title legalization and land registration does not lessen the serious lack of security endured by many farm operators.

A suggestion of the varying importance of owneroperated explotaciones in Central America is presented as Figure 9. In this figure the owner and part-owner explotaciones of I manzana or more have been combined, and divided by the most uniform base population available. The base data are all males employed in agricultural occupations in each major civil division in Central America. These two sets of figures, the first from the agricultural census, the second from the enumeration of the population, make it possible to have a reasonably standardized index of owner-operatorship on a geographic basis. It is readily apparent that highland Guatemala and Costa Rica stand out as the two major areas in which owner-operated units are quite important. In contrast, in the Pacific coastal regions of Guatemala, El Salvador, Honduras, and Nicaragua where cotton plantations were booming at the time of the censuses, the case was very much otherwise, 


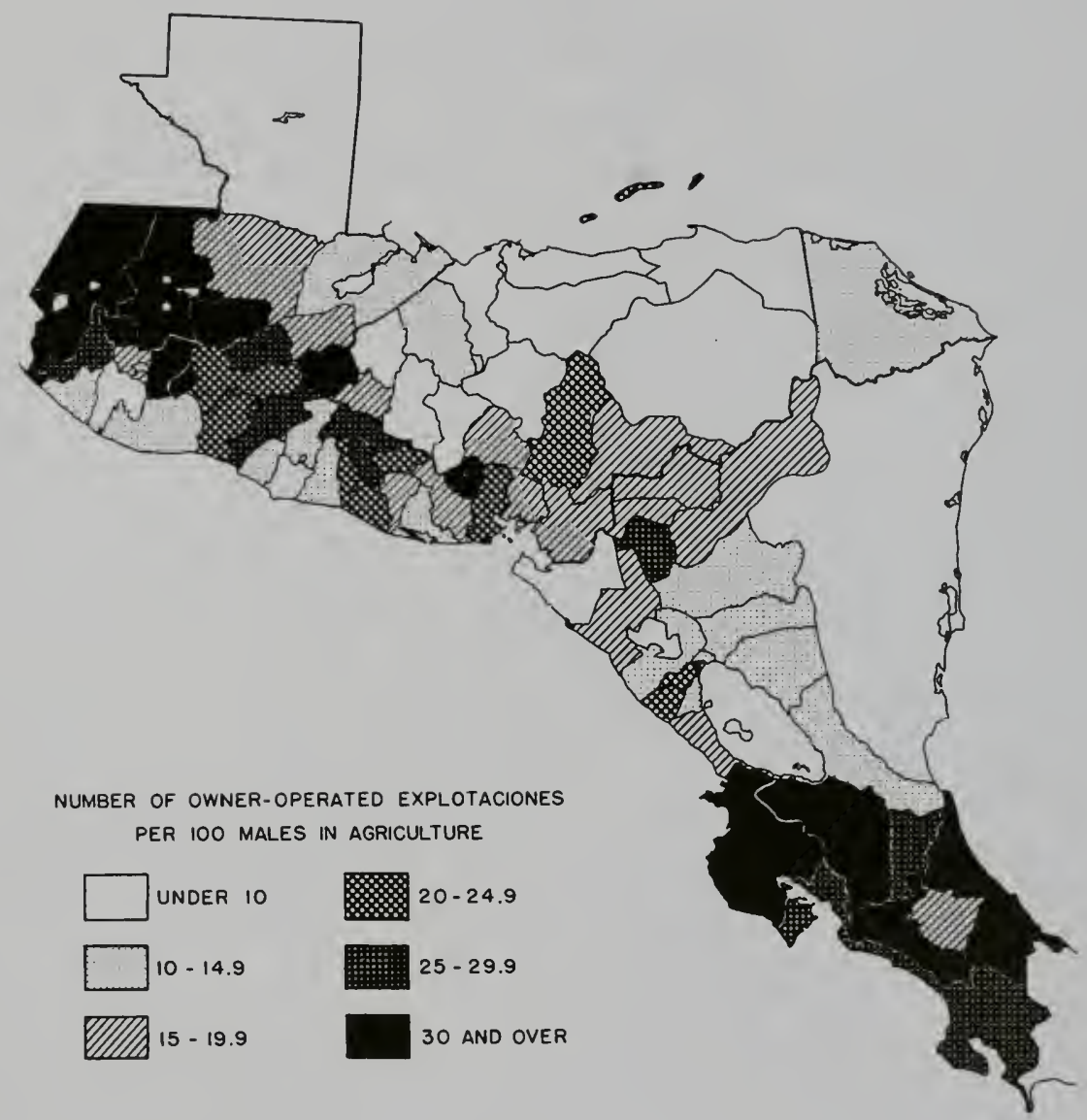

Figure 9. Number of owner-operated explotaciones per 100 males employed in agricultural occupations, by major civil divisions: Central America in the 1960's. (Data compiled and computed from Guatemala, DGE, 1966: Cuadro 11, and 1968:Cuadros 5, 5-1, 6, and 6-1; El Salvador, DGEC, 1965 : Cuadros 23-37, and 1967:Cuadro 31; Honduras, DGEC, 1964b:Cuadro 5, and 1967:Cuadro 1 for each department; Nicaragua, DGEC, 1967c:Tabla 37 and 1966:Tabla 27; and Costa Rica, DGEC, 1966:Cuadro 9, and 1965a:Cuadro 8.) 
as it was also in the vast and relatively little-developed areas of the Atlantic coasts (and the banana plantation areas).

Administrators or managers.-A considerable number of the larger explotaciones in Central America are under the direction and administration of hired farm managers, while the census-designated "producer" lives in a distant city fully occupied in other business or professional pursuits. This is true throughout the region, and I suspect that if data were available it would be found that well over half of all agricultural and pastoral units of 1,000 or more manzanas are run in this fashion. For Guatemala and Costa Rica administrators were in charge of 67 and 80 per cent, respectively, of the explotaciones of 1,280 and 1,000 manzanas or more at the latest census.

These administrators are not to be thought of as a group of highly trained professional managers, although some of them are that, particularly in the highly commercial banana plantations, and in some of the cotton and coffee farms as well. Many are more like the 48-year-old man whom I interviewed as the "administrator" of a 70-manzana farm in the department of Cabañas in El Salvador. Neither he nor his wife had ever been to school, nor could they read or write. Two of their three sons were agricultural laborers, the third a porter in the city. The farm was very traditionally 
run with 9 manzanas in sugar cane and most of the rest in pasture for the 10 oxen and one cow. There was a small amount of hybrid corn (1-1/2 manzanas) on which it was necessary to use fertilizer. Otherwise the operation was elementary plow culture with several part-time laborers to plow, and to cut and haul the cane. The principal characteristic of the administrator was not his training but his honesty and dependability.

By contrast, on a 6,000-manzana cotton plantation on the coast of El Salvador the administrator was a university graduate ingeniero agrónomo, or agronomist. The property belonged to one of the nation's top industrialists, and the farm was one of the most technologically advanced in Central America. The labor force consisted of 5,000 laborers at the peak of the season, assisted by 46 tractors, 250 oxen (for the wet areas where tractors could not work), 200 horses for field supervisors, two spray planes with full-time pilots. This man had his hands full with all sorts of details and records to be kept. I do not know to what extent he had studied management itself, in addition to technical agriculture, but certainly he was an unusually well-qualified administrator.

The agricultural censuses of Guatemala and Costa Rica are the only ones to identify the farms operated by administrators, although they do so not as a form of tenure but as 
an entirely separate bit of information. A summary of this information by several sizes of explotaciones is given in Table 14. It can be assumed that a great majority of administrators manage property fully owned by the producer, although in the largest sizes in Guatemala a greater area is operated by administrators than is held in ownership, so this must be borne in mind. The much greater importance of administrators in Costa Rica may be partly due to a difference in definition which possibly permits a broader class of workers to be counted as administrators than in Guatemala. Renters.-The renter or tenant category is the least consistently defined major land tenure classification in the censuses. Very few explotaciones above 10 manzanas utilized rented lands, and among the units under that size the problem of identifying and distinguishing genuine farm operators from laborers is great. Table 13 presents as much tenure detail as the censuses provide, showing the wide variation in schema. In Guatemala, Honduras, and Nicaragua agricultural laborers who are paid by the operator with a plot to farm for foodstuffs are included among producers, and in Nicaragua they are considered to be renters paying for land in "services." Most similar persons in Guatemala and El Salvador are categorized as colonos. In Costa Rica and El Salvador, the "renter" category includes only those who pay either cash or in specie, but not other forms of tenancy. 
Tuble 1.1. Absolute and relative numbers of explotaciones agropecuarias managed by administrators, and absolute and relative amounts of farmland in such explotaciones, by size of explotación: Guatemala, 1964, and Costa Rica, 1963

\begin{tabular}{|c|c|c|c|c|}
\hline \multirow{2}{*}{$\begin{array}{c}\text { Size } \\
\text { (Manzanas) }\end{array}$} & \multicolumn{2}{|c|}{$\begin{array}{c}\text { Explotaciones Managed by } \\
\text { Administrators }\end{array}$} & \multicolumn{2}{|c|}{$\begin{array}{l}\text { Land Managed by } \\
\text { Administrators }\end{array}$} \\
\hline & Number & $\begin{array}{l}\text { Per Cent of All } \\
\text { Explotaciones } \\
\text { in Size Group }\end{array}$ & $\begin{array}{c}\text { Area } \\
\text { (Manzanas) }\end{array}$ & $\begin{array}{l}\text { Per Cent of All } \\
\text { Manzanas in } \\
\text { Size Group }\end{array}$ \\
\hline
\end{tabular}

\begin{tabular}{|c|c|c|c|c|}
\hline & & Guatemala: & 1964 & \\
\hline All Sizes $\alpha$ & 3,254 & 0.9 & $1,635,685$ & 34.1 \\
\hline $1-4.9$ & 453 & 0.2 & 910 & 0.2 \\
\hline $5-9.9$ & 98 & 0.2 & 687 & 0.2 \\
\hline $10-63.9$ & 432 & 1.0 & 14,114 & 1.6 \\
\hline $64-639.9$ & 1,505 & 19.2 & 375,228 & 28.7 \\
\hline $640-1,279.9$ & 301 & 53.6 & 271,771 & 55.0 \\
\hline \multirow[t]{2}{*}{1,280 and over } & 261 & 67.3 & 972,858 & 76.0 \\
\hline & & Costa Rica: & 1963 & \\
\hline All Sizes & 10,844 & 16.8 & $1,848,361$ & 48.4 \\
\hline $1-5.9$ & 2,967 & 14.1 & 8,293 & 13.8 \\
\hline $6-9.9$ & 1,020 & 14.9 & 7,613 & 15.0 \\
\hline $10-49.9$ & 3,141 & 13.8 & 73,788 & 13.7 \\
\hline $50-99.9$ & 1,244 & 17.2 & 85,782 & 17.5 \\
\hline $100-499.9$ & 1,774 & 30.9 & 378,316 & 34.8 \\
\hline $500-999.9$ & 361 & 60.6 & 241,997 & 61.4 \\
\hline 1,000 and Over & 337 & 80.4 & $1,052,572$ & 88.4 \\
\hline
\end{tabular}

SOURCE: Compiled and computed from Guatemala, DGE, 1968:Cuadros 1 and 5; and Costa Rica, DGEC, 1965:Cuadro 15.

Q"All sizes" for Guatemala includes 204 administrators of places of less than I manzana not included in the size breakdown. The explotación base for the percentages for Guatemala excludes colonos in both units and land area. 
In every country some persons who would be called "sharecroppers" in the United States, and who are recognized as laborers paid by a share of the crop instead of cash, are included as renters. Generally the latter have only small tracts of land, and therefore do not figure when the places of 10 manzanas or more are under consideration.

Almost universally rentals are for either a crop season (often less than a year) or for one year. Contracts for longer than a year definitely are not the rule, although in the growing of sugar cane such agreements are common, and there is often an understood option to renew. Most agreements for small tracts are strictly oral, lacking any written form to provide security for the tenant. For larger areas, and particularly where the renter operates on a credit basis, careful contracts are standard. Maturana Medina (1962:371) found in a survey of the Pacific region of Nicaragua that of 49 farm renters, 15 had written contracts, 33 had agreements for less than a year, and only 22 had cash contracts. The United Fruit Company (Tela Railroad Company) in Honduras recently negotiated a renewed contract for the rental of $12,802.4$ hectares of national land for a term of 25 years, beginning in 1964. The contract is between the government and the company, and in this case not only is there a detailed contract, but it had to be approved 
by the Jefe de Gobierno, Oswaldo López Arellano, before it could become effective (Honduras, 1963-1968:August 12 and 13, 1966).

In undeveloped but potentially valuable areas of every country except El Salvador, the writer found that some large landowners rented land to campesinos for one year solely (from the owners' point of view) to get the land cleared for pastures or cropland. Frequently the charge for the land is not great, but the tenant must leave the area planted to pasture grass at the end of the year. The tenant in such a situation starts with more or less dense forest, clears it sufficiently with hand tools, and grows and harvests two or possibly three crops. At the end of the year he knows he must move on and repeat the process on another tract, either on the same property or elsewhere. The practice has been particularly common in Guatemala, where both Iadinos and Indians, whose very tiny tracts in the highlands are too small to support their families, have sought this means of enlarging their income. (Parsons, 1967, gives an excellent treatment of this, as does Adams, 1957:305. See also Salazar N., 1962:243.)

The writer feels he lacks the necessary information to attempt to adjust the data on renters so as to reflect more accurately the independent operators, on the one hand, 
or the real laborer status of others. ' It is certain that a considerable number of persons designated as renters are half-hands or others who work for a share of the crops. On the other hand in many areas there are genuine renters, paying a tenth, a fifth, or a quarter of the produce in rental. Adams (1957:543) found that "sharecropping" or payment in a fixed proportion of the crop was in decline in Honduras in 1955, and I believe this could be generally said of the region as a form of rental. (It is still common as a form of obtaining labor, however, perhaps because it gives the laborer a semblance of being a farmer instead of just a wage-earner.) Instead of shares, most rentals seem to be based on a fixed payment either in cash or specie. Obviously this form of rental is more onerous for the tenant, since regardless of the quality of the harvest he is committed to a fixed payment. (See Martinez Arguera, 1956:82, for a vigorous complaint about this practice in El Salvador.)

Nevertheless, the importance of having land which one may use independently instead of simply laboring for

INesman (1969:89) did attempt this for Nicaragua, and in the process he reduced the reported renters from nearly 13,000 to only 4,000. The proportion of laborers among the so-called renters may be nearly as high elsewhere, although he had to remove colonos also, and in Guatemala and EI Salvador these are already separate. 
others is captured by Reina $(1960: 85)$ in his account of Chinautla, Guatemala:

The fact that land in the coastal area is available and that much of the crop planning can be done by the individual who leases it, has given to the chinautlecos the feeling of security as possessors. The Chinautleco talks about "my land ( $m i$ terreno) on the coast." In the meantime he experiences the prestige of a man with property, and enjoys the opportunity to talk of his mozos [workers], his associations with the coastal finquero, and the use of modern means of transporting corn to Chinautla [truck].

To the people of Chinautla even though the rented land did not provide the security of ownership, it was enormously better than being landless: "Milpa is still of such high value that the landless individual experiences indescribable shame . . " (Reina, 1960:97).

Ejidatarios and communal lands.-Technically the ejidatario is the operator of land ceded to him by the authorities of a municipio or county-like unit of local government. The ownership of the land is held by the governmental unit, and the usual practice is to charge a canon or fee for its use, although this varies (Adams, 1957:169, $303,541-542)$. In theory the ejidos are subject to reallocation whenever circumstances require it for the good of all eligible residents, or when land is neglected. In practice these lands tend to be assigned perpetually-a particular plot to a given family, with the rights of heritability-so long as the social interest of the community is served. In some areas of Nicaragua Adams reports 
that tradition has so strongly established individual rights to tracts of such land that the authorities have only the right to collect the canon, but cannot remove the holder, who may use it, abuse it, or pass on his right to someone else by a bill of sale (Adams, 1957:169; see also Nesman, 1969:87).

The ejido system sounds quite democratic, with the use of public land being apportioned among the residents, and redistributed as needed. However, as always when dealing with people whose political and economic powers are unequal, the possession of the land tends to be divided unequally in many cases. Some latifundios definitely consist of ejido lands. Ejidatarios do tend to have an advantage over the rented lands obtained from private owners. The ejido landholders usually have more secure tenure and therefore the operator has more incentive to develop such lands rationally.

In Central America, Honduras is the only country strongly maintaining the ejido system of landholding, the others having attempted to replace this form of holding with private ownership during the last century. Costa Rica and El Salvador appear to have successfully eliminated ejidos, and in Guatemala they are not very extensive. In some cases in Guatemala the substantial effect of ejical land has been maintained by placing all the land of a 
community in a private name for legal purposes (to satisfy the presidential decrees of Barrios and his successors), but with control being retained by the community (Hill and Gollas, 1968:30-31). At any rate, this practice was found in four municipios in Totonicapán.

Guatemalan census figures show that most ejidal or "comunero" holders have less than 10 manzanas (many under I manzana), and that collectively they control only a very small share of the land (see Table 13A). Presumably during the 1950's much of the remaining ejido land was distributed to individuals by agrarian reform measures, but the reform was abortive, and the 1964 census counted slightly more comuneros than were shown in 1950, although the land area so held declined slightly (Guatemala, DGE, 1968, Cuadro 5; Villacorta Escobar, 1952:74). Villacorta also suggested in his commentary on the 1950 census that many "comuneros" call themselves that without any proper right to do so, perhaps meaning that they are really squatters, though he does not say what other tenure they might hold (p. 76).

Honduran census figures for 1966 show 30 per cent or more of the land in units under 100 manzanas was ejidal. Only a small proportion of all farmland registered was in holdings of 100 manzanas or more, which is consistent with the discovery of Hill and Loftin cited above regarding grants of large areas of ejidos to individuals who rerent 
it to small-scale tenants at up to 80 times its original annual cost to the legitimate grantees. Real ejido lands thus sometimes are counted for census purposes as rented lands since they have been sublet by the ejidatario.

This again points up the fact that the Central American census custom of counting the land of sharecropping laborers or colonos as if they were independent farms does not accord with the real facts of the control of land. The extent to which large landowners and the holders of large concessions of public terrain control the lives of masses of campesinos is effectively masked, and the latter are made to appear independent when in reality they are not. ${ }^{1}$

It must be mentioned also that the tracts in the category of "national lands" in Honduras are sometimes acquired in the same manner as ejido terrain, the difference being principally that their acquisition must be sought from the departmental authorities rather than from the municipio. Since the category of national lands

${ }^{1}$ Some of the censuses included a table for ascertaining land area and tenure which required the listing of all land in the particular district owned or held by the producer, and then provided a line for subtraction of any such land he rented out or allotted for the use of workers. Such land was to be claimed by these others instead of the original holder. It would be valuable to analyze this information to learn to what extent it showed the concentration of real control of additional land through landlordism. 
includes most of the territory that is neither private nor ejidal, a great many of the 344,215 manzanas reported in this class are probably occupied by squatters. The census authorities thought it wise to count all national land together without distinguishing whether the nature of the claim was legal or extralegal (Honduras, DGEC, 1965:15-17). Thus no one knows what portion of this land should be classed as being under the control of squatters. Nicaragua is the only country in which the majority of the ejido lands are in large tracts. Over 60 per cent of the municipio-owned lands there are in holdings of 100 or more manzanas. In this case the ejido system apparently is not successful in providing security of tenure for the average members of communities of this type. Perhaps the fact that many Nicaraguan ejidatarios are large holders explains why Adams found that municipio councils often were unable to redistribute the control of their land as circumstances might warrant.

In some of the predominantly Indian municipios of Guatemala the ejido type of landholding has proved to be fairly secure and equitable. In these areas no powerful minority has monopolized the land. In contrast, however, Nicaragua and Honduras have many places in which only a few of the powerful have benefited. Apparently little 
effort has been made to see that the distribution of rights to ejidos would contribute to the well-being of all residents.

In the past the effort to convert the ejidos into private property has been largely at the expense of the very people who depended upon them. Nevertheless, it appears to this writer that some reform is required to distribute the rights to such land in family-sized tracts. If the lands were reapportioned in ownership, however, some method would need to be provided for replacing the revenue which the municipios would lose. Preferably such an end would be accomplished by means of a local property tax on all land within the bounds of the municipio.

Squatters.-In every country of the region there is a definite problem of the simple "occupation" or appropriation of land for the establishment of farms.' The extent of the problem is unknown, however, since the censuses are not able to deal with this type of tenure adequately. Indeed in Guatemala and El Salvador they have chosen to group the squatters in with various other unspecified tenure types rather than to try to obtain specific information on illegal occupants.

${ }^{1}$ A common term for squatters throughout the region is ocupantes or "occupants." The. term is used in this section in that same sense. 
The number of identified squatters with I manzana or more of land for all of Central America, according to the latest censuses, was only 22,000 , and the vast majority of these were in Nicaragua (see Table 12). However, this number is a tremendous understatement, for in the same year as Costa Rica's census was reporting 1,597 users "without permission," its Instituto de Tierras y Colonización (Land and Iand Settiement Institute-ITCO) identified some 20,000 cases of squatting, colloquially referred to as parásitos (Costa Rica, ITCO, 1963c:34). At that time some 15,000 of the squatters were on private property and about 5,000 on state land (much of which had been bought by the nation in an "occupied" condition for the purpose of getting the private owners out of trouble). The most extreme case in costa Rica at that time was the Hacienda Miravalles in Bagaces, Guanacaste. The hacienda controlled 38,000 hectares, with 23,000 fully owned by the proprietors. In 1962 it was reported to have 3,000 families occupying some 13,400 hectares of its land, and that they had such permanent establishments as a school, church, movie house and stores (Salazar N., 1962:137). Some of these squatters were relatively largescale operators of mechanized farms of from 600 to 700 hectares. On the other hand, the 1963 census recorded only 337 squatter explotaciones in that cantón and only 26 more in the three surrounding jurisdictions. These 337 units 
did embrace a large amount of land, however, a total of 10,936 hectares, or 10.4 per cent of all the farmland in the cantón (Costa Rica, DGEC, 1965:Cuadros 2 and 4).1

Among other fincas in Costa Rica reported as having large numbers of "occupants" were San Juanillo (300 families), Jesús Marla (114), La Lola (101), and Penshurst (80). The figures are taken from various reports of the Institute (Costa Rica, ITCO, $1963 \mathrm{a}$ and 1963b) and from personal interviews with personnel of the Institute, the United States Agency for International Development (AID), and others. These do not include extensive tracts still owned by the United Fruit Company that are also thoroughly infested with parásitos, nor many other farms yet to be studied at the time of my visits.

Many occupants are actually speculators who obtain land by "invasion" and then sell their rights to others who come later. Salazar (1962:97) demonstrates how some relatively wealthy people hire others to "homestead" land for them in just this fashion. From alphabetical lists of the

'Of the two best explanations for the discrepancy, either that the census simply missed many explotaciones, or that the producers reported some different tenure status, the latter is far more likely. This is because the explotaciones included in the census equalled 104 per cent of the estimated area of the cantorn, according to the Instituto Geográfico de costa Rica (Costa Rica, IGCR, 1960). 
squatters ITCO had surveyed on several properties I noted an example of a squatter who I assumed was genuinely attempting to establish himself as a farmer. Juan Arguello Valenciano held three parcels in Finca Reventazón. He has purchased the rights to the first of these in 1941 and to the last in 1962. He also held two parcels in Finca Cacao and one in Finca Germania, for a grand total of 53 manzanas of land, all of which he had obtained from earlier claimants. His claims are all on old United Fruit Company lands in Limón Province which had been taken over by the state. Eventually the nation planned to give titles to claimants such as Arguel10. In the meantime, however, they lack security of tenure and have no access to credit on reasonable terms. Furthermore, most such claims are in economically backward areas where effective public services generally are lacking.

Nicaragua also reported that squatters definitely constitute a problem. The 1963 census identified nearly 16,000 cases, and the Instituto Agrario de Nicaragua (IAN) (1968b:17) stated that

the occupation of land without any legal title is a characteristic of the Nicaraguan countryside. When these occupations are found on private property then an inevitable conflict arises, the solution to which in many cases proves to be the acquisition [by the state] of the necessary land to establish the campesino and his family on the farm.

The report of IAN goes on to name 25 cases of conflicts 
between owners and occupants in which the Institute had intervened during 1966, and indicates that there also were others. The study of Nicaragua by the International Bank for Reconstruction and Development (1953:310) indicated that squatters made up a very considerable share of the small producers of food crops. The census data gathered a decade later bear this out.

As previously stated, the 1966 Honduran census conceals the existence of many squatters by not reporting those on national and ejido lands. The 1952 census reported that 11 per cent of the explotaciones, containing over 5 per cent of the farmland, were run by squatters. Moreover, many persons in Tegucigalpa and in the countryside agreed that squatting still was common in 1963, especially on the north coast on or near lands of the banana companies. Regarding the United Fruit Company lands, no company officials would give me any estimate of the extent of squatting on the abandoned plantations, but one technician inadvertently showed me extensive areas that had been taken over by them. The company was probably reluctant to discuss the matter because of the newly-enacted Agrarian Reform Law. The Organization of American States' Mission 105 reported the incidence of squatters was generally high in the less developed and more pioneering areas of the country (OAS, 1963, I:72). 
For El Salvador no numerical data pertaining to squatting were found, but Jaime Chacón, a high official of the Instituto de Colonización Rural (ICR), reported to me personally that there were many cases (personal conference, August 18, 1963). These occur usually on privately-owned haciendas which the proprietors have left virtually unused. Robert Hardee, United States AID adviser to the Presidential office of Planning, said that he suspected the large number of explotaciones under "other" tenure arrangements in the census reports indicated that squatting was increasing (personal conference, August 12, 1963). A notorious example is the 11,000-hectare Hacienda El Encantado. It had many illegal occupants, and its owner was able to sell it to the state's Instituto de Colonización Rural (ICR) in 1956 to resolve his problem. Torres (1961:30) indicates that similar occupations have occurred on "several" of the largest "latifundios" of the country where the soil was not excellent and the owner was not attempting to have the land "properly cultivated."

In Guatemala the final reports of the agricultural censuses in both 1950 and 1964 grouped occupants with other classes in such a way as to make it impossible to determine their numbers. However, the preliminary reports of 1950 data (Guatemala, DGE, 1952:40) gave the number as 13,468, of which 10,782 were 1 manzana or larger. Only 32 were 
64 manzanas or over, but one of these was in the 3,200-to6,399 manzana class. Altogether they accounted for only slightly over 1 per cent of the land area. It is certain that these figures also understate the incidence of squatting, but no one knows how much.

It must be pointed out emphatically that traditionally and legally squatting has been the recognized means of "homesteading" the public lands of Central America. On such lands the occupants could claim titles of ownership after 10 years of proven residence and cultivation. Recent laws have tended to reduce the time required to as little as three years. Generally it has been legal to squat on private lands as well, so long as the owner did not have his property fenced or clearly bounded. However, during the first ten years of occupancy by a squatter, a private owner of record could object and force the "occupant" to move. In some cases the owner was required to purchase the improvements made by the newcomer; in others he was not. On many large estates the owners themselves often did not know exactly where the boundaries lay, and more frequently they were unaware of the encroachments on their property. The situation may now be changing, but historically the civil codes have permitted a squatter on privately-owned land to obtain a clear title in his own name after a 30 -year period 
of public, peaceful, and uninterrupted possession "as owner." In recent decades the trend has been to reduce this time to ten years. ${ }^{1}$

The squatter problem for private landowners has a considerable history in Costa Rica. It had reached such proportions by 1942 that a general law concerning "Ocupantes en Precario" was passed (No. 88, July 14) which attempted to solve the problem by offering to give property owners whose land was "parasitized" the option of exchanging the occupied portions of their territory for its equivalent value in national land (baldíos). This was done so that the state would own the "occupied" portion and could grant titles to the squatters and regularize the situation. Salazar (1962:101-105) quotes a report from the National Agrarian Attorney General to the effect that in 82 such exchanges the occupied land which had been vacant and unused prior to its occupation was valued for exchange purposes at 200 colones or more per hectare, while the more distant national lands were exchanged at rates of 10 colones or less! An earlier report on the squatter situation (Costa Rica, MAI, 1949:465) stated that by 1949 the state had

${ }^{1}$ Two laws specifying ten years are one of 1926 for Guatemala in Méndez Montenegro (1960:423-426), and a Costa Rican law of "Ocupantes en Precario" (Costa Rica, 1824:Dec. Leg. No. 88) of July 14, 1942. 
already acquired 190,000 hectares of private land in its attempts to resolve squatter problems.

A law creating the Institute of Lands and Land Settlement was passed (No. 2825, October 14, 1961) which established that the right to enter into national and private property was ended, and that all further claims for public land had to be made by prior application through the Institute (Costa Rica, ITCO, 1963c:37). The same report (Ch. 3) stated that ITCO was actively working with squatters on 527 properties containing 270,340 hectares and 15,155 occupants. Many grants have already been made to legalize the possessions of former squatters, but newspaper reports from San José suggest that the problem is still acute ( $L a$ Republica, November 23, 1968).

The occupant "en precario" has the least secure tenure of any of the operators, and his life is generally not far above the mere creature level. He lacks such services as agricultural extension, which is hard pressed to serve even the most deserving residents. Moreover, since he has taken over unused land, he usually is in areas of extremely poor transportation-this often being one of the reasons the owner himself did not utilize the land. Sandner (1962, I:91) found these settlers in many areas of Costa Rica, and generalized thus: 
The illegal and destructive colonización [settlement], which can as well be called plundering, is carried out principally by parásitos who, although clearing huge expanses, obtain a small production on their plantings, and when there is a good crop, find themselves without roads to take it to market.

Squatters have little opportunity for schooling, medical care or recreation, and their homes are among the poorest. Consider in these connections the notes from my journal of July 2-4, 1963, made during a trip down the San Carlos River in Costa Rica through an area of public lands that had been occupied by squatters:

I set out Tuesday, July 2, at 6 a.m. from Alajuela with Edgar Nesman, technical rural extensionist with the Methodist Church of Costa Rica. At $9 \mathrm{a} . \mathrm{m}$. we left Ciudad Quesada, having added to our group Don Cipriano Martinez, the rural pastor whose district we were going to be visiting. Shortly we ran out of paved road and continued on a gravel road until we reached the settlement of Boca de Arenal, where we were to transfer to a dugout boat for the trip down the San Carlos. Our gear consisted of bed rolls, a change of clothes, a kerosene slide and filmstrip projector, and a briefcase full of church literature and literacy and health materials. We also had a ten horsepower outboard engine and 21 gallons of gas in cans which served as seats as well.

The San Carlos is only one of 14 points in the charge of Don Cipriano. The pastor is much like his people. He is of Nicaraguan background, and used to be a laborer on the banana plantations. He has only about a third grade education, but knows the Bible well and has been appointed as "supply" pastor for the area that has no officially organized churches. Small groups gather whenever he makes the trip down the river in his strictly itinerant ministry.

The area is a frontier region where most of the people have settled their land in this generation, and they are not a highly placed group in the economic scheme of things, many being illiterate. Most are squatters on baldíos, although some have encroached. on an abandoned hacienda. 
We traveled perhaps 40 miles down the river, and from the point where we entered, called Boca (mouth) de Arenal, there is no school or church (Catholic or protestant), no doctor or post office, nor even a road, until one reaches the Boca de San Carlos where the river empties into the Rio San Juan at the Nicaraguan border. In general there are family-sized farms all along the river, with a strictly isolated settlement pattern. There is not a single community of several adjacent houses to be found along the river between the two Bocas, each of which has a little settlement of sorts, a school, post office and transportation. To Arenal there is bus service regularly from Ciudad Quesada, although Arenal is the end of the line. To Boca de San Carlos there is small plane service twice a week that brings mail, passengers and cargo. There is also a customs house and the headquarters of the captain of the rural guard, with some dozen houses.

The actual travel down the river included the following highlights: We had arranged for a boat and loaded up in time to depart downstream at 11:30 in the morning. We had to keep moving pretty steadily in order to reach the mouth of the river by dusk, since that was where we planned to spend the first night. Along the way we made two stops to alert families that we would be back the following two days and would like them to gather the neighbors for a meeting on that occasion. I also quickly learned that one adapts to the changing needs of the day, taking along "hitchhikers" and cargo (small) as need develops.

The usual thing on these runs by Ed and Don Cipriano was simply to stay with families along the route overnight, and for meals as well, but the first day Ed handed each of us a 5-cent package of crackers and remarked that that would be lunch for the day. He was right! But from then on we were fed the best people had to offer, which from my perspective was quite humble indeed, and very poorly balanced nutritionally.

Ed's technical message on this trip was a filmstrip on good and bad water, showing microbes, and stressing the need to boil water before drinking it. He also plugged for the building of latrines to hande waste elimination, but I only saw one on the whole trip.

Most of the land along the way was held by "derechos" rather than by "escritura." This means that the holders do not have registered titles, but do have a generally recognized right to the land, often with a bill of sale 
from a previous holder. To have a registered title one has to pay a land surveyor to make a plat of the property in question, spelling out the boundaries clearly. Then one has to have a lawyer process the claim legally. And with a registered title goes the natural obligation to pay land taxes which amount to one colón per manzana per year. So the costs of getting a title, plus the involvement with taxes, discourage those who could get a title. And some have not got good grounds for a title.

Generally speaking the houses of the area are located close to the river bank. The majority have thatched roofs, while some have zinc [corrugated, galvanized tin], and a few have wooden shingles. of those we visited most had at least a part of the floor made of boards, with the rest just packed dirt. In general just outside the "sides" of the house (which were often actually open on one or more sides, with nothing but poles supporting the roof) where the rainwater from the roof dripped there was a band of mud only partly relieved by attempts to carry away the water in ditches. Also in the mud were the droppings of the farm animals: pigs, chickens, cats and dogs, and in a couple of places calves. The animals were usually free to roam any parts of the house where there was a dirt floor, and there was no stopping the cats, dogs, and chickens from entering everywhere. The cats were considered a very important part of the farm in every case, being needed to help keep the rodent population under control, although most people felt there was still plenty of a problem with mice. The walls of the houses were typically a rather ramshackle collection of boards, more or less papered over with newspaper and magazines.

In spite of its poverty and low levels of living the area is more than just a subsistence farming area. Ed said many of the farmers are able to get agricultural credit, and that the bank sends an agricultural credit man down the river to help plan the use of loan money and follow it up. The economy of the area depends mostly on hog raising, and to a lesser extent on rice, corn, and bean production. There is a barge that plies the river hauling logs and rice upstream to Muelle, and there is a launch that comes up as far as Tres Amigos every week to ten days buying bananas. Except for the bananas the area sends its produce upstream to Muelle or Arenal for shipment to market by truck from there. River transport is either by dugout, or by the barge. 
Generally the houses had about the following arrangement of rooms: a kitchen (always part of the house and never detached as in some parts of Central America), often with one side open, a room for sleeping (this usually had a wooden floor), and a sort of half open-air living-dining combination in which there would be a couple of three- or four-legged stools, a backless bench and a table. The beds were usually raised platforms of boards about 18 inches off the floor, sometimes without any sort of padding. Some also have hammocks. No house had any paint, and there were not many pictures on the walls except where one was part of the wall-covering. Iight was provided by candles or small oil lamps made from jars with a wick inserted. A couple of houses had gas or kerosene lanterns but I did not see them in use.

other operators. -As already noted, the officials of several of the census bureaus felt it was better or more practical not to try to classify separately some forms of tenure. This was true of squatters in Guatemala and El Salvador, 1 and to some extent in Honduras. There were also many mixed forms of tenure which could not be grouped in any of the standard classes. All of these help to make the category of "other forms" of tenure almost impossible to interpret. Whatever forms of tenure are represented, including the separately reported usufructuarios in Nicaragua, they are likely to be quite provisional. probably many of them are explotaciones operated by squatters. Many others

${ }^{1} A$ census official in El Salvador responded to my question about the possible separate enumeration of squatters with the comment, "We would have to carry guns!" They felt that a sensible decision was to count only the basic types of owners, renters, and colonos, without even breaking down renters into different forms of payment or arrangement of responsibility. 
are laborers who have the tenuous use of a plot of land in addition to their employment.

Due to the uncertainty of the real nature of these "others," there is little point in elaborating their number. The vast majority of these unidentifiable producers are the holders of multiple parcels under different tenure arrangements; and this is true for those in all different size groupings, with the single evident exception of the 1-to-9manzana sizes in Guatemala, where about 45 per cent of the explotaciones are "other" single tenure holders. In all likelihood the latter are squatters. Undoubtedly many are also "fire agriculturists" whose continual shifting from one plot to another represents a sort of temporary squatting. (See Ulrich, 1966:364, for a concise description of this landholding pattern around San Luis, El Petén, Guatemala.) One point may be made in conclusion, which applies in greater or lesser degree to all operators except owners. The tenants and squatters generally are not merely less secure in their rights to the land and to the return they gain for their labor; usually they also must use land so poor that it is of no direct interest to the owner, or public land in such isolated locations as to be of relatively little value. The point which was made in the preceding chapter bears repeating here: 
In general the best land, apart from that occupied by the fruit companies, is not intensively cultivated, while the hillsides are. The landowners have typically sold, leased, or tolerated the unauthorized occupancy of their poorest land by the small farmers who produce the major part of the crops grown in the country, and reserved the better tracts for their own use or even dis-use (Checchi, 1959:53).

So the disadvantages common to the nonowners are several: insecurity of tenure, relatively high cost of obtaining land, inability to be reimbursed for permanent improvements if they have to move, and the relatively poor quality of land they are able to obtain.

Evolution and Development of the Labor System

The continual problem in Central American agrarian society has been that of how to satisfy simultaneously the land hunger of the common rural people and the labor demands of the owners of the great plantations and haciendas. So far, all things not being equal, the evident conflict of interest has been resolved more in favor of the estate owners than of the average working people.

Szavery. The first attempted solution of the labor shortage was slavery. Prior to their conquest, the Indians of Central America were nearly all free persons. If they were agriculturists like the Mayas, they labored relatively independently in the fields. Their chief obligation was to pay high tributes of produce. Slaveholding was practiced only by the higher classes, and the slaves were often of 
other tribes, captured for that purpose. With the arrival of the spaniards, whose law allowed the enslavement of Indians who refused to acknowledge the crown peacefully and to obey its officers, the holding of slaves became a convenient device for the conquerors. Many Central American Indians were enslaved to work in the fields and mines and in the building of the towns. Much of this was ended by royal decree about 1550, over the vociferous protests of the colonists. (See Simpson, 1940, for much material about Guatemala in 1548-1553.)

Some slavery continued in the region throughout the colonial era, however, including the use of Negro slaves from the Caribbean, and some Indian slaves. Official abolition came in 1824 as one of the first acts of the independent congress, but by that time slaves provided an almost inconsequential segment of the labor force, due to the success of other systems of labor relations.

The encomienda de Indias.-Virtually as soon as the Spaniards got control in areas already settled by Indians there arose the question of the relationship between the European and indigenous peoples. It was not primarily an academic or philosophical matter (in spite of all the devout and rhetorical arguments which ensued at court and in the farflung audiencias of the empire), but one of survival. So 
long as there were Indians, the spaniard had neither desire nor willingness to labor either in the production of food or in the mining of precious metals. As indicated above, slavery was the first way of forcing the Indians to work for the benefit of the conquerors, but long before slavery was virtually abolished by the New Laws of 1542 the substitution of the encomienda made it unnecessary.

At first the encomienda was to be a perpetual trusteeship over a community of Indians granted to one of the conquerors, who, in return for teaching them the Christian faith and its civilization and protecting them from the avarice of others, was entitled to tribute (in effect, taxes) and personal service from them.' In Guatemala, Indians were first granted in encomienda in accord with a royal instruction dated March 14, 1531 (quoted in Fuentes y Guzman, 1932, I:112-1i5). As Simpson (1966:xiii) expresses it:

${ }^{1}$ Some authors have referred to the encomienda as a land grant as well as a trusteeship of Indians. Zavala (1943:80-83) has attempted to rectify this error:

Property in the soil was not conveyed by the granting of an encomienda. Within the boundaries of a single encomienda could be found land held individually by the Indians; land held collectively by the villages; Crown lands; lands acquired by the encomendero through a grant distinct from his title as encomendero . . . and lastly lands granted to spaniards other than the encomendero.

Moreover, in his study of Guatemala specifically, he cites the case of the encomienda of Bernal Diaz del Castillo, the famed historian, to prove his point $(1967: 74-77)$. See also Cerwin (1963:213-217). 
In reality the encomienda, at least in the first fifty years of its existence, was looked upon by its beneficiaries as a subterfuge for slavery, and it was only after half a century of furious agitation on the part of Las Casas and the reformers, and the active interest of the Crown in suppressing it, that it was shorn of its most profitable and harmful feature, the privilege of using the services of the Indians, and was reduced to some semblance of a social system.

Under the encomienda system the Indians of particular towns were assigned to particular spaniards, sometimes several towns to one man, sometimes a number of men were to divide the tribute paid by the natives of a single community. At times the services were so onerous that the Indians were unable to work their own fields and starvation ensued. In response to the complaints of the mendicant clergy, of Fray Bartolomé de las Casas in particular, and to the New Laws and their sequel, the cédula of February 23, 1549, the Audiencia de los Confines abolished the right to personal services in Central America and somewhat restricted the tributes (Zavala, 1943:85). The modified encomienda continued as a kind of pension system. Frequently, until as late as 1721, it was violated by the continued use of Indian services in the traditional manner (Bancroft, 1886, I:264). In much of Central America the encomienda never attained the importance it had in Guatemala. Bancroft (1886, II:434) reports that in 1555 there were 27 Indian towns in Nicaragua held in encomienda. The largest, Nicoya (now in Costa Rica), had 500 families, and all the others less than 100. Many had fewer than 20 families. In 
Costa Rica when encomiendas were established in 1569 there were fewer than 4,000 Indians in the area around Turrialba, one of the more popular areas (Morrison and León, 1951:189). The repartimiento or mandamiento system. - When the encomenderos lost their legal power to force the Indians to perform the necessary labor on their estates a new device was required. In 1552 the Audiencia in Guatemala received royal instructions to send out oidores (judges or inspectors) to see that the Indians were not idle, and to make them work "for their own good" (Marroquín, 1965:12). This quickly evolved into a distinctly Central American institution: the juez de milpa, or judge (inspector) of cornfields. His duty was to tour the towns and villages designating Indians to do the planting of certain crops for the spaniards. The legality of the repartimiento or assignment ("drafting" would be a more appropriate word) of Indians to planters varied through the first century of the colony, but in 1616 a royal cédula clearly validated it, and the system continued well into the independent.era in Central America. In Guatemala repartimientos were not finally abolished until 1894, though they had been suspended from 1837 to 1876 (Whetten, 1961:118). Barrios, the "Liberal" Guatemalan strongman, specifically reestablished the system in 1877 (Burgess, 1946:155). 
In colonial times the system functioned under the Audiencia. A planter presented his request for workers, and the judges studied the lists for the appropriate community and decreed a standing order that a given number of hands be provided for him. Supposedly no more than one-fourth of the eligible males should be taken from a community. (See Simpson, 1938:Chapter VI, for a full treatment of the mandamiento in agriculture in Guatemala.) As for the selection of the particular workers who were to serve at a given time, Thomas Gage (1946:231-232) reports the observations he made in the early seventeenth century:

The Indians of the several towns are to have in a readiness so many labourers as the court of Guatemala hath appointed to be weekly taken out of such a town, who are conducted by an Indian officer to the town of general meeting; and when they come thither with their tools, their spades, shovels, bills, or axes, with their provision of victuals for a week. . . and with beds on their backs (which is only a coarse woollen mantle to wrap about them when they lie on the bare ground) then are they shut up in the town-house, some with blows, some with spurnings, some with boxes on the ear, if presently they go notin.

Now all being gathered together, and the house filled with them, the juez repartidor, or officer, calls by the order of the list such and such a spaniard, and also calls out of the house so many Indians as by the court are commanded to be given him (some are allowed three, some four, some ten, some fifteen, some twenty, according to their employments) and delivereth unto the spaniard his Indians, and so to all the rest, till they be all served; who when they receive their Indians, take from them a tool, or their mantles, to secure them that they run not away.

Debt servitude or peonage.-During the eighteenth century, the effectiveness of the mandamiento waned as the 
larger landowners entered into competition with one another for the available labor. Two factors induced change. On the one hand, the landowners had found various means of encroaching on the lands of the native communities so that in some areas, especially in Guatemala, the Indians had to seek work on plantations in order to live. On the other hand, the hacendados were anxious to secure a permanent, cheap labor supply. As a result, many owners offered the Indians the opportunity to settle on their plantations, requiring them to work there for their keep (McBride, 1923: 58; Weeks, 1947b:160). In such cases, the landowners kept records of the value of the land and other perquisites received by the Indians, and credited them for the value of their labor. Under this system, the Indians always proved to be indebted to the planter. Moreover, under laws in force well into the twentieth century, the debt was hereditary and the poor serf could not leave his master until the debt was removed.

As recently as 1929, some peons were in a rather hopeless predicament. Thus a letter dated in that year from Guatemala reported:

I know of one poor fellow who was sent to the army and stationed in the lowlands near Ayutla. There he was taken sick and spent some weeks in the army hospital. The government passed the bill for his care back to the finquero, and the latter added it to the peon's debt. So the poor chap got home to find he owed 3000 pesos (\$50 gold) more than when he left; and he had an old contract, by which he was making only ten cents a day (quoted in Chapman, 1937:251, note 3 ). 
Guatemala's vagrancy law. - In most countries peonage just faded into either the "free" labor system or colonato, but in Guatemala General Ubico introduced a "liberal" reform in 1934. He decreed that all peonage debts would expire in 1936, and the property holders would have two years to try to collect. But to help ensure a steady work force, labor was declared to be a social obligation for every ablebodied adult male. Those who did not work could be arrested and forced to do so. The practice of a regular trade or profession, or the cultivation of 4 manzanas of land was sufficient to fulfill this obligation. The unskilled and landless had to work a minimum of 150 days a year. Each person had to carry his record book in which each employer noted the days worked. The law put the worker in the position of having to go out and look for work, thus relieving the finquero of the need to recruit his hands. This law continued in effect until the revolution of 1944 resulted in its revocation (Whetten, 1961:120-122).

Farm Laborers Today

The farm laborers are covered even less adequately in the statistical sources for Central America than are the farm operators. In fact to determine their approximate number it was necessary to estimate by simply subtracting the farm operators from all farm households. The results of 
this operation were presented in Table 11, and show 59 per cent of the agricultural households to be headed by farm laborers. That is to say that about 770,000 families are supported by people who work under the direction and supervision of some operator or his representative, without themselves exercising any of the managerial powers. ${ }^{1}$ In economic terms such people receive relatively low incomes since they do not have any return from land or management, and gain only the share attributed to their lavishly-used unskilled labor. In addition they suffer from the debilitating effect of lack of decision-making experience which handicaps them in any hope to rise to independence via the "agricultural ladder." Their ability to take a meaningful part in family and community decisions is also reduced by this lack of managerial experience and their subservient status. Such a status also fosters a timidity with respect to all new ideas.

${ }^{1}$ Marroquín (1965:27) estimates that for Central American rural areas as a whole there are three social classes: a "dominant" class composed of large landholders and corporations with 5 per cent of the people; a middle class of moderate and small scale farmers, minifundistas and sharecroppers, and a few commercial people totaling 15 per cent of the population; and a lower class (clase baja) composed of peones, jornaleros, colonos, and artesans (the latter only 2 per cent) comprising 80 per cent of the rural population. His estimate of the laboring group is vastly greater than mine, and he does not cite any sources or methods from which one might explain the difference. Since he is a native Salvadoran, I respect his familiarity with the situation but am unable to accept his figures. 
The low social status and the poor self-esteem of the agricultural laborer has been frequently mentioned. Something less obvious but equally real is the tenacity with which the holder of even a small parcel of land clings to his status as a landholder rather than laborer. Marroquín (1965:27) has well described the reaction of the landholder to loss of his land:

The life of a campesino who has lost his land is a life full of frustrations and nostalgia; his only idea is to again possess a piece of land of his own, and as time passes and deprivation increases this ideal, practically unattainable, . . becomes a destructive obsession. The campesino without land has to work as a peon to subsist, but he doesn't feel like a peon; he lacks the ties that would create solidarity with his fellow workers; he continues to think and feel like a proprietor, and any law or state regulation which tends to improve the conditions of life of the farm worker is immediately hated and opposed by him, at times with greater vehemence than by the true proprietors.

This desire to be a landholder rather than a laborer is what makes the census data so difficult to use, for those who have possession of even very small tracts refuse to think of themselves as mere laborers, though objectively most of them are. Even though the censuses include the many minifundistas as producers or operators, I consider them as laborers.

Peons and jornaleros-wageworkers. - It is hard to determine the proportion of genuine wageworkers among contemporary agricultural laborers. There are no reliable 
statistics, and with the seasonality of agricultural enterprises surveys give varying results depending upon the timing. Two of the most useful surveys on a region-by-region basis are those of Adams (1957) and Dozier (1958), in which the authors personally traveled throughout Central America and reported many of their observations separately for each place visited. But neither was able to give statistical information-only generalizations such as Dozier's (1958:121-122) comment on a finca at Ahuachapán, El Salvador:

There are up to 2,000 workers during the season, - . [and] there are several hundred "colonos" living on the plantation. Living conditions are poor, with the diet of tortillas, beans and rice provided by the plantation. Wages are normal for coffee workers in Salvador: $50-65$ centavos per day (with food), the lowest in Central America.

He goes on to say that with its sugar mill by-product of molasses the owner distills his own rum, and "this is another way of exploiting the native: the plantation owner, through the manufacture and sale of the alcoholic beverage so widely consumed, regains a portion of the low wages paid his laborers."

The figures cited above represent two different sorts of data. The 2,000 workers probably represent the total number of wageworkers since all will be on the payroll. The colonos, on the other hand, represent families several of whose members may work with the family head on the plantation without being counted separately. The colono himself gets 
paid for work done by the whole family. Thus the number of colonos reported often understates the labor force they actually represent.

Various reports give different impressions of the balance between full-time and temporary workers. The Ahuachapán finca mentioned above had a vast predominance of temporary workers. On the other hand, in a study by Hoyt (1955:34) in the 1946-1947 season, 50 coffee fincas in Guatemala had 12,000 permanent workers, largely colonos, and 16,000 temporary or seasonal workers, so that the predominance of temporary employees was not so overwhelming. I was told by the administrator of the Hacienda La Carrera in Usulután, El Salvador, that the hacienda had 800 permanent workers, and as many as 5,000 at the peak of the cotton harvest. Other Salvadoran data show that on 21 sugarcane plantations in about 1962 there were 5,524 permanent workers and 7,171 temporary workers (EI Salvador, MAG, 1963:35). The figures indicate the variability that exists, and demonstrate the unreliability of even an "educated guess" as to the number of paid wageworkers. Most of the laborers reported above may be wage hands, because of the crops on which they are employed, but the same man may be a permanent worker on one place and a temporary one on another.

On most of the larger operations the typical organizational pattern is about as follows. On the top echelon of 
the staff is the administrator. Except in rare instances, where the owner is unusually active in the management of the farm, the administrator is the operator, or the basic decision-maker in the agricultural enterprise. Below him are the field bosses (often referred to as mayordomos) who exercise supervision of particular sections of the farm, or of different kinds of operations when there are several activities going on simultaneously. Under the field bosses are the actual work gangs of ordinary laborers, each headed by one of their own number, a caporal or "straw boss," who is expected to see that the rest keep the work going in proper order. In addition there are nonagricultural workers who have other responsibilities. Generally there is a timekeeper who keeps the records for the payroll. Sometimes in the peak seasons there will be cooks to prepare food for the workers. There are workers engaged in processing the crop: in the beneficio to prepare the coffee berries, in the trapiche or ingenio to grind and process the sugarcane, oxcart and truck drivers to transport the products, and so forth.

Wage hands may be full-time, year-round workers on a particular farm, living either on the place in the owner's housing, or in their own homes off the place. But many are only seasonal workers. These may continue to live at home if close by, or may live in housing provided by the farm operator. 
The banana, oil-palm, and other plantations of the foreign fruit companies almost always use wage hands who live in company facilities. Most of these laborers are unionized and are paid the highest farm wages in the respective countries. Furthermore, they are more likely than the others to be protected by the national labor codes. The United Fruit Company $(1966: 16)$ reported 43,000 employees in all its tropical divisions in 1963, the vast majority of whom are common agricultural laborers. I estimate that at least 25,000 of these jornaleros are on the United Fruit Company's plantations in Guatemala, Honduras, and Costa Rica. To the extent that "workers" are identified in the agricultural censuses, the latest information for El Salvador and Costa Rica, by size of explotación, is presented in Table 15. The notable variation in the use of farmhands between the two countries reflects a difference in the labor supply rather than any basic difference in farm enterprises. In Costa Rica land is relatively plentiful and few heads of agricultural households are satisfied with the status of a laborer. In contrast, in El Salvador there are many landless and nearly landless men who willingly accept such security as that offered to the year-round laborer. If data were available, Guatemala would be more on the Salvadoran pattern, while Honduras and Nicaragua would be found to approach the Costa Rican mold with regard to the use of farmhands. 
Table 15. Number of permanent agricultural workers per explotación, by size of explotación: El Salvador, 1961, and Costa Rica, 1963

\begin{tabular}{|c|c|c|}
\hline \multirow{2}{*}{$\begin{array}{l}\text { Size of } \\
\text { Explotación } \\
\text { (Hectares }\end{array}$} & \multicolumn{2}{|c|}{ Permanent Workers per Explotacióna } \\
\hline & El Salvador & Costa Rica \\
\hline $1-2.9$ & 1.8 & 1.3 \\
\hline $3-4.9$ & 2.1 & 1.4 \\
\hline $5-9.9$ & 2.8 & 1.6 \\
\hline $10-19.9$ & 3.0 & 1.8 \\
\hline $20-49.9$ & 3.0 & 2.0 \\
\hline $50-99.9$ & 5.2 & 2.7 \\
\hline $100-199.9$ & 9.8 & 3.1 \\
\hline $200-499.9$ & 15.4 & 8.3 \\
\hline $500-999.9$ & 34.9 & 18.0 \\
\hline $1,000-2,499.9$ & 77.7 & 26.2 \\
\hline 2,500 and over & 89.4 & 50.3 \\
\hline Total & 2.4 & 2.2 \\
\hline
\end{tabular}

SOURCE: Compiled and computed from El Salvador, DGEC, 1967:Cuadro 63; and Costa Rica, DGEC, 1965 :Cuadro 225.

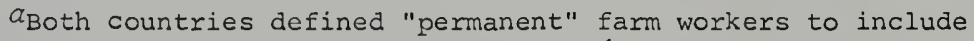
all those who were occupied on the explotación for a minimum of six months during the agricultural year, including the producer himself, and members of the producer's family, whether paid or unpaid. Costa Rica counted all unrelated workers as well, while El Salvador excluded any unpaid persons who were not related to the producer. 
Migratory workers. - In the entire region there is a great seasonal movement of agricultural laborers who participate in the harvest of the major crops of coffee, cotton, and sugarcane. Adams (1967:130) says that migrant workers in Guatemala alone number 300,000. No good estimates were found for the other four countries.

In Guatemala a distinction is made among the migrant workers based on the system of recruitment. Those who betake themselves to the plantations to hire out on an individual basis are commonly called voluntarios. These men (sometimes accompanied by their families) go from farm to farm, striking the best bargain they can for as long as they wish, and receive a somewhat higher wage than those called cuadrizleros (Schmidt, 1967:27). The latter are workers who are recruited by an agent (habilitador) who goes to their home communities, gets them to sign contracts, advances them smail sums of money for expenses, and furnishes them transportation to the farms where they are to work. The agent is paid by the owner, and the cuadrilleros work together in work gangs from their own locality under a boss from their own group. Schmidt (1967:48-49) found that the voluntarios tended to be more literate and to have more potential for independent operatorship than the others. This is hardy surprising, since it takes more determination for an Indian 
to strike out alone into a world where he will be an alien, and be forced to live and work in close quarters with people of many different backgrounds.

Most of the migrant workers in Guatemala have tiny plots of their own in the highlands, i.e., they are minifundistas who are forced to hire out in order to augment their meager incomes. Some are tenants of the finquero, renting land he owns in the highlands. In such cases the large landowner has almost surely purchased his highland holding simply in order to facilitate the recruitment of labor. Ordinarily he will not rent enough land to anyone to make it unnecessary for his tenant to hire out.

The migrant workers in Guatemala almost always are paid partly in cash and partly with a ration of corn, beans, salt, lime (for soaking their corn), and perhaps coffee. On one finca I watched the weekly distribution of the rations after the payline was finished. At that time each worker received 14 pounds of dried corn, five pounds of beans, and a cup of salt.

The future of these migrant workers is uncertain. On cotton farms, at least, the threat of enforced minimum wages and social benefits appeared to Parsons (1967:23-24) to foreshadow a shift to mechanical picking. That would probably be a disaster for many Guatemalan and Salvadoran minifundistas 
who have no alternative ways of supplementing the living they wrest from their tiny tracts.

Colonos.-The colonos and sharecroppers make up the principal permanent farm labor force in Guatemala, El Salvador, Honduras, and probably Nicaragua. In Guatemala and $E I^{\prime}$ Salvador, at least, the colonos probably outnumber even the share workers.

"The colono is essentially a farm laborer who is paid in the temporary or traditional usufruct of a parcel of land which is the property of his employer." This statement by Schulman (1955:34) in his article on "The Colono system in Latin America" needs to be supplemented by the fact that generally the colono also receives a cash wage (or credit) which is considerably less than that of the independent laborer. Schmidt (1967:34) found that in Guatemala a significant number of migratory workers would prefer to be colonos, for generally there is relative security in the latters' position. As compared with the migratory workers, the colonos are more likely to live in separate dwellings (instead of barracks), to have higher levels of living, and to be able to read and write. Legally the patronos are required to provide schools and medical services if they employ a certain number of workers. However, this provision of the labor code is honored only half-heartedly by many owners, if indeed they try at all. 
The numbers of colonos enumerated in the various censuses are considerably fewer than the actual numbers of such workers. The Guatemalan census reported 48,604 for 1964, that of El Salvador counted 55,769 in 1961, and that of Honduras 6,423 in 1952. Under the designation of "usufructuarios" and "gratuito," respectively, the 1963 censuses of Nicaragua and Costa Rica reported 7,543 and 1,243. These figures total approximately 120,000 families out of the 770,000 laborer households previously estimated. It should be stressed, however, that the figure is an understatement since it is clear that many colonos also pass as renters in census records. Stouse (1965:46) describes the practice of establishing workers in the colono pattern on the large cattle ranches on both coasts of Costa Rica, where a total of only about 300 gratuito workers were reported by the census.

As Schulman (1955:34) pointed out, the colono is found throughout Latin America, almost anywhere the "plantation economy" (as he called it) prevails. Its roots go all the way back to pre-Christian Rome as part of the latifundia-coloni complex that was transplanted to spain and thence to the New World.

Under this system, the colono has a certain security of a place to live and grow some food, but to keep it he is obliged to bow to the wishes of the patrón far more than the wageworker. The master, practically speaking, has both the 
civil and police power over his own property, and his own rules as well. In many cases he has his own jail. In 1827 the Englishman Henry Dunn (1828:292-294) described the system as it appeared on a cattle estate in Guatemala:

This estate contained about two hundred of these poor creatures, who at different times had obtained from the proprietor, permission to build their thatched huts upon the ground, and to cultivate the portion he allots to them. For this permission, they agree to pay to him annually a certain portion of maize, to render occasional gratuitous services, and to supply eggs or fowls when wanted. . . When the proprietor visits his estate, he sends for the alcalde and his officers, who almost kiss his feet, by the humility of their obeisance. He then states the number of fowls, eggs, \&. . he wishes to have that day, and the number of men he requires to assist him, and the alcalde's only business is to find them. . . Under such circumstances it is evident, that the comfort of the Indian, depends not so much upon any justice he can obtain when oppressed, as upon the mildness and humanity of his master.

The changes have not been very extensive since then.

Sharehands or sharecroppers.-Many workers are sharehands, generally denoted as aparceros, and they are classified by the censuses as renters. The true sharerenter who pays a portion of the crop for the use of land provides all or nearly all of the managerial input and his own work stock as well as the labor. As a result he should receive a major share of the crop. In contrast, the typical shareworker gets one half of the crop and works under the directives, and often the supervision of the landowner.

In the course of my field study I found that sharecropping was common around Esteli, Nicaragua. Analysis of 
the census data shows that this department had the largest proportion of land operated on shares in the nation, but it was only 1 per cent of the area in explotaciones (Nicaragua, DGEC, $1966:$ Tabla 2). In numbers of explotaciones classified as aparceria, the department of Matagalpa had 734, or about 25 per cent of the 2,906 such places reported (Tabla 3). The practice in Esteli was for the landowner to provide the land, a house, work oxen, and seed. The laborer simply did the work, and the ensuing crop was split half-and-half. No written contracts were used-and the workers said they preferred it that way since they distrusted contracts. The half-hand on this pattern is usually called just that: mediero or medianero. The mediero's "traditional" crops are corn and beans, but his share of the harvest is typically too little to live on and he and his fellows also work for cash wages in the sugarcane zafra (harvest). In other words the finquero keeps a hungry labor force handy for his needs by letting out just enough land to keep the families nearby but not enough to let them be independent with that income. He is as much interested in their labor in the zafra as he is in the corn and beans he gets in "rent." To confirm personally that these sharecroppers were really laborers, I talked to the owner of a 50-manzana farm in the same area. He told me he had "medieros who worked much of the land for him" on a 50-50 basis. He referred to 
them as "trabajadores permanentes" when I asked whether he had any permanent or seasonal laborers (interview with Elisandro Orozco near Estelí, July 17, 1963).

Goncalves de Souza (1960:33) stated that sharecropping is the most common form of "tenancy" in Costa Rica, but neither the census nor my own explorations confirm this. On the other hand I do not believe it is as rare as the census reports (438 cases of specie rental, some of which are probably genuine rentals).

Minifundistas. - In estimating the number of families headed by farm operators, drastic measures were taken to eliminate many of the smaller explotaciones. This was because the plots controlled by these families are so small that their members must work elsewhere as well simply to subsist. Specifically, not including the colono units already mentioned, there were 137,201 explotaciones under I manzana or hectare in extent which were removed from the operator class at the start. In addition, one-half of the places of 1 to 4 manzanas and one-third of those 5 to 9 manzanas (together totaling 221,635 explotaciones) were disqualified from consideration as operators. All of these nearly 360,000 tiny or small parcels I have transferred to the category of places worked by farm laborers with the assumption that each represents one household. Some of them are undoubtedly colonos. Others are sharehands. Some may 
be peons who simply receive a house lot on which they have managed to plant a few plants for home use. Most spend a great share of their time either as steady workers on neighboring places, or as migrant workers in the coffee, cotton, cane, or banana harvests. Stouse (1965:43-44) described this system well as he wrote of the Quepos-Parrita region of Costa Rica:

Medium sized land owners often proliferate the Garden plot type by giving recent in-migrants house lots along roads where these cross their properties. The family so established is known as an arrimado. Sometimes a conveniently located parcel of a large or medium sized property will be subdivided and sold in very small pieces to incoming migrants or others. - . This is probably done by the larger landowners to ensure a nearby supplementary labor supply.

\section{Trends in Land Tenure}

It is impossible to give any long-term quantitative picture of changes in land tenure in Central America. The reason is that until very recently there have been almost no solid data on which to base conclusions. The base line for such information is the 1950 agricultural census, taken by every country except Nicaragua, and the 1963 census in that republic. There is no lack of fine-sounding statements, and even quoted figures about land tenure in the past. Thomas Meagher (1939:703) wrote glowingly of Costa Rica in 1858 :

To me the most satisfactory of the agricultural statistics of the country is the capital fact that 
two-thirds of the population is composed of landowners. Almost every man has his finca, his mules, his chickens, his hogs and his plantation of sugar or coffee. The same persons whom we have seen barefooted and with ragged clothes winding through the forest beyond Barranca, carting the coffee to the port were proprietors at the same time as they were cart drivers.

One can take that two ways. Literally it gives a figure about a high level of ownership. But the fact of these men being cart drivers may mean this was their necessary offfarm employment. In sharp contrast is the statement about Guatemala by Chester Jones (1940:176) that "all but a very small proportion of the people are landless. A review as of December 31, 1926, showed that among a population of some $2,000,000$ only 146,379 , or 7.3 per cent, had property." of course there are various ways to interpret the figures. If a family's property is normally held by one person, and if a family averaged 5 persons, the figure could reasonably be said to represent about 36 per cent of all famizies. But the figure also includes urban real estate. It therefore seems that either things have dramatically improved, or his figures from the ministry of agriculture were faulty. To me it was obviously the latter; much property was simply not registered. Many other optimistic and pessimistic statements about land tenure in past times could be cited, but they would be equally poor as a basis for establishing trends. Over the long run, probably these generalizations are about all that it is safe to make. First, as the population 
has grown, many family holdings have been subdivided until the individual shares are now only a small fraction of what they once were. The present generation may own land, but less of it per capita in many cases. This is particularly true of the Indians in Guatemala, and of the majority of the people in El Salvador. Second, as the population has grown settlement has continued apace into new areas and created new landholdings, making owners of some formerly landless people, and adding to the holdings of many who already were owners (see the various studies by Sandner in Costa Rica). Finally, as coffee and other popular export crops have boomed, many landholders have borrowed cash for planting the crop only to face loss of their land by foreclosure on high-interest loans they could not repay. These have joined the laboring groups. But no one knows the numbers or proportions of the above for the region, for individual nations, or for regions within the separate countries.

Recently, however, four of the countries have taken a second agricultural census, and for three of them data can be compared over 11- to 14-year intervals. Table 16 has been prepared to present the data in a concise manner. Utilizing estimates of the number of genuine farm operators in 1950 made in the same manner as was done for the 1960's (see Table 10), and dividing these figures into the total number of persons engaged in agricultural pursuits in that same 
Table 16. Numbers of persons employed in agriculture and estimated number of farm operators, and the ratio of farm-employed persons to farm operators at the time of the two most recent censuses: Guatemala, El Salvador and Costa Rica

\begin{tabular}{|c|c|c|c|c|c|c|}
\hline \multirow[b]{2}{*}{ Country } & \multicolumn{2}{|c|}{$\begin{array}{l}\text { Persons Employed } \\
\text { in Agriculturea }\end{array}$} & \multicolumn{2}{|c|}{$\begin{array}{c}\text { Estimated Farm } \\
\text { Operators } b\end{array}$} & \multicolumn{2}{|c|}{$\begin{array}{l}\text { Ratio of Farm- } \\
\text { Employed Persons } \\
\text { to Farm Operators }\end{array}$} \\
\hline & 1950 & 1960 's & 1950 & 1960 's & 1950 & 1960 's \\
\hline Guatemala & 651,802 & 848,660 & 164,592 & 201,035 & 4.0 & 4.2 \\
\hline El Salvador & 403,921 & 480,100 & 64,072 & 72,054 & 6.3 & 6.7 \\
\hline Costa Rica & 147,577 & 186,596 & 32,436 & 52,283 & 4.5 & 3.6 \\
\hline
\end{tabular}

SOURCE: Compiled and computed from Guatemala, DGE, 1954a:Cuadro 5; 1957:Cuadro 44; 1966:Cuadro 11; 1968:Cuadros 5 and 6; El Salvador, DGEC, 1954a:Cuadro 5; 1954b:Cuadro 21; 1965:Cuadro 31; 1967:Cuadro 23; and Costa Rica, DGEC, 1953a:Cuadro 27; 1953b:Cuadro 4; 1965a: Cuadro 8; 1966 : Cuadro 17.

$\alpha_{\text {Farming and stock raising in El Salvador; farming, stock }}$ raising, hunting, fishing, and logging in Guatemala and Costa Rica.

$b_{\text {Estimates made by counting no explotaciones under } 1 \text { manzana }}$ or hectare, one-half of those from 1 to 4 manzanas or hectares, twothirds of those of 5 to 9 manzanas or hectares, and all units of 10 manzanas or hectares and up. 
year, a ratio of the number of agriculturalists per farm operator was obtained. Where the ratio increased, during the inter-censal period, as it did in Guatemala and El Salvador, independent farm operators were becoming a smaller proportion of the farm population, and a higher percentage of the people dependent upon agriculture was being forced into the laborer class. In Costa Rica just the opposite was occurring, confirming the study in Atenas mentioned below (see "The Agricultural Ladder"). There the proportion of operators increased dramatically over the 13-year interval, and the census definitions and procedures did not vary to introduce any doubt in the interpretation. The absolute number of both operators and laborers increased, of course. At this crude level, then, it is apparent that there is no uniformity in what is occurring in this part of the Americas. Costa Rica has a great deal of space and a small population, and opportunity is vastly different from that in crowded El Salvador. Moreover, within the countries the changes vary from one area to another. In the southwestern highlands of Guatemala there is no doubt but that the already small owner-operated properties are continuing to be subdivided by inheritance at an alarming rate and that higher and higher proportions of the agriculturists are becoming farm laborers. On the other hand on the Pacific litoral, and in the zones of Agrarian Development 
being established by the Instituto Nacional de Transformacion Agraria (INTA), new owner-operated holdings are being created. The same is true in El Petén, both under government sponsorship and by individual initiative.

A more detailed analysis of tenure changes for explotaciones of 1 manzana and larger is possible using the information compiled and presented in Tables 17A, 17B, and 17C. The explotaciones between 1 and 9 areal units do not approximate genuine operators as no adjustments have been made to publish figures, but those above that size are largely run by true farm operators. ${ }^{1}$

For Costa Rica one is very safe in saying that ownership is still the tenure of the vast majority of operators, although in all three size classes the percentage of owner-operators declined somewhat with regard to both explotaciones and land area. Only renting failed to show significant increases, while squatting unfortunately surged forward in all three size groupings.

In El Salvador the most significant change was the very obvious subdivision of farms over the ll-year time span. There were fewer farms and also fewer hectares in

${ }^{1}$ Unfortunately, however, the tenure categories for Guatemala are not the same for both censuses and a large margin for variation must be allowed. Of the Central American countries only Costa Rica has maintained a consistent and fairly detailed tenure schema. 


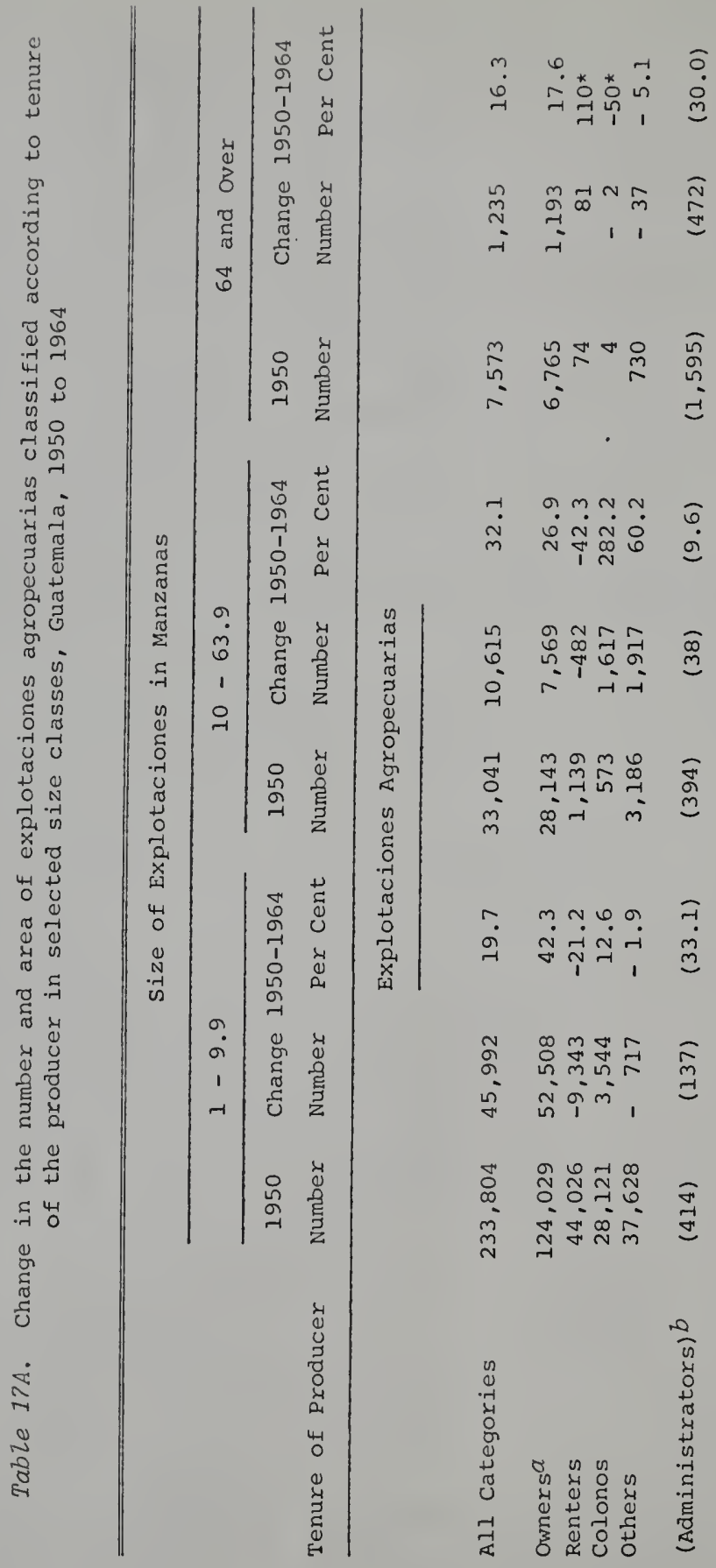




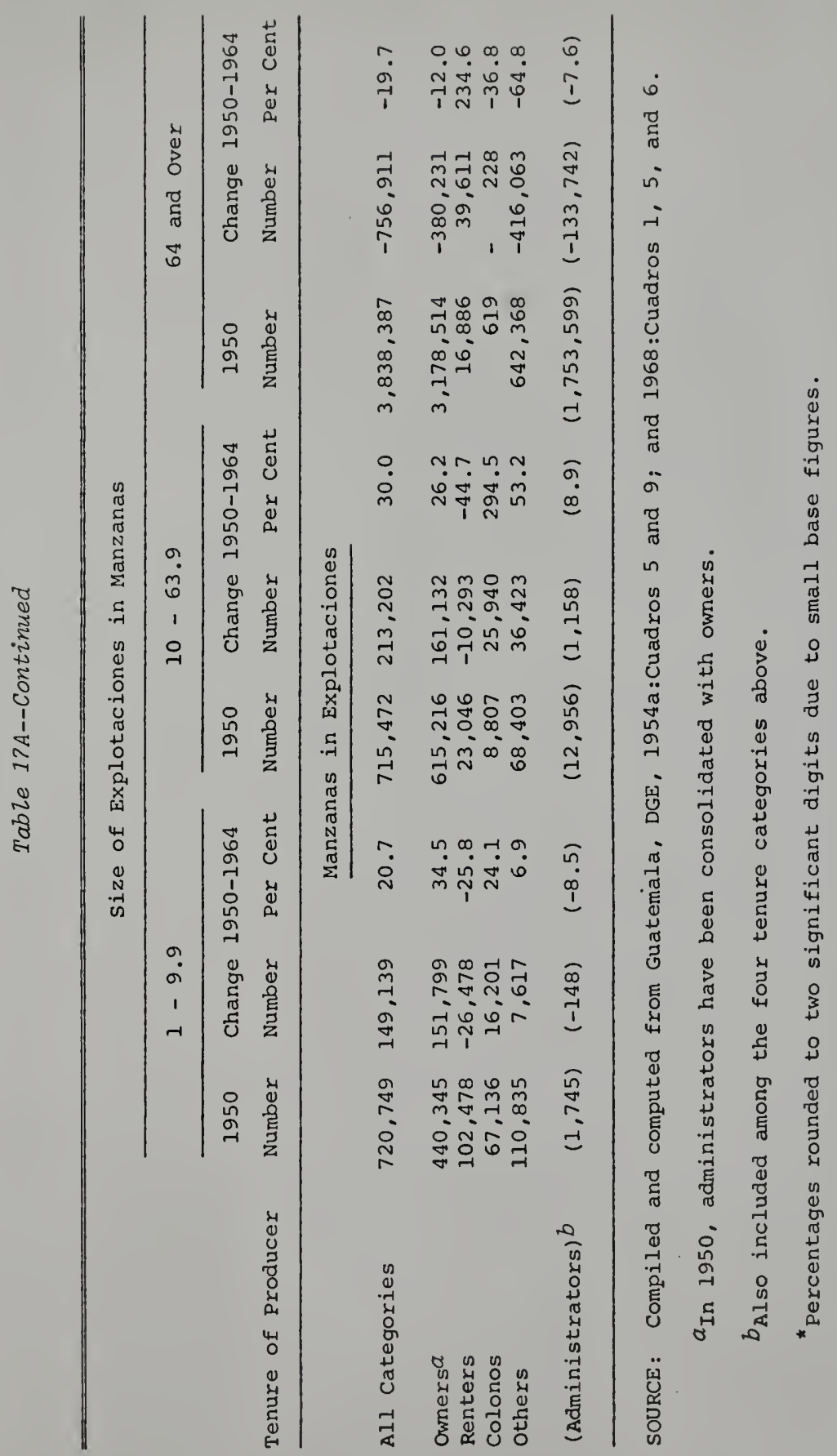




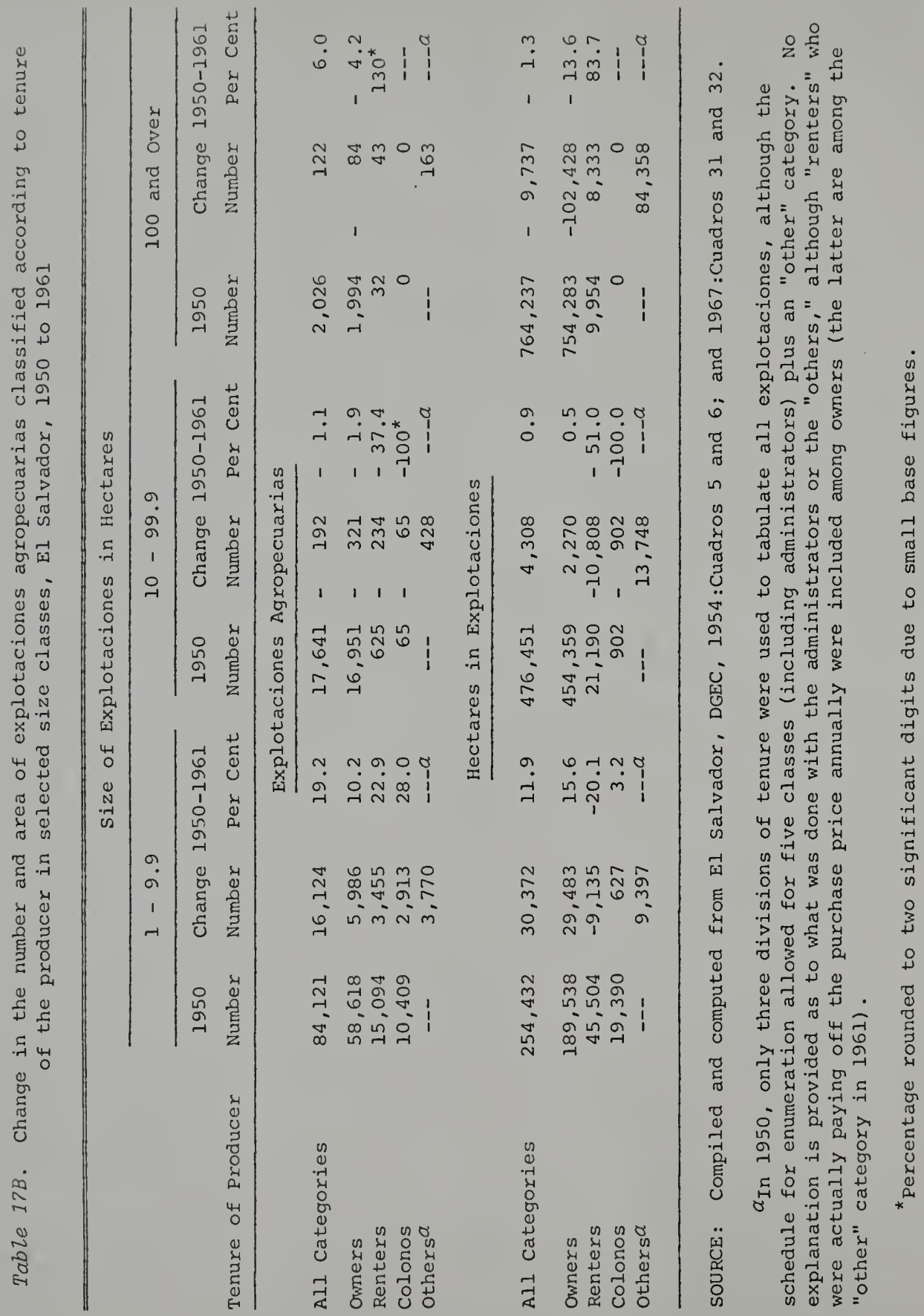




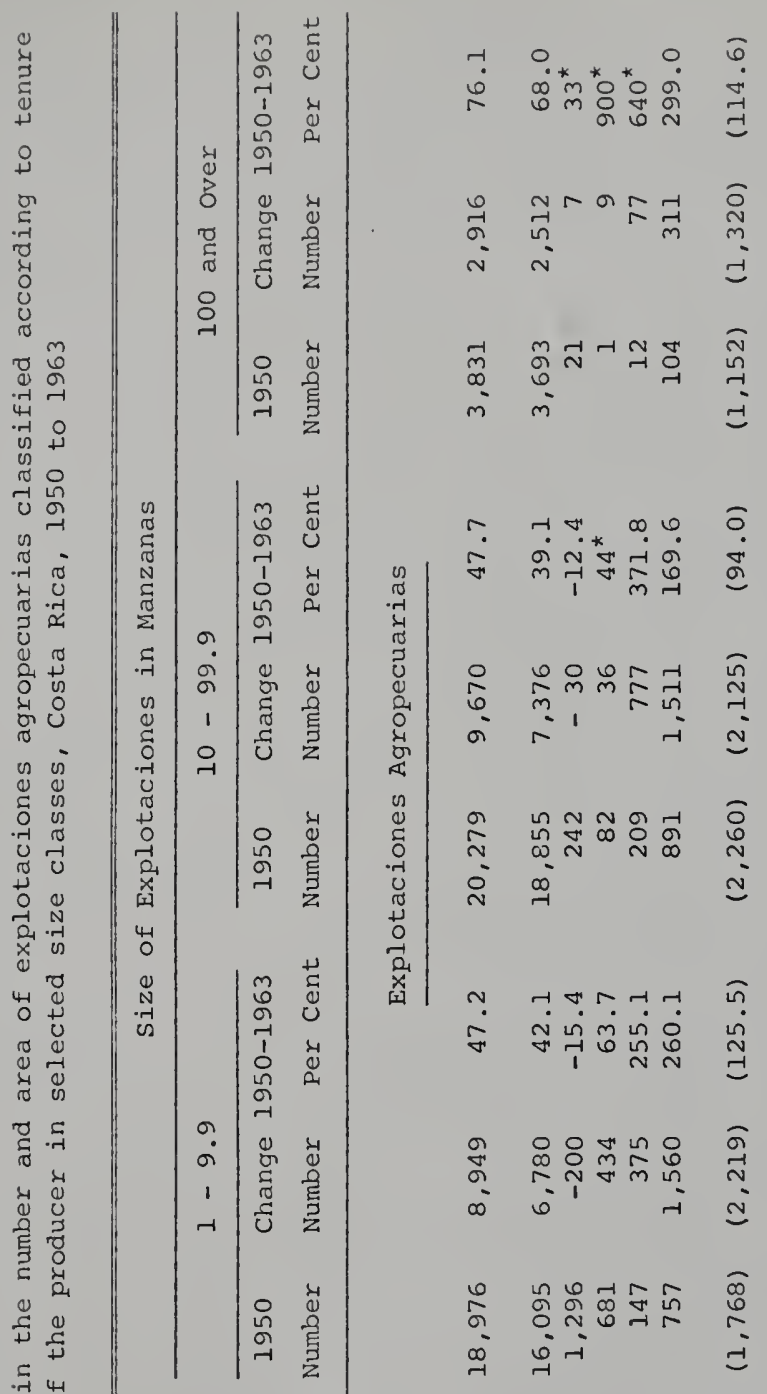

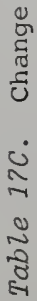

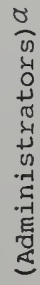




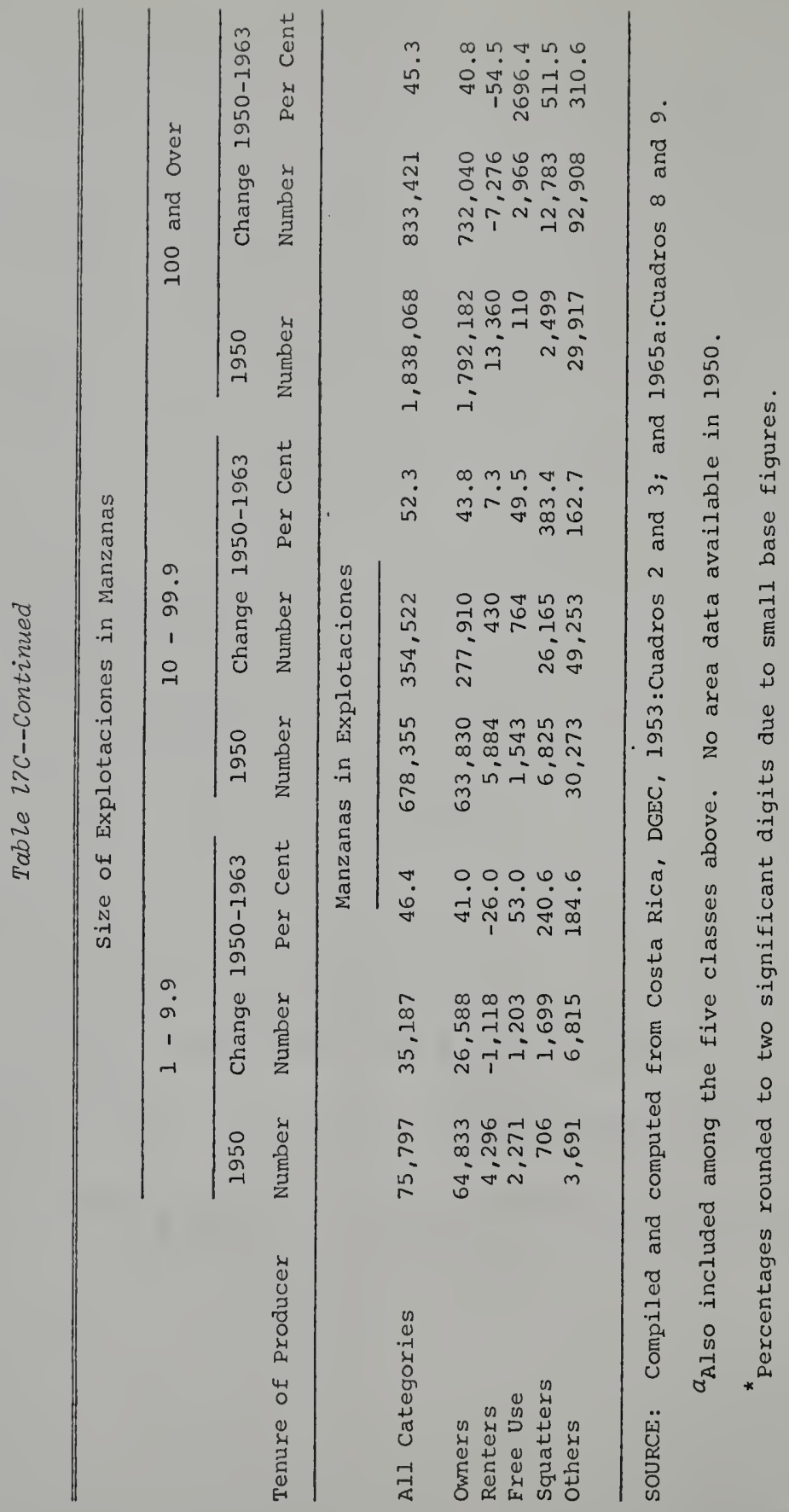


farmland in places of 10 hectares or larger in 1961, compared to the situation at the time of the first census in 1950. There were no really significant tenure changes among explotaciones of these sizes, either. On the other hand, in the grouping under 10 hectares owners gained less than either renters or colonos in number of places, and renters actually controlled less land in 1961 while increasing their numbers by 23 per cent. This suggests that more of the renters in 1961 may have been sharecroppers (not reported as a separate category) although an interview with the Sub-Director of the Census, Luis Raúl Rodríguez, (August 13, 1963) revealed that sharecroppers were supposed to be included in the colono category. The "other" category did not exist in the 1950 reports, while in 1961 it includes producers buying land who do not yet have clear titles (who were grouped with owners in 1950). It also includes undivided inheritances and other miscellaneous types.

There is a special problem with the Guatemalan data. The 1950 classification of operadores employs "administrators" as a basic tenure class without providing information as to how the land the administrators managed was actually held: whether in ownership, ejidal, rented or what. In 1964 the tenure classification schema ignores administrators entirely, although in separate tables the number and area of explotaciones with administrators are given. Therefore it has 
been necessary to assume that the units under the direction of administrators in 1950 were all owner-operated, and to assign them to the owner class in Table 17A. How close this approximates the reality is not known.

The Guatemalan data are interesting since this intercensal period included the only Central American experience of aggressive agrarian reform. ${ }^{1}$ Although they were one of the main objects of the 1952 reform, colonos increased in number during the 14-year interval and apparently came to have larger plots, on the average, since the area they controlled increased more than the number of them. Apparently the finqueros felt reasonably secure in the counterrevolution of Castillo Armas since they allowed the colono system to continue expanding. However, most of the increase in the number of farms of all sizes was accounted for by the increase in ownership, much of which results from the reform since 1954, and also from the continued division of real estate among heirs. Among small-and medium-sized parcels renting in any form declined in importance: This may be due to the increasing tendency for finqueros and hacendados

${ }^{1}$ It must be remembered that the takeover by colonel Carlos Castillo Armas in 1954 turned back much of the agrarian reform, in favor of a much more gradual program, but one designed to given land in ownership, while the Arbenz reform had been restricted largely to granting usufruct to the land distributed. 
on the Pacific coast to use machines to clear land, replacing the slower and less complete method of renting out patches to people from the highlands to clear and plant their milpa (Parsons, 1967:14-17). Renting of larger tracts has increased in response, I assume, to the prospects of such speculative crops as cotton, rice, lemon grass, and others which can be quickly undertaken or dropped in response to the changing market. The owned area in the explotaciones of 64 manzanas or more declined while the number of owned properties increased. ' The change in owned area probably reflects two main factors: the United Fruit Company's return of land to the government and the tendency of reformshy owners to publicly claim less than formerly.

\section{The Agricultural Ladder}

In areas of the world where family-sized farms are commonplace and where being an independent farmer is a satisfying status it is the normal aspiration of agricultural and stock raising people to own their own land.

\footnotetext{
${ }^{2}$ The total area in farms declined between 1950 and 1964, as reported by the two censuses. There was a slight change in the qualification to be included in the census, since in 1950 there was a requirement that at least 1 cuerda ( $1 / 16$ of a manzana) of land be involved, while in 1964 no minimum area was imposed. Thus the definition of an explotación would have increased the area if anything. The census authorities blame it on "inexact declarations" due to fear of tax and land reform obligations, and to "administrative deficiencies" during the enumeration (Guatemala, DGE, 1968:23, 24, 28).
} 
By doing so, the operator is able to reap all the benefits accruing to his investments in land and other capital goods, and also the return from his management and labor. Since few people are able to be landowners when they first begin to support themselves, the concept of the "agricultural ladder" is applied to the process whereby the young man who begins adulthood working as a farm laborer carefully saves toward the time when he can buy equipment of his own and rent land to work on his own initiative. Continuing to save as he can, eventually he may make a down payment on some land and move a large step toward his goal of eventual ownership. The agricultural ladder refers to the process of moving toward ownership without simply depending upon the eventual inheritance of some family property, although that also takes place in many cases.

There is little solid evidence by which to evaluate the working of the agricultural ladder in Central America. In spite of what some may say (Stokes, 1950, for example), except in Costa Rica I found an apparently increasing number and proportion of people throughout the region who were simply unskilled agricultural laborers. I am inclined to attribute much of the difference in Costa Rica to the stronger educational system in that country rather than to factors of population density, race, or the other explanations often offered for the alleged progressiveness of the costarricenses. 
Only one good study of the intergenerational tenure mobility of farm people was found, and this was a study by J. F. Montoya and L. A. Reuss (1960) in the Cantón of Atenas, Costa Rica. The principal findings were that access to land was definitely available and that sons of landless peons as well as those of landowners had found the opportunity to become owners in their own right. Among sons of nonowners 51 per cent had become owners, while 76 per cent of owners' sons were also proprietors. However, there was also the inevitable shrinking of the size of farms as more and more were created in the area. Many of the tracts belonging to sons were inherited, and there was an average of seven heirs for each tract. Nevertheless, among the 31 cases with the necessary detailed information, some 21 had acquired land in addition to that which they inherited. It was apparent that the agricultural ladder had been working in this particular region prior to the 1959 survey. Circumstantial evidence is also found in a Turrialba, Costa Rica, study by Norris (1953a:99-100) where he relates age to tenure status and finds that the owners' average age was 51, owner-laborers averaged 40, and pure laborers, 37. In the same place, however, Sariola (1954: 104-109) found little hope for the landless laborer, though a few rose by increasing the number of family members who worked for wages to gain unusually large incomes (for laborers). 
Perhaps the situation in the entire region is reflected in Goldkind's observation (1961:374-375) on Costa Rica:

The biggest gap in social status in the peasant community is between those who own land, or grew up in landowning families, and those who are removed from landownership by two or more generations. Those who are landless themselves but grew up in families in which their fathers farmed at least some land of their own tend to attempt to work their way up the agricultural ladder by engaging in commercial tenancy, i.e., tenancy operations large enough to assure some cash profit over and above subsistence needs. . . . Persons growing up in families in which their fathers managed their own agricultural enterprises tend to be industrious, responsible, and ambitious with respect to work and land ownership, in sharp contrast to those whose fathers were mere wage earners.

Not so with respect to the remainder of the hamlet community, the landless laborers and subsistence tenants. . These activities no longer can provide the possibility of accumulating sufficient wealth to buy land, as they did several decades ago when land was cheap and fewer people were competing for it. Thus these people tend to place value on what can be of some immediate use in their continuous desperate struggle for the bare necessities.

There are many rural people in Central America for whom the desire to own land is a fondly-held dream, but most of the evidence indicates that the dream is unlikely to come true for the majority. In addition to the desire for land on the part of the landless, however, the success of the agricultural ladder depends upon several other factors: (1) access to land in manageable sizes at reasonable prices and terms, (2) the willingness and capacity to save for the desired future, and (3.) opportunity to gain managerial experience. 
With regard to the availability of land, it is common in Central America to hear complaints that land was not for sale on reasonable terms. At highly speculative prices it could be had, with very heavy interest charges as well. Even in Costa Rica and Honduras where land is still relatively plentiful one hears the complaint that

Land represents, on the one hand, a secure form of wealth in Costa Rica. In contrast, the long term interest on other alternative investments is relatively low. Even more, the ownership of land is even free of taxation which increases the opportunity of speculation in land. Consequently the factors of production are out of adjustment (Alleger, 1957:13).

The proposed real property tax reforms could alleviate this problem so that owners would be glad to rent or sell their unused land to avoid having taxes devour it.

With regard to saving, Central America is relatively fortunate in one way. While there has been inflation, it has been moderate, so that savings have not been economically impossible. However, there have been two truly overwhelming obstacles to saving. First, other than in the zones given over to the banana plantations owned by foreign capitalists, the wages of agricultural laborers have been so low as to create a hand-to-mouth existence for the workers. And even if one of them saved regularly it would require a very long time for him to accumulate the amount of money required for the purchase of any but the very simplest tools. 
Virtually all manufactured goods have been imported, and through a high-duty tariff system at that. Second, no respected example of saving is presented to the campesino. Savings banks and associations scarcely exist, and no effort is made to inculcate notions of thrift and looking ahead. In fact it is almost as if there were a conspiracy by the money-lenders to discourage such stalwart traits among the rural masses. Of course the high incidence of alcoholism also drains off a good deal of the financial resources of the campesinos. And without saving, no agricultural ladder can operate.

Finally, as to opportunities to gain experience in decision-making, two factors discourage the young hopeful. First, the lack of adequate school systems in rural areas, and the common lack of appreciation of even such education as is available, means that habits of searching for information and of keeping records are virtually unknown among the country dwellers. Second, rare indeed is the work opportunity that provides any chance for creativity or innovative thinking. Most agricultural tasks assigned to laborers have been done in traditional ways so long that neither owners, managers, or peons ever question the age-old practices. Fortunately the growing agricultural extension services, the banks making agricultural loans, and the large commercial farms are bringing many modern 
techniques onto the rural scene. Even so they are often adopted without the creative, active thinking that leads to inventions and new procedures to handle one's own particular needs.

Finally, after having sketched these three discouraging general perspectives on the bases for the agricultural ladder, mention must be made of an overt obstacle as well. Central American rural society is dominated by the large hacienda and by estate owners who rely upon plentiful labor for their properties. The social structure is such that there is a strong emphasis on the status quo in all of the countries except Costa Rica; and in a lesser degree it is there also. As long as vested interests are firmly seated in the places of power and policy-making, one can expect no marked changes in the accessibility of land, the stimuli to save, or improvement of education for the common campesino.

One basic change might effectively crack all three of these barriers, if there were a way to enact the necessary law and put it into effect. That reform is the creation of a locally-levied tax on real property, administered by popularly elected administrators at the municipio level. By this I have in mind a local board empowered to levy the tax and also to direct the expenditures for local public schools. Of course the vested interests would 
still be powerful, and in areas where laborers are strictly controlled by the landowners progress would be slow. Such a tax, however, in addition to raising new revenue for the schools, would make the use of land as a speculative investment more costly. It would reduce land prices and rents to a more reasonable level, and thus provide a stimulus to savings on the part of those who presently feel that the ownership of land is an unreachable dream.

Whether the property tax-local school is employed, or some other change is made, it appears that positive action is needed to enable the agricultural ladder to maintain the owner-operated farm in areas where it is now common, and to assist in its development in other localities. To date, as far as can be determined, the agricultural ladder is not accomplishing much, except in some areas of Costa Rica, although perhaps detailed studies would reveal other limited areas where it is effective.

\section{Summary and Conclusions}

Two important aspects of the relationships between men and the land in Central America are discussed in this chapter. The first is the evolution of property rights to land and the nature of these rights at the present time. The second is the analysis of the manner in which rights to the land are distributed among the agricultural people 
of the region. For our purposes land tenure is considered to include all of the rights, legal and traditional, by which people gain access to and control over land. Since land is available in a limited quantity, the distribution of the rights to it as well as the limitations which may be imposed upon its use are extremely important in determining the well-being and relative levels of living of agricultural and pastoral peoples.

The development of the rights to the land has been traced from preconquest times to the present. In general this development resembled that in other parts of Spanish America, since the same colonial policy was in effect for all areas. The land rights granted in Central America represented a departure from those current in Spain in the fifteenth century and later, as the council of the Indies strove to take advantage of a relatively fresh slate on which to write its laws. Thus land came to be held in a relatively absolute fashion, essentially equivalent to ownership in fee simple, and the same type of rights were confirmed constitutionally and legally as the Captaincy General of Guatemala passed to become, in time, the five republics of Central America. In addition to private ownership, some lands continue to be held by municipios as ejidos, or communal land. 
The principal limitations on ownership are those of eminent domain and the right to levy taxes, which the governments retain. Each nation has also placed limitations on property for the good of society-requiring the socalled social function of property-but the real effect of these recent laws is not certain. Generally the governments have been conservative in applying restrictions.

This analysis of the contemporary distribution of rights to land in Central America is a pioneering effort. I have sought to determine the number of families dependent upon agriculture and to separate these into those headed by farm operators and farm laborers, respectively. As a result, this work differs considerably from most other studies of the region. Based upon the reworking of the census data, about 59 per cent of all agricultural households are headed by those who perform farm labor for their livelihoods and only 41 per cent of the farm families are those of genuine farm operators.

Among the operators, the majority are owners in the region as a whole, and in Costa Rica, El Salvador, and Guatemala. In Honduras and Nicaragua less secure forms of tenure predominate. Ownership is more common for the larger establishments, and sharecropping, colonato, squatting, and other forms are most frequent for the smaller parcels. In this study sharecroppers and colonos are considered as farm laborers and not as farm operators. 
The evolution of the Central American labor systems is traced, and then an estimate is presented for each country of the present number of households headed by farm laborers. Also provided is a description of the various types of farm laborers. Nearly half of the farm laborers possess some land, but not enough for them to qualify as independent farmers. In addition, another 13 per cent are colonos who are allowed the use of a small plot of land by their employer. Thus not all farm laborers in Central America are landless, but almost all of them have very low levels of living.

Finally an effort has been made to determine the trends which are taking place with regard to land tenure. In Central America as a whole it appears that as time passes a greater proportion of the farm population is being forced down into the status of farm laborers. Although data are not available for an adequate analysis, it appears that in Costa Rica farm operatorship is becoming more prevalent. Except for this country, however, the agricultural ladder does not seem to be functioning effectively in the region.

From all of this one may conclude that although landowners have almost complete rights to their land, the majority of the people have few or no rights to any land. Moreover, if present trends continue, farm laborers, 
many of whom are the sons of landowners, have slight chances of being able to ascend the agricultural ladder.

In an age when the transistor radio constantly bombards even the landless, illiterate laborer with information about the affluence of others, no one can tell how long such deprivation will be suffered in relative peace. If the nations of Central America are to avoid an eventual cataclysm, steps should be taken to enable agricultural laborers to $r i s e$ in the socioeconomic scale. It may be necessary, and it certainly would be advisable, to institute more substantial agrarian reform and colonization programs. 


\section{CHAPTER V}

\section{SYSTEMS OF AGRICULTURE}

Among the several highly important relationships between men and the land, the complex of ideas and practices by which agriculturists extract a living from the soil is the most critical factor affecting the level of living of families engaged in cultivating the land. In this chapter the contemporary systems of agriculture in Central America are analyzed, and some evidence of the manner of their evolution is given. Finally, available indications of trends in the recent past are traced to indicate the extent to which changes are occurring.

The Nature of a System of Agriculture

The term "system" is deliberately employed here with regard to what may appear to be simply elements of agricultural technology. ${ }^{1}$ This is because the whole approach to the cultivation of crops is integrated into a way of life which tends to be unitary-in which each element fits into a complex set of beliefs, practices, prejudices,

${ }^{1}$ A basic, careful analysis of the systematic nature of a system of agriculture is given by $T$. Lynn Smith in his volume on Colombia (1967a:168-172). 
and other culture traits which are accepted by their practitioners as "natural." Any change in one part of the system is likely to require that changes of a complementary sort be made in other aspects of the complex, with the result that a generally conservative set of values prevails favoring the preservation of existing ways of life and farming. For example, among the Indians of Guatemala the cultivation of corn in the milpa involves a series of religious rituals and festivals. The timing of these social and religious events, as well as their justification, hinges on the performance of a given "technical" agricultural practice. Wagley (1941:31), referring to Chimaltenango, says that these customs

cannot be separated from the mechanical processes of cultivation. To the Chimalteco, maize will no more grow without the prayer and ceremonies than without the careful planting, the various weekings, and the careful harvest. The one group of activities is as important as the other, and the two spheres are closely interwoven.

Wagley also $(31-44)$ traces the various rituals which are intimately related to the cultivation of corn, and it becomes apparent to his readers that a change in agricultural technology would challenge very strongly-held beliefs and endanger the social position of the chimane (shaman) about whom so much of community life revolves.

The agricultural practices and their associated beliefs and preferences are likewise highly systematized 
in more "modern" circumstances. Those persons who use the practices of scientific agriculture employ a series of values and preferences which are similarly structured. A man who operates a farm with mechanized equipment will probably place strong reliance on scientific knowledge of seed selection, fertilization, pest control, and commercial credit. His greater openness to new ideas is itself structured as a part of the system. It could not exist if he were integrated into a traditionally-oriented community. The structured nature of systems of agriculture is much more than simply technology. It often involves community-reinforced values such as religion, education, family life, leisure time, and social status.' Even when the practices by which plants and livestock are raised do not so clearly affect other aspects of the society, the several elements of the given agricultural-pastoral complex are closely integrated with one another and gain their specific meanings only in that context. The manner in which distinct farming practices are integrated into a complex social system is treated in detail by Smith in a paper he presented at a conference on social change (T. Iynn Smith, 1960b). At the end of the pertinent

${ }^{1}$ These various aspects are mentioned in the studies of T. Lynn Smith (1963a:357-360), Wagley (1941:31044; 1949), Lewis (1949 (, LeBeau (1956:270-301), Morley (1956:129-137), and many others. 
discussion he said, "Therefore it seems to me that we err when most of our endeavors are concentrated upon changing the parts and not upon modifying the system as a whole" (p. 151).

\section{Contemporary Systems of Agriculture} in Central America

The framework for the sociological analysis of systems of agriculture has been evolving for over 20 years in the works of Smith $(1946 ; 1949 ; 1953: 330-356 ; 1963 a: 357-$ 390). This aspect of rural social organization has been broken down into six basic systems which are designated as follows: (1) riverbank plantings, (2) fire agriculture, (3) hoe culture, (4) elementary plow culture, (5) advanced plow culture, and (6) mechanized farming.

Central America is a region which contains a great variety of specific systems of agriculture-some predating the conquest of the area by the Spaniards and others representing the most modern principles of agricultural science. In the cultivation of rice, for example, I observed the use of tractors, disc harrows, planters, combines and airplanes on the Guanacaste plains of Costa Rica. In the hills and mountains of the same country, I saw this crop being grown by subsistence farmers practicing fire agriculture. Thus, in addition to describing the 
nature of each of these sociocultural complexes, it is necessary to indicate the approximate numbers of agriculturists employing each system and also to relate some of the circumstances under which each is found.

\section{Riverbank Plantings}

The riverbank planting is one of the first and simplest forms of agriculture. In it the "farmer" has barely advanced beyond a simple collecting economy. The man, or more probably the woman, who engages in this system has learned to save some seeds of the most highly-valued plants and to imbed them in the soft earth of a riverbank as the water recedes after flood stage. Dropping the seeds and pressing them into the soil with her foot completes the task of planting, and all that remains is to await the growth and take the harvest. There is no actual cultivation, but there is that essential aspect of saving the seeds and planting them in the ground which nature herself has prepared.

In Central America I personally did not observe any example of riverbank planting. Nesman (1969:159) reports that on occasion he found small plots of corn or other crops planted on the riverbanks in Nicaragua, but he also adds that this was to take advantage of the alluvial soil and the dependable moisture. The implication is that 
these farmers are not limited to this primitive system of agriculture, but use it to supplement other forms of cultivation. Certainly the cases he describes have tools (hoes and machetes) which are more advanced than those of the truly primitive riverbank planters. Whether some of the latter also exist in the area is not clear, but I am confident that few Central Americans still employ this limited form of agriculture in this decade.

Fire Agriculture

The system denoted as "fire agriculture" is a step advanced beyond the riverbank planting, but nonetheless it still employs an extremely low level of technology. In this complex, the seed is not planted in earth prepared entirely by nature. Instead the "farmer" must use some sort of cutting tool (commonly the machete) to clear the underbrush from the chosen plot. Then he fells at least the majority of the trees, and leaves the debris to dry for a while in the field. When the wood and brush is dry, and just before the rainy season, he sets fire to the lot, accomplishing both the removal of most of the trash which clutters the area, and the softening of the earth for planting. Fire leaves the soil spongy and easily opened for the depositing of the seeds. When the rains come, small holes are opened in the soil either with the big 
toe, a digging stick, or a crude hoe, and the seeds are covered with a swipe of the foot. The old stumps, logs, and what not are left lying in the field and the seeds are sown among them. The field may or may not be weeded during the growing season, so this way of farming frequently does not involve any genuine cultivation. Crops will be grown for one or perhaps several seasons on a field, and then it is abandoned, and the sequence begins again on new land. The process of preparing the land for planting is extremely prodigal with human labor, using no labor-saving technique at all, except the fire. This kind of plant culture usually lacks other labor-saving devices and methods as well, leaving the human being as the only beast of burden.' of course, the same is true of the riverbank planting.

The principal tools employed in this migratory form of agriculture are the machete, the axe, and the digging or planting stick. The latter is sometimes simply fire-hardened, but more frequently a metal tip is placed on the long wooden handle to improve its efficiency in piercing the soil. The digging or dibbling stick is often called a macana or espeque.

'A complete description of fire agriculture in one area of Guatemala is given by Carter (1969:340131). Another discussion relating to Central America is that of Haney (1968), while Crist (1967) gives the general Latin American picture. 
The effects of this system of agriculture on the soil resource are quite serious. Perhaps the worst consequence is the destruction of the organic matter or humus in the soil. In addition, since it is practiced principally in the humid tropics, one of the problems created is the severe leaching of nutrients from the earth exposed to the heavy rainfall. The rains also cause a great deal of erosion wherever this type of cropping is practiced on sloping land-in some localities vast areas have been destroyed as effectively as if the surface had been attacked by strip miners. ${ }^{1}$

Fire agriculture is widespread in Central America. In fact, this is what Muller referred to in "Agriculture in Central America" (1961:135) when he reported that: shifting cultivation [sic] is the characteristic pattern of land utilization on the mountainsides, and this means short period use of a given piece of land for cropping. After a parcel of forest is burned and cleared, it is cropped by manual labor. A few seasons later, invasion by grass and weeds makes its use undesirable. After abandonment to second growth vegetation for several years the area is again subjected to clearing and planting.

Even more explicitly, West and Augelli (1966:383) note that "Primitive slash-burn [sic] or dibble farming is even more

${ }^{1}$ Dumont (1966:5I) documents the per-acre losses produced by fire agriculture in equatorial Africa as "enormous quantities of humus, of 600-900 lb. of nitrogen and of 120-400 tons of wood." This volume by Dumont is an excellent treatise on systems of agriculture by a French agronomist with an unusually wide perspective. 
widespread here [in Central America generally] than in Mexico, and more common among subsistence farmers than is the ox-drawn wooden plow."

No statistics are available as to the relative importance of this agricultural complex compared to other systems which also rely solely upon manpower. However, the data in Table 18, indicate to me that probably at least 75 per cent of all explotaciones in Central America are exclusively hand powered. Moreover, my observations throughout the length and breadth of the region convince me that as many as one-third to one-half of all farms dependent upon human effort alone are probably relying upon fire agriculture. The use of this felling and burning technique is particularly prevalent in the coastal plain and piedmont areas where the settlements are relatively recent and population density is low, although in many sections it is also found high in the mountains. Stouse (1965:28-32) refers to this way of farming on former Costa Rican banana lands as his "land rotation agricultural settlement type," and he depicts extensive areas where it is predominant (see his Figure 1-13). The literature on agriculture in every one of the five nations refers to the extensive use of this system, frequently in considerable detail.1

'See, for example, the appropriate passages in works by Marroquín (1959:191-194); Sandner (1962:109, 131-132); León (1943:449); Raynolds (1967:21; Dozier (1958:16, 88): West and Augelli (1966:423); and Kirchoff (1948:219). 
Table 18A. Numbers and proportions of explotaciones agropecuarias reporting no power except human effort, by size of explotaciones: Guatemala, 1950

\begin{tabular}{|c|c|c|c|}
\hline \multirow[t]{2}{*}{$\begin{array}{c}\text { Size of Explotaciones } \\
\text { (Manzanas) }\end{array}$} & \multirow[t]{2}{*}{$\begin{array}{l}\text { Number of } \\
\text { Explotaciones }\end{array}$} & \multicolumn{2}{|c|}{$\begin{array}{c}\text { Explotaciones Dependent } \\
\text { Solely unpon Manpower }\end{array}$} \\
\hline & & Number & Pex Cent \\
\hline Under 1 & 74,269 & 72,247 & 97.3 \\
\hline $1-4.9$ & 191,360 & 180,625 & 94.4 \\
\hline $5-9.9$ & 42,444 & 37,521 & 88.4 \\
\hline Under 10 & 308,073 & 290,393 & 94.3 \\
\hline $10-31.9$ & 26,916 & 22,458 & 83.4 \\
\hline $32-63.9$ & 6,125 & 4,777 & 78.0 \\
\hline $10-63.9$ & 33,041 & 27,235 & 82.4 \\
\hline $64-639.9$ & 6,488 & 4,461 & 68.8 \\
\hline $640-1,279.9$ & 569 & 360 & 63.3 \\
\hline $1,280-3,199.9$ & 358 & 239 & 66.8 \\
\hline $3,200-6,399.9$ & 104 & 60 & 57.7 \\
\hline $6,400-12,799.9$ & 32 & 18 & $56^{\star}$ \\
\hline 12,800 and Over & 22 & 13 & $59^{\star}$ \\
\hline 64 and Over & 7,573 & 5,151 & 68.0 \\
\hline Total & 348,687 & 322,779 & 92.6 \\
\hline
\end{tabular}

SOURCE: Compiled and computed from Guatemala, DGE, 1954c:Cuadro 12. *Percentages rounded to two significant digits due to small base figures. 
Table 18B. Numbers and proportions of explotaciones agropecuarias reporting no power except human effort, by size of explotaciones: El Salvador, 1961 .

\begin{tabular}{|c|c|c|c|}
\hline \multirow[t]{2}{*}{$\begin{array}{c}\text { Size of Explotaciones } \\
\text { (Hectares) }\end{array}$} & \multirow[t]{2}{*}{$\begin{array}{l}\text { Number of } \\
\text { Explotaciones } a\end{array}$} & \multicolumn{2}{|c|}{$\begin{array}{c}\text { Explotaciones Dependent } \\
\text { Solely upon Manpower }\end{array}$} \\
\hline & & Number & Per Cent \\
\hline Under 1 & 65,094 & 46,882 & 72.0 \\
\hline $1-4.9$ & 72,786 & 42,906 & 58.9 \\
\hline $5-9.9$ & 13,988 & 8,382 & 59.9 \\
\hline Under 10 & 151,868 & 98,170 & 64.6 \\
\hline $10-19.9$ & 8,523 & 5,130 & 60.2 \\
\hline $20-49.9$ & 6,711 & 4,026 & 60.0 \\
\hline $50-99.9$ & 2,214 & 1,178 & 53.2 \\
\hline $10-99.9$ & 17,448 & 10,334 & 59.2 \\
\hline $100-199.9$ & 1,121 & 512 & 45.7 \\
\hline $200-499.9$ & 713 & 259 & 36.3 \\
\hline $500-999.9$ & 189 & 50 & 26.4 \\
\hline $1,000-2,499.9$ & 91 & 23 & $25^{\star}$ \\
\hline 2,500 and Over & 34 & 7 & $21^{*}$ \\
\hline 100 and Over & 2,148 & 851 & 39.6 \\
\hline Total & 171,464 & 109,355 & 63.8 \\
\hline
\end{tabular}

SOURCE: Compiled and computed from El Salvador, DGEC, 1967:Cuadro 65.

$a_{\text {Excludes explotaciones for which the source of power were not }}$ reported.

*Percentages rounded to two significant digits due to small base figures. 
Table 18C. Numbers and proportions of explotaciones agropecuarias reporting no power except human effort, by size of explotaciones: Costa Rica, 1963

\begin{tabular}{|c|c|c|c|}
\hline \multirow[t]{2}{*}{$\begin{array}{l}\text { Size of Explotaciones } \\
\text { (Manzanas) }\end{array}$} & \multirow[t]{2}{*}{$\begin{array}{l}\text { Number of } \\
\text { Explotaciones }\end{array}$} & \multicolumn{2}{|c|}{$\begin{array}{l}\text { Explotaciones Dependent } \\
\text { Solely upon Manpower }\end{array}$} \\
\hline & & Number & Per Cent \\
\hline $\begin{array}{l}1-3.9 \\
4-9.9\end{array}$ & $\begin{array}{l}14,931 \\
12,994\end{array}$ & $\begin{array}{r}11,669 \\
9,629\end{array}$ & $\begin{array}{l}78.2 \\
74.1\end{array}$ \\
\hline $1-9.9$ & 27,925 & $\underline{21,298}$ & $\underline{76.3}$ \\
\hline $10-19.9$ & 9,542 & 6,798 & 71.2 \\
\hline $20-49.9$ & 13,167 & 9,323 & 70.8 \\
\hline $50-99.9$ & 7,240 & 4,903 & 67.7 \\
\hline$\underline{10-99.9}$ & 29,949 & 21,024 & $\underline{70.2}$ \\
\hline $100-249.9$ & 4,441 & 2,719 & 61.2 \\
\hline $250-499.9$ & 1,291 & 720 & 55.8 \\
\hline $500-999.9$ & 596 & 253 & 42.4 \\
\hline $1,000-3,499.9$ & 360 & 101 & 28.0 \\
\hline 3,500 and Over & 59 & 13 & $22^{\star}$ \\
\hline 100 and Over & $\underline{6,747}$ & 3,806 & $\underline{56.4}$ \\
\hline Total & 64,621 & 46,128 & 71.4 \\
\hline
\end{tabular}

SOURCE: Compiled and computed from Costa Rica, DGEC, 1965a:Cuadro 148. * Percentage rounded to two significant digits due to small base figure. 
My own notes on Costa Rica are not as accurate as those for the other countries, for at first I mistakenly accepted the burning of perennially-cropped fields as evidence of fire agriculture. Actually, burning is a common method of removing the remnants of the previous season before beginning to till the land for a new planting, even in permanent hoe culture. I am sure that the shifting form of fire agriculture is relatively common in the Costa Rican lowlands. Sandner (1964:8) says of Costa Rica:

In the peripheral zones of the country there is a steel plow for every 28 farms, which in many cases do not use it at all, or only occasionally. Outside of the Central Valley, the peasant crops are in their majority [planted] by macana in soils prepared by felling and burning.

From this and other reports, it seems fair to conclude that fire agriculture is actually the dominant form of cropping on small properties in Costa Rica, and that it probably has a similar importance in Nicaragua (Nesman, 1969:162) and in Honduras.

Hoe Cuzture

The simplest system of agriculture involving actual cultivation of the soil is termed hoe culture. This is the first form of permanent agriculture, and it evolved in the course of time as men found that the same macana that was used in planting could be applied to the task of spading and breaking the earth. Soon a bent stick with a 
stone, shell, or metal point became a hoe and a system for using the same tract of land continuously, or for long periods of time, had come into being.

The typical tools of the hoe farmer include the machete (often in several sizes, with shapes adapted for different purposes) and the hoe. He may also have an axe, a shovel, and a variety of other accessories such as his seed carrier. Some hoe farmers possess animals which they use for transportation, but the more common practice is for the farmer and his family to carry their crops, firewood, and other goods on their own backs or heads.

Hoe culture may be the most common form of agriculture in all of Central America. In densely populated areas, such as in the Department of Totonicapán, Guatemala, and in much of El Salvador, land is too scarce to allow the long fallow periods involved in fire agriculture. Instead, a permanent cropping system is required. Since even a relatively crude hoe provides a means of controlling weed and grass infestations, hoe culture is particularly prevalent in areas of high population density. The data in Tables $18 \mathrm{~A}, 18 \mathrm{~B}$, and $18 \mathrm{C}$ have already been mentioned as demonstrating how greatly the Central American agriculturists rely upon hand methods in their farming. To the extent that I was able to observe systems of agriculture in my travels, hoe culture appeared to be most prevalent in the highland Indian areas of Guatemala 
(Totonicapán, Quezaltenango, Sololá, and Sacatepéquez, particularly), and in many parts of El Salvador. The extreme case is Totonicapan, where of 17,620 explotaciones reported in the 1950 census, only 18 possessed plows, thus removing them from the hand-cultivation systems (Guatemala, DGEC, 1954c:76). Fire agriculture and hoe culture are more evenly divided among the farmers of Honduras, and fire agriculture is quite common in areas other than the Pacific coastal plain in Nicaragua.

An indication of the importance of hoe culture is found in the fact that this is the system used in the raising of coffee on plantations of all sizes. It is also common in the subsistence growing of corn, beans, squash, and other vegetables, and is employed on many of the small commercial farms producing vegetables for sale in the cities. The widespread employment of fire and hoe culture must be understood, not simply in terms of cultural backwardness, but also as almost necessary aspects of Central American life. As Adams (1967b:77) put it:

In Nicaragua, the same cultivator may use oxen and plow on his level lands and then take up the digging stick and machete to plant his hilly lands. For the most part, however, the farmer who can afford much level land, and therefore oxen and plows, will either put his marginal lands out for rent or sharecropping or plant them in coffee or some other cash crop for which the terrain is appropriate.

The terrain itself prohibits the use of plows or tractors on much farmland, and the tiny plots of the subsistence 
farmers make it impractical to employ these more highly capitalized procedures on many other parcels. At any rate, from 60 to over 90 per cent of the explotaciones in the several countries appear to be operated by purely hand techniques (see Tables 18A, 18B, and 18C).

\section{Elementary Plow Culture}

The use of the wooden rooting plow is the next technological improvement in agricultural systems in Central America. This type of plow (arado criozzo) was introduced in Central America by the Spaniards, as were the oxen which provide the traction for it. It may have evolved from a hoe that was pulled by one person and pushed by another, but all of its evolution occurred prior to the arrival of the Iberian conquerors in the fifteenth and sixteenth centuries. Since then both the Spanish plow and the oxcart have remained virtually unchanged. The combination of the plow and oxcart, or even the use of the plow alone, does much to ease the burden of the farmer in the preparation and cultivation of the soil.

Elementary plow culture employs the tools of the more primitive systems of agriculture (with the frequent exception of the digging or planting stick), and adds to these the use of the animal-powered plow and a drag (rastro, tuco) made of logs which both breaks and smooths the land. 
There are many farms and subsistence tracts in Central America which employ the creole plow as the basic means of cultivation, but in none of the countries is this system found on anything like a majority of the explotaciones. The data on places which reported the use of animal power are given in Table 19. These figures include farms which utilized animals for transport, but not in the work of cultivation, so they actually represent more than the farms employing plow culture. It is interesting to note that in El Salvador and Costa Rica there was little difference in the use of animal power by size of farm, except on the few places of largest acreage (where mechanization is a significant factor). On the other hand, in Guatemala the plow is rarely found on small subsistence tracts, but becomes increasingly common as size increases.

A more definite idea of the extent to which elementary plow culture is found in Central America may be gained by examining the following data from the 1950 censuses: ${ }^{1}$

Wooden Plows

Guatemala

El Salvador

Honduras
32,284

122,878

35,257
Metal Plows

5,464

5,146

1,040

${ }^{1}$ Compiled from Guatemala, DGE, 1954c:75; El Salvador, DGEC, 1954a:403; and Honduras, DGCE, 1954:39. 
Table 19A. Numbers and proportions of explotaciones agropecuarias reporting the use of animal power, by size of explotaciones: Guatemala, 1950

\begin{tabular}{|c|c|c|c|}
\hline \multirow[t]{2}{*}{$\begin{array}{c}\text { Size of Explotaciones } \\
\text { (Manzanas) }\end{array}$} & \multirow[t]{2}{*}{$\begin{array}{l}\text { Number of } \\
\text { Explotaciones }\end{array}$} & \multicolumn{2}{|c|}{$\begin{array}{l}\text { Explotaciones Using } \\
\text { Animal Powera }\end{array}$} \\
\hline & & Number & Per Cent \\
\hline Under 1 & 74,269 & 1,907 & 2.6 \\
\hline $1-4.9$ & 191,360 & 10,509 & 5.5 \\
\hline $5-9.9$ & 42,444 & 4,883 & 11.5 \\
\hline Under 10 & 308,074 & 17,299 & 5.6 \\
\hline $10-31.9$ & 26,916 & 4,396 & 16.3 \\
\hline $32-63.9$ & 6,125 & 1,300 & 21.2 \\
\hline $10-63.9$ & 33,041 & $\underline{5,696}$ & 17.2 \\
\hline $64-639.9$ & 6,488 & 1,867 & 28.8 \\
\hline $640-1,279.9$ & 569 & 165 & 29.0 \\
\hline $1,280-3,199.9$ & 358 & 81 & 22.6 \\
\hline $3,200-6,399.9$ & 104 & 24 & 23.1 \\
\hline $6,400-12,799.9$ & 32 & 6 & $19^{*}$ \\
\hline 12,800 and over & 22 & 4 & $18^{*}$ \\
\hline 64 and Over & 7,573 & 2,147 & 28.4 \\
\hline Total & 348,687 & 25,142 & 7.2 \\
\hline
\end{tabular}

SOURCE: Compiled and computed from Guatemala, DGE, 1954c:Cuadro 12.

$a_{\text {Does not include those which also had mechanically powered }}$ devices as well as work animals. base figures.

*Percentages rounded to two significant digits due to small 
Table 19B. Numbers and proportions of explotaciones agropecuarias reporting the use of animal power, by size of explotaciones: El Salvador, 1961

\begin{tabular}{|c|c|c|c|}
\hline \multirow[t]{2}{*}{$\begin{array}{l}\text { Size of Explotaciones } \\
\text { (Hectares) }\end{array}$} & \multirow[t]{2}{*}{$\begin{array}{l}\text { Number of } \\
\text { Explotaciones }\end{array}$} & \multicolumn{2}{|c|}{$\begin{array}{l}\text { Explotaciones Using } \\
\text { Animal Power }\end{array}$} \\
\hline & & Number & Per Cent \\
\hline Under 1 & 65,094 & 17,607 & 27.0 \\
\hline $1-4.9$ & 72,786 & 28,616 & 39.3 \\
\hline $5-9.9$ & 13,988 & 5,284 & 37.8 \\
\hline Under 10 & 151,868 & $\underline{51,507}$ & 33.9 \\
\hline $10-19.9$ & 8,523 & 3,128 & 36.7 \\
\hline $20-49.9$ & 6,711 & 2,396 & 35.7 \\
\hline $50-99.9$ & 2,214 & 846 & 38.2 \\
\hline $10-99.9$ & 17,448 & 6,370 & $\underline{36.5}$ \\
\hline $100-199.9$ & 1,121 & 445 & 39.7 \\
\hline $200-499.9$ & 713 & 281 & 39.4 \\
\hline $500-999.9$ & 189 & 61 & 32.3 \\
\hline $1,000-2,499.9$ & 91 & 11 & $12^{*}$ \\
\hline 2,500 and over & 34 & 4 & $12^{*}$ \\
\hline 100 and Over & 2,148 & $\underline{802}$ & 37.3 \\
\hline Total & 171,464 & 58,679 & 34.2 \\
\hline
\end{tabular}

SOURCE: Compiled and computed from El Salvador, DGEC, 1967:Cuadro 65.

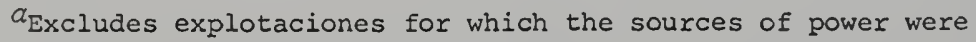
not reported.

*Percentages rounded to two significant digits due to small base figures. 
Table 19C. Numbers and proportions of explotaciones agropecuarias reporting the use of animal power, by size of explotaciones: Costa Rica, 1963

\begin{tabular}{|c|c|c|c|}
\hline \multirow[t]{2}{*}{$\begin{array}{l}\text { Size of Explotaciones } \\
\text { (Manzanas) }\end{array}$} & \multirow[t]{2}{*}{$\begin{array}{l}\text { Number of } \\
\text { Explotaciones }\end{array}$} & \multicolumn{2}{|c|}{$\begin{array}{l}\text { Explotaciones Using } \\
\text { Animal Power }\end{array}$} \\
\hline & & Number & Per Cent \\
\hline $\begin{array}{l}1-3.9 \\
4-9.9\end{array}$ & $\begin{array}{l}14,931 \\
12,994\end{array}$ & $\begin{array}{l}2,060 \\
2,279\end{array}$ & $\begin{array}{l}13.8 \\
17.5\end{array}$ \\
\hline $1-9.9$ & $\underline{27,925}$ & 4,339 & 15.5 \\
\hline $\begin{array}{l}10-19.9 \\
20-49.9 \\
50-99.9\end{array}$ & $\begin{array}{r}9,542 \\
13,167 \\
7,240\end{array}$ & $\begin{array}{l}1,891 \\
2,775 \\
1,669\end{array}$ & $\begin{array}{l}19.8 \\
21.1 \\
23.0\end{array}$ \\
\hline $10-99.9$ & 29,949 & $\underline{6,335}$ & 21.2 \\
\hline $\begin{array}{l}100-249.9 \\
250-499.9 \\
500-999.9 \\
1,000-3,499.9 \\
3,500 \text { and Over }\end{array}$ & $\begin{array}{r}4,441 \\
1,291 \\
596 \\
360 \\
59\end{array}$ & $\begin{array}{r}1,066 \\
265 \\
94 \\
52 \\
2\end{array}$ & $\begin{array}{l}24.0 \\
20.5 \\
15.8 \\
14.4 \\
3^{*}\end{array}$ \\
\hline 100 and Over & $\underline{6,747}$ & $\underline{1,479}$ & $\underline{21.9}$ \\
\hline Total & 64,621 & $\frac{12,153}{\cdot}$ & 18.8 \\
\hline
\end{tabular}

SOURCE: Compiled and computed from Costa Rica, DGEC, 1965a:Cuadro 148. base figures. 
The figures given are the numbers of plows, and not the numbers of farms using plows. (The category of metal plows may represent advanced plow culture, but the wooden plows are clearly part of the elementary form of plow agriculture.) On the average, there was one wooden plow for every 10 farms in Guatemala, one for every 1.4 explotaciones in El Salvador, and one for each 4.4 in Honduras. Many of these may actually be grouped on a small number of farms. No data are available for Nicaragua, but Table 20 provides information for Costa Rica on the number of explotaciones employing plows, subdivided by type of traction and size of explotación. A total of about 5,500 farms ( 8.5 per cent) used animals to draw the plows.

None of the statistical sources proves adequate for an accurate analysis of the number of farms or subsistence tracts which employ the old creole plow and use oxen as draft animals. It would appear, on comparing Tables $19 \mathrm{C}$ and 20 , that the use of "animal power" on the farms is considerably more widespread than the use of the plow. Therefore it is reasonable to assume that perhaps no more than about one-quarter of the explotaciones agropecuarias in Central America employ a system of agriculture as high as elementary plow culture. 
Table 20. Numbers and proportions of explotaciones agropecuarias reporting the use of animal- and tractor-drawn plows, by size of explotaciones: Costa Rica, 1963

\begin{tabular}{|c|c|c|c|c|}
\hline \multirow{3}{*}{$\begin{array}{c}\text { Size of } \\
\text { Explotaciones } \\
\text { (Manzanas) }\end{array}$} & \multicolumn{4}{|c|}{ Explotaciones Reporting Using Plows } \\
\hline & \multicolumn{2}{|c|}{ Animal-Drawn } & \multicolumn{2}{|c|}{ Tractor-Drawn } \\
\hline & Number & Per Centa & Number & Per Cent $a$ \\
\hline $\begin{array}{l}1-3.9 \\
4-9.9\end{array}$ & $\begin{array}{l}870 \\
976\end{array}$ & $\begin{array}{l}5.8 \\
7.5\end{array}$ & $\begin{array}{l}261 \\
338\end{array}$ & $\begin{array}{l}1.7 \\
2.6\end{array}$ \\
\hline $1-9.9$ & $\underline{1,846}$ & 6.6 & $\underline{599}$ & $\underline{2.1}$ \\
\hline $10-19.9$ & 841 & 8.8 & 232 & 2.4 \\
\hline $20-49 \cdot 9$ & 1,223 & 9.3 & 358 & 2.7 \\
\hline $50-99.9$ & 783 & 10.8 & 235 & 3.2 \\
\hline $10-99.9$ & 2,847 & $\underline{9.5}$ & $\underline{825}$ & $\underline{2.8}$ \\
\hline $100-249.9$ & 519 & 11.7 & 283 & 6.4 \\
\hline $250-499.9$ & 170 & 13.2 & 137 & 10.6 \\
\hline $500-999.9$ & 73 & 12.2 & 106 & 17.8 \\
\hline $1,000-3,499.9$ & 42 & 11.7 & 110 & 30.4 \\
\hline 3,500 and over & 6 & $10^{*}$ & 32 & $54^{*}$ \\
\hline 100 and Over & 810 & 12.0 & $\underline{668}$ & $\underline{9.9}$ \\
\hline Total & 5,503 & $\underline{8.5}$ & $\underline{2,092}$ & 3.2 \\
\hline
\end{tabular}

SOURCE: Compiled and computed from Costa Rica, DGEC, 1965a:Cuadros 8 and 158 .

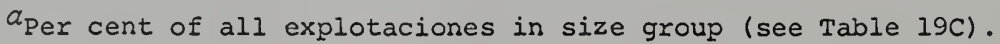

*Percentages rounded to two significant digits due to small base figures. 


\section{Advanced Plow Culture}

As the name suggests, advanced plow culture represents the refinement of the older rooting plow. The basic discoveries which made this possible were: (1) the horse as a draft animal (horses had long been used by the upper classes for riding, but were kept from contact with the lower classes who did the work on the land); (2) the horse collar, which enabled the animal to strain against a load without cutting off his wind; and (3) the invention of the turning plow, to replace the ancient rooting type. The combination of these three elements so improved the application of animal power to the tasks of cultivation that a new system of agriculture was born. The horse's even, steady pull also made possible the development of other machines to aid the farmer and improve his efficiency: reapers, combines, planters, and riding plows, for example. The four-wheeled wagon is also included here.

The development of advanced plow culture has taken place in northwestern Europe, and in the United States and Canada, where the members of a strong class of family-sized farmers have been very much concerned with improving their efficiency. Since in this case the same man is responsible for securing the capital, providing the management and strategy, and doing the work of the farm, he has every incentive to seek means to increase the effectiveness of 
his own limited time and energy. On the other hand, where the provision of capital and management are separated from the function of labor, as is true in a system of large estates, there is little concern to save on labor. This is particularly true where there is a plentiful supply of laborers and alternative investments for capital are attractive.

It is, unfortunately, logical to expect that central America, with the majority of its farmer class either possessed of large estates, or scratching out a living on tiny parcels, will neglect this important system of agriculture which has been cieveloped by and for the familysized farm. Many operators of large plantations devoted to cotton and rice, for example, have already skipped over this stage entirely in favor of mechanization. Most other farmers still rely on inefficient hand tools or plod along with ungainly oxen. There is a feeling on the part of some that if one is going to modernize and invest in machinery he should go to the more advanced use of tractors rather than simply a different breed of animals and animaldrawn equipment. The recommendation of Vance Rogers (1947: 15-16) for Costa Rica does not appear to have been received with much enthusiasm. He suggested that mechanization is a response to high labor costs and that the need in 
Costa Rica was for more animal-drawn machinery for cultivating, planting, and harvesting. He urged that, as far as possible, an effort be made to adapt the equipment to oxen since these animals are more economical to feed and care for. In 1963, Costa Rica had 30,967 oxen and 107,533 horses, mules, and asses on its farms (Costa Rica, DGEC, 1965a:Cuadros 177 and 190), but according to my observation the animal-drawn plows, harrows and the like were almost always pulled by the lumbering oxen. The horses were used for riding and packing almost exclusively and this is largely a matter of cultural definition. When I asked farmers who owned horses whether they were used for plowing, I usually received an almost incredulous look of surprise that I even thought of this. To some it seemed insulting. A similar attitude toward the horse was found widely disseminated throughout the region.

Mechanized Farming

In mechanized farming the emphasis is upon the application of capital and technology in the production of agricultural products, and the ever more sparing use of human labor. Virtually all of the inventions of mechanized implements for farm work have occurred in North America and western Europe where the cost of labor has been an important consideration, and farming is undertaken with a 
very commercial or business-like emphasis. The mechanized farming complex in its highly developed form includes the tractor for pulling some forms of equipment, and a variety of self-propelled machines for harvesting and other tasks. Tractors are specially developed for different types of crops and soils, and planters, cultivators, harvesters and sprayers are made to fit the specific requirements of particular enterprises. In the production of cotton, for example, everything from laying out the contours in the fields, through plowing, planting, fertilizing, spraying, weeding, harvesting, and hauling the bolls to the gin can be done without the use of hand tools or animal power. The equipment for such an operation is very expensive, and mistakes in management or weather problems can be extremely costly, but much of the world's cotton is now produced on farms employing the sort of equipment indicated. Many other crops are equally adapted to mechanized farming, including even such perishable fruits as tomatoes.

Mechanized farming is not very highly developed in Central America due to the prevalence of the minifundia and the large estates which have traditionally depended upon the lavish use of human labor. Certain highly commercial crops are rapidly being mechanized, however.

In the past decade or two the raising of cotton in Central America has boomed, with most production intended 
for the world market. At first much of the cropping was done with the wooden plow and intensive application of labor, but more recently the farmers have emphasized mechanization. The result is that cotton growing is probably the most fully mechanized type of farming in the region. The use of fertilizers and insecticides is far more thorough than it is even in coffee orchards, and spraying and dusting by airplane is standard procedure with cotton. On a single plantation in EI Salvador I saw 46 tractors and their associated machinery being employed in tilling the fields. Recently, in spite of the relatively low wages paid for picking cotton, some mechanical cotton pickers have come into use. There were 161 of these in Nicaragua in 1967, capable of handling a considerable acreage of cotton (Banco Central de Nicaragua, n.d.:104). Banana plantations are probably the next most mechanized type of farming, but the mechanization involves more the building of the supporting infrastructure than the cropping itself. Sugarcane culture is highly mechanized in some tracts in each country, but a great deal is also grown with elementary plow culture on small plots.

An indication of the limited extent of mechanization in the region may be gained by noting that in El Salvador and Costa Rica, respectively, the most recent censuses reported that approximately 2 and 10 per cent of the 
explotaciones used "mechanical power." El Salvador did not publish any information on the use of tractors, but in Costa Rica 6,340 farms used mechanical power, and only 3,020 ( 4.7 per cent) of these had tractors (see Table 21, and Costa Rica, DGEC, 1965a:Cuadros 148 and 156). The explanation lies in the fact that mechanical power includes any mechanical devices, even windmills, and so does not fairly represent mechanized farming.

On the other hand, one can readily appreciate the increasing mechanization that is occurring by examining the following data from the agricultural censuses: ${ }^{2}$

Year Tractors

$\begin{array}{lll}\text { Guatemala } & 1950 & 775 \\ \text { El Salvador } & 1950 & 885 \\ \text { Honduras } & 1952 & 283 \\ & & \\ \text { Costa Rica } & 1950 & 456 \\ \text { Costa Rica } & 1955 & 504 \\ \text { Costa Rica } & 1963 & 4,454\end{array}$

In 1950 the number of tractors was very small in every case. If the experience in the other countries parallels that of Costa Rica, then the years since 1950 have been ones of

${ }^{2}$ Compiled from Guatemala, DGE, 1954C:Cuadro 15; El Salvador, DGEC, 1954a:Cuadro 48; Honduras, DGEC, 1954:Cuadro 9; Costa Rica, DGEC, 1953a:Cuadro 55, 1959:Cuadro 135, and 1965a:Cuadro 156. Other censuses provide no data on tractors. 
Table 21. Numbers and proportions of explotaciones agropecuarias reporting the use of tractors, by size of explotaciones: Costa Rica, 1963

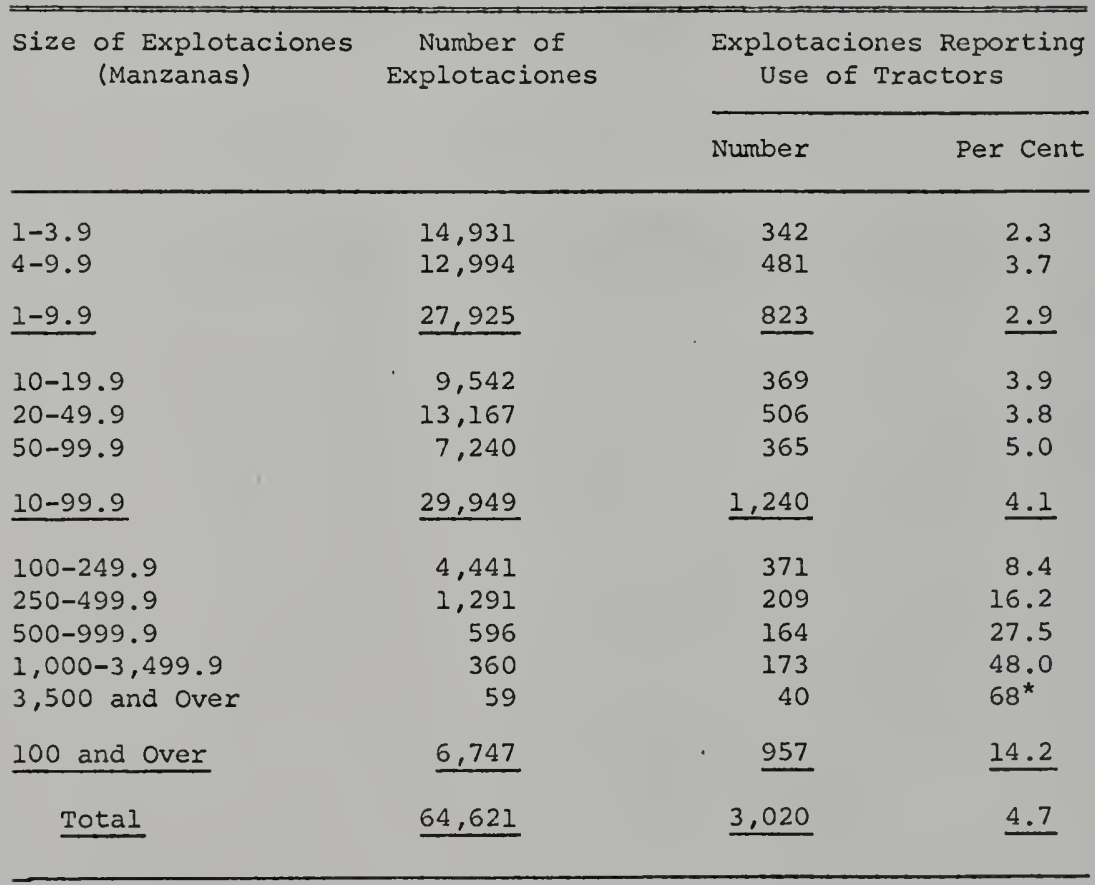

SOURCE: Compiled and computed from Costa Rica, DGEC, 1965a:Cuadros 8 and 156 . base figures.

*Percentage rounded to two significant digits due to small 
vast change. In the eight years between 1955 and 1963 tractors multiplied ninefold in the one country for which data are available.

In summary, while the whole range of agricultural systems may be found in Central America, the dominant forms-probably as many as 75 per cent of the explotacionesdepend upon fire agriculture or hoe culture. In other words, the work of clearing and preparing the soil, weeding the fields, and harvesting the crop is done entirely with hand tools. Next in importance is elementary or rudimentary plow culture in which the inefficient wooden rooting plow creases and breaks the earth as a form of tillage. This system may be in use on about one-fourth of the farms. and subsistence tracts in the region, though its usage varies from country to country. The wooden plow is more common in El Salvador than elsewhere, and perhaps least common in Guatemala. Advanced plow culture is almost nonexistent in the region, while mechanization of farming is now being introduced on a considerable scale.

\section{Evolution of Systems of Agriculture} in Central America

Central American agriculture has experienced remarkably little change during the period for which its history is clearly discernible. It is one of the areas of the world in which stable agricultural practices evolved 
independently, and it is still basically an agricultural civilization. Nevertheless, during the more than 400 years since the arrival of the Spaniards on these shores few major changes have occurred in the systems of agriculture by which the majority of the people gain a livelihood.

Prior to the Spanish Conquest, the people inhabiting Central America could be classified as belonging to two basically different agricultural traditions. Most of them were corn-growers or seed-planters, related to the Maya and Mexican families of Indians. ${ }^{1}$ The second group of aboriginal farmers were the vegetable-planters whose culture revolved about the root of the yuca plant. These had their origin in what is now Colombia, and spread northward along the Atlantic coastal plain of Central America, particularly in Costa Rica, Nicaragua, and Honduras.

The systems or agriculture employed were basically those of fire agriculture, with the likelihood that some riverbank planting was done on the Atlantic littoral as well. The account given by the chronicler oviedo y Valdés (1851: 263-269) in the early part of the sixteenth century is a

${ }^{1}$ Sauer (1952:40-60) discusses the development of various agricultural products and systems on a world-wide basis, and distinguishes the seed-planters and vegetableplanters of the New World. 
classic statement of fire agriculture. A free translation of some of his key sentences follows:
- . and when they want to plant, they fell the forest or canes (for land where only grass grows is not considered as fertile in these parts as the lands of trees and shrubs), and after they have made that cutting or roca (clearing), they burn it, and the ashes of the cut wood remain there, giving such an effect to the land as if it had been fertilized. hand - and with planting sticks or macanas in their hands, they strike the earth with the point of the stick, and bend it to one side to open up the earth a bit more. Removing it, then, into the hole which it made they place four or five grains of corn... and then with the foot they close up the hole with the grain, so that the . . birds do not eat them. (264-265).

From these comments Oviedo y Valdés passes almost immediately to the further fact that the Spaniards in the Caribbean and on the mainland had adopted the practices of the Indians in large part: "This method of planting was learned from the Indians . . but the Christians do it better, because they plow the land where there is a disposition for it" (266). Owing to the fact that the agricultural work was mostly done by the Indians, whether on their own plots or those of the Spaniards, the plow was not introduced as widely as might be expected.

Virtually every study of the pre-Columbian and early colonial Indian practices in Central America emphasizes the dependence of these people on a shifting subsistence agriculture carried on by the use of the axe and fire. Willey and his associates $(1964: 447)$ summarizes the practice for all of the Central American area where corn was dominant: 
The lands for these crops were cleared with stone tools, the fallen trees burned, and the seeds or cuttings planted with the aid of a fire-hardened digging stick. This system of clearing and planting was, and is, widespread in Mesoamerica, with adaptations to the particular environment.

Thomas Gage (1946:220-221, and passim) described the manner in which wheat, corn, and other crops were grown in the seventeenth century in Guatemala and Honduras, and was incredulous at the manner in which timber trees were felled and burned in the normal course of each year's cropping. Subsequent travellers in the nineteenth century left accounts which confirmed that little innovation had occurred. Because this system of felling and burning was new to these foreign visitors, their accounts are full of both words and pictures which vividly describe the procedures used to destroy the forests in making the milpas. 1

The wooden plow drawn by oxen was slowly making its presence felt also, and these same travellers recorded their observations regarding the use of this instrument (Squier, 1860:327; Wells, 1957:388). Nevertheless, its introduction was so slow that regarding the area around the principal city of Costa Rica (Cartago), Governor Tomás de Acosta reported in 1803 that "the plow is not customarily used here, nor any other utensils for work in the fields

1 See, for example, the sketches and paragraphs in Squier (1855:215; 1860:200), Wells (1857:393), and Scherzer (1857, II:5-6). 
except the ax, machete, digging stick (macana), and shovel (pala), the latter of wood that they themselves make" (quoted in Sandner, 1962:34).

Efforts were made by many authorities to introduce more modern devices, and more productive agriculture, but change was slow in coming. One of the reasons for this was the Spanish tradition of large estates and very low-paid labor. Smith (1949:23-27) has indicated that the large plantations and haciendas proved to be a "cultural sieve" which effectively filtered out many of the needed elements of the Iberian culture. Those devices and practices which would have been particularly beneficial to the independent family-sized farmer were most neglected, since with plenty of labor at their disposal, the hacendados did not concern themselves with efficiency of either labor or land.

Since national policies were entrusted to the local power structure (the owners of large estates) for implementation, it is not surprising the President Barrios of Guatemala was able to accomplish little in the way of modernizing agriculture in Guatemala. In 1879 he issued Decree 242 , instructing the municipios (counties) to introduce plows and carts in their localities in place of the heavy Indian hoe and tump line. The decree was in force until about 1930, but had very little effect. Even today 
Guatemala has the largest proportion of farms entirely dependent upon hand power in Central America.

The vast majority of Central American farmers today still use the age-old practices of fire agriculture and the hoe. Among the Indian communities this might be attributed to resistance to change-stubborn clinging to inefficient methods that were cherished by the ancestors. But this is not true, certainly, for the many young people who leave the established areas of the countries and make their way to the frontiers of settlement in the outlying districts. Here Sandner $(1959: 27)$ has found that many give up the stable, intensive forms of agriculture they have known in their home districts, and take up fire agriculture instead. This, he notes, is a retrogression which leads to the necessity of eventually upgrading once more to a stable, productive form of farming.

On the other hand, there has been a considerable endeavor in recent years to mechanize the production of a few selected crops. The most explicit case is in the raising of cotton, to which reference has already been made. Probably a large proportion of the new tractors and associated equipment being imported into the region in recent times have been put to work on the cotton plantations. The rush to get in on the cotton bonanza has resulted in 
the cropland used for this crop being expanded at the expense of food production (Dorner, et al., 1969:9). The heavy use of machinery has resulted in the loss of jobs for considerable numbers of the poor campesinos who depended upon plantations for their livelihood, and has been of little benefit to the majority of the people-perhaps actually hurting more than it has helped. This new development again points up the problem of the agricultural sector dominated by the large estate, where the well-being of many is dependent upon the economic interests and decisions of a relatively few persons.

The recent mechanization has occurred on a relatively few large farms. It has affected more of the farm laborers than of the genuine operators, and its overall effect in the rural setting may well be unfortunate rather than beneficial.

There has been no commensurate development of the advanced plow culture. The use of the horse and horsedrawn machinery would benefit the family-sized farm, making this kind of farm operation vastly more attractive and efficient. Unfortunately, the cultural milieu is such that few people aspire to operate their own farms with their own labor since manual labor has such a negative evaluation. Those with whom I spoke who appeared to be 
in a position to adopt the horse-drawn equipment showed little interest in doing so. This may be due in part to the prevailing tendency to glamorize everything having to do with powerful machines. Another aspect, I believe, is related to the lack of any form of promotion of such equipment. Since farm equipment is almost entirely imported, this may stem from the approach to agriculture in the manufacturing countries, where mechanization is the appropriate thing. The producing companies may be, in effect, preventing or slowing this phase of modernization.

One can summarize the evolution of ways of farming in Central America rather simply. The vast majority of the farmer and laborer families are the beneficiaries of the cultural tradition which was present in the area at the time of the Conquest, or which has been modified only by the addition of the steel hoe and the permanent use of the same tracts of land. The spanish rooting plow was introduced early in the colonial period, and is the only widespread advancement over hand labor that has yet been made. Advanced plow culture has made almost no inroads into the economy, either in actual use or in terms of aspiration. Mechanization has occurred on a select number of farms, producing principally for the export market, but this "advance" has diverted farmland from food production 
and displaced workers from jobs, resulting in a questionable gain for the inhabitants of the rural zones where the change has occurred.

\section{Present Trends}

The data which would be necessary to make a satisfactory analysis of trends simply do not exist, and it will be some time before they do. In the light of this, the best available information is presented in Table 22 , and a few observations may be made from these data. In the Costa Rican censuses of agriculture of 1950 and 1963 each producer was asked to indicate the sources of power employed on his explotación. These are summarized as being human, animal, or mechanical, but these terms are misleading. In the cases of both animal and mechanical power, these do not necessarily refer to the actual operation of equipment for cultivating the soil. Mechanical power may include gasoline motors for pumping water, windmills for the same purpose, and a host of other devices such as huskers for coffee cherries. One can be sure, for example, that the 2,288 explotaciones of less than 10 manzanas in Costa Rica in 1963 which reported having mechanical power did not all have tractors; as a matter of fact, only 957 possessed such machines (see Table 21). The use of animals for riding or 
Table 22. Changes in the number of farms employing different sources of power, by three size categories:

Costa Rica, 1950 to 1963

Source of Power and Year
Size of Explotaciones (Manzanas)

1-9.9 10-99.9 100 and over Total

All Explotaciones

1950

1963

Per Cent Change

Human Effort only

1950

1963

Per Cent Change

Animal Power

1950

1963

Per Cent Change

Mechanical Power ${ }^{a}$

1950

1963

Per Cent Change

$\begin{array}{rr}18,976 & 20,279 \\ 27,925 & 29,949 \\ 47.2 & 47.7\end{array}$

3,831

6,474

43,086

76.1

64,621

50.0

$\begin{array}{rrrr}16,225 & 16,535 & 2,727 & 35,487 \\ 21,298 & 21,024 & 3,806 & 46,128 \\ 31.3 & 27.1 & 39.6 & 30.0\end{array}$

$\begin{array}{rrrr}2,684 & 3,569 & 894 & 7,147 \\ 4,339 & 6,335 & 1,479 & 12,153 \\ 61.7 & 77.5 & 65.4 & 70.0\end{array}$

$\begin{array}{rrrr}67 & 175 & 210 & 452 \\ 2,288 & 2,590 & 1,462 & 6,340 \\ 3300^{*} & 1380^{* *} & 596^{* *} & 1300^{* *}\end{array}$

SOURCE: Compiled and computed from Costa Rica, DGEC, 1953a:Cuadro 53, and 1965a: Cuadro 148.

Ancludes explotaciones employing animals as well as mechanical power.

*Percentage rounded to two significant digits due to small base figure.

**Percentages rounded to three significant digits. 
for carrying goods qualifies the farm as having animal power even though the animals are not hitched to even a wooden plow. Thus the interpretation of the figures is difficult. Since the base figures are so small for mechanically-powered farms in 1950, the very large proportional changes indicated are not as significant as they appear. Nevertheless, there is no doubt that both animal and mechanical power for the cultivation of fields are definitely increasing in Costa Rica, and the same is probably true for the other nations as well. I think it probable that the increase in the use of animal power is almost entirely accounted for by the use of oxen in rudimentary plow culture, but this is still a notable improvement over hoe or fire agriculture. The increase in employment of tractors (as inferred from comparison of Tables 21 and 22) appears to be greatest in the family-sized category, and this can only be seen as an encouraging sign that perhaps the family-sized farm will become dominant in this country. Data are not available for the other countries, but given the distribution of farms by size in these places, mechanization cannot have the impact in favor of the family-sized farm that it has in Costa Rica. 


\section{CHAPTER VI}

\section{PATTERNS OF SETTLEMENT}

The arrangement of the houses of rural and agricultural people on the land is one of the most important aspects of man-land relationships, and to the trained observer it is one of the most obvious. Generally people who live by farming accept one or another particular type of settlement as natural for themselves, and as almost inevitable wherever unusual geographic circumstances do not intervene. Exceptions to this generalization usually are due to the presence of a heterogenous population stemming from varied backgrounds. Sometimes variations are owing to administrative decisions which have attempted to establish a divergent pattern at some point in the history of the area. There may also be evolutionary modifications which have occurred over a considerable period of time. The pattern employed in a given area may be one of compact villages or of widely scattered farmsteads, or some variation of these. Once a given form has become established, however, it tends to be institutionalized and self-perpetuating. This holds true for new houses established in the area, and also for those persons who 
may leave to settle elsewhere. The fact that people have a proclivity to accept their own particular custom as "natural," and to resist. changes in it with a great deal of determination, makes it extremely important for persons interested in planning new settlements to take the culturally established pattern into account. There may be excellent reasons to desire to introduce changes, but if the new forms are to be accepted by the population the rationale for the change must be made explicit and meaningful. Even then the new pattern may be rejected in actual practice.

\section{The Conceptual Framework}

It is obvious that those who farm must be related to sizable extensions of land if they are to do more than simply satisfy their own subsistence. Since the division of the land into plots, each having even a few manzanas, results in considerable distance separating the nonadjacent fields, the farmer and his family must make a basic decision: to live on the land to be worked, or to live in a community of homes located close to one another. The results of this decision are so important that an understanding of them has come to be an important part of the sociological study of rural life. T. Lynn Smith (1953:Chapter 10) has provided the basic framework for such study, and he utilized it 
himself in the study of Brazilian and colombian societies (Smith, 1963a and 1967a).' The principal types of settlement are three in number.

Agricultural Vizlages

In much of Spanish America it is commonplace to find the farm population dwelling in compact villages and towns with their houses clustered close to one another. In such cases the farmers and farm laborers live on small house lots, separated from their cultivated fields and pastures, which lie scattered about the countryside at some distance from the place of residence. This separation of the dwelling from the fields is the distinguishing characteristic of the agricultural village. In such a village a great majority of the people are active farmers

"The United Nations Economic Commission for Latin America recognized the importance of settlement patterns in social and economic development by the publication of a paper by Marshall Wolfe (1965) which he presented as a reference document at the 1964 Latin American Regional Seminar on the Role of Community Development in the Acceleration of Economic and Social Development. The paper has had wide circulation, being printed in the proceedings of the VII Congreso Latinoamericano de Sociología (Bogota, 1965), and the Latin American Research Review (Spring, 1966). Unfortunately he paid very little attention to the farm management aspects of the different classes of settlements which he formulated, and failed to include in his schema the possibility of the "line village." Rural sociologists, geographers and anthropologists have long stressed the importance of the pattern of settlement, and it is unfortunate that his article, presented in such an influential setting, was inadequate to the task undertaken-especially in its policy recommendations. 
who daily go out from the village to labor in the cultivation of crops or the care of livestock, and return home to the village at the end of the day's work. To be sure, there are other villages also, where most of the people work at other occupations, filling the trade and service needs of the surrounding farmers. These latter villages or towns serve the farm population in important ways, but they are not themselves agricultural villages. Where the farmers live in agricultural villages they can enjoy the many social and cultural advantages which accrue to those who dwell close to their neighbors. The personality of such persons tends to be more broadly developed since there is much more everyday social interaction with others by all members of the family, children and adults alike. In addition to general social activity, the formal social institutions of the school and church are readily at hand, and neighbors are available for mutual aid when the occasion arises. In the village, likewise, there will be stores where needs can be more immediately fulfilled, and there may also be an opportunity to obtain medical attention, agricultural credit and technical assistance. Moreover the provision of costly physical improvements such as all-weather roads, potable water, sewers, electric power and telephones for the residents can be made with much more economy if a village form of settlement prevails. 
In contrast to these manifold advantages, the choice of a village type of settlement imposes many hardships on farmers. Probably most important is the fact that they must "commute" to their everyday work, bearing with them such tools and equipment as may be required. In places where the only means of travel available to the farmer is walking, this consumes a great deal of both time and energy. The village dwellers almost universally maintain their barns or storehouses near the house where they can keep watch over their goods. At harvest time those who depend upon their broad bare feet for bearing homeward the results of their season's labors find the task a particularly arduous one.

With regard to the keeping of livestock the problem is also great. Either these must be left unprotected in the countryside, they must be driven daily to and from the village for pasturage, or all the forage must be carried to the houseyard for them. There are obvious problems of sanitation when many animals and people are crowded together in a limited area, and the utilization of the manure in a productive fashion is much more difficult when it must be carried to the fields. ${ }^{1}$

${ }^{1}$ The use of the manure, as well as simply its disposal, can be very important. In Cajolá, Quezaltenango Department, Guatemala, where the average farm family has 


\section{Isolated Farmsteads}

This second pattern of settlement is found where each farmhouse is placed on the tract where the farmer and other members of his family do their daily work. Such a system does much to ease the everyday burden of the agriculturist as he cares for his crops and livestock. However, even when the landholdings are of only moderate size, the result of this pattern is usually the wide dispersal of farm homes and the relative social isolation of each family from its neighbors. In order to achieve managerial convenience the general social development of the rural population suffers, and the provision of physical facilities such as water and electricity is made immensely more expensive. Moreover, the establishment of effective social control is very difficult when people are set down in isolation from their fellow citizens. Monge Alfaro (1958:154) expressed one of the results of living widely scattered in the early nineteenth century as he wrote of the "undisciplined descendents of the peasants of the eighteenth," saying:

less than one manzana of land, the people keep a few sheep which they graze along the roadsides and high in the mountains on untillable soil. Every day some member of the family takes them out to feed, and carefully gathers all the manure to carry back to the family fields to fortify the overcropped land as much as possible (from an interview with Dr. Dudley Peck in Cajolá, September 2, 1963). 
The matter of submitting themselves to rules, of paying taxes, of respecting the authorities, constituted something new for the cost Ricans. . . As the culmination of evils, there broke out in the country an irresponsibility, vagabondage and lack of respect for the property of others which kept the entire nation at the edge of the abyss. Only a strong hand... could hold back chaos.

Monge does not explicitly state that the chaos he describes derives from the scattered mode of settlement, but it is apparent from his whole description in the preceding 50 pages. The same conclusion may be drawn from a perceptive reading of the account which Pedro Cortés y Larraz (1958), Archbishop of Guatemala, left of his itinerant inspection of the diocese of Guatemala in 1769 and 1770 .

\section{The Line Vilzage}

There is a compromise form of settlement which combines most of the advantages of both village life and the maintenance of the residence on the farm.' When the tracts of land being utilized for farming are laid out in such a way that only a relatively narrow part fronts on a road, river, or other means of transportation and the length of the tract running back from this line is several times that of the frontage, then a pattern similar to the

${ }^{1}$ Unfortunately, many reform programs and their advocates seem to be virtually unawary of this alternative. Even Wolfe (1965:16), while aiming to assist in a "strategy of rural development," gave less than a paragraph to the identification and discussion of the line village. 
keyboard of a piano results. Houses located along the road are near their neighbors, while at the same time they remain on the land they work. Of course this pattern is less effective as farms increase in size. A farm as large as 100 hectares with a frontage one-quarter of its depth would have 500 meters of frontage, and no village could result if many such units were involved, unless they also placed the houses of many laborers along the frontage. On the other hand, a farm of 15 hectares (about 20 manzanas) would have a front measurement of only 200 meters, keeping the proportions the same. Proportions are variable, depending upon the terrain.

In addition to the farm management and social advantages of the line village, there are certain geographic features which very naturally lend themselves to a system of land division which particularly favors the line village. Whenever a belt of land lying between a ridgeline and a stream is to be divided into farms, the most efficient division is likely to be had by running property boundaries in parallel lines from the stream to the ridge. In such a case each tract has access to the water and to the various qualities of land and forest in approximately equal degree. It is very likely that if these tracts are relatively narrow, the occupants will construct their houses along a common line of access, spontaneously creating a village of this type. 
General Evaluation

The relative merits of the several patterns of settlement must be evaluated from both social and managerial perspectives, and the two are often in conflict. Few would question the superiority of clustered dwellings for the provision of schools, public utilities, marketing, and many of the other social and economic aspects of modern society. It is important, however, to learn how great is the cost to the farmer of living off his land in order to have these other benefits. Therefore the value of the farm management advantages of living on the estate are the ones which need testing, and it would be desirable to focus research specifically on this aspect of the matter. No study of this sort was found in Central America. ${ }^{1}$

${ }^{1}$ A study was made in Costa Rica which specifically focused on settlement patterns and their development. Done as a Ph.D. dissertation by Pierre stouse (1965), it was from a geographer's perspective. In his study stouse attempted to judge the benefits of the various forms of settlement he found in lands formerly devoted to banana production. Since among his criteria of adequacy he emphasized the social and public utility conveniences and neglected the farming operations, the result was biased from the start toward the village pattern and against the scattered farmsteads. He concluded that the villages not only enjoyed more of the basic utilities such as potable water and effective transportation, schools and services, but that these farmers had a greater productivity of nonsubsistence crops. Unfortunately the comparison was not a fair one since the village versus scattered settlement was not the basis of the real differentiation as to crops. The Negro farmer fruit company employees who were already accustomed to village life 
In terms of lands not yet occupied the question of alternatives is a different one, since the line village may be promoted by any of several rectangular, circular or hexagonal systems of land division which have been proposed (see Smith, 1947a:133; and 1967b:61-62). Even in areas long settled, Smith has emphasized the potential for revision in the shape of properties through the evolutionary divisions and consolidations that are continually going on. He stresses that with a strategic plan for the location of rural roads property owners would tend to reorient their houses along these, and subdivision would then be likely to occur with lines perpendicular to the roads (Smith, $1953: 273$ ).

Contemporary Settlement Patterns in Central America

Regarding the present-day patterns of settlement in Central America there has been little explicit study.'

remained village settlers and were aided in developing cacao plantings of their own in company land. The utilities and the rail transportation were already established. The farmers he found in isolated circumstances were costa Rican migrants from the highlands who came into the lowland area specifically to become subsistence farmers, and who largely had to take the outlying unclaimed lands.

${ }^{1}$ The analysis for Guatemala by whetten (1956; $1961: 36-43)$ is the most ambitious study, while that of Tax (1937) is much more explicit. The effort of Stouse (1965) for parts of Costa Rica has already been mentioned. Nesman (1969:134-154) presents the general situation for 
Drawing on my own observations made throughout the region, and upon available topographic maps, as well as the comments of others for particular communities or localities, it is possible to make some generalizations about the extent to which different patterns are employed. Since the isolated farmstead is the most widespread type of settlement, it is practical to give first attention to the villages and line villages, and to follow these with a few comments about the scattered farmsteads found over most of the rest of the cultural landscape.

\section{Vizzage Settrements}

There are two principal circumstances in which the agricultural village is commonly found in Central America. The first represents the remnant of patterns of clustered settlement established by the Spanish colonial authorities all over their dominions, and also some cases of preColumbian Indian towns. The second is composed of landless agricultural or pastoral laborers who live in hamlets on

Nicaragua as one of the parts of his overall analysis of man-land relationships in that country. Aside from these, one must rely on reports for small areas or particular communities for published information, and even so it is often necessary to gain insight from maps and photographs in the studies to be sure what the authors mean. For example, Johannessen (1963:65) speaks of a "dispersed pattern of settlement," and it sounds like isolated farmsteads, but the plate which he uses to illustrate what he means proves to be a "dispersed" village without straight streets and only a small area between homes. 
or near the property of their employers. This latter form is properly a variation of the true agricultural village since these people live on the property where they work, but it is not theirs.

Genuine agricultural villages are more common in Guatemala than elsewhere in the region. In the western highlands of that country, particularly around lake Atitlán, there are numerous examples of genuine farm villages from which the men go out to work their fields in the surrounding hills. Many of these have been studied by Tax (1937) and McBryde (1945). San Lucas Tolimán and its surroundings are shown in Figure 10 to illustrate the compact town. (By conventional usage, no houses are shown.in the area with squarish blocks. Nevertheless, the whole area is actually occupied.) In 1964 San Lucas had 3,810 inhabitants (Guatemala, DGE, 1964:8). Very few homes are located outside of the "urbanized" area, and yet farming is the major occupation of the inhabitants. The remaining towns around the lake similarly are composed largely of agriculturists. Other notable villages and towns which are largely agricultural but have few open country residents in their surroundings include Santiago Chimaltenango, Concepción Jacalteca, San Luis Jilotepeque, San Marcos, Poptún, San Luis (in Petén), Magdalena Milpas Altas 


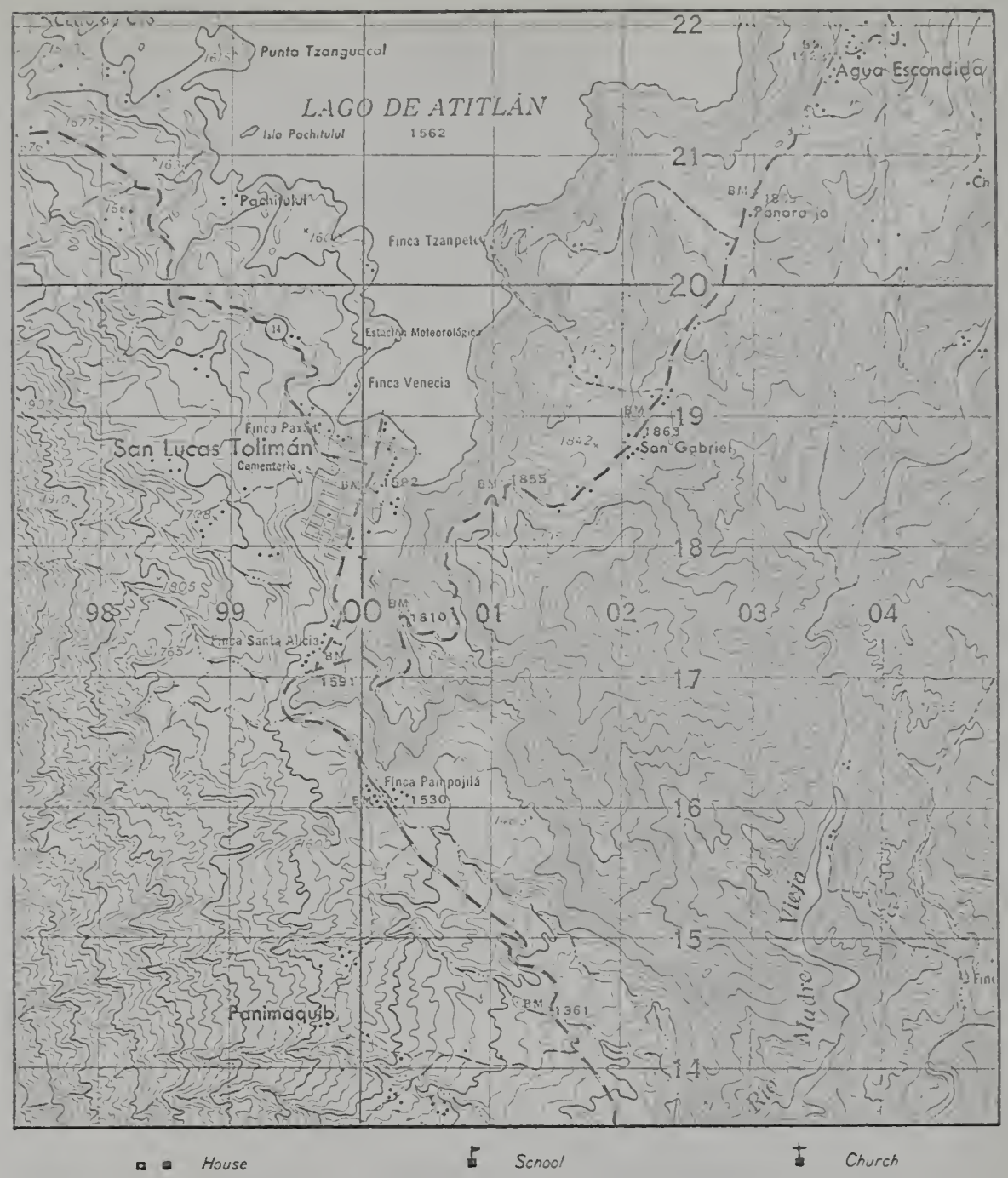

Figure 10. True agricultural village of San Lucas Tolimán at the southeast corner of Lake Atitlán, Guatemala. The area of regular town blocks is fully built up but no house symbols are shown in the town proper. (Reproduced from Guatemala, Dirección General de Cartografía, Hoja 1959 I, "San Lucas Tolimán," published in 1960. Scale 1:50,000.) 
and Cantel. ${ }^{1}$ In addition to these Guatemalan places either seen personally or reported by others, it was possible to examine over 200 sheets of the Mapa Topográfico de la República at a scale of 1:50,000 produced by the Institute Geografico Nacional and its predecessor, the Dirección General de Cartografía. These maps cover all of the country with the exception of the northern part of the Petén, and from them Figure 11 has been generalized. For the present it is sufficient to note the relatively few areas of distinctly village settlement, although the other features will be mentioned later.

In an effort to gain some understanding of Guatemalan settlement patterns on a national basis, Whetten arranged with the Instituto Indigenista Nacional to circulate a questionaire to the alcalde (mayor) of each municipio in 1952. Each was asked to list the segments of his municipio outside of the cabecera (county seat), and to indicate for each whether clustered or scattered settlement prevailed. He found that 20 per cent of the rural settlements were clustered, and that the remaining 80 per cent were arranged in a scattered or isolated pattern (Whetten, 1956:53; 1961:37). Unfortunately, the

${ }^{1}$ Many of these have been studied by anthropologists and geographers in the following studies not previously cited in this chapter: Gillin (1951), Higbee (1947), McBride and McBride (1942), Méndez Domínquez (1967), Nash (1967), Scheele (1957), Stratemeyer and Stratemeyer (1966), Ulrich (1966), Upchurch (1960) and Wagley (1941 and 1949). 


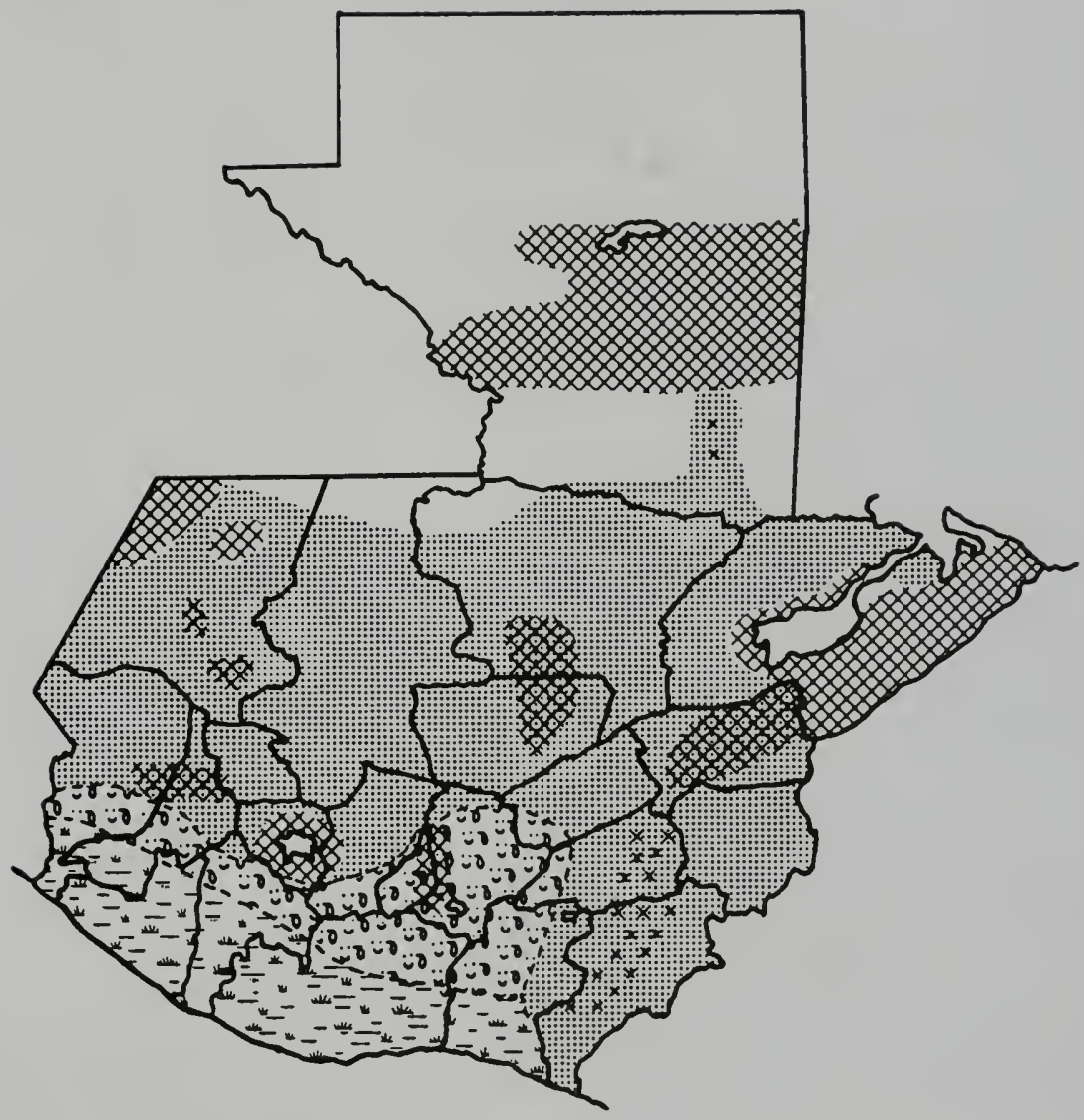

网

Village settlement

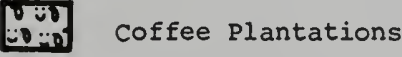

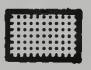

Isolated settlement

$E=-7$

Plantations and Haciendas

Figure 11. Schematic representation of the predominant settlement patterns in Guatemala, generalized from large-scale topographic maps showing house locations throughout the country. 
survey was done by political subdivisions of municipios, and no effort was then made to relate these to census data so as to learn the numbers of families or people whose homes were arranged in each manner. Nor did whetten report any geographic distribution of the different types, although this should also have been possible.

A considerable number of farm families live in villages in the other four countries of Central America as well. In El Salvador there appear to be no areas lacking in a goodly number of isolated farmhouses. Nevertheless, in the departments of La Paz, San Vicente, Usulután and San Miguel the village is more common than elsewhere. Actually in many cases, as illustrated in Figure 12, the houses are clustered in small hamlets or caserios which provide more social contacts that the isolated pattern, but few other advantages. In the 64 square kilometers shown (each square being one kilometer on a side), with over 600 houses, a single church symbol appears, and the only schools evident are at Cantón El Jicaro and Cantón El Cantil. This area is typical of the relative lack of services in many parts of the region.

A few areas of village settlement were seen personally by the writer in Honduras, and again it was 


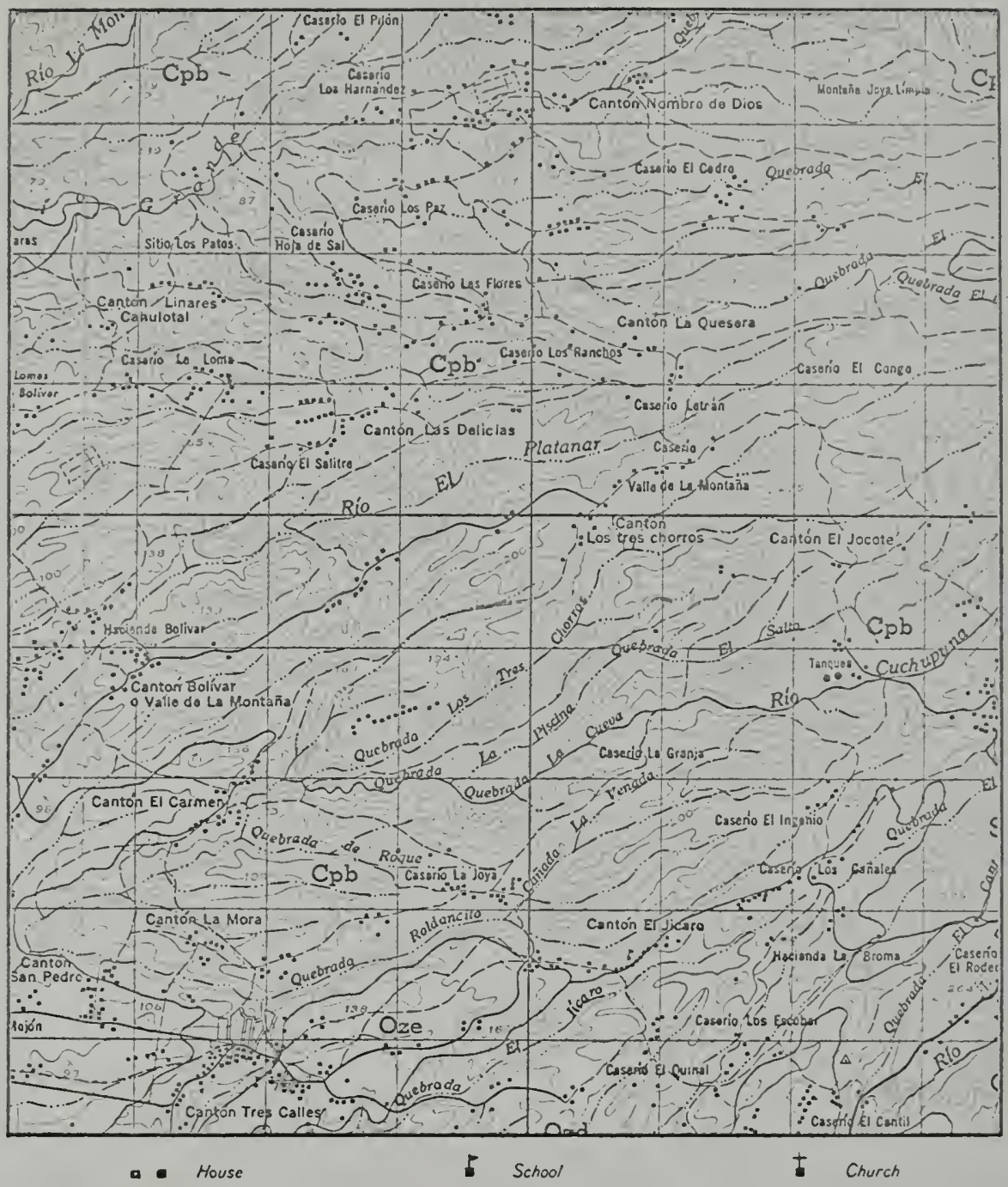

Figure 12. A rural section of Usulután Department, El Salvador, showing the distribution of rural houses in hamlets (caserios) which lack virtually all services, but are clustered enough for considerable social contact. (Reproduced from El Salvador, Ministerio de Agricultura y Ganadería, Levantomiento General de Suelos, with soil types imposed on Cuadrante 2456 II, "Berlin," of the 1:50,000 series of topographic maps. Published in 1962.) 
possible to examine many topographic maps. Nearly all of the occupied portions of the republic have a good sprinkling of scattered farmsteads. However, throughout the Department of Copán and in the northern portion of Santa Bárbara, villages predominate. Around Lake Yojoa as well as in the Comayagua valley and in much of the Department of Yoro the village is the prevailing pattern of settlement, while significant numbers of the farm people in most of the rest of the country may be found dwelling in villages.

Independent farm operators who live in the typical village or town manner are not common in either Nicaragua or Costa Rica. They may be found in the Masaya area of Nicaragua, and in scattered locations elsewhere, but they do not predominate. In the Nicoya peninsula of Costa Rica the longer-established farmers in many cases are settled in towns such as Filadelfia, Santa Cruz, Nicoya, and La Mansion (Wagner, 1958:208), while more recent settlers live on their farms some distance away from the villages.

The second type of village community found in Central America is the hamlet or cluster of farm laborers' houses established by the operators of coffee fincas, cotton farms, cattle haciendas or banana plantations. One can generalize with confidence that on.such places 
it is the custom to erect a series of similar or identical houses in rows or squares where members of the permanent labor force live. This is true even of a large number of colonos and sharecroppers. The largest single employer utilizing such villages, of course, is the United Fruit Company and its subsidiaries. Figure 13 shows a section of the Sula Valley in Honduras in which a series of such villages may be seen (Campos 11, 12, 14, 16, and 18), each housing the workers for the corresponding finca or producing unit. Schools are evident in campos 11 and 12, as well as in nonplantation towns to the east. Such camps generally have frame houses (multifamily style in the older settlements), sanitary water supplies and latrines or sanitary sewers, as well as athletic fields and a store or comissary. In 1963 fruit company villages were to be found on both coasts of Guatemala (around Tiquisate and in the Motagua valley), on the Atlantic coast of Honduras, and on both coasts of Costa Rica. There is considerable turnover in the labor force on the banana plantations, and many of the workers are not accompanied by families, a fact which is of considerable importance in determining the nature of the "community" that exists in a settlement."

${ }^{1}$ See May and Plaza Lasso (1958) for photographs and commentary which present the United Fruit Company in a fairly impartial light, and Kepner (1936) for an older and critical report. 


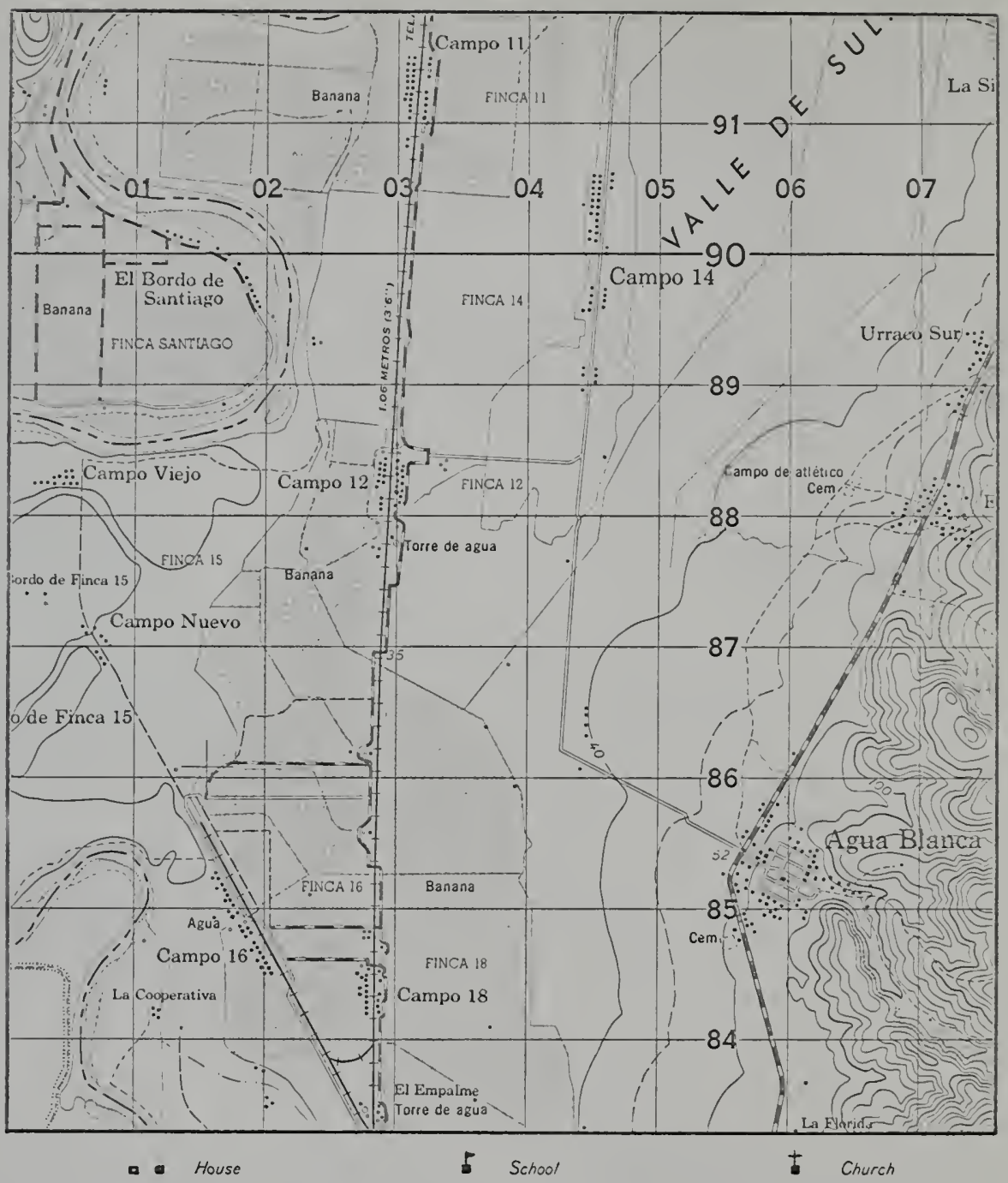

Figure 13. Fruit company settlements in the sula valley of Honduras. (Reproduced from Honduras, Dirección General de Cartografía, Hoja 2661 IV, "Villanueva," published in 1965. Scale 1:50,000.) 
On the coffee fincas the pattern is more varied since so many different owners are involved. Hoyt (1955:35) reported a study of 50 Guatemalan fincas which averaged 4,500 acres each. She found that on "some of the fincas the houses were arranged rather close together in rows like a little village, called a rancheria, which might have alleys or streets at right angles; on other fincas the houses were scattered almost anywhere, not necessarily in close proximity." Other reports (e.g., McBryde, 1945:16; Adams, 1957:449) and personal observation lead me to conclude that the clustered pattern is prevalent in plantation areas of all kinds throughout Central America, irrespective of whether or not the workers are colonos or wagehands.

The examination of the topographic maps of Guatemala enabled me to generalize the coffee finca and hacienda areas on the Pacific side of the country quite well, since most fincas and haciendas are named and their settlements shown (see Figure 11). In that country coffee fincas are also numerous around Cobán. In El Salvador coffee is grown largely in the mountainous areas of Ahuachapán, Santa Ana, La Libertad, and San Salvador in the west, and around Volcán San Miguel in the east. In Honduras the coffee farms were reported to be smaller making the use of workers' villages less common, but in 
Nicaragua the villages are again numerous. These are mostly in Managua, Carazo, Jinotega, and Matagalpa departments. In Costa Rica the use of permanent wage laborers who live on the property is less common. Nevertheless, there are many fincas which use the same clustered settlement pattern found elsewhere. ${ }^{1}$ Similar hamlets are found associated with the larger sugar cane plantations all over the region.

The newest type of plantation agriculture in Central America is the cotton plantation. These establishments are found only on the Pacific coastal plain, and exist in all five countries, though in 1963 there was only a very limited acreage devoted to this crop in Costa Rica. These plantations are generally large and employ many workers, housing them in nucleated fashion. In 1963 the Hacienda La Carrera at Usulután, El Salvador, employed 800 permanent workers living in several clusters. The village at the casco (headquarters) provided the school and the church. The four-grade school had two teachers and 106 pupils, and the church offered a mass every week. There was also a weekly clinic, and since there was electricity the farm provided several television sets for workers to watch. When I visited the hacienda

${ }^{1}$ A good illustration of the pattern is shown in Norris (1953a:91). The extent to which these clusters form self-sufficient communities is suggested in Painter (1953). 
in August, 1963, the administrator told me that they planned to begin constructing multi-family apartment units for permanent hands soon. Since cotton farming is relatively new as a large operation, a number of the operators seemed to regard it as too speculative to invest in permanent housing and facilities. Therefore, in 1963 at least, conditions in the cotton sections were often not comparable to La Carrera.

Many farm workers do not live on the land of the hacienda at all, but are minifundistas whose tiny plots grant them places to live and at the same time require them to work for others. Owing to the small size of these tracts, the houses are in clusters even though they live on such land as they have. This may be the situation illustrated in Figure 12, which is just a few kilometers north of the cotton plantations of the Usulután coastal plain.

There are two sorts of ethnic differentiation which have been noted regarding the settlement patterns of Central America. For Guatemala, Tax (1937:432), McBryde (1945:128), and West and Augelli (1966:394) all suggest that the Ladinos (non-Indians) tend to live in villages and towns and the Indians more commonly reside in the open country. Actually there are manifold exceptions to this generalization, though it is accepted as "common knowledge" by many welleducated Guatemalans. In Costa Rica, Stouse (1965:85-89) 
found that in the Atlantic coastal area the Negro families tended to settle in the villages along the railroads to raise cacao, while the highland Costa Ricans who came down into the area moved out into the countryside to establish isolated subsistence farms. No explanation was offered, but it seems likely that the Negroes were already accustomed to the plantation town pattern as former fruit company employees, while the highlanders were poor homésteaders who were used to the isolated pattern and thought it was "natural."

In spite of the variety of circumstances in which the agricultural village has been reported in these pages, the writer would estimate that the farm population residing in villages is a minority of the agriculturists in each of the countries concerned. Probably El Salvador has the highest proportion living in villages and caseríos, and it may be that, as Wolfe reports, the majority of Zandless farm workers in that country today live, not on the farms and haciendas, but in the genuine towns and villages. ${ }^{1}$

\footnotetext{
${ }^{1}$ Wolfe (1965:9) quotes Tricart (1962) as his source. The important word here is "landless," since this excludes the colono, the sharecropper and the minifundista. Wolfe also cites Adams (1957) but takes him out of context in trying to stress the urbanization of agricultural laborers.
} 


\section{Line Vizlages}

The line village is a rarity in the whole of Central America. There are innumerable cases of plantation or worker hamlets arranged with the houses in one or two rows along a road. But since the key characteristic of the line village is living on the family's farmland, these do not qualify. The best examples which I personally saw were on the Meseta Central of Costa Rica, from which the example of the Turrúcares area is selected for Figure 14. In a few cases riverfront homesteads may be close enough together to qualify as a rudimentary line settlement (see Nesman, 1969:146, 147), and in some of the more densely settled areas of the Guatemalan highlands and $E I$ Salvador there are what appear to be line villages. It must be pointed out that many "linear" villages are true farm villages with the farmers working land quite separate from the visible houseplot. Such is the case wherever fire agriculture is practiced. Carter (1969) fully describes such a village, Chichipate, newly established near the Atlantic coast of Guatemala. The inhabitants are Kekchi-speaking Indians who migrated from Alta Verapaz, and who practice fire agriculture in the areas off the road to both sides. Figure 15 shows the perfect line formed by the houses of Chichipate which extend for more than a kilometer along both sides of 


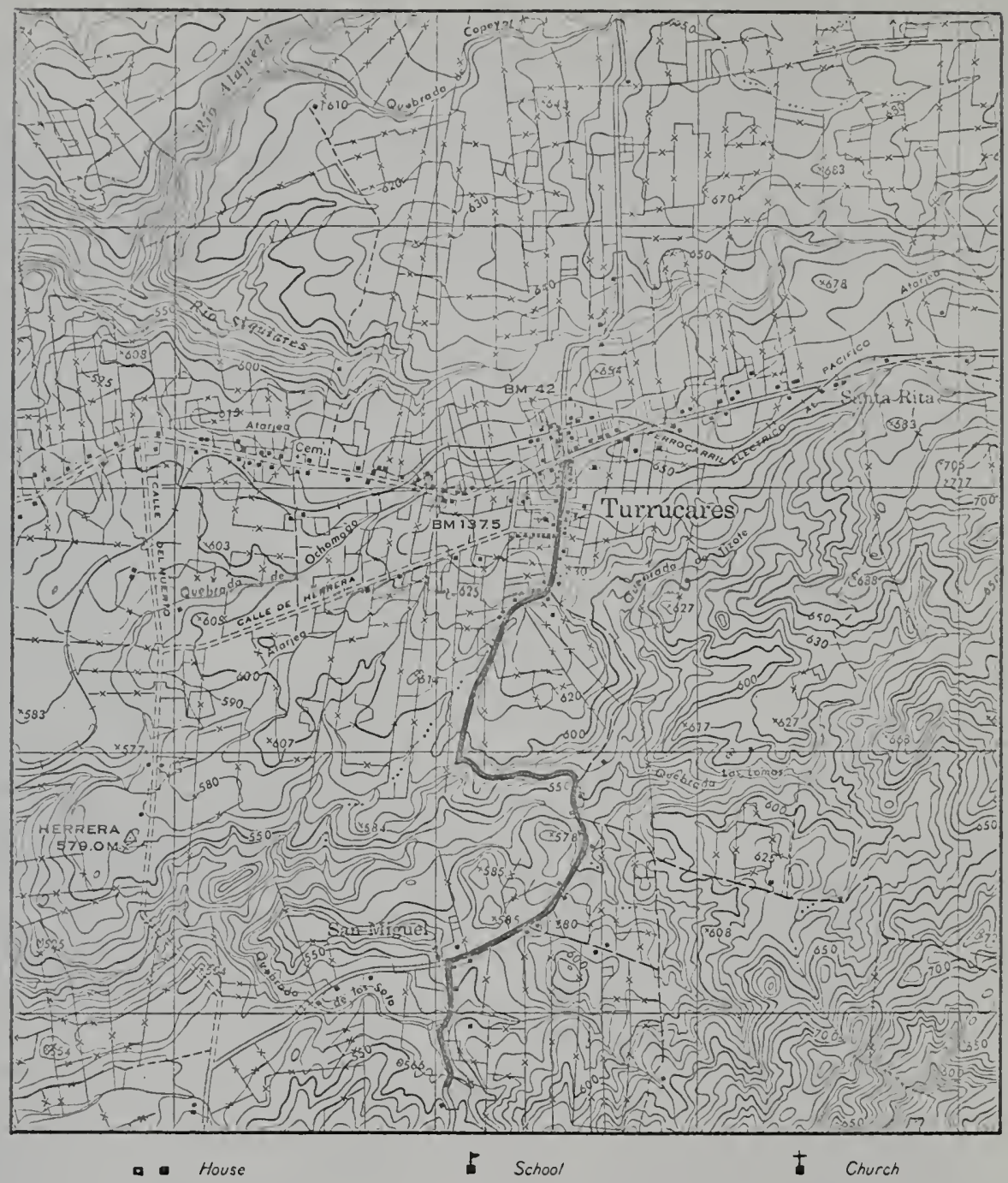

Figure 14. A line village development extending to the east and west of the village of Turrúcares, Province of Alajuela, Costa Rica. (Reproduced from Instituto Geográfico de Costa Rica, Hoja 3345 IV NE, "Turrúcares," published in 1954. Scale 1:25,000.) 


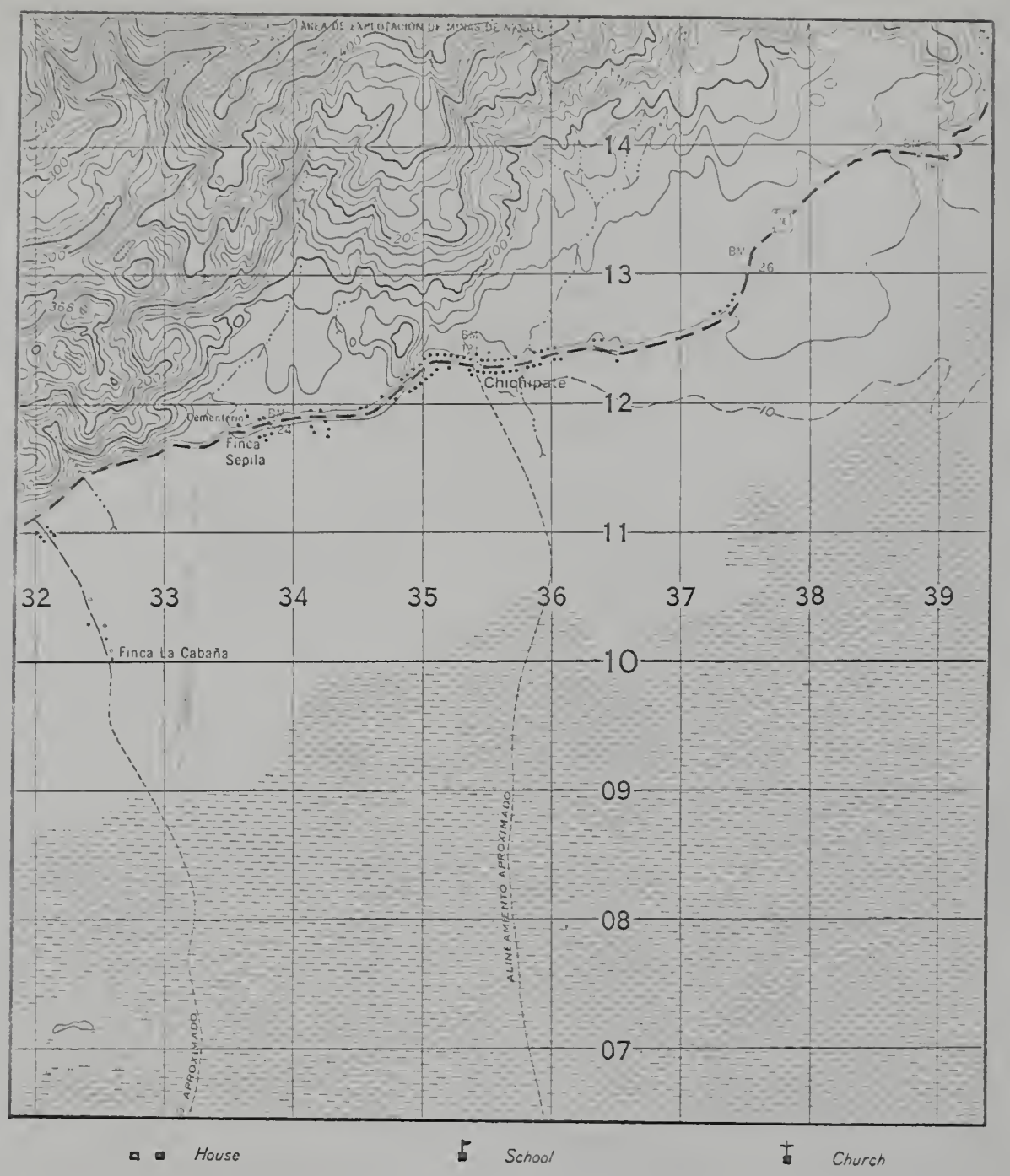

Figure 15. False line village of Chichipate, near El Estor, Guatemala. The families living in this village practice "Fire agriculture" on scattered tracts in the surrounding area. (Reproduced from Guatemala, Instituto Geográfico Nacional, Hoja 2362 III, "Rio Polochic," published in 1966. Scale 1:50,000.) 
the road. It is easy to see how it could be mistaken for a genuine line village, if one did not know the relationship of the families to the cropland.

One experimental line village which the writer was unable to visit is in the form of a circle somewhat like those used in Israel (see Smith, 1953:214-216; 1967b:63). Salazar (1962:232-236) reports that following a flood in a Guanacaste community in 1955, the Costa Rican government determined to relocate the affected families in an undeveloped area of the country. At Santa María de Upala in western Alajuela Province a site was selected and Colonia La Libertad was laid out, utilizing two concentric circles. Each colonist was to be given five hectares between the two circles, and the area inside the inner circle was the service section of the community. In 1961 it had a sawmill, sugar mill (trapiche), and grain drier installed. Additional land in the amount of 20 hectares was also alloted to each colonist outside the circles, but Salazar described these tracts as "irregularly" placed. No definitive titles had been issued at the time of his report.

As far as the writer was able to learn, this was the status of the line village in 1963. There was talk of using this advantageous form of settlement in certain 
colonization schemes and agrarian development zones, but none had materialized at that time. ${ }^{1}$

\section{Isolated Farmsteads}

It has already been indicated that the majority of the agricultural people of Central America live in dispersed farmhouses located out on the land they work. Two figures have been prepared to illustrate differences in Central American areas of scattered settlement. Figure 16 displays a section on the border between Guanacaste and Puntarenas provinces, Costa Rica, where houses are few and far between. (Distances may be gauged on all of these figures by remembering that the vertical and horizontal lines are drawn at one kilometer intervals.) In the situation around Pozo Axul, a household may easily be half of a kilometer from any neighbor. On the other hand, the Quiché Indians of Guatemala who dwell on the hills north of Santa Cruz del Quiché are in a land of minifundios where most live within 100 meters of another house (Figure 17).

Outside of the crowded central valley of Costa Rica, a pattern more like that at Pozo Azul prevails in

${ }^{1}$ Costa Rica had established the principal in 1934 that public lands adjoining existing or planned means of communication should be rectangular in shape with frontages no greater than one-fourth of the depth. It was not apparent that the laws to this effect were very effective (see Costa Rica, 1824:Dec. Leg. No. 29, dated December 3, 1934; and Dec. Leg. No. 13, dated January 10, 1939). 


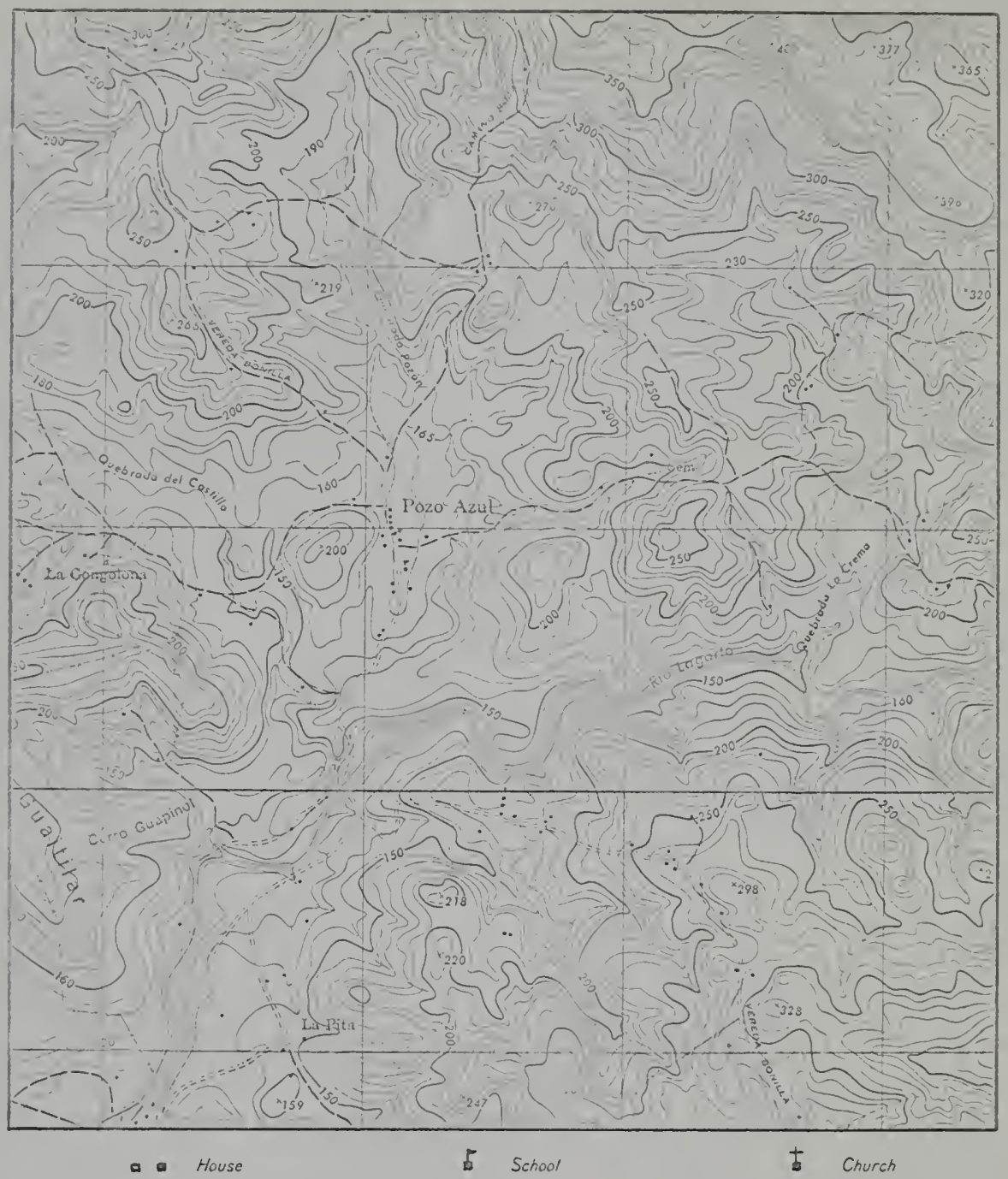

Figure 16. Scattered farmsteads in the cereal and cattle zone of Pozo Azul, Guanacaste, Costa Rica. (Reproduced from Instituto Geográfico de Costa Rica, Hoja 3246 IV SW, "Pozo Azul," published in 1956. Scale $1: 25,000$.) 


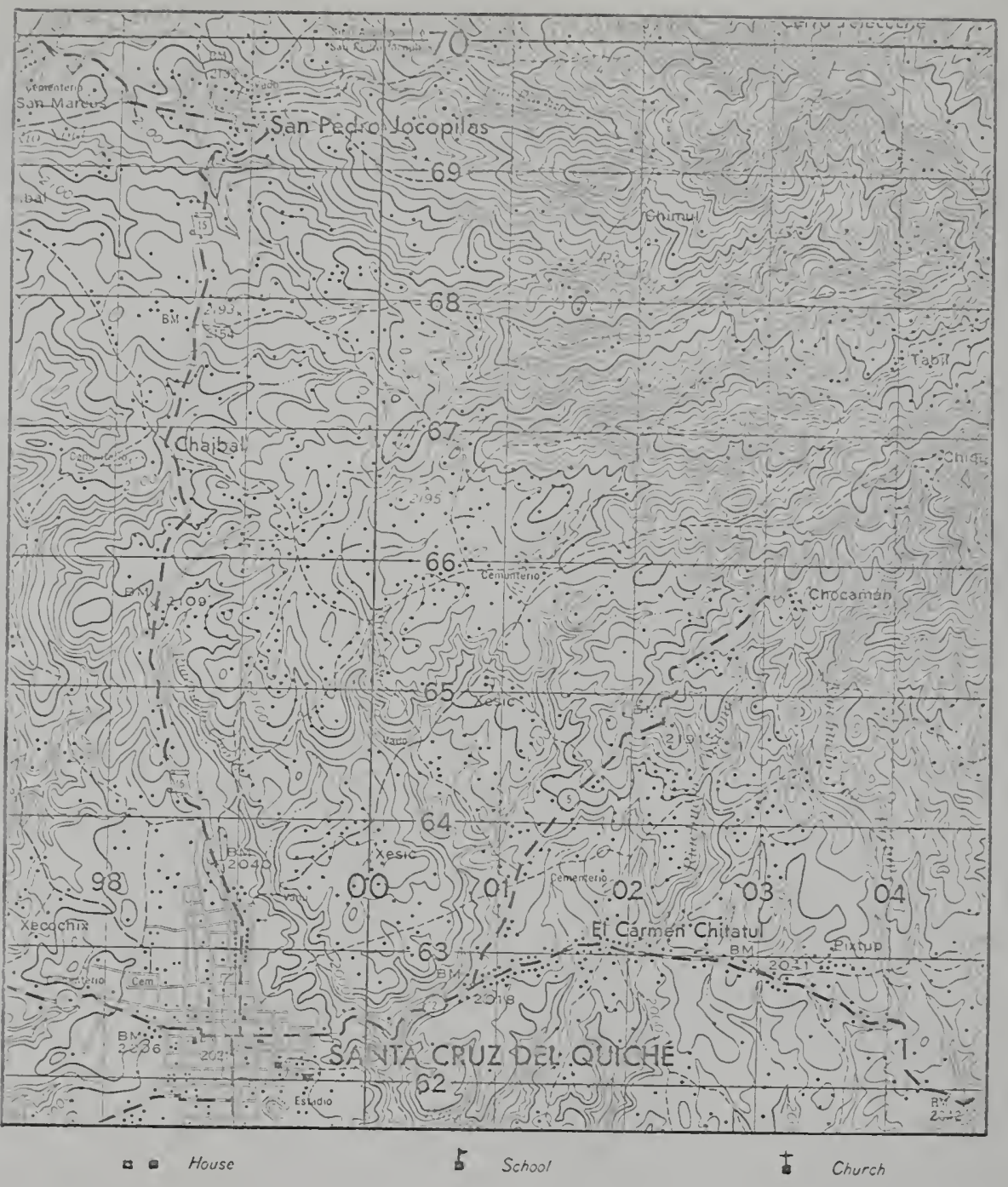

Figure 17. Scattered farmsteads in a zone of minifundios, Santa Cruz del Quiché, Guatemala. (Reproduced from Guatemala, Instituto Geográfico Nacional, Hoja 1961 II, "Santa Cruz del Quiché," published in 1968. Scale 1:50,000.) 
the rest of the country, while is Western Guatemala people are as crowded as at Santa Cruz. A few areas in Honduras and Nicaragua are quite crowded, but on the whole these two countries resemble more the Costa Rican illustration. El Salvador, as the most densely populated Spanish American nation, has already been shown to be so thickly sprinkled with rural houses as to approach a village status.

In order to gain some insight into the actual proportion of farm families who live scattered over the countryside, Table 23 was prepared to display the available data for Costa Rica. In this table only the farms operated by individuals are included, the corporate, cooperative, and other types of producers being eliminated since by census definition they live off the farm. The further division of the producers by occupation into a farmer category and a group who professed to be something other than farmers throws real light on the residence of the farm population. On the average, 81 per cent of the fulltime farmers lived on their properties, and thus almost surely in the scattered farmstead pattern. Even among those whose principal interest was in some other field of endeavor, more than 60 per cent lived in the open country on the farm. Thus there is numerical confirmation of the 
Table 23. Relative number of individual producers who lived on their explotaciones, by size of explotación and occupation of producer: Costa Rica, $1963^{a}$

\begin{tabular}{|c|c|c|c|c|}
\hline \multirow{2}{*}{$\begin{array}{c}\text { Size of } \\
\text { Explotación } \\
\text { (Manzanas) }\end{array}$} & \multicolumn{2}{|c|}{$\begin{array}{l}\text { Producers Whose } \\
\text { Occupation Was "Farmer" }\end{array}$} & \multicolumn{2}{|c|}{$\begin{array}{l}\text { Producers Whose Occu- } \\
\text { pation Was Not "Farmer" }\end{array}$} \\
\hline & $\begin{array}{l}\text { Total } \\
\text { Number }\end{array}$ & $\begin{array}{l}\text { Per cent } \\
\text { Living on } \\
\text { Explotación }\end{array}$ & $\begin{array}{l}\text { Total } \\
\text { Number }\end{array}$ & $\begin{array}{l}\text { Per Cent } \\
\text { Living on } \\
\text { Explotación }\end{array}$ \\
\hline $\begin{array}{l}1-3.9 \\
4-9.9\end{array}$ & $\begin{array}{l}9,244 \\
8,866\end{array}$ & $\begin{array}{l}74.6 \\
79.5\end{array}$ & $\begin{array}{l}5,159 \\
3,662\end{array}$ & $\begin{array}{l}62.9 \\
62.3\end{array}$ \\
\hline $1-9.9$ & 18,110 & 77.0 & $\frac{8,821}{:}$ & 62.6 \\
\hline $\begin{array}{l}10-19.9 \\
20-49.9 \\
50-99.9\end{array}$ & $\begin{array}{l}6,736 \\
9,762 \\
5,282\end{array}$ & $\begin{array}{l}82.8 \\
86.6 \\
86.5\end{array}$ & $\begin{array}{l}2,400 \\
2.908 \\
1,551\end{array}$ & $\begin{array}{l}64.0 \\
67.7 \\
62.0\end{array}$ \\
\hline $10-99.9$ & 21,780 & 85.4 & 6,859 & 65.1 \\
\hline $100-249.9$ & 2,919 & 81.5 & 1,079 & 49.7 \\
\hline $250-499.9$ & 730 & 70.3 & 362 & 38.1 \\
\hline $500-999.9$ & 261 & 59.0 & 164 & $30_{\star} 5$ \\
\hline $1,000-3,499.9$ & 115 & 52.2 & 75 & $21_{\star}^{\star}$ \\
\hline 3,500 and over & 11 & $27^{\star}$ & 3 & $0^{\star}$ \\
\hline 100 and Over & 4,036 & 77.0 & 1,683 & 44.0 \\
\hline Total & 43,926 & 81.2 & 17,363 & 61.8 \\
\hline
\end{tabular}

SOURCE: Compiled and computed from a special tabulation of the Costa Rican Agricultural Census of 1963, using a data set from the University of Florida Latin American Data Bank (n.d.).

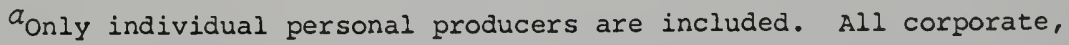
cooperative, and other producers have been eliminated.

* Rounded to two significant digits due to small base. 
overwhelming extent to which the costa Rican farmer lives on the land, foregoing many of the advantages of more clustered living. It is notable that in the case of the "farmer" producers this is true of all sizes except the explotaciones of 3,500 manzanas or more. Even among the nonfarmers, most producers holding fewer than 100 manzanas were country dwellers.

It is possible to garner some clues to the extent of the isolated farmstead in Guatemala, also. The 1964 censuses of population and housing included a question that read, "Is this housing unit located in an explotacion agricola?" In an attempt to relate this information to farm operators, Table 24 presents the percentages of all the heads of households who stated that their occupation was "farmer" or "cattleman" who were living in an explotacion. The occupations identified as farm laborers and peones were excluded from the tabulation, but it is not clear just how the colono is likely to identify his occupation to the census-taker. Among those who professed to be farmers and cattleraisers 57 per cent lived on the land and 43 per cent lived elsewhere. At the national level the ethnic differentiation is just as people commonly say it is: Indians live in the countryside in higher proportion than do the ladinos. However, the regional data prove to be more significant than the ethnic ones, 
Table 24. Relative number of heads of households who were farmers and cattlemenaliving on an explotación agrícola, by ethnic group and region: Guatemala, 1964

Economically Active Population with Occupation as Farmer or Cattleman (Excluding Laborers)

\begin{tabular}{|c|c|c|c|c|c|c|}
\hline Region $b$ & $\begin{array}{l}\text { Total } \\
\text { Number }\end{array}$ & $\begin{array}{l}\text { Per Cent } \\
\text { Living on } \\
\text { Expl. Agr. }\end{array}$ & $\begin{array}{l}\text { Total } \\
\text { Number }\end{array}$ & $\begin{array}{l}\text { Per Cent } \\
\text { Living on } \\
\text { Expl. Agr. }\end{array}$ & $\begin{array}{l}\text { Total } \\
\text { Number }\end{array}$ & $\begin{array}{l}\text { Per Cent } \\
\text { Living on } \\
\text { Expl. Agr. }\end{array}$ \\
\hline Republic & 264,500 & 57.4 & 113,000 & 48.3 & 151,500 & 64.1 \\
\hline Central & 36,000 & 40.3 & 17,800 & 41.6 & 18,200 & 39.0 \\
\hline South & 21,600 & 59.7 & 20,800 & 59.6 & 800 & $62^{\star}$ \\
\hline West & 100,700 & 67.3 & 24,300 & 61.7 & 76,400 & 69.1 \\
\hline North & 54,000 & 74.6 & 13,600 & 62.5 & 40,400 & 78.7 \\
\hline East & 52,200 & 31.0 & 36,500 & 31.0 & 15,700 & 31.2 \\
\hline
\end{tabular}

SOURCE: Compiled and computed from a special tabulation of a 1 per cent sample of heads of households of the Guatemalan Population Census of 1964, using a data set from the University of Florida Latin American Data Bank (n.d.).

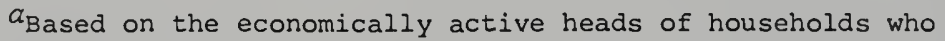
reported their occupation as agricultor or ganadero on the population schedule. Figures in the table have been inflated by a factor of 100 .

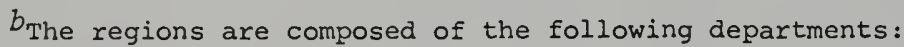

Central: Guatemala, Progreso, Sacatepéquez, Chimaltenango;

South: Escuintla, Santa Rosa;

West: Solola, Totonicapán, Quezaltenango, Suchitepéquez, Retalhuleu, San Marcos, Huehuetenango;

North: Quiché, Baja Verapaz, Alta Verapaz, Petén, Izabal;

East: Zacapa, Chiquimula, Jalapa, Jutiapa. 10,000 .

* Rounded to two significant digits since the base was less than 
for within the regions the residential patterns of both groups prove remarkably similar, and in fact disappear in the Central, South, and East. Unfortunately the sample is too small to carry the analysis to the departmental level, but there is general confirmation of the tendency to live on the farm, and presumably in the scattered pattern. Similar results would probably be found for the independent farmers of all the republics, but there is a tendency for the minifundista to cluster, as there is also with the colono and the farm laborers of other sorts.

Evolution of Settlement Patterns in Central America

To understand how the Central American region came to be arranged in such a conglomerate fashion with regard to settlement patterns, it is useful to trace briefly the historic influences which have played over the area. In the four and one-half centuries during which the indigenous and Spanish traditions have been mixing and competing, each has made its contribution. The situation today is not a matter of any particular strain having become dominant, but instead represents the current stage in the continual search for desirable man-land relationships. The Aboriginal Pattern at the Conquest When the Spanish explorers arrived at the land which has since been variously the Captaincy-General of 
Guatemala, the United Provinces of Central America, and the five independent nations of today, they found a great variety of Indian groups in various stages of social development. Chief among these in terms of numbers and civilization were the members of the great Maya family of tribes who spread over Guatemala and much of El Salvador and Honduras as these states are now constituted. Dozens of scholars have devoted themselves to the study of the ancient Mayas, and many have dealt specifically with "settlement patterns" of one sort or another." Haviland (1966) has recently exposed their dissension among themselves, and called for more rigorous research in their field before any more theory building is attempted. For the purposes of this study, however, the main outlines seem to be clear.

Among the ancient Mayas there was a highly developed ritual and political system which resulted in there being many ceremonial centers with temples, stelae, and other durable constructions. These have attracted continuing interest. However, the majority of the people were dependent upon fire agriculture and their use of

${ }^{3}$ Some of the most direct study of settlement patterns is summarized in the following reports, all of which draw on the work of others as well as the authors: Willey (1956); de Borhegyi (1956); Wolf (1959); Vogt (1964a and 1964b); de Borhegyi (1965); Willey et al. (1964); and Willey and Bullard (1965). 
the land was temporary. Therefore they did not dwell on the land we would today call their "farm," or cropland. Naylor (1967:622-623) describes the pattern well:

Among the more advanced horticultural peoples of the New World, the pattern of settlement tended to be that of a rural community with clusters of houses indiscriminately located. . . Adjacent to each house was often found a cultivated family plot, but with the milpa system of Mesoamerica the individually assigned lands were customarily located outside the rural village.

Such places as Naylor describes probably coincide with the "dispersed hamlets" Johannessen (1963:65) describes in Honduras today, and those reported during colonial times.' Most reports suggest that the Maya and other Indians were widely distributed over the landscape and not gathered into compact towns (Jones, 1940:169; Marroquín, 1965:15; Sandner 1962:22-26). There may well have been groupings of houses in very small numbers, as de Borhegyi (1965:61) suggests, but even so they would have been separated by considerable distances quite different from the typical

${ }^{1}$ Part of the confusion existing among the earliest chroniclers appears to be due to a semantic problem. Each viewer used his own conception of a town or village as the base against which to compare the native settlements. If the houses were more dispersed than a particular observer's notion of a village required then he reported them as isolated or dispersed. If, on the other hand, residents appeared to be closely related to one another socially, religiously, and politically, and if no preconception of clustered settlement prevented it, the same group of natives might be described by another as a village. 
Spanish town. In any case, the pattern was destined to be disrupted by the advent of the conquering Iberians soon after 1500 .

\section{Village Settlement under Spanish Rule}

In much of Europe in the fifteenth and sixteenth centuries agricultural and pastoral people were scattered widely across the countryside. Owing largely to the centuries of occupation by the Moors and to the long effort to reconquer the Iberian peninsula, the farm people of Spain in this period were clustered in villages and towns (Schulman, 1954:80-81). The village pattern was found in Portugal, likewise, and has continued there to the present day (T. Lynn Smith, 1963b:323).

As the Spaniards entered the New World a period of laissez-faire confusion regarding settlement patterns was evident at first (Stanislawski, 1947). Very soon, however, the Council of the Indies took cognizance of the need for orderly settlement and began to issue instructions for the establishment of carefully-planned towns and cities, ordering that the encomenderos should live in these places and not on their land (Spain, 179l:Libro IV, Título VIII, and Libro VI, Título IX). In order to facilitate better control over its native subjects, and to ensure their proper Christian training, the Crown issued 
cédulas on many occasions, beginning under Queen Isabella about 1503, instructing that the Indians should be gathered together in towns or large villages (Haring, 1963:64; Sol6rzano F., 1963:78; Marroquín, 1965:165-166).1 As Marroquín said, "With this procedure an attempt was made to put an end to the system of dispersed communities, which was the prime characteristic of the indigenous community" (p. 166). Kelsey and Osborne (1952:55) tell how this was often accomplished peacefully:

To persuade the Indians to leave their scattered, independently located huts and fields, they used a most convincing argument. Selecting a strategic site for a village, the priests planted corn about it, built huts and started the foundation for a church. When the corn was ripe, the Indians were invited to see it and to dance and feast. Shortly each hut would have its occupants, more would be under construction, and the village was a fact accomplished.

Thus by the end of the first century of spanish domination a village pattern of settlement had been imposed on the Indian population, and travelers such as Gage (1964:278-279) reported that in many places the countryside was fairly deserted in favor of towns.

${ }^{1}$ For the general plan and procedure of reducing scattered Indians to village settlements, see simpson, 1934b. The Laws of Burgos (Simpson, 1934a) were the first place where the policy was stated in general terms. 
Many of the towns present today owe their origin to the creation of towns of Indians. '

More recent travelers and emissaries in the nineteenth century were struck by the scarcity of rural dwellings, thus attesting to the success of the Spanish colonial policy in many areas. Stephens (1841, II:200, and passim) remarked on the agricultural towns of Guatemala, and Dunlop (1847:61-63) reported traveling whole days at a time in El Salvador without finding more than a few houses outside the towns and viliages. The clearest description is that provided by an American diplomat, Ephraim George Squier (1855:326), who reported of EI Salvador:

It is unquestionably more populous than any other equal portion of Spanish America. The traveler, however, would not be apt to receive this impression in traveling through the country, since comparatively few of the people live outside of the numerous villages which dot over the state in every direction. The inhabitants of these towns have their little patches of ground at distances varying from one to five miles from their residences, and think little of traveling that distance in the morning to work them, returning at night. It is this circumstance which lends much

${ }^{1}$ Among the Guatemalan towns created in the establishment of Indian reducciones, according to solbrzano $F$. (1963:80-81), were Santa Cruz del Quiché, Santo Tomás Chichicastenángo, Zacualpa, Santa María, San Antonio, San Bartolomé, San Miguel, Chalcuhua, San Pedro Jocopilas, Cuñen, San Andrés, and San Juan de Amatitlán. Wagley (1949:8) says that Santiago Chimaltenango is also a result of the spanish policy, but one of relatively few in the department of Huehuetenango, Guatemala. 
of the picturesqueness and life to the journeys of the traveler, who, as he approaches the villages in the evening, or departs from them in the early morning, finds the paths thronged with people bearing their implements of cultivation, or loaded with the produce of their little huertas or chacras.

He also made similar observations about the settlements in Nicaragua (Squier, 1860:649).

The Transition to Scattered Farmsteads

The historic circumstances are not entirely clear, but the habit of living in villages and towns was never fully established by the colonial authorities in Central America. Moreover, where the pattern was instituted a variety of factors soon resulted in a movement of farmers into the countryside again. Chief among these factors were the following: (1) a shortage of Indian laborers forced many colonists to work their own farms on a family-sized subsistence basis; (2) the rapid rise of a class of mestizos for whom no provision was made in the colonial plans; (3) almost continual warfare during the decades following the attainment of independence; (4) the desire to flee from constituted authority-especially by Indians; and (5) in many cases the legal provisions for occupying new land required living on the land for a given number of years to obtain title to it.

The shortage of Indian labor in Costa Rica has been mentioned frequently as one of the factors responsible 
for the country's democratic heritage (e.g., Biesanz, 1944:6). Certainly it is also a major cause of the pattern of isolated settlement, since the death of many of the Indians in encomiendal left virtually no one to perform the labor of even subsistence agriculture except the colonists themselves. Sandner $(1962: 35-36)$ has summarized the developments in Costa Rica during colonial times thus:

The pronounced tendency toward dispersed settlement made it difficult to form towns. When the aboriginal workers, the Indians who had been assigned in encomiendas, disappeared, the white encomenderos moved to reside on their farms and came to the city only on sundays and holidays. The subsistence economy, forced upon them by the lack of commerce and markets, had already pushed the settlers toward. the farms, where they lived in adobe houses or poor huts. The settlement of the central valley, begun at the beginning of the eighteenth century, was initiated in the form of dispersed settlements and huts disseminated here and there. . . . The royal and church officials many times attempted to require the people to renounce the dispersed settlement.

Finally, after less forceful efforts had failed, don Tomás Lopez de Corral, mayor of Cartago, in 1755 ordered all the residents in the region to build dwelling houses in town

${ }^{1}$ The deaths attributable to smallpox and other diseases are traced in some detail in Thiel's monograph (1967:91-95), as are the devastations caused by the Mosquitos (Indians) of the Atlantic lowlands and the English pirates who frequently attacked both shores and entered, at times, far inland. 
within 60 days (Biesanz, 1944:8). The reform was shortlived, and soon the old tendency reexerted itself; people again were living on their farms throughout the valley.

A similar occurrence could be traced in the other parts of Central America among those Spanish persons who were unable to obtain Indian laborers through the encomienda or the repartimiento. Many of these, when forced to perform the labor on their own lands, chose to live there as well.

A second factor which undoubtedly played a major role in the transition to isolated settlement was the appearance on the scene of large numbers of mestizos-the half-breed offspring of Spanish men and Indian women. Generally speaking, the colonial system was not prepared for these persons, and they were forced to fend for themselves. Rarely did they have the opportunity to rise above the class of small farmers, and as such they frequently found it desirable to live on their parcels in the countryside. Smith (1967a:277) reports a similar development in Colombia in the colonial era.

Another factor encouraging isolated settlement was the chaotic political history of the region following its independence. The Central American states gained their independence from spain without a struggle. However, 
there was no consensus as to the government to be adopted thereafter, with the result that internal strife was rampant. A tenuous union of the five provinces existed until 1839, when it ended in bloody civil war. Thereafter, one caudillo after another attempted to reunify the states by force, and there was the long filibustering episode of William Walker. In addition, there were coups d'etat within the different republics. These forms of disorder involved both bloody fighting and forced drafts of financial support, leading many of the inhabitants to forsake the established towns and make new homes in the lessaccessible countryside. There they hoped to escape the turmoil through isolation (see Parker, 1964:80-82 and passim).

The heavy-handed rule of spain in colonial times gave rise to a further reason to seek isolation. Since the Indians were subject to virtual enslavement in the reducciones and pueblos, many fled into the hills and inaccessible valleys to gain a sort of freedom. Archbishop Cortés y Larraz (1958,I:150) reported the situation around Usulután in 1769 thus:

On the good land and in the fertile settlements which the ladinos [Spaniards and mestizos] enter, the Indians are very soon finished off, as the whole province of San Salvador is testimony, where, as I have said, there are perhaps not even one-tenth of the Indians [left]. This may be attributed to a 
variety of motives, but among these I am afraid that the Indians flee to the woods to escape from the injuries, trickeries and robberies with which the ladinos endanger and destroy them.

Throughout his long report he continually refers to the flight of Indians from Spanish authority as he explains the deficiency of the statistics which he is able to present on the indigenous population.

However, it was not only the Indians who fled the power of the established authorities. Cortéz y Larraz (1958, I:154, 251 and passim) also frequently notes that the poorer Spaniards and mixed-blood persons often fled "justice and the parish" with the goal of living in complete freedom and without regulations. Monge (1958:110-126) ascribes comparable motives to a great many Costa Ricans in the eighteenth century, and a similar impression is gained as one reads of cockburn's travels through all five provinces about the same time (Termer, 1962). The tendency to spread into the hinterland was condemned regularly but ineffectively by both civil and religious leaders. Again the Archbishop of Guatemala may be cited as an example of the official evaluation of this move toward isolation. In his report on Metapán, El Salvador, he wrote:

On the plain of this town alone, which as has already been said is of one league, there would be room enough for all the membership of the parish, 
which [presently] occupies 14 long and nine wide. Reduced to the aforesaid league of land, it would be well administered and served; but scattered so much they are in total abandon and need, especially having such bad roads; thus the only remedy is to burn down the hamlets and huts so they will live in the town; and if this does not seem [wise], there could be two towns apart from the lakes a little way, where there is much flat land and good soil (Cortés y Larraz, 1958, I:260).

All of the foregoing tendencies were spontaneous, and not the result of any conscious policies. There remains one factor which was the result of legal requirements in the alienation of public land. In laws dating from 1909, and valid until 1934, Costa Rica's legislators specified that to make a valid claim to public lands the claimant had to build his house on the property and reside on it with his family. ${ }^{1}$ In Guatemala, two acuerdos of President Lázaro Chacón in 1929 (Sept. 26 and 28, in Méndez Montenegro, 1960:445-449) offered land to expatriate Guatemalan farm laborers who were willing to return and live on the assigned parcels for a period of five years. The Salvadoran Instituto de Colonización Rural (ICR) has a provision in its 1961 charter which obligates the awardee of a parcel "to work the parcel himself, and to live on it with his family"

${ }^{1}$ There may well be other such laws as well, but the writer has copies of the following legislative decrees, all requiring residence on the land to validate the claim: No. 3, the first "Ley de Cabezas de Familia," dated Nov. 17, 1909; No. 13, of Sept. 13, 1923; No. 137, the second "Ley de Cabezas de Familia," dated Oct. 2, 1924; and No. 30, of Nov. 8, 1927 (see Costa Rica, 1824). 
(El Salvador, ICR, 1962:Article 107). These, and undoubtedly other laws, fostered the isolated pattern of settlement in their effort to ensure that the beneficiaries of grants of national land were genuine farmers and not speculators. However, the more recent tendency is for laws to provide for awards of farmlands and house lots as two separate tracts, with the houses clustered in a village pattern (Costa Rica, 1824:Dec. Leg. No. 29 of Dec. 3, 1934; Dec. Leg. No. 13, Jan. 10, 1939; and Dec. Leg No. 2825, Oct. 14, 1961; also Honduras, 1962, and Nicaragua, 1963:Decreto 797 of April 19).

\section{Trends in Settlement Patterns}

One can generalize about past events and say that over the last three centuries the trend has been toward the dispersed form of settlement. This has been true throughout the entire region, but with local exceptions. The large plantations have maintained their village settlements, and Sandner notes $(1964: 32-34)$ that after an area becomes well settled there is a tendency for the farmers to begin to move to clustered settlements and towns-at least in Costa Rica. The dispersed pattern has been most pronounced in certain Indian areas of Guatemala, and in the zones of pioneer settlement virtually everywhere in the region. 
In Costa Rica the agricultural censuses of 1950 and 1963 included information on the producers who did not live on their explotaciones. Table 25 presents the percentages of the producers who lived elsewhere than on their land in both years, by the size of the land unit. In every size class the proportion dwelling off the farmland had increased significantly, but it is hard to interpret these data clearly, since many of these producers were not in direct charge of their lands. The information in the last two columns of the table indicates that the use of administrators for the everyday management of farming operations also increased during the 13-year interval. Nevertheless, even if all the administrators happened to work for producers who lived away from the land (and the census data do not imply this directly), the increase in off-the-farm residence is greater than the increase in the use of managers. Thus there would appear to be a notable increase in both the numbers and proportions of Costa Rican agriculturists who are living away from their farms and presumably in villages, towns or even cities. No similar data are available for the other nations.

The trend in formal, officially-sponsored settlement programs is more and more toward the grouping of houses in nucleated settlements. This form was established in 
Table 25. Relative numbers of producers residing off the explotación, and employment of farm administrators, by size of explotación: Costa Rica, 1950 and 1963

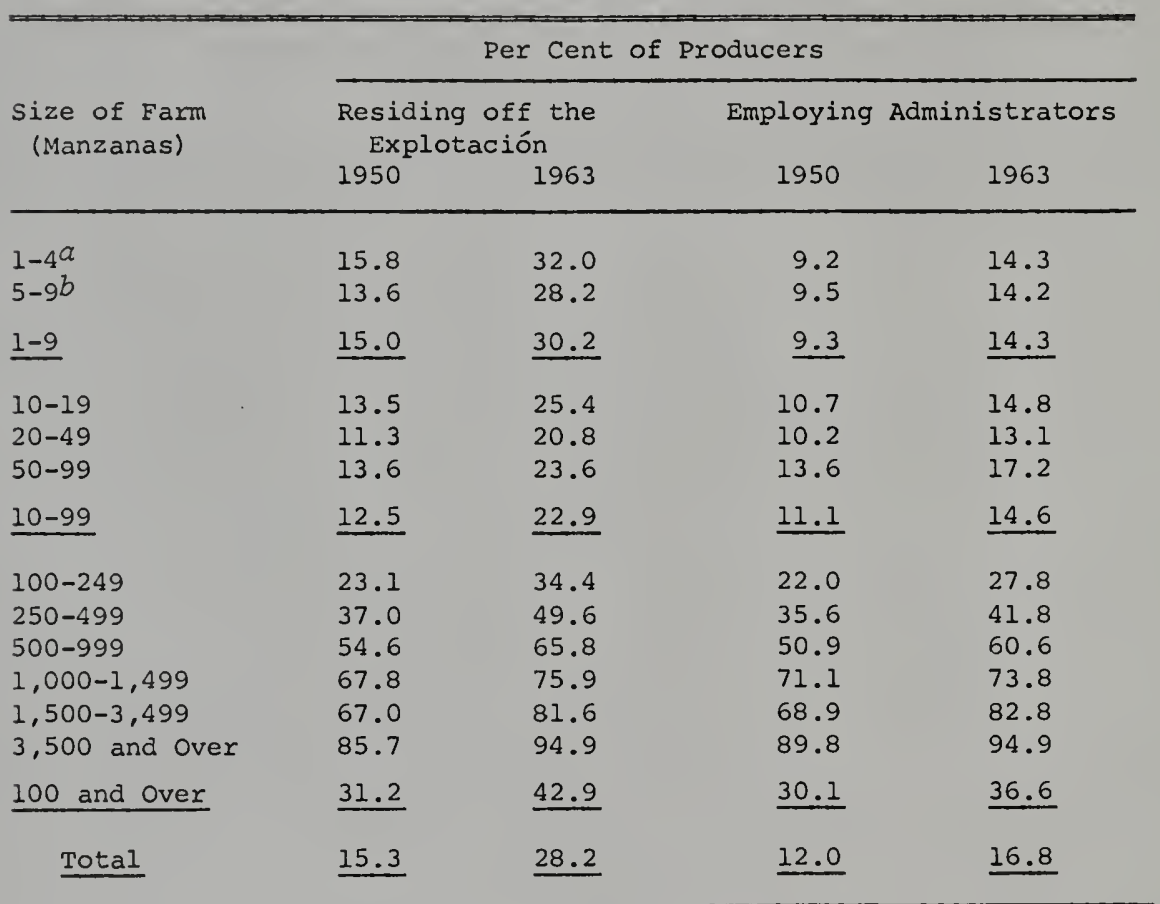

SOURCE: Compiled and computed from Costa Rica, DGEC, 1953:Cuadro 8; and 1965a:Cuadros 8 and 15 .

an 1963 this interval is 1-3 manzanas, since no break was * provided between 4.9 and 5 manzanas.

$b_{\text {In }} 1963$ this interval is $4-9$ manzanas, since no break was provided between 4.9 and 5 manzanas. 
Los Laureles, a Nicaraguan agrarian reform colony, and in more recent projects in that country. Costa Rica's "Colonización de Bataan" in a former United Fruit Company plantation is designed for settling 600 families in seven old company centers (see costa Rica, ITCO, 1963d), and clustered colonies were envisioned elsewhere when I talked with ITCO officials in 1963. An exception among official colonization plans (in addition to the new Salvadoran requirement mentioned earlier) is the rapid development of the Guatemalan Zones of Agrarian Development. These are planned and executed so that the great majority of beneficiaries live in the isolated pattern in spite of the greatly increased problems of providing services. Frost (1964) made an excellent study of the efforts in two projects: Nueva Concepción and La Máquina. (See the plans for many of the INTA projects in Alvarado Pinetta, 1964.) In spite of some exceptions, the impression gained in talking with officials of most of the reform agencies in 1963 was that they felt strongly impelled toward the village system since they saw no other way to provide the sort of modern services they considered politically necessary.

\section{Summary and Conclusion}

It has been shown that a very large proportion of the farm operators actually dwell on theix land in an isolated pattern of settlement, while in certain areas 
there are true farm villages or towns, and occasionally the line village is found. Historically the trend has been from the village to isolated settlement over the past 300 years. In spontaneous settlements that are occurring along the present-day pioneer fringes, the trend is to continue the scattering of homes indiscriminately across the countryside. On the other hand, the official efforts at sponsored settlement are tending more and more toward the nucleated settlement in which each settler has a house plot separate from the farmland. The motivation is to achieve the most economical provision of desirable public services, and to encourage the formation of cooperative organizations among farmers.

No significant effort was found in which official policy was oriented toward the division of land in a manner promoting the line village with its many advantages. It is frankly to be expected that many settlers, moved initially into the village form of settlement, will be inclined to adjust to the more accustomed form by living part or even all of the year in secondary houses on their parcels. This would be much less likely on a line village pattern, and I would strongly recommend that at least trials of this system be undertaken to test its acceptance. 
CHAPTER VII

\section{SUMMARY AND CONCLUSIONS}

This study is concerned with the institutionalized relationships between men and the land in Central America. A consistent sociological frame of reference is applied to the analysis of these relationships, after the development of this framework over several decades is traced through a review of the literature in which it has been evolved.

Central America is a constellation of five independent nations which have shared a common history during much of their existence, and which logically have a common future. In the past decade, particularly, these nations have been building a framework for economic integration and political cooperation. The five countries together comprise an area about two-thirds that of the state of Texas, or slightly more than that of the state of California. Their combined population of over 14 million is very unevenly distributed, both with regard to the five countries as entities, and within each of the nations individually. The regional density of about 32 persons per square kilometer means little when El Salvador has a density of 150 persons per square kilometer, and the comparable figure for Nicaragua is only 14. While the population is widely distributed in 
El Salvador, the remaining four nations have large areas with relatively few inhabitants and other sections with quite high concentrations of people. These variations in density of population are quite meaningful in understanding the relationships between the people and the land.

The people of Central America are predominantly rural and agricultural. As a consequence, that which affects the families dependent upon farming for their livelihoods is of major importance in these countries. In the region as a whole I have estimated that about 1.3 million families were dependent upon agricultural pursuits in the first half of this decade. The number would be even higher today. of these agricultural families, nearly 60 per cent are farm laborers and only about 40 per cent may be described as genuine farm operators.

Employing a carefully developed conceptual framework to classify the farms and subsistence tracts of Central America as either family sized, minifundia, or multi-family in extension, it is shown that approximately four out of every five explotaciones are minifundia, smaller than the minimum area for family-sized tracts. On the other hand, places adequate for operation by families with their own members providing the bulk of the labor constitute about 18 per cent of all farming units, and multi-family estates account for only 3 per cent. These proportions vary greatly 
from country to country. In costa Rica family-sized places are more numerous than either of the other classes, and make up 46 per cent of all explotaciones. In contrast, over 90 per cent of the farms and subsistence tracts in El Salvador are minifundia.

An important aspect of the size of farms is the extent to which control over the land is concentrated in the hands of relatively few people. Although the full extent of control over the land cannot be ascertained from census data, it is clear that the operators of 1,777 explotaciones have direct control of the 26 per cent of farmland which is held in tracts of 1,000 manzanas or more.' These tracts range in size up to at least 76,000 manzanas, while the median size of explotación in Central America is only 3.2 manzanas. The broad category of multi-family farms includes nearly 63 per cent of all land in farms in Central America. Another important facet of the size of farming units is the extent to which the land is utilized, and the types of use to which it is put. In Central America the plantations and haciendas of larger area report relatively small portions of their land engaged in the growing of crops of any kind, and considerable expanses left in woods and forests. On the

${ }^{1}$ Actually, these size limits vary due to census usages, as was indicated in Table 3 . 
other hand, the minifundia (which in many cases are crowded on slopes which should never be tilled) devote nearly all of their land to the raising of annual or perennial crops. Most of the staple food crops in the region are grown on small or family-sized farms, and in every case these explotaciones account for more than their pro rata share of cattle as well, though the haciendas have much more pasture land available.

Many forms of land tenure are found in Central America, and there are striking differences in the degree of security by which people hold land. Although tenure classes employed by the censuses vary considerably from country to country, the proportion of owner-operators consistently increases as the size of the farms increases. Moreover, the owners of multi-family-sized farms generally have recorded titles, while the smaller property owners rely on traditional titles or bills of sale.

The majority of the farm operators in the region and in Costa Rica, El Salvador, and Guatemala axe the owners of their properties. In Honduras and Nicaragua owners are only a minority. Throughout the region squatters are a problem. Although data are hard to obtain (many censuses simply avoid the issue, and others acknowledge that the data are inaccurate), there is no doubt that these informal possessors of land are present in all the countries in considerable numbers. Renting of land is quite rare in Central America 
except for minifundistas who secure small tracts of a subsistence character in this way. Many of these persons are either share-hands or sharecroppers with very little security in their tenure, properly belonging in the category of farm laborers instead of farm operators.

In general, farm laborers are marked by their lack of rights to land. However, nearly half of the families of farm laborers in Central America have access to some land for their own use, either as owners of inadequate acreages, or as sharecroppers or colonos. The colonos are the least secure of all those who have some rights to land. Since they receive the use of a small tract (often less than 1 manzana) as part of their remuneration for working on the plantation or other establishment, their tenure of the land depends on maintaining their status as laborers. Recently the introduction of cotton-pickers has caused many to lose their small parcels as well as their jobs. Even the small landowners have faced the loss of their supplementary income. The livelihoods of all of these families, including those with no land and those with small plots, are very minimal under any circumstances, but they suffer most from the fact that their day-to-day existence is under the control of their employers.

Central American farmers are heavily dependent upon the physical effort of human muscles to accomplish their 
tasks on the farm. While there are a relatively few modern mechanized farms in the region employing the latest methods of cultivation, disease and weed control, and harvesting, most explotaciones are using practices which date from the Stone Age. That is to say that well over half-perhaps as many as three-fourths $\longrightarrow f$ the farming entities in Central America are using hand tools for all of the work of preparing the land, cultivating the crops, and gathering the harvest. Even where animals are employed for plowing, the common practice is to use oxen and a wooden rooting plow that is quite inefficient. Only a very few horse-drawn plows and other advanced implements of a similar character are in use despite their adaptability to the environment and to farms of moderate size. On large farms devoted to export crops, as well as on some other places, full-fledged mechanization with self-propelled machinery has begun to be adopted, with the consequent displacement of the laborers who were formerly required. The rush to get into the production of some bonanza crops (such as cotton has been recently) has also diverted some land from food production and forced the importation of grains which were previously grown in adequate quantity in the area.

The typical farm family in Central America lives on its land in a pattern of scattered farmsteads. This is so in spite of a vigorous official effort in colonial days to 
create a village arrangement. The village settlement pattern is more likely to be found today where the communal landholdings are still intact, or where their abolition is relatively recent. Villages are sometimes found where fire agriculture is practiced, since in this case the plots in use change and the farmers often do not attempt to live on their parcels. The scattered settlement pattern makes it much more difficult to have social contacts with a variety of neighbors, and it also creates obstacles to the most economical provision of schools, social services, utilities, and roads. All of the latter services are relatively lacking in Central America, and the pattern of settlement which is so widely accepted at present is one contributing factor. Conditions in the rural areas of Central America are not static, and several important trends have been identified. Perhaps the most important trend, or that which affects the most people in the area, is the tendency for explotaciones to be subdivided into ever smaller tracts. While this process of breaking down the explotaciones into smaller units is going on continually in the densely populated areas, new tracts of more adequate size are being carved out of the public domain on the frontiers of settlement. At the same time, there are a relatively few large estates being consolidated or enlarged at any given point in time. The overall trend is that the median size of farm is declining. 
However, in Guatemala there was a proportional increase in the number of family-sized farms between 1950 and 1964 , and in Costa Rica family-sized places gained the most in the past intercensal period.

All of the Central American countries have enunciated policies favoring the medium- or family-sized farm, and agrarian reform programs have undertaken to promote these everywhere except El Salvador, where agrarian reform per se has not been instituted.

Improvements in the land tenure arrangements are occurring for some people, particularly those who are carving out new properties on the fringes of settlement. However, for the region as a whole it appears that the proportion of farm laborers is increasing. Independent farm operators are growing in number, but less rapidly than the number of families dependent on agriculture, except in Costa Rica. In that country the ratio of operators to laborers is increasing. Throughout the region the agrarian reform agencies have found it necessary to concentrate on the squatter problem in two senses. They are attempting to resolve the presently existing cases of squatter occupation, and they also hope to prevent future "invasions" of property by making alternatives available for legitimate settlement. This is the main point of official concern with tenure questions at present. 
The agricultural ladder is quite ineffective in Central America, from what fragmentary evidence I have been able to gather. There is a regular occurrence of land being passed from one generation to another in ever smaller parcels, but little chance of a landless person being able to begin to purchase property for himself. Again Costa Rica was something of an exception, for there are indications that a significant number of persons are able to move up to operator status in that country.

The systems of agriculture employed on most farms are rudimentary, but changes are occurring with regard to this question, also. The principal change is the introduction of tractors and self-propelled machinery on the larger farms or plantations. This way of farming has little application on the majority of places which are small and presently worked strictly with hand tools and human effort. Thus fire agriculture is continuing to destroy untold manzanas of land that can ill afford to be lost in an area of extremely rapid population growth, and it continues to provide a very poor level of living for its practitioners. Much is being done to encourage mechanization, even though this is best justified in the face of labor shortages which Central America need not worry about for many years to come. Instead, the mechanization of the large estates is creating problems of unemployment in the rural sector where generally a larger share 
of the population is being forced to look for supplementary work due to declining farm sizes. Mechanization is beneficial only to the larger landholders, as a rule, thus widening the gap between the large and small farms. There appears to have been a complete neglect of the tools and techniques which would be beneficial to the family-sized farmers, and still be within their reach, financially. These would include, principally, the ways of farming involving the draft horse: plows, harrows, reapers, wagons, and so forth.

The trend with regard to settlement patterns is the perpetuation of the scattered farmstead as the dominant feature of the cultural landscape. At least isolated houses are the rule in the frontier areas of new settlement. In the more densely populated areas the subdivision of properties is lessening the distances between homes as new houses go up on the newly dismembered tracts. Present government policies seem to relate only to colonization projects, and regarding these particular situations most agencies are supporting the village type of settlement. Guatemala is still using the isolated farmstead located on the claimant's parcel. Nowhere was I able to find any policy favoring the line village as an effective compromise, even when level land would have permitted the parcels to be any shape desired.

The overall conclusion must be that in their "natural course" things are trending toward a less favorable situation 
for the average rural family which must gain its livelihood from the land. More explicitly, the following trends may be generalized: (1) through the subdivision of properties more and more of the explotaciones are falling below the size which can be considered adequate for a substantial family-sized farm; (2) as farm sizes decline, a larger number of families become dependent upon income from farm labor as their basic source of subsistence, and these people receive only the share of farm income attributable to labor, gaining nothing as a result of management or capital investment; (3) the agricultural ladder is almost nonexistent, leaving little hope of improving his tenure status for one who does not inherit land; (4) the present improvement in ways of farming emphasizes mechanization, which benefits mostly the larger farmers, and there is apparent neglect of equipment particularly fitted to the local situation of the familysized farmer; (5) except in some of the formal settlement projects, little or nothing is being done to encourage the clustering of farm people in practical forms of settlementespecially the line village.

I must admit that what I have described is what I see to be the overall trend. There are many particular cases which are exceptions to the general run of things, and I have not mentioned any of these to temper the generalization, as perhaps I should have done. 
Having painted such a dark picture, it is incumbent upon me to comment on some things which might change the picture to a healthier hue in the course of a few years time. First of all, each of the countries (except El Salvador which has none) is currently involved in planning and developing access to its remaining public lands, and this is being done with emphasis on what the respective authorities deem to be family-sized farms. These will become vested in the operator if he meets the requirements specified by law, and if enough of these parcels are adjudicated there will be improvement in terms of both size and tenure. I would encourage the authorities involved, the legislators as well as the agrarian agencies, to consider including in their land division scheme all the advantages of definite, determinate, and permanent boundaries, and also the principle of the "long-lot" farm so that in the natural course of settlement the advantages of the line village are attained at no additional expense to either the state or the settler.' I am convinced that investments in simply opening up access to public lands and surveying them according to a fixed national plan will enable

'Descriptions of such schemes are given in Smith's Brazil (1963a:276-282), and the text of a law which would accomplish these objectives is given in several places (Smith, 1947a; 1967a:158-167). A full discussion of the ideas involved is presented in Smith's Sociology of Rural Life (1953:268-273). 
spontaneous creation of more independent family-sized farms than any effort to develop planned colonies could do. The colonies have been far too expensive per beneficiary family to ever have a hope of seriously changing the trend of things as they are going.

This does not mean that there is no need to supplement this form of development for family-sized farms with a program for encouraging the subdivision of some large estates. In El Salvador this is perhaps the only alternative open, but it will be desirable elsewhere as well. In this regard, the several countries are committed to developing land taxes which were virtually or actually nonexistent in the past. This simple step, if administered fairly, will force the owners of large extensions of property to either utilize the land themselves, or dispose of land that they are not inclined to cultivate (or make productive in some other fashion, such as ranching). This will make some land available for those who want it, but it will be necessary to increase the credit available for the purchase of land by potential family-sized farmers if these families are to be able to benefit from the availability. A program of government mortgage insurance might be feasible, so as to open both the government and private resources to the buyer. 
The income derived from the general land tax should be used for the benefit of the rural areas from which it is derived. One suggestion is that it be used to develop local public schools, or to upgrade those that exist. These monies could also well be devoted to promoting soil conservation so that the small farms which are overcropped could improve their techniques of cultivation, or perhaps adopt crops which are better suited to the particular terrain. A third alternative might be to finance the agricultural extension programs with money from the land tax.

In spite of the urging of national pride which seems to demand the promotion of the most modern systems of agriculture available, I recommend that for the most part this be played down. Highly mechanized agricultural equipment and machinery is designed to be laborsaving, and Central America at present faces an increasing number of persons available for farm labor. The adoption of mechanized farming may simplify things for the owners of large estates, but some balance must be found that does not make laborers bear all the costs, and alternative employment does not seem to be on the horizon. Instead of allowing import tax breaks for agricultural equipment which will displace workers, it may even be desirable to use import duties to discourage those imports. One study even suggested that the cost of 
equipment for cotton production in Central America might have equalled all the foreign exchange credits built up by the increased exportation of the cotton produced (Dorner, et ar., 1969:9).

Consistent with my conviction that the family-sized farms are the most desirable size of farm for Central America, I would like to see the encouragement of ways of farming that are particularly adapted to this size. Given the limited education possessed by most of these farmers, and the very small amounts of capital or credit which are available to them, it appears that the adoption of the "advanced plow culture" (the horse, with its more even power, and plows and other equipment specifically designed to be hitched to it) would be much more suitable than tractors. It might even be possible to develop a manufacturing industry for this sort of equipment in Central America more easily than for tractors and their more complex paraphernalia. Even horse-drawn machinery would displace some farm laborers, but I am assuming that they would be displaced from the farms that most need to be encouraged to be family operated, and not from the very largest ones exclusively. This equipment would require less foreign exchange, and would not demand imported fuel.

I suspect that everyone with a relatively high education, and with middle-class financial standing, 
automatically thinks of mechanized farming, and for such a person it would be more appropriate than the horse, if he were a farmer. But in spite of the fact that just such people make up the government, the banking circles, the extension service, and the universities, they are few and far between in rural areas. (Even though many have farms, they tend to be absentee farmers.) Moreover, the farm equipment importers are probably influenced by these same factors, and in addition, the manufacturers are geared for the markets in the United States, western Europe, and other so-called developed areas where they could hardly give away equipment for use with horses. So it is not hard to understand why horses are neglected as work animals, especially since traditionally the horse has been reserved for riding use by the middle and upper classes. An intensive propaganda campaign combined with promotional efforts by farm equipment salesmen could probably bring about a change of attitude, but this would require testing on a small scale.

Finally, regarding the patterns of settlement, changes can only be introduced gradually. I have suggested that the line village be fostered in the division of untitled public lands (baldios). But this leaves all the settled areas of the country untouched. Since land transactions are taking place all the time, and estates 
are regularly being subdivided by inheritance, a campaign could be launched to encourage these divisions to be made by parallel lines all starting from a common front such as a road or stream. Then a farm divided into five parcels would result in five strips lying side by side, and in time the homes of the different owners might well be built at the end by the road. If this could be "sold" to people by means of films shown in local theaters, and by extension agents or others in a position to do so, some improvement might result.

The chief problem in all of my remarks about ways to improve the rural social systems is that the changes have to be implemented by persons who would not benefit directly from their introduction. The wealthy and the well-educated are the decision-making authorities. In some cases they would be penalyzing themselves, as by establishing the land tax (which has been so strongly resisted since its proposal in the Alliance for Progress), or discouraging the mechanization of large estates. In other cases they simply may not care, or may do nothing because there is no public demand. There is not likely to be any large demand for the long-lot farm, or for horsedrawn equipment, and if these are to be encouraged they will have to be promoted from above, by those who do not stand to gain anything by their encouragement. 
These persons have more to gain, prestigewise, by establishing elaborate agrarian reform colonies and providing all of the desirable services for these. Assuming the colonies succeed, the directors, ministers, and even presidents can glory in their success and build political capital from these spectacles, even though they do not accomplish anything for the vast majority of those in need of better opportunities. It will take unusually concerned men to avoid this common approach to governmental and public positions, and to attempt less spectacular accomplishments which would benefit more people over a longer time. It could even backfire, if the public was not convinced that the government was doing something meaningful. (Public opinion may sometimes virtually require the big display instead of the more prosaic but longer-lasting efforts.)

At any rate, the present trends are clear. Farms are getting smaller, more people are having to work for others to eke out a living, there is little opportunity to become a farm operator except by inheritance, and antiquated ways of farming continue to be the mainstay of the vast majority of the farmers. Unless something is done which gives hope to the rural residents of the region that their futures or those of their children can be better, this will be fertile ground for subversives to play upon raw 
feelings, there may well be increased tension within the bounds of several countries and more guerrillas of the Che Guevara type.

I feel change is going to come sooner or later. If it comes sooner it will probably be because some enlightened men in government chose to seek the larger interest instead of their own selfish ones. If it comes later it may be the result of violent strife between fellow citizens. I hope that changes come soon. 

APPENDIX A

LEGAL PROVISIONS TO REQUIRE THAT LAND BE MADE TO FULFILL A SOCIAL FUNCTION IN CENTRAL AMERICA

This appendix presents a chronological citation of the particular constitutional articles which have been enacted in each of the five Central American nations to place social restrictions on the use of property in land. In addition, a few of the laws which have been passed to put the constitutional provisions into effect are indicated.

Guatemala

Constitutional Provisions: ${ }^{1}$

Constitution of 1879, as amended in 1935: Articles 16 and 28; Constitution of 1945: Articles 90 and 91;

"Estatuto Político" of 1954: Article 15;

Constitution of 1956: Articles 124 and 125;

Constitution of 1965: Articles 69, 70, 71 and 126

Principal Laws: ${ }^{2}$

1936: Decreto Gubernativo No. 1885, "Ley de Impuestos Sobre Eriales y Latifundios" (Law of Taxation on Idle Lands and Latifundios), October 10.

1949: Decreto Legislativo No. 712, "Ley de Arrendamiento Forzoso" (Law of Forced Rentals), December 21.

${ }^{1}$ The constitutions of Guatemala, through the one of 1956, have been collected in Spanish by Mariñas Otero (1958), and the 1965 constitution is available in English in the Pan American Union's series of American Constitutions (see PAU, Department of Legal Affairs, 1966a).

${ }^{2}$ These laws, through 1956, are available in Méndez Montenegro (1960). 'The 1962 law has been published by the agency which administers it (Guatemala, INTA, 1964). 
1951: Decreto Legislativo No. 853, Revises No. 712 of 1949, reducing rent.

1952: Decreto Legislativo No. 900, "Ley de Reforma Agraria" (Agrarian Reform Law), June 17. (Revised by Dec.

Leg. No. 991, June 29, 1953.)

1954: Decreto No. 31, "Estatuto Agrario" (Agrarian Law), enacted July 26 to replace the 1952 law temporarily.

1956: Decreto Gubernativo No. 559, "Estatuto Agrario"

(Agrarian Law), decreed February 25 to replace the 1954 decree.

1962: Decreto Legislativo No. 1551, "Ley de Transformación Agraria" (Law of Agrarian Transformation), October 17.

\section{El Salvador}

Constitutional Provisions: ${ }^{3}$

Constitution of 1950: Articles 135, 136 and 137;

Constitution of 1962: Articles 137 and 138.

\section{Honduras}

Constitutional Provisions: ${ }^{4}$

Constitution of 1957: Articles 157 and 252;

Constitution of 1965: Article 97.

Principaz Law: 5

1962: Decreto Legislativo No. 2, "Ley de Reforma Agraria" (Agrarian Reform Law), September 29. (Amended by Dec. Leg. No. 127, June 14, 1963.)

${ }^{3} E 1$ Salvador's constitutions, except for that of 1962, are given by Gallardo (1961, II), and that of 1962 may be found in PAU, Department of Legal Affairs, $1966 \mathrm{~b}$.

${ }^{4}$ The Honduran constitution of 1957 is found in Mariñas Otero's volume (1962) of the Hispanic American Constitutions series (also in PAU, Department of International Law, 1958), and that of 1965 in the Pan American Union series (PAU, Department of Legal Affairs, 1966c).

${ }^{5}$ Decreto No. 2 is available in booklet form (Honduras, 1962), and the amendment was published in La Gaceta (Honduras, 1963-1968) for June 28, 1963. 
Nicaragua

Constitutional Provisions: ${ }^{6}$

Constitution of 1939: Articles 63,65, 66, 69 and 70;

Constitution of 1948: Articles 58, 60 and 62;

Constitution of 1950: Articles 63, 65, 66 and 71 .

Principal Law: 7

1963: Decreto Legislativo No. 797, "Ley de Reforma Agraria" (Agrarian Reform Law), April 3.

Costa Rica

Constitutional Provisions: ${ }^{8}$

Constitution of 1871, as amended in 1943: Article 29;

Constitution of 1949: Articles 45 and, perhaps, 69 .

Principal Laws: ${ }^{9}$

1944: Decreto Legislativo No. 58, "Ley de Esquilmos" (ShareRental Law), March 10.

1961: Decreto Legislativo No. 2825, "Ley de Tierras y

Colonización" (Law of Lands and Land Settlement),

October 14. (Amended several times: Dec. No. 3033

of Sept. 25, 1962; Dec. No. 3042 of Oct. 4, 1962;

Dec. No. 3336 of July 31, 1964.)

${ }^{6}$ The Nicaraguan constitutions are gathered in Lejarza's volume (1958) and the 1950 constitution with amendments through 1962 is available in English (PAU, Department of Legal Affairs, 1966d). $19,1963$.

${ }^{7}$ Published in La Gaceta (Nicaragua, 1963) for April

${ }^{8}$ Peralta (1962) collected all of the constitutions to date, while an English version of that of 1949, with its amendments, has been made by the Pan American Union (PAU, Department of Legal Affairs, 1965).

${ }^{9}$ All may be found in the semiannual publication of Costa Rican Laws (Costa Rica, 1824) by decree number and date. 
Key to Major Civil Divisions in Central America

\section{Guatemala}

1 Alta Verapaz

2 Baja Verapaz

3 Chimaltenango

4 Chiquimula

5 El Petén

6 El Progreso

7 El Quiiché

8 Escuintla

9 Guatemala

10 Huehue tenango

11 Izabal

12 Jalapa

13 Jutiapa

14 Quezaltenango

15 Retalhuleu

16 Sacatepéquez

17 San Marcos

18 Santa Rosa

19 Sololá

20 Suchitepéquez

21 Totonicapán

22 Zacapa

\section{EZ SaZvador}

1 Ahuachapán

2 Cabañas

3 Chalatenago

4 Cuscatlán

5 La Libertad
El Salvador-Cont'd

6 La Paz

7 La Unión

8 Morazán

9 San Miguel

10 San Salvador

11 Santa Ana

12 San Vicente

13 Sonsonate

14 Usulután

Honduras

1 Atlántida

2 Colón

3 Comayagua

4 Copán

5 Cortés

6 Choluteca

7 El Paraíso

8 Francisco Morazán

9 Gracias a Dios

10 Intibucá

11 Islas de la Bahía

$12 \mathrm{La} \mathrm{Paz}$

13 Lempira

14 Ocotepeque

15 Olancho

16 Santa Bárbara

17 Valle

18 Yoro
Nicaragua

1 Boaco

2 Carazo

3 Chinandega

4 Chontales

5 Estelí

6 Granada

7 Jinotega

8 León

9 Madriz

10 Managua

11 Masaya

12 Matagalpa

13 Nueva Segovia

14 Río San Juan

15 Rivas

16 Zelaya

Costa Rica

1 Alajuela

2 Cartago

3 Guanacaste

4 Heredia

5 Limón

6 Puntarenas

7 San José 
APPENDIX B

ORIENTATION MAP

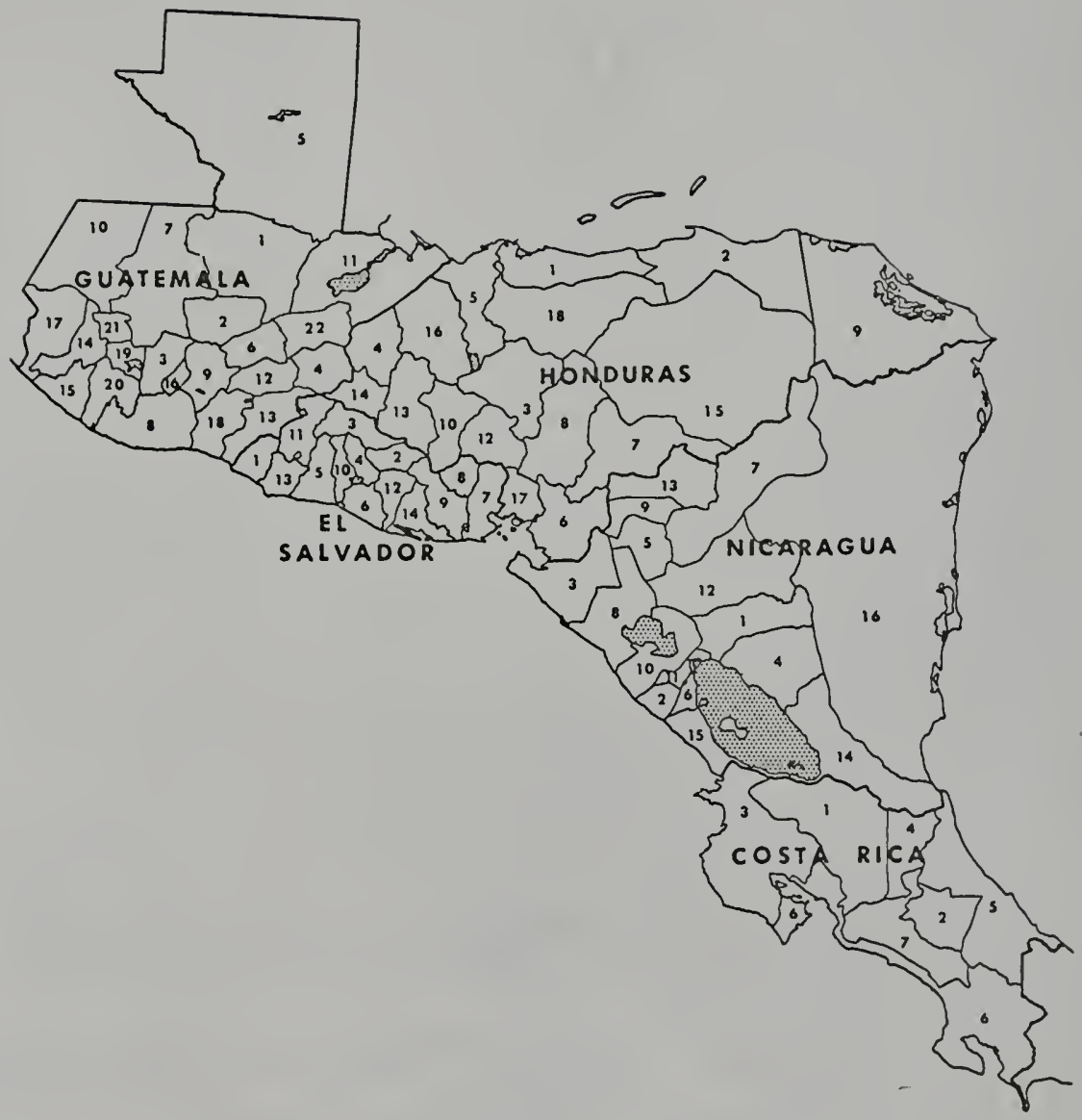

Figure 18. Map identifying the major civil divisions of the Central American nations. 


\section{APPENDIX C \\ TABLE OF EQUIVALENT MEASURES \\ OF LAND AREA}

A. Equivalents of Common Central American Units

\section{Manzanas}

1.0
2.0
5.0
10.0
50.0
100.0
$1,000.0$
1 caballería $(64 \mathrm{mz}$.

\section{Hectares \\ (metric)}

$$
\begin{array}{r}
0.7 \\
1.4 \\
3.5 \\
7.0 \\
35.0 \\
70.0 \\
700.0
\end{array}
$$

45.0
Acres

(English)

1.7

3.5

8.6

17.2

86.5

173.0

(2.7 sq. miles) $1,730.0$

111.3

B. Equivalents of Metric Units
Hectares
Manzanas
Acres
1.0
1.4
2.9
7.2
14.3
72.0
143.0
2.5
5.0
10.0
50.0
$100.0\left(1 \mathrm{~km}^{2}\right)$
$1,000.0\left(10 \mathrm{~km}^{2}\right)$
$1,430.0$
4.9
12.4
24.7
123.0
247.0
(3.9 sq. miles) $2,470.0$ 


\section{APPENDIX D \\ LIST OF ABBREVIATIONS}

In the interest of brevity, the following abbreviations have been used in the text and references in place of the full names of the agencies or institutions in question:

CIDA Comité Interamericano de Desarrollo Agrícola (InterAmerican Committee for Agricultural Development;

also known under its English acronym, ICAD)

DGC Dirección General de Cartografia (General Bureau of Cartography)

DGCE Dirección General de Censos y Estadísticas (General Bureau of Censuses and Statistics [Honduras])

DGE Dirección General de Estadística (General Bureau of Statistics)

DGEC Dirección General de Estadistica y Censos (General Bureau of Statistics and Censuses)

FAO Food and Agriculture Organization of the United Nations

IAN Instituto Agrario de Nicaragua (Nicaraguan Agrarian Institute)

IBRD International Bank for Reconstruction and Development

ICAD Inter-American Committee for Agricultural Development (Also known as CIDA, above)

ICR Instituto de Colonización Rural (Institute of Rural Land Settlement [El Salvador])

IGCR Instituto Geográfico de Costa Rica (Costa Rican Geographic Institute)

IGN Instituto Geografico Nacional (National Geographic Institute) 
IIES Instituto de Investigaciones Económicas y Sociales (Institute for Economic and Social Research)

INTA Instituto Nacional de Transformación Agraria (National Institute for Agrarian Transformation [Guatemala])

ITCO Instituto de Tierras y Colonización (Institute of Lands and Land Settlement [Costa Rica])

MAG Ministerio de Agricultura y Ganadería (Ministry of Agriculture and Livestock Raising)

MAI Ministerio de Agricultura e Industrias (Ministry of Agriculture and Industry)

OAS Organization of American States

PAU Pan American Union

UNAH Universidad Nacional Autónoma de Honduras (Autonomous National University of Honduras)

USAID United States Agency for International Development 


\section{SELECTED BIBLIOGRAPHY}

Ackerman, Joseph, and Marshal Harrie (eds.)

1947 Family Farm Policy. Chicago: University of Chicago Press.

Adams, Richard N.

1957 Cultural Surveys of Panama-Nicaragua-GuatemalaEl Salvador-Honduras. Washington: Pan American Sanitary Bureau. Scientific Publications, No. 33.

1967 a "El sector agrario inferior de Guatemala: 19441965." Offprint from Les Problèmes Agraires des Amériques Latines. Paris: Editions de Centre National de la Recherche Scientifique.

1967b The Second Sowing: Power and Secondary Development in Latin America. San Francisco: Chandler Publishing Company.

Agri Research, Inc.

1962 Increasing and Diversifying Agricultural Production in El Salvador: A Report to the Agency for International Development, United States of America, and the Ministry of Agriculture, Republic of El Salvador. San Salvador: Agri Research, Inc.

Alers Montalvo, Manuel

1960 Sociologia: Introductión a su uso en programas agricolas rurales. Turrialba: Editorial SIC.

Alfaro, Gregorio

1966 Problemas que afectan el desarrollo agropecuario en cuatro cantones de la peninsula de Nicoya. San José: Ministerio de Agricultura y Ganadoría, oficina de Planeamiento y Coordinación.

Alleger, Daniel E.

1957 Asociación de economia agricola en Costa Rica: Informe final del contrato. San José. (Mimeographed)

Alvarado Pinetta, Rony $S$.

1964 La transformación agraria en Guatemala. [Guatemala: Instituto Nacional de Transformatión Agraria?] 
Alvarez Lejarza, Emilio

1958 Las constituciones de Nicaragua. Madrid: Ediciones Cultura Hispánica. Las constituciones hispanoamericanas, 9 .

Arce, Antonio M.

1961 Sociologia y desarrolzo rural. Turrialba, Costa Rica: Editorial SIC. Serie textos y materiales de enseñanza No. 9.

1965 Desarrolzo social y reforma agraria. San José, Cosţa Rica: Instituto Interamericano de Ciencias Agricolas de la OEA, Oficina de Planeamiento. Serie planeamiento No. 1 .

Banco Central de Nicaragua

n.d. Informe anual: 1967. Managua: The Bank.

Bancroft, Hubert Howe

1886 History of Central America. San Francisco: The History Company. 3 volumes. Works of Hubert Howe Bancroft, Vols. 6-8.

Barraclough, Solon L., and Arthur L. Domike

1966 "Agrarian Structure in Seven Latin American

Countries." Land Economics 42 (November): 391-424.

Biesanz, John and Mavis

1944 Costa Rican Life. New York: Columbia University Press.

Blandón, Alfonso

1962 "Land Tenure in Nicaragua." Gainesville: University of Florida. M. A. thesis in Agricultural Economics.

Bourne, w. Clinton, et al.

1946 Preliminary Survey of Conservation Possibilities in El Salvador. San Salvador: Servicio Cooperative Interamericano de Salud Pública.

Brigham, William T.

1887 Guatemala: The Land of the Quetzal; a Sketch. New York: Charles Scribner's Sons.

Brunner, Edmund des.

1927 Vilzage Communities. New York: George H. Doran Company. 
Brunner, Edmund des., Gwendolyn s. Hughes, and Marjorie Patten

1927 American Agricultural Vilzages. New York: George H. Doran Company.

Brunner, Edmund deS., and J. H. Kolb

1933 Rural Social Trends. New York: McGraw-Hill Book Company.

Brunner, Edmund des., and Irving Lorge

1937 Rural Trends in Depression Years: A Survey of Village-Centered Agricultural Communities, $1930-$ 1936. New York: Columbia University Press.

Buell, Raymond Leslie (ed.)

1935 Problems of the New Cuba: Report of the Commission on Cuban Affairs. New York: Foreign Policy Association.

Benzel, Ruth

1952 Chichicastenango: A Guatemalan Village. Seattle: University of Washington Press. Publications of the American Ethnological Society, No. 22.

Burgess, Paul

1946 Justo Rufino Barrios, 2nd ed. Quezaltenango, Guatemala: Privately printed.

Carroll, Thomas F.

1953 Report on the Latin American Seminar on Land Problems Held at Campinas, Brazil, 25 May to 26 June, 1953. Rome: Food and Agriculture organization of the United Nations. FAO-ETAP Report No. 205.

1961 la La creación de nuevas unidades agricolas: Informe del segundo seminario Latinoamericano sobre problemas de la tierra, celebrado en Montevideo, Uruguay, del 23 de noviembre al 9 de didiembre de 1959. Santiago, Chile: Organización de las Naciones Unidas para la Agricultura y la Alimentación.

1961b "The Land Reform Issue in Latin America." Pp. 161201 in Albert O. Hirschman (ed.), Latin American Issues: Essays and Comments. New York: The Twentieth Century Fund.

Carter, William E.

1969 New Lands and old Traditions: Kekchi Cultivators in the Guatemaian Lowlands. Gainesville: University of Florida Press. Latin American Monographs, Second Series, No. 6 . 
Cerwin, Herbert

1963 Bernal Diaz: Historian of the Conquest. Normal: University of Oklahoma Press.

Chapman, Charles Edward

1937 Republican Hispanic America: A History. New York: Macmillan.

Checchi, Vincent, et al.

1959 Honduras: A Problem in Economic Development. New York: Twentieth Century Fund.

Chryst, walter E.

1962 "Land Tenure, Income Distribution and Selected

Aspects of Economic Development." Cuidad Universitatia, San Pedro de Montes de Oca [Costa Rica]. (Mimeographed)

Clements, Harold M., Sr.

1966 A Sociological Study of the Mechanization of Agriculture in Minas Gerais, Brazil. Gainesville: University of Florida. Ph.D. dissertation in sociology.

\section{Clifford, Roy A.}

1953 "Levels of Living in Hacienda and Small-Farm Villages." Pp. 231-259 in Charles P. Loomis et al., Turrialba: Social Systems and the Introduction of Change. Glencoe, Illinois: The Free Press.

Comite Interamericano de Desarrollo Agrícola (CIDA)

1965 Tenencia de la tierra y desarrollo socio-económico del sector agricola: Guatemala. Washington: Unión Panamericana.

\section{Cortés y. Larraz, Pedro}

1958 Descripción geográfico-moral de la diócesis de Goathemala. Guatemala: Sociedad de Geografia e Historia de Guatemala. 2 volumes. Biblioteca "Goathemala," Vol. 20.

Costa Rica

1824 Corección de Zeyes y decretos. San José: Published annually since 1824. (Laws are cited by decree number and date of presidential signature.)

1949 Codigo civil de Costa Rica. Compiled by Hector Beeche, 2nd ed. San José: Imprenta Atenea. 
Costa Rica, Dirección General de Estadística y Censos (DGEC)

1953a Censo agropecuario de 1950. San José: Instituto Geográfico.

1953b Censo de población de Costa Rica: 22 de mayo de 1950. San José: The Dirección.

1953c Atlas estadístico de Costa Rica. San José: Casa Gráfica.

1959 Censo agropecuario de 1955. San José: The Dirección.

1965a Censo agropecuario: 1963. San José: The Dirección.

1965b Evaluación: censos de población, vivienda, agropecuario; $1^{\circ}$ de abril de 1963. San José: The Dirección.

1966 Censo de población: 1963. San José: The Dirección.

n.d. Censo agropecuario de 1962: fincas menores de 1 manzana y animales fuera de finca. San José: The Dirección.

Costa Rica, Instituto de Tierras y Colonización (ITCO)

$1963 a$ "Información socio-económica sobre ocupantes en precario: Finca Jesús María." San José: Departamento de Planificatión Agraria. (Informe preliminar, Mimeographed)

1963b "Información socio-económica sobre ocupantes en precario: Fincas Penshurst, La Rita... Irlanda." San José: Departamento de Planificatión Agraria. (Informe preliminar, mimeographed)

1963c "Programa para la solución del problema de poseedores en precario de Costa Rica." (Typed manuscript in the office of ITCO's Departamento de Planificación Agraria)

1963d "Proyecto de colonización de Bataan." San José: The Institute. (Mimeographed)

Costa Rica, Instituto Geográfico de (IGCR)

1954 Hoja 3345 IV NE, "Turrúcares, Costa Rica," of the $1: 25,000$ series of topographic maps. 
1956 Hoja 3246 IV SW, "Pozo Azul, Costa Rica," of the $1: 25,000$ series of topographic maps.

1960 Mapa general de Costa Rica con indicatión de la división cantonal. San José: The Institute.

Costa Rica, Ministerio de Agricultura e Industrias (MAI)

1949 Informe de dieciséis meses de labor del Ministerio de Agricultura e Industrias del gobierno de la Junta Fundadora de $Z_{a}$ Segunda República. San José: Sección de Publicaciones y Biblioteca (Editorial Borrase).

Crist, Raymond E.

1952 The Cauca Valley, Colombia: Land Tenure and Land Use. Baltimore: The Waverly Press.

1961 "Central America: Aspects of the Physical and Cultural Landscapes." Pp. 3-17 in A. Curtis Wilgus (ed.), The Caribbean: The Central American Area. Gainesville: University of Florida Press.

1967 "Tropical subsistence agriculture and settlement." Pp. 130-146 in Kenneth L. Tuck and Loy V. Crowder (eds.), Rural Development in Tropical Latin America. Ithaca: New York State College of Agriculture, Cornell University.

de Borhegyi, Stephan F.

1956 "Settlement Patterns in the Guatemalan Highlands: Past and Present." Pp. 101-1.06 in Gordon R. Willey (ed.), Prehistoric Settlement Patterns in the New Worid. New York: Wenner-Gren Foundation for Anthropological Research. Viking Fund Publications in Anthropology, No. 23.

1965 "Settlement Patterns of the Guatemalan Highlands." Pp. 59-75 in Robert Wauchope (ed.), Handbook of Middle American Indians. Vol. II. Austin: University of Texas Press.

Denevan, William M.

1961 The Upland Pine Forests of Nicaragua: A Study in Cultural Plant Geography. Berkeley: University of California Press. Publications in Geography $12: 4$.

Dorner, Peter, Marion Brown, and Don Kanel

1969 "Land Tenure and Reform: Issues in Latin American Development." War on Hunger (U.S. Agency for International Development) 3 (September):8-13. 
Dozier, Craig Lanier

1958 Indigenous Tropical Agriculture in Central America:

Land Use, Systems, and Problems. Washington: National Academy of Sciences - National Research Council. Publication No. 594.

Dumont, René

1966 Types of Rural Economy: Studies in World Agridulture. London: Methuen and Company.

Dunlop, Robert Glasgow

1847 Travels in Central America, Being a Journal of Nearly Three Years' Residence in the Country, Together with a Sketch of the History of the Republic, and an Account of Its Climate, Productions, Commerce, Etc. London: Longman, Brown, Green, and Longmans.

Dunn, Henry

1828 Guatimala [sic], or, The United Provinces of Central America in 1827-1828; Being Sketches and Memorandums Made During a .Twelve Months' Residence in that Republic. New York: G. and C. Carvill.

El Salvador, Dirección General de Estadística y Censos (DGEC) 1954 a Primer censo agropecuario: octubre-diciembre de 1950. San Salvador: The Dirección.

1954b Segundo cense do pobzación: junio 2950. San Salvador: The Dirección.

1955 Atlas censal de El Salvador. San Salvador: The Dirección.

1961 Compendio del segundo censo nacional del café: Cosecha 1957-1958. San Salvador: The Dirección.

1965 Tercer censo nacional de población: 1961. San Salvador: The Dirección.

1967 Segundo censo agropecuario: 1961. San Salvador: The Dirección.

El Salvador, Instituto de Colonización Rural (ICR) 1962 Ley orgánica del Instituto de Colonización Rural. San Salvador: Imprenta Nacional.

El Salvador, Ministerio de Agricultura y Ganadería (MAG) 1962 Levantamiento General de Suelos. Soil map imposed on Cuadrante 2456 II, "Berlin," of the 1:50,000 series of topographic maps. 
El Salvador, Ministerio de Agricultura y Ganaderia (MAG), Dirección General de Economía Agropecuaria, Sección de Previsión de Cosechas

1963 Anuario de pronósticos de cosechas, año agrícola 1961-1962, y retrospectiva de 20 años. San Salvador: Sección de Información Agricola of the Ministry.

Facio, Rodrigo

1948 "Las cláusulas económico-sociales en la constitución de Costa Rica." Pp. 9-12 in Academia de Ciencias Económicas [Argentina]. Las cláusulas económicosociales en las constituciones de América. Tomo II. America Central y del Norte. Buenos Aires: Losada.

Fals-Borda, Orlando

1955 A Sociological Study of the Relationships between Man and the Land in the Department of Boyaca, Colombia. Gainesville: University of Florida. $\mathrm{Ph} . \mathrm{D}$. dissertation in Sociology.

Feuerlein, W. J.

1954 Proposals for the Further Economic Development of El Salvador. New York: United Nations, Technical Assistance Programme. DOC. NO. ST/TAA/K/EL SALVADOR/5.

Ford, Thomas R.

1955 Man and Land in Peru. Gainesville: University of Florida Press.

Frost, Melvin Jesse

1964 Pioneer Settrements in the Pacific Low zand of Guatemara. Gainesville: University of Florida. $\mathrm{Ph} . \mathrm{D}$. dissertation in Geography.

Fuentes y Guzman, Francisco Antonio de

1932 Recordición florida, discurso historigl y demostración natural, material, militar y politica del reyno de Guatemala. Guatemala: Tipografía Nacional. 3 volumes. Biblioteca "Goathemala," Vols. 6-8

Gage, Thomas

1946 The English American: A New Survey of the West Indies, 1648. London: George Routledge \& Sons. [Originally published in 1648] 
Galindo Pohl, Reinaldo

1948 "Instituciones económico-sociales en la constitución política de la República de El Salvador." Pp. 137153 in Academia de Ciencias Económicas [Argentina]. Las cláusulas económico-sociales en las constituciones de América. Tomo II. América Central y del Norte. Buenos Aires: Losada.

Gallardo, Ricardo

1961 Las constituciones de EZ Salvador. Tomo II. Derecho constitucional salvadoreño. Madrid: Ediciones de Cultura Hispánica. Las constituciones hispanoamericanas, 14 .

Galpin, Charles Josiah

1915 The Social Anatomy of an Agricultural Community. Madison: University of Wisconsin Agricultural Experiment Station. Research Bulletin No. 34

1920 Rural Life. New York: The Century Co.

1924 Rural Social Problems. New York: D. AppletonCentury Company.

Gillette, John Morris

1913 Constructive Rural Sociology. New York: Sturgis and Walton.

1922 Rural Sociology. New York: The Macmillan Co. (1925 printing of 1922 edition used.)

Gillin, John

1951 The Culture of Security in San Carzos: A Study of a Guatemalan Community of Indians and Ladinos. New Orleans: Tulane University, Middle American Research Institute. Publication No. 16.

Goldkind, Victor

1961 "Sociocultural Contrasts in Rural and Urban Settlement Types in Costa Rica." Rural Sociology 26 (December) : 365-380.

Goncalves de Souza, João

1960 "Aspects of Land Tenure Problems in Latin America." Rural Sociology 25 (March) :26-37.

Griffith, William J.

1965 Empires in the Wizderness: Foreign Colonization and Development in Guatemala, 1834-1844. ChapeI Hill: University of North Carolina Press. 
Guatemala, Dirección General de Cartografía (DGC)

1960 Hoja 1959 I, "San Lucas Tolimán," of the $1: 50,000$ series of topographic maps.

Guatemala, Dirección General de Estadística (DGE)

1951 "Primeros resultados del censo agropecuario en la República." Boletin of the Dirección General de Estadistica 32 (Agosto): $41-44$.

1952 "Otros resultados del censo agropecuario de 1950." Boletin of the Dirección General de Estadistica 39-40 (Octubre-Diciembre) : 29-46.

1953 Censo cafetalero 2950. Guatemala: The Dirección.

1954 a Censo agropecuario 1950. Tomo I. Agricultura. Guatemala: The Dirección.

1954b Censo agropecuario 1950. Tomo II. Ganaderia. Guatemala: The Dirección.

1954c Censo agropecuario 1950. Tomo III. Población agricola y otros aspectos. Guatemala: The Dirección.

1957 Sexto censo de población: Abril 18 de 1950. Guatemala: The Dirección.

1964 Trimestre estadistico (Julio-Agosto-Septiembre). [Contains preliminary 1964 census results.]

1965 Estudio post-enumerative censal: '1964. Guatemala: The Dirección.

1966 Censos 1964: Población. Resultados de tabulación por muestreo. Guatemala: The Dirección.

1968 II Censo agropecuario 1964. Tomo I. Caracteristicas generales, concentración y tenencia de la tierra. Guatemala: The Dirección.

Guatemala, Instituto Geográfico Nacional (IGN)

1966 Hoja 2362. III, "Rio Polochic," of the 1:50,000 series of topographic maps.

1968 Hoja 1961 II, "Santa Cruz del Quiché," of the $1: 50,000$ series of topographic maps. 
Guatemala, Instituto Nacional de Transformación Agraria (INTA) 1964 Ley de transformación agraria: Decreto 1551. Guatemala: Tipografía Nacional.

Guillen Villalobos, José

1963 Estructura agraria de Guatemala: Antecedentes y consecuencias. Guatemala: Privately printed.

Haney, Emil B., Jr.

1968 "The Nature of shifting Cultivation in Latin America." Madison: University of Wisconsin, Land Tenure Center. Paper No. 45 (Mimeographed)

Hanke, Lewis

1938 "The 'Requerimiento' and Its Interpreters." Revista de Historia de América 1:25-34.

Haring, C. H.

1963 The Spanish Empire in America, corrected ed. New York: Harcourt, Brace and World. [Originally published in 1947]

Haviland, William A.

1966 Maya Settlement Patterns: A Critical Review. New Orleans: Tulane University, Middle American Research Institute. Publication No. 26.

Higbee, E. C.

1947 "The Agricultural Regions of Guatemala." Geographical Review 37 (August):177-20l.

Hill, George W., and Manuel Gollas

1968 "The Minifundia Economy and Society of the Guatemalan Highland Indian." Madison: University of Wisconsin Land Tenure Center. Processed Research Paper No. 30 .

Hill, George W., Manuel Gollas Quintero and Gregorio Alfaro 1964 Un áréa rural en desarrolzo: sus problemas económicos y sociales-Costa Rica. San José: Instituto Universitario Centroamericano de Investigaciones Sociales y Economicas.

Hill, George $W .$, and Marion T. Loftin

1961 "Characteristics of Rural Life and the Agrarian Reform in Honduras." Tegucigalpa. (Typescript of the Report of the Rural Sociology Team of Mission 105 of the Organization of American States Direct Technical Assistance Program) 
Honduras

1962 Ley de reforma agraria: Decreto No. 2. Tegucigalpa.

1963- La gaceta: Diario oficial de Za República de 1968 Honduras. Tegucigalpa: Tipografía Nacional.

Honduras, Dirección General de Cartografía (DGC)

1965 Hoja 2661 IV, "Villaneuva," of the 1:50,000 series of topographic maps.

Honduras, Dirección General de Estadística y Censos (DGEC)

1964 a Censo nacional de Honduras: caracteristicas generales y educativas de la población, abril 1961. Tegucigalpa: The Dirección.

1964b Características económicas de la población: abril 1961. Tegucigalpa: The Dirección.

1965 Manual de instrucciones para enumeradores: segundo censo nacional agropecuario, 1965-1966. Tegucigalpa: The Dirección.

1967 Número y superficie de las fincas, existencia de ganado, segun tamaño y tenencia de las fincas por departamento y municipio: cifras preliminares, segundo censo nacional agropecuario, 1965-1966. Tegucigalpa: The Dirección.

1968 Comercio exterior de Honduras: 1967. Tomo III. Importación. Tegucigalpa: The Dirección.

Hoyt, Elizabeth $\mathrm{E}$.

1955 "The Indian Laborer on Guatemalan Coffee Fincas." Inter-American Economic Affairs 9 (Summer):33-46.

Inter-American Committee for Agricultural Development (ICAD)

n.d. Inventory of Information Basic to the Planning of Agricultural Development in Latin America: Central America. Washington: Pan American Union.

International Bank for Reconstruction and Development (IBRD)

1951 The Economic Development of Guatemala: Report of a Mission Sponsored by the International Bank for Reconstruction and Development in Colzaboration with the Government of Guatemaza. Baltimore: The Johns Hopkins Press. 
1953 The Economic Development of Nicaragua: Report of a Mission Organized by the International Bank for Reconstruction and Development at the Request of the Government of Nicaragua. Baltimore: The Johns Hopkins Press.

International Development Services, Inc.

1960 Costa Rica-Toward Rural Security! New York: International Development Services, Inc.

James, Preston E.

1959 Latin America, 3rd ed. New York: The Odyssey Press.

Johannessen, Carl L.

1963 Savannas of Interior Honduras. Berkeley: University of California Press. Ibero-Americana, No. 46.

Jones, Chester Lloyd

1935 Costa Rica and Civilization in the Caribbean. Madison: University of Wisconsin.

1940 Guatemala: Past and Present. Minneapolis: University of Minnesota Press.

Kelsey, Vera, and Lilly de Jongh Osborne

1952 Four Keys to Guatemala, Rev. ed. New York: Funk \& Wagnals.

Kepner, Charles David, Jr.

1936 Social Aspects of the Banana Industry. New York: Columbia University Press.

Kirchhoff, Paul

1948 "The Caribbean Lowland Tribes: The Mosquito, Sumo, Paya, and Jicaque." Pp. 219-229 in Julian H. Steward (ed.), Handbook of South American Indians. Vol. IV. The Circum-Caribbean Tribes. Washington: Government Printing office. Smithsonian Institution, Bureau of American Ethnology Bulletin 143.

Kirkpatrick, F. A.

1942 "The Landless Encomienda." Hispanic American Historical Review 22 (November): 765-774.

Kolb, J. H., and Edmund des. Brunner

1935 A Study of Rural Society: Its Organization and Changes. Boston: Houghton Mifflin Co. 
Lambert, Jacques

1967 Latin America: Social Structure and Political Institutions. Trans. by Helen Katel. Berkeley: University of California Press.

Landa, Diego de

1941 Landa's Relación de las Cosas de Yucatán. Edited and annotated by Alfred M. Tozzer. Cambridge, Mass.: Harvard University, Peabody Museum of American Archeology and Ethnology. Papers, Vol. 18.

Landis, Paul $\mathrm{H}$.

1940 Rural Life in Process. New York: McGraw-Hill.

Lanzas B. , Enrique

1954 "Encuesta agropecuaria de Nicaragua, 1952." Estadistica: Journal of the Inter-American Statistical Institute 12 (Septiembre):431-448.

Lavine, Harold

1964 Life World Library: Central America. New York: Time Incorporated.

LeBeau, Francis

1956 "Agricultura de Guatemala." Pp. 267-312 in Jorge Iuis Arriola (ed.), Integración social en Guatemala. Guatemala: Seminario de Integración Social Guatemalteca. Publicación No. 3.

León, Jorge

1943 "La agricultura y la colonizacion en Sarapiqui." Revista del Instituto de Defensa del Café de Costa Rica 13:445-452.

1948 "Land Utilization in Costa Rica." Geographical Review 38 (July) : 444-456.

1952 Nueva geografía de Costa Rica, 10a ed. revisada. San José, Costa Rica: Iibrería La Española.

Leonard, Olen E.

1947 Pichilingue: A Study of Rural Life in Coastal Ecuador. Washington: U. S. Department of Agriculture, Office of Foreign Agricultural Relations.

1948a Canton Chulzpas: A Socioeconomic Study in the Cochabamba Valley of Bolivia. Washington: U. S. Department of Agriculture, Office of Foreign Agricultural Relations. 
1948b Santa Cruz: A Socioeconomic Study of an Area in Bolivia. Washington: U. S. Department of Agriculture, Office of Foreign Agricultural Relations.

1952 Bolivia: Land, People and Institutions. Washington: The Scarecrow Press, 1952.

Lewis, Oscar

1949 "Plow Culture and Hoe Culture: A Study in Contrasts." Rural Sociology 14 (June):116-127.

Loomis, Charles P.

1945 Studies of Rural Social Organization in the United States, Latin America, and Germany. Ann Arbor, Michigan: Edwards Brothers, Inc.

Loomis, Charles P. and J. Allan Beegle

1950 Rural Social Systems. New York: Prentice-Hall.

Loomis, Charles P., et al.

1953 Turrialba: Social Systems and the Introduction of Change. Glencoe, Illinois: The Free Press.

Lopez Porras, Roberto

1961 Formas de tenencia de la tierra y algunos otros aspectos de la actividad agropecuaria. Guatemala: Universidad de San Carlos de Guatemala, Instituto de Investigaciones Economicas y Sociales, Facultad de Ciencias Económicas.

Manger-Cats, Sebald Godfried

1966 Land Tenure and Economic Deveropment in Guatemala. Ithaca, New York: Cornell University. Ph.D. dissertation in Agricultural Economics.

Mariñas Otero, Luis

1958 Las constituciones de Guatemala. Madrid: Instituto de Estudios Políticos. Las constituciones hispanoamericanas, 11 .

1962 Las constituciones de Honduras. Madrid: Ediciones Cultura Hispánica. Las constituciones hispanoamericanas, 15.

Marroquín, Alejandro Dagoberto

1959 Panchimalco: Investigación sociológica. San Salvador: Editorial Universitaria. 
1965 "Cambios en la agricultura y sus repercusiones sociales." América Latina 8 (Juhlo-Setembro): 3-39.

n.d. San Pedro Nonualco. San Salvador: Editorial Universitaria.

Marsh, Margaret Alexander

1947 "Monoculture and the Level of Living: An Hypothesis." Inter-American Economic Affairs 1 (June):77-111.

Martinez Arguera, Amilcar, and Pedro Abelardo Delgado B. 1956 "Ideas generales sobre un plan de desarrollo agrícola." Economía Salvadoreña 5 (Julio-Diciembre): 79-84.

Masing, Ulv

1964 Foreign Agricultural Colonies in Costa Rica: An Analysis of Foreign Colonization in a Tropical Environment. Gainesville: University of Florida. Ph.D. dissertation in Geography.

Maturana Medina, Sergio

1962 Las relaciones entre la tenencia de la tierra y la eficiencia del uso de los recursos agricolas en Centro América. Ciudad Universitaria, San Pedro de Montes de Oca [Costa Rica]. (Mimeographed)

1966 "Land Tenure." Pp. 73-94 in Egbert de Vries (ed.), Social Research and Rural Life in Central America, Mexico and the Caribbean Region. Paris: UNESCO.

May, Stacy, and Galo Plaza Lasso

1958 The United Fruit Company in Latin America. Washington: National Planning Association. United States Business Performance Abroad, Case Study No. 7.

May, Stacy, et al.

1952 Costa Rica: A Study in Economic Development. New York: The Twentieth Century Fund.

McBride, George McCutchen

1923 The Land Systems of Mexico. New York: American Geographical Society. Research Series No. 12.

1936 Chile: Land and Society. New York: American Geographical Society. Research Series No. 19. 
1948a "Land Grants-Latin America." Pp. 39-43 in Encyclopedia of the Social Sciences. Vol. IX. New York: The Macmillan Company.

1948b "Land Tenure-Latin America." Pp. 118-127 in Encyclopedia of the Social Sciences. Vol. IX. New York: The Macmillan Company.

McBride, George McCutchen, and Merle A. McBride

1942 "Highland Guatemala and Its Maya Communities." Geographical Review 32 (April):252-268.

McBryde, Felix Webster

1945 Cultural and Historical Geography of Southwest Guatemala. Washington: Government Printing office. Smithsonian Institution, Institute of Social Anthropology, Publication No. 4.

Meagher, Thomas Francis

1939 "Mis vacaciones en Costa Rica." Pp. 677-766 in Alberto Quijano Quesada, Costa Rica, Ayer y Hoy: 1800-1939. San José: Editorial Borrase Hnos. [Originally published in New Monthly Magazine, New York, 1858]

Méndez Domínguez, Alfredo

1967 Zaragoze: La estratificación social de una comunidad ladina guatemalteca. Guatemala: Tipografía Nacional. Seminario de Integración Social Guatemalteca, Publicación No. 21.

Méndez Montenegro, Julio César

1960 "Sumario: 444 años de legislación agraria, 15131957." Revista de la Facultad de Ciencias Juridicas y Sociales de Guatemala, Epoca VI, Nos. 9012:1-919.

Menjivar, Rafael

1962 Formas de tenecia de la tierra y algunos otros aspectos de la activadad agropecuaria. San Salvador: Editorial Universitaria. Instituto de Estudios Económicos, Monografía No. 1.

Monge Alfaro, Carlos

1958 Historia de Costa Rica, 8th ed. San José: Trejos Hnos.

Montealegre, Mariano R.

1942 a "Colonias agricolas." Revista del Instituto de Defensa del Café de Costa Rica. Vol. 11, No. 87: 593-602. 
$1942 \mathrm{~b}$ "La pequeña propiedad rural." Revista del Instituto de Defensa del Café de Costa Rica. Vol 12, No. 97: 517-525.

Monteforte Toledo, Mario

1952 "La reforma agraria en Guatemala." El Trimestre Económico (México) 19 (Julio-Septiembre):389-407.

1959 Guatemala: Monografía sociológica, lst ed. Mexico, D.F.: Instituto de Investigaciones Sociales, Universidad Nacional Autónoma de México.

1965 Guatemala: Monografía sociológica, 2nd ed. Mexico, D.F.: Instituto de Investigaciones Sociales, Universidad Nacional Autónoma de México.

Montoya R., José Francisco

1954 Estudio economico de administración rural de la Zona Atlántica. San José, Costa Rica: Seccibn Publicaciones y Biblioteca. Ministerio de Agricultura e Industrias, Boletín Técnico No. 14 .

Montoya, J. F., and I. A. Reuss

1960 Changes in Occupation and in Size of Land Holdingswith Some Father-Son Comparisons-Selected Rural Households, Canton of Atenas, 2959. San José, Costa Rica: Ministry of Agriculture and Industries.

Morley, Sylvanus Griswold

1956 The Ancient Maya. 3rd ed. revised by George $W$. Brainerd. Stanford, Calif.: Stanford University Press.

Morrison, Paul C., and Jorge León

1951 "Sequent Occupance, Turrialba Central District, Costa Rica." Turrialba: Revista Interamericana de Ciencias Agricola I (Abril):185-198.

Muller, Albert $S$.

1961 "Agriculture in Central America." Pp. 134-144 in A. Curtis Wilgus (ed.), The Caribbean: The Central American Area. Gainesville: University of Florida Press.

Nash, Manning

1967 Machine Age Maya: The Industrialization of a Guatemazan Community. Chicago: University of Chicago Press. [A 1958 edition was published as Memoir No. 87 of the American Anthropological Association.] 
Naylor, Robert A.

1967 "Guatemala: Indian Attitudes Toward Land Tenure." Journal of Inter-American Studies 9 (October):619639.

Nelson, Lowry

1930 The Mormon Vilzage: A Study in Social Origins. Provo, Utah: Brigham Young University. Brigham Young University Studies No. 3.

1950 Rural Cuba. Minneapolis: University of Minnesota Press.

Nesman, Edgar G.

1969 A Sociological Study of the Relations of Man to the Land in Nicaragua. Gainesville: University of Florida. Ph.D. dissertation in Sociology.

Nicaragua

1963 La gaceta: Diario oficial. Managua.

Nicaragua, Dirección General de Estadística y Censos (DGEC)

1954 "Encuesta Agro-Pecuaria, 1952." Boletin Estadistico 4.

1964 Censos nacionales: 1963. Población. Vol. I. Caracteristicas generales por departamentos y municipios. Managua: Departamento de Publicaciones.

1965a Censos nacionales: 1963. Población. Vol. II. Caracteristicas educativas por departamentos y municipios. Managua: Departamento de Publicaciones.

1965b Censos nacionales: 1963. Vivienda. Vol. I. Caracteristicas generales por departamentos $y$ municipios. Managua: The Dirección.

1966 Censos nacionales: 1963. Agropecuario. Managua: The Dirección.

$1967 a$ Censos nacionales: 1963. Población. Vol. III. Caracteristicas económicas de la población por departamentos y municipios. Managua: The Dirección.

1967b Censos nacionales: 1963. Población. Vol. IV. Caracteristicas demográficas detalzadas de la población por departamentos y cuidades principales. Managua: The Dirección. 
1967c Censos nacionales: 1963. Población. Vol. V. Características económicas detalladas de la población por departamentos y cuidades principales. Managua: The Dirección.

Nicaragua, Instituto Agrario de Nicaragua (IAN)

1968a Memoria: 1964-1965. Managua: The Institute.

1968b Memoria: 1966. Managua: The Institute.

Norris, Thomas L.

1953a "Economic Systems: Large and Small Land Holdings." Pp. 89-104 in Charles P. Loomis et at. (eds.), Turrialba: Social Systems and the Introduction of Change. Glencoe, Illinois. The Free Press.

1953b "A Colono System and Its Relation to Seasonal Labor Problems on a Costa Rican Hacienda." Rural Sociology 18 (December) :376-378.

Ordóñez Molina, Salomón

n.d. "Planteamiento de la reforma agraria hondureña." Paper presented in a Forum on Agrarian Reform in the Paraninfo of the University. (Mimeographed)

Organization of American States (OAS)

1963 Informe oficial de la misión 105 de asistencia técnica directa a Honduras sobre reforma agraria $y$ desarrollo agricola. Washington: Pan American Union. Tomos I, II, and III.

Organization of American States (OAS). Interamerican Economic and Social Council

1962 Informe complementario de Nicaragua: Las actividades de la oficina de Planificación del Gobierno de Nicaragua. Mexico, D. F. Doc. of. 31 add./Ser. H/ X.3 $(\mathrm{H}-76)$. (Microcard)

Ots Capdequí, José María

1945 Manual de historia del derecho español en las Indias $y$ del derecho propiamente indiano. Buenos Aires: Losada.

1959 España en América: el régimen de tierras en la epoca colonial. México: Fondo de Cultura Económica.

Oviedo y Valdes, Gonzalo Fernandez de

1851 Historia general y natural de las Indias, islas $y$ tierra-firme del mar oceano. Madrid: Imprenta de la Real Academia de la Historia. 
Painter, Norman Wellington

1953 "The Ecological Basis of Social Systems in Turrialba." Pp. 105-117 in Charles P. Loomis et al. (eds.), Turrialba: Social systems and the Introduction of Change. Glencoe, Illinois: The Free Press.

1956 The Delineation, Demographic Comparison and Population Stability of Selected Types of Locality Groupings in the Central District of Turrialba Canton, Costa Rica, 1951. East Lansing: Michigan State University. Ph.D. dissextation in Sociology.

Pan American Union (PAU)

1965 A Statement of the Laws of Guatemala in Matters Affecting Business, 2nd ed.; Supplement No. 2. Washington: Pan American Union.

Pan American Union (PAU), Department of International Law 1958 Constitution of the Republic of Honduras: 1957. Washington: Pan American Union.

Pan American Union (PAU), Department of Legal Affairs 1965 Constitution of the Republic of Costa Rica: 1949. Amended. Washington: Pan American Union.

1966a Constitution of the Republic of Guatemala: 1965. Washington: Pan American Union.

1966b Constitution of the Republic of EI Salvador: 1962. Washington: Pan American Union.

1966c Constitution of the Republic of Honduras: 1965. Washington: Pan American Union.

1966d Constitution of the Republic of Nicaragua: 1950. Amended. Washington: Pan American Union.

Pan American Union (PAU), Inter-American Statistical Institute (IASI)

1967 America en cifras: 1967; Situación fisica: Territorio y clima. Washington: The Institute.

1968 America en cifras: 1967; Situación económica 3. Comercio, transporte, comunicaciones y turismo. Washington: The Institute. 
Paredes Moreira, José Luis, et al.

1961 Tierras y colonización. Guatemala: Universidad de San Carlos de Guatemala, Instituto de Investigaciones Económicas y Sociales, Facultad de Ciencias Económicas.

Parker, Franklin D.

1964 The Central American Republics. London: Oxford University Press for the Royal Institute of International Affairs.

Parsons, William John

1967 "The Evolution of Patterns of Seasonal Migration from San Juan Ostuncalco." Kalamazoo: Western Michigan University. (Mimeographed)

Pedraza, Cristobal de

1898 "Relación de la prouincia de Honduras y Higueras por el obispo D. Cristobal de Pedraza, Obispo de Honduras." Pp. $385 \mathrm{ff}$. in Colección de documentos inéditos relativos al descubrimiento, conquista y organización de las antiguas posesiones españoles de UZtramar. Tomo 11. Madrid: Establecimiento Tipográfico "Sucesores de Rivadeneyra" for the Real Academia de Historia. [Originally written in 1544]

Peralta, Hernan G.

1962 Las constituciones de Costa Rica. Madrid: Instituto de Estudios Políticos. Las constituciones hispanoamericanas, 16.

Peterson, Arthur W., and Quentin M. West

1953 Agricultural Regions of Costa Rica. Turrialba, Costa Rica: Inter-American Institute of Agricultural Sciences. Miscellaneous Publication, No. 4.

Porras Mendieta, Nemesio

1962 "Formas de tenencia de la tierra y algunos otros aspectos de la actividad agropecuaria." Managua: Universidad Nacional Autónoma de Nicaragua. Proyecto Tenencia de la Tierra en Centro America, Monografía No. 1. (Typewritten draft)

Ramírez Fajardo, Aníbal

1961 Formas de tenencia de tierras en Costa Rica y algunos otros aspectos de la actividad agropecuaria. San José, Costa Rica: Universidad de Costa Rica. 
Raynolds, David R.

1967 Rapid Development in Small Economics: The Example of EZ Salvador. New York: Frederick A. Praeger.

Reina, Ruben E.

1960 Chinautra, A Guatemalan Indian Community: A Study in the Relationship of Community Culture and National Change. New orleans: Tulane University, Middle American Research Institute. Publication No. 24.

La República

1963-

1968 San José, Costa Rica.

Reuss, L. A.

1960 "Completion of Assignment Report: July 1, 1959June 30, 1960; Land Tenure, Type and Size of Farm, Canton of Atenas, and Notes Concerning Resource Development Problems." San José, Costa Rica. (Mimeographed)

Reuss, L. A., and J. F. Montoya

1960 Size and Type of Farm, Atenas Canton, 1959. San José, Costa Rica: Ministry of Agriculture and Industries.

Rippy, J. Fred

1932 Historical Evolution of Hispanic America. New York: F. S. Crofts \& Co.

Rogers, Vance

1947 "Introduction." Pp. 1-24 in Lyall E. Peterson, et al., Agricultural Development in Costa Rica: Report to the Inter-American Development Commission. Washington: Inter-American Development Commission.

Rojas E., Alvaro

1961 "Algunas conceptos sobre el problema agrario costarricense." Suelo Tico (San Jose, Costa Rica), 13 (Enero-Diciembre) : 40-48.

Rojas E., Alvaro, and Claudio Escoto Le6n

$1960^{\circ}$ Algunos conceptos sobre el problema agrario costarricense: Respuesta de Costa Rica al cuestionario de la comisión especial de expertos para el estudio de las necesidades financieras que 
plantea la ejecucion de planes de reforma agraria. [San José]: Ministerio de Agricultura y Ganadería, oficina de Planeamiento y Coordinación.

Ross, Edward Alsworth

1915 South of Panama. London: George Allen and Unwin, Ltd.

1923 The Social Revolution in Mexico. New York: The Century Company.

Salazar N., José Manuel

1962 Tierras y colonización en Costa Rica. Ciudad Universitaria: Universidad de Costa Rica, Departamento de Publicaciones. Serie Tesis de Grado y Ensayos, No. 15.

Sanderson, Dwight

1942 Rural Sociology and Rural Social Organization. New York: John Wiley and Sons, Inc.

Sandner, Gerhard

1959 "La colonizacion interna o expansión agrícola en Costa Rica: progreso o retroceso?" Pp. 25-33 in Informe semestral del Instituto Geográfico de Costa Rica, Enero a Junio de 1959. San José.

1960 Turrubares; estudio de geografía regional; problemas sociales y económicos de la expansion agricola en Costa Rica. San Jose, Costa Rica: Instituto Geográfico de Coata Rica.

1961 Aspectos geográficos de la colonización agricola en el Valle del General. San Jose, Costa Rica: Instituto Geográfico de Costa Rica.

1962 La colonización agrícola de Costa Rica. Tomo I. San José: Instituto Geográfico de Costa Rica.

1963 El concepto espacial y los sistemas funcionales en la colonización espontanea constarricense. San José: Instituto Geográfico de Costa Rica.

1964 La colonización agrícola de Costa Rica. Tomo II. San José: Instituto Geográfico de Costa Rica.

Sardo, Joseph

1968 A Comparative Study of Selected Aspects of Rural Social Organization in Valle del Cauca, Columbia 
and Sicily, Italy. Gainesville: University of Florida. Ph.D. dissertation in Sociology.

Sariola, Sakari

1954 Social Class and Social Mobility in a Costa Rican Town. Turrialba, Costa Rica: Inter-American Institute of Agricultural Sciences. Miscellaneous Publication No. 5 .

Sauer, Carl 0 .

1936 "American Agricultural Origins: A Consideration of Nature and Culture." Pp. 279-297 in Robert H. Lowie (ed.), Essays in Anthropology in Honor of $A$. L. Kroeber. Berkeley: University of California Press.

1952 Agricultural Origins and Dispersals. New York: American Geographical Society. Bowman Memorial Lectures, Series 2 .

Saunders, John V. D.

1961 "Man-Land Relations in Ecuador." Rural Sociology 26 (March) :57-69.

Scheele, Raymond I.

1957 "Santo Domingo Xenajoj: 1944-1951." Pp. 37-39 in Richard N. Adams (ed.), Political Changes in Guatemazan Indian Communities: A Symposium. New Orleans: Tulane University, Middle American Research Institute. Publication No. 24.

Scherzer, Carl

1857 Travels in the Free States of Central America: Nicaragua, Honduras, and San Salvador. London: Longman, Brown, Green, Longmans, \& Roberts.

Schmid, Lester

1967 The Role of Migratory Labor in the Economic Development of Guatemala. Madison: University of Wisconsin, Land Tenure Center. Research Paper No. 22 .

Schulman, Sam

1954 A Sociological Analysis of Land Tenure Patterns in Latin America. Gainesville: University of Florida. Ph.D. dissertation in Sociology. 
1955 "The Colono System in Latin America." Rural Sociology 20 (March) : 34-40.

1956a "Land Tenure among the Aborigines of Latin America." The Americas [Franciscan] 13 (July):43-67.

1956b "A Proposed Schema of Latin-American Tenure Classes." Southwestern Social Science Quarterly 37 (September): 122-135.

Simpson, Eyler N.

1937 The Ejido: Mexico's Way Out. Chapel Hill: University of North Carolina Press.

Simpson, Lesley Byrd

1934 a Studies in the Administration of the Indians in New Spain. I. The Laws of Burgos of 1512. Berkeley: University of California Press. Ibero-Americana, No. 7 .

1934b Studies in the Administration of the Indians in New Spain. II. The Civil Congregation. Berkeley: University of California Press. Ibero-Americana, No. 7 .

1938 Studies in the Administration of the Indians in New Spain. III. The Repartimiento System of Native Labor in New Spain and Guatemala. Berkeley: University of California Press. Ibero-Americana, No. 13 .

1940 Studies in the Administration of the Indians in New Spain. IV. The Emancipation of the Indian Slaves and the Resettiement of the Freemen, 1548-1553. Berkeley: University of California Press. IberoAmericana, No. 16.

1966 The Encomienda in New Spain: The Beginning of Spanish Mexico.' Berkeley: University of California Press.

Small, Albion $W .$, and George E. Vincent

1894 An Introduction to the Study of Society. New York: American Book Company.

Smith, Robert $S$.

1962 "Population and Economic Growth in Central America." Economic Development and Cultural Change 10 (January) : $134-149$. 
Smith, T. Lynn

1940 The Sociology of Rural Life, lst ed. New York: Harper \& Brothers.

$1945 a$ "The Cultural Setting of Agricultural Extension Work in Colombia." Rural Sociology 10 (September): 235-246.

1945b "Notes on Population and Rural Social Organization in El Salvador." Rural Sociology 10 (December): 359-379.

1946 Brazil: People and Institutions, lst ed. Baton Rouge: Louisiana State University Press.

1947 a "Colonization and Settlement in Colombia." Rural Sociology 12 (June):125-139.

1947b "Sistemas agrícolas." Revista Brasizeira de Geografia $9: 159-184$.

1949 "Agricultural Systems and Standards of Living." Inter-American Economic Affairs 3 (Winter):15-20.

1953 The Sociology of Rural Life, 3rd ed. New York: Harper \& Brothers.

$1957 a$ Current Social Trends and Problems in Latin America. Gainesville: University of Florida Press. Latin American Monographs, No. 1.

$1957 \mathrm{~b}$ "Rural Sociology: A Trend Report and Bibliography." Current Sociology 6:1-75.

1958 "Conflicto de teorías sobre la propiedad de la tierra en Colombia." Revista Mexicana de Sociología 20 (Mayo-Agosto) : 371-384.

1959 "Some Observations Relating to Population Dynamics in Plantation Areas of the New World." Pp. 126133 in Vera Rubin (ed.), Plantation Systems of the New World. Washington: Pan American Union. Social Science Monographs, 7.

1960a "Some Neglected Spanish Social Thinkers." The Americas 17 (July):37-52. 
1960b "The Cohesiveness of Social Systems: A Factor of Resistance to Social Change." Pp. 147-156 in

Resistências à mudanca--Fatôres que impedem ou dificultam o desenvolvimento: Anais do Seminário Internacional, reunido no Rio de Janeiro, em outubro de 1959. Rio de Janeiro: Centro LatinoAmericano de Pesquisas em Ciências Sociais. Publicacão No. 10 .

1961 "The Population of the Central American Countries." Pp. 38-47 in A. Curtis Wilgus (ed.), The Caribbean: The Central American Area. Gainesville: University of Florida Press.

1963a Brazil: People and Institutions, 3rd ed. Baton Rouge: Louisiana State University Press.

$1963 \mathrm{~b}$ "The Social Relationships of Man to the Land in Portugal." Sociologia [São Paulo] 25 (Dezembro): 319-343.

$1963 \mathrm{C}$ "Algumas consideracões sôbre o estatuto da lavoura canavieira." Juridica: Revista trimestral da Divisão Juridica do Instituto do Acúcar e do Alcol [Rio de Janeiro] 28 (Julho-Setembro):5-18.

1965a Agrarian Reform in Latin America. New York: Alfred A. Knopf.

1965b "Aportaciones para el estudio de los dos sistemas sociales rurales." Pp. 190-210 in Tomo I of Sociologia y sociedad en Latinoamerica: Estudios sobre su desarrollo. (Memoria del VII Congreso Latinoamericano de Socíología). Bogotá: Asociación Colombiana de Sociología.

1967a Colombia: Social Structure and the Process of Development. Gainesville: University of Florida Press.

1967b The Process of Rural Development in Latin America. Gainesville: University of Florida Press. University of Florida Monographs, Social Science, No. 33.

1969 a "Agricultural-Pastoral Conflict: A Major Obstacle in the Process of Rural Development." Journal of Inter-American Studies 11 (January):16-43. 
1969b "The Sociology of Agricultural Development." Presently unpublished manuscript.

1969c "Some Major Current Rural Social Trends in the United States of America." International Social Science Journal 21:272-285.

Smith, T. Lynn, Justo Díaz Rodríguez and Luis Roberto García

1945 Tabio: A Study in Rural Social Organization. Washington: United States Department of Agriculture, Office of Foreign Agricultural Relations.

Soley Güell, Tomás

1940 Compendio de historia económica y hacendaria de Costa Rica. San José: Editorial Soley y Valverde. Serie Escolar "Costa Rica," No. 2.

Solorzano F., Valentín

1963 Evolución económica de Guatemala. Guatemala: Centro Editorial José de Pineda Ibarra, Ministerio de Educación Pública. Seminario de Integracion Social Guatemalteca, Publicación No. 11.

Solórzano Pereyra, Juan de

1793 Politica indiana. Madrid: Gabriel Ramírez.

Sorokin, Pitirim A. and Carle C. Zimmerman

1929 Principles of Rural-Urban Sociology. New York: Henry Holt \& Company.

Sorokin, Pitirim A., Carle C. Zimmerman and Charles J. Galpin, eds.

1930 A Systematic Source Book in Rural Sociology. Minneapolis: The University of Minnesota Press. 3 volumes. [1930, 1931, and 1932]

Spain

1791 Recopización de leyes de los Reynos de las Indias, mandadas imprimir y publicar por la Magestad Católica del Rey Don Carlos II. Quarta impresión. Madrid: Viuda de Joaquín Ibarra. 3 volumes. [Originally published in 1680]

Squier, Ephraim George

1855 Notes on Central America; Particularly the States of Honduras and San Salvador: Their Geography, Topography, Climate, Population, Resources, 
Productions, etc., etc., and the Proposed Honduras Inter-Oceanic Railway. New York: Harpers \& Brothers.

1860 Nicaragua: Its People, Scenery, Monumonts, Resources, Condition, and Proposed Canal, Rev. ed. New York: Harper \& Brothers.

Stanislawski, Dan

1947 "Early Spanish Town Planning in the New World." Geographical Review 37 (January):94-105.

Stephens, John Lloyd

1841 Incidents of Travel in Central America, Chiapas and Yucatan. New York: Harper \& Brothers. 2 volumes.

Steward, Julian H., and Louis G. Faron

1959 Native Peoples of South America. New York: McGrawHill Book Company, Inc.

Stokes, William S.

1950 Honduras: An Area Study in Government. Madison: University of Wisconsin Press.

Stone, Doris

1962 The Talamancan Tribes of Costa Rica. Cambridge, Mass.: Harvard University, Peabody Museum of American Archeology and Ethnology. Papers, Vol. 43 , No. 2 .

Stouse, Pierre A. D., Jr.

1965 Agricultural Settlement in Former Costa Rican Banana Regions. Madison: University of Wisconsin. Ph.D. dissertation in Geography.

Stratmeyer, Dennis and Jean

1966 "Jacalteca." Pp. 279-310 in Instituto Linguistico de Verano, Lenguas de Guatemala. Guatemala: Ministerio de Educación, Departamento Editorial José de Pineda Ibarra. Seminario de Integración Social Guatemalteca, Publicación No. 20.

Tannenbaum, Frank

1962 Ten Keys to Latin America. New York: Alfred A. Knopf. 
Tax, Sol

1937 "The Municipios of the Midwestern Highlands of Guatemala." American Anthropologist (New Series)

39 (July-September) : 423-444.

Taylor, Carl C.

1926 Rural Sociology: A Study of Rural Problems. New York: Haxper \& Brothers.

1948 Rural Life in Argentina. Baton Rouge: Louisiana State University Press.

Taylor, Carl C., et al.

1949 Rural Life in the United States. New York: Alfred A. Knopf.

Termer, Franz

1962 "El valor historico, geográfico y etnológico de los apuntes de John Cockburn sobre Centroamérica en el siglo XVIII." Pp. 57-93 in Los viajes de Cockburn y Lievre por Costa Rica. San José: Editorial Costa Rica. Biblioteca de Autores Costarricenses, Tomo 9 .

Terpenning, Walter A.

1931 Village and Open-Country Neighborhoods. New York: The Century Co.

Thiel, Bernardo Augusto

1967 "Monografía de la población de la República de Costa Rica en el siglo XIX." Revista de Estudios y Estadisticas [San José: Dirección General de Estadistica y Censos] 8 (Octubre):77-119. [Originally published as a monograph in 1900]

Thomas, Norman

1960 "Report on Costa Rica: Agriculture." Latin American Report 4 (November):22-24.

Torres, Abelardo

1961 Tierras y colonización. San Salvador: Universidad de El Salvador, Instituto de Estudios Económicos. Monografia No. 2.

Tricart, Jean

1962 "Un example du déséquilibre villes-campagnes dans une économie en voie de développement: Le Salvador." Développement et Civilisations [Paxis] 11 (July-september) : 80-102. 
Tumin, Melvin M.

1952 Caste in a Peasant Society: A Case Study in the Dynamics of Caste. Princeton, N.J.: Princeton University Press.

Ulrich, Matthew and Rosemary

1966 "Mopan-Maya." Pp. 355-382 in Instituto Linguistico de Verano, Lenguas de Guatemala. Guatemala: Ministerio de Educacion, Departamento Editorial Jose de Pineda Ibarra. Seminario de Integracion Social Guatemalteca, Publicación No. 20.

United Fruit Company

1963 Annual Report: 1962. Boston: The Company.

1966 Annual Report: 1965. Boston: The Company.

United Nations. Food and Agriculture Organization.

1967 Nicaragua: Caracteristicas generales de ia utilización y distribución de la tierra. Mexico. (Preliminary edition)

Universidad Nacional Autónoma de Honduras, Instituto de Investigaciones Económicas y Sociales (UNAH-IIES)

1961 a Tenencia de la tierra y condiciones del trabajo agricola. Tegucigalpa: Departamento Editorial $y$ de Publicaciones, UNAH.

1961b Tierras y colonización. Tegucigalpa: Departamento Editorial y de Publicaciones, UNAH. Monografía No. 2 .

$1961 \mathrm{c}$ Aspectos juridico-Zaborales de Za actividad agropecuaria. Tegucigalpa: Departamento Editorial y de Publicaciones, UNAH. Monografía No. 3.

University of Florida, Latin American Data Bank

n.d. Costa Rican Agricultural Census of 1963. Magnetic tape data set of the complete universe of IBM card number 1 for each explotación agropecuaria. Data Set A-01004, card 1 .

n.d. Guatemalan Population and Housing Census of 1964. Perforated cards of a one per cent sample of household heads. Data Set A-02002.

Upchurch, Harley M.

1960 "Magdalena Milpas Altas: A Study of Society in Miniature." Gainesville: University of Florida. M.A. thesis in Sociology. 
Villacorta Escobar, Manuel

1952 "Tenencia de la tierra." Boletin of the Direccion General de Estadistica of Guatemala 35 (Febrero): 74-84.

Vogt, Evon $Z$.

1964 a "The Genetic Model and Maya Cultural Development." Pp. 9-48 in Evon $z$. Vogt and Alberto Ruz I. (eds.), Desarrolzo cultural de los Mayas. México: Universidad Nacional Autónoma de México.

1964b "Summary and Appraisal." Pp. 385-403 in Evon Z. Vogt and Alberto Ruz I. (eds.), Desarrolzo cultural de los Mayas. México: Universidad Nacional Autónoma de México.

Vogt, Paul L.

1917 Introduction to Rural Sociology. New York: D. Appleton and Company.

Wagley, Charles

1941 Economics of a Guatemalan Vilzage. Menasha, Wisconsin: American Anthropological Association. Memoirs, No. 58.

1949 The Social and Religious Life of a Guatemalan Vilzage. [Menasha, Wisconsin?] American Anthropological Association. Memoirs, No. 71.

Wagner, Philip I.

1958 Nicoya: A Cultural Geography. Berkeley: University of California Press. Publications in Geography 12:3.

Weeks, David

1947a "European Antecedents of Land Tenures and Agrarian Organization of Hispanic America." The Journal of Land and Public Utility Economics 23 (February): $60-75$.

$1947 \mathrm{~b}$ "The Agrarian System of the Spanish American Colonies." The Journal of Land and Public Utility Economics 23 (May): 153-168.

Wells, William V.

1857 Explorations and Adventures in Honduras, Comprising Sketches of Travel in the Gold Regions of orancho, and a Review of the History and General Resources of Central America. New York: Harper \& Brothers. 
West, Robert C., and John P. Augelli

1966 Middle America: Its Lands and Peoples. Englewood Cliffs, New Jersey: Prentice-Hall.

Whetten, Nathan L.

1948 Rural Mexico. Chicago: University of Chicago Press.

1954 "Land Reform in a Modern World." Rural Sociology 19 (December) : 329-336.

1956 "Patrones de población." Pp. 39-61 in Jorge Luis Arriola (ed.), Integración social en Guatemala. Guatemala: Seminario de Integración Social Guatemalteca. Publicación No. 3.

1961 Guatemala: The Land and the People. New Haven: Yale University Press.

Willey, Gordon R.

1956 "Problems Concerning Prehistoric Settlement Patterns in the Maya Lowlands." Pp. 107-114 in Gordon R. Willey (ed.), Prehistoric Settlement Patterns in the New World. New York: WennerGren Foundation for Anthropological Research. Viking Fund Publications in Anthropology, No. 23.

Willey, Gordon R., and William R. Bullard, Jr.

1965 "Prehistoric Settlement Patterns in the Maya Lowlands." Pp. 360-377 in Robert Wauchope (ed.), Handbook of Middle American Indians. Vol. II. Austin: University of Texas Press.

Willey, Gordon R., F. Ekholm and René F. Millon

1964 "The Patterns of Farming Life and Civilization." Pp. 446-498 in Robert Wauchope (ed.), Handbook of Middle American Indians. Vol. I. Natural Environment and Early Cultures. Austin: University of Texas Press.

Wolf, Eric R.

1959 Sons of the Shaking Earth. Chicago: University of Chicago Press.

Wolfe, Marshall

1965 "Rural Settlement Patterns and Social Change in Latin America: Notes for a Strategy of Rural Development." United Nations Economic Bulletin 
for Latin America 10 (March):1-21. English and Spanish editions. Also published in Latin

American Research Review 1 (Spring, 1966):5-50.

Young, Thomas

1847 Narrative of a Residence on the Mosquito Shore, with an Account of Truxizzo, and the Adjacent Islands of Roatan and Bonacca. London.

\section{Zavala, Silvio}

1940 De encomiendas y propiedad territorial en algunas regiones de la América Española. México: Antigua Librería Robredo.

1943 New Viewpoints on the Spanish Colonization of America. Philadelphia: University of Pennsylvania Press.

1967 Contribución a la historia de las instituciones coloniales en Guatemala. Guatemala: Imprenta de la Universidad de San Carlos. Estudios Universitarios, Vol. 5. [Originally published in 1945 in Mexico] 


\section{BIOGRAPHICAL SKETCH}

William Kennedy Upham was born October 8, 1930, at St. Petersburg, Florida. In June, 1948, he was graduated from St. Petersburg Senior High School. He attended Princeton University for his freshman year, transferring to Maryville College, Maryville, Tennessee, in 1949. In May, 1952, he received the degree of Bachelor of Arts cum laude from Maryville College. From 1952 to 1955 he attended McCormick Theological Seminary in Chicago, where he received the degree of Bachelor of Divinity in May, 1955. From 1955 to August, 1959, he was the pastor of the Church of the Master, Presbyterian, in Miami, Florida.

In September, 1959, the writer enrolled in the Graduate School of the University of Florida. He was graduate research assistant to Dr. T. Lynn Smith from September, 1960, until September, 1961, when he was appointed to a Graduate School Fellowship for the 1961-1962 academic year. He was awarded a Doherty Fellowship for the support of field research in Central America in 1962-1963, as the basis for this doctoral dissertation. He also held a National Science Foundation Fellowship in 1963-1964. Since September, 1964, he has been employed as Assistant Professor of Sociology at Texas A\&M University. 
William Kennedy Upham is married to the former Margaret Joy Hickman, and is the father of two sons. He is a member of the American Sociological Association, the Southern Sociological Society, the Rural Sociological Society, the Latin American Studies Association, the Population Association of America, Alpha Kappa Delta, national honorary sociological fraternity, and Phi Kappa Phi honor society. 
This dissertation was prepared under the direction of the chairman of the candidate's supervisory committee and has been approved by all members of that committee. It was submitted to the Dean of the College of Arts and Sciences and to the Graduate Council, and was approved as partial fulfillment of the requirements for the degree of Doctor of Philosophy.

December, 1969

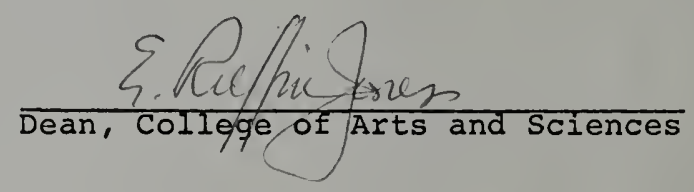

Dean, Graduate School

Supervisory Committee:
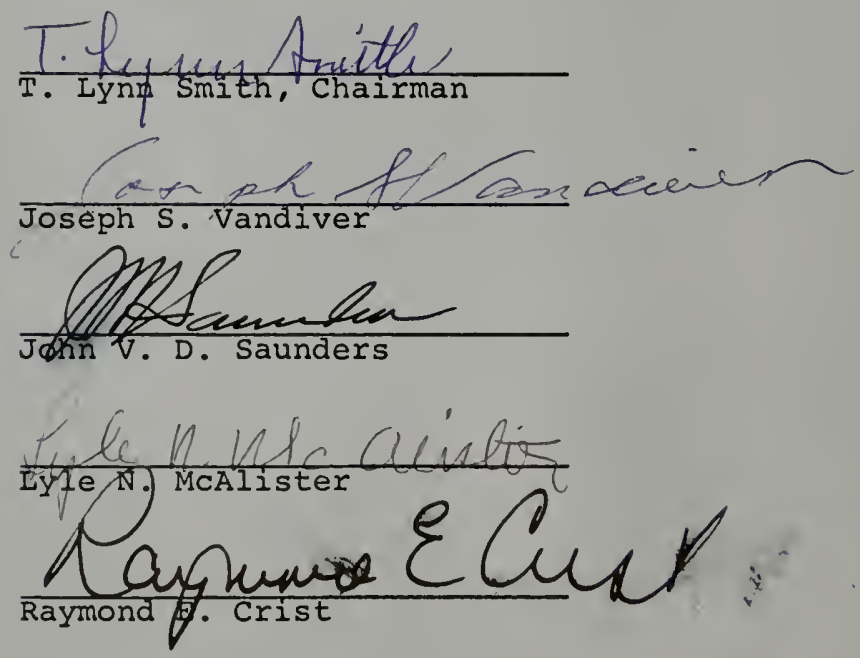